\title{
Evaluation of novel therapeutic targets and diagnostic tools for atherosclerotic plaque progression : immunosuppression and proteomics
}

Citation for published version (APA):

Donners, M. M. P. C. (2005). Evaluation of novel therapeutic targets and diagnostic tools for atherosclerotic plaque progression : immunosuppression and proteomics. [Doctoral Thesis, Maastricht University]. Universiteit Maastricht. https://doi.org/10.26481/dis.20050304md

Document status and date:

Published: 01/01/2005

DOI:

10.26481/dis.20050304md

Document Version:

Publisher's PDF, also known as Version of record

Please check the document version of this publication:

- A submitted manuscript is the version of the article upon submission and before peer-review. There can be important differences between the submitted version and the official published version of record.

People interested in the research are advised to contact the author for the final version of the publication, or visit the DOI to the publisher's website.

- The final author version and the galley proof are versions of the publication after peer review.

- The final published version features the final layout of the paper including the volume, issue and page numbers.

Link to publication

\footnotetext{
General rights rights.

- You may freely distribute the URL identifying the publication in the public portal. please follow below link for the End User Agreement:

www.umlib.nl/taverne-license

Take down policy

If you believe that this document breaches copyright please contact us at:

repository@maastrichtuniversity.nl

providing details and we will investigate your claim.
}

Copyright and moral rights for the publications made accessible in the public portal are retained by the authors and/or other copyright owners and it is a condition of accessing publications that users recognise and abide by the legal requirements associated with these

- Users may download and print one copy of any publication from the public portal for the purpose of private study or research.

- You may not further distribute the material or use it for any profit-making activity or commercial gain

If the publication is distributed under the terms of Article $25 \mathrm{fa}$ of the Dutch Copyright Act, indicated by the "Taverne" license above, 
Evaluation of novel therapeutic targets and diagnostic tools for atherosclerotic plaque progression:

Immunosuppression and Proteomics 
(C) M.M.P.C. Donners, Maastricht 2005

ISBN 90-9019064-3

Printed by: Grafisch bedrijf Ponsen \& Looijen B.V. 


\title{
Evaluation of novel therapeutic targets and diagnostic tools for atherosclerotic plaque progression:
}

\author{
Immunosuppression and Proteomics
}

\section{PROEFSCHRIFT}

ter verkrijging van de graad van doctor aan de Universiteit Maastricht, op gezag van de

Rector Magnificus, Prof. Mr. G.P.M.F. Mols volgens het besluit van het College van Decanen, in het openbaar te verdedigen op vrijdag 4 maart 2005 om 14.00 uur door

Marjo Maria Petronella Catharina Donners

Geboren te Sittard, 18 juli 1978 
Promotor:

Prof. Dr. M.J.A.P. Daemen

Co-Promotor:

Dr. S. Heeneman

Beoordelingscommissie:

Prof. Dr. J. Rosing (voorzitter)

Prof. Dr. C.A. Bruggeman

Prof. Dr. M.P. van Dieijen-Visser

Prof. Dr. J.P. van Hooff

Dr. G. Pasterkamp (Universiteit Utrecht)

Financial Support by the Netherlands Heart Foundation for the publication of this thesis is gratefully acknowledged.

Financial support by Fujisawa Holland BV for the publication of this thesis is also gratefully acknowledged. 
Contents

Abbreviations

Chapter 1

General introduction

Chapter 2

Models of atherosclerosis and transplant arteriosclerosis: the quest for the best

Chapter 3

Low dose FK506 blocks collar-induced atherosclerotic plaque development and stabilizes plaques in ApoE-/- mice

Chapter 4 Low dose FK506 inhibits atherosclerotic plaque development in the ApoE-/-mouse model of spontaneous atherosclerosis

Chapter 5

Effects of low dose FK506 on neointima formation and arterial remodeling in a mouse carotid artery ligation model

Chapter 6

Proteomic analysis of differential protein expression in human 109 atherosclerotic plaque progression

Chapter 7

Preliminary analysis of serum proteomic profiles to discriminate atherosclerotic plaque rupture using SELDI-TOF mass spectrometry

Chapter 8

General Discussion

Summary

Samenvatting

Dankwoord

Curriculum Vitae

List of publications 


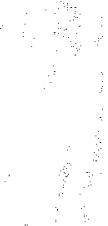




\section{Abbreviations}

\begin{tabular}{|c|c|}
\hline AAT & Alpha- 1 antitrypsin \\
\hline ACE & Angiotensin-converting enzyme \\
\hline ApoE & Apolipoprotein $E$ \\
\hline ASMA & Alpha-smooth muscle actin \\
\hline ATII & Angiotensin II \\
\hline bFGF & Basic fibroblast growth factor \\
\hline BMT & Bone marrow transplantation \\
\hline Cdk & Cyclin-dependent kinase \\
\hline CE & Capillary electrophoresis \\
\hline CHAPS & 3-(3-(Cholamidopropyl)-dimethylammonio)-1-propanesulfonate \\
\hline $\operatorname{cox}$ & Cyclooxygenase \\
\hline CRP & C-reactive protein \\
\hline $\operatorname{Cs} \mathrm{A}$ & Cyclosporin A \\
\hline CSF & Colony-stimulating factor \\
\hline $\mathrm{Da}$ & Dalton \\
\hline DIGE & Difference gel electrophoresis \\
\hline DNA & Deoxyribonucleic acid \\
\hline DTT & Dithiotreitol \\
\hline $\mathrm{EC}$ & Endothelial cells \\
\hline ECM & Extracellular matrix \\
\hline EEL & External elastic lamina \\
\hline eNOS & Endothelial nitric oxide synthase \\
\hline ESI & Electrospray ionization \\
\hline EvG & Elastica von Giesson \\
\hline FACS & Fluorescence-activated cell sorting \\
\hline FKBP & FK506-binding protein \\
\hline GFP & Green fluorescent protein \\
\hline GM-CSF & Granulocyte-macrophage colony stimulating factor \\
\hline HE & Haematoxylin and eosin \\
\hline HSP & Heat shock protein \\
\hline ICAM & Intercellular adhesion molecule-1 \\
\hline ICAT & Isotope-coded affinity tags \\
\hline
\end{tabular}


Isoelectric focusing

IEL

Internal elastic lamina

IFN

Interferon

IGF

Insulin-like growth factor

IL

Interleukin

INOS

Inducible nitric oxide synthase

IPG

Immobiline $\mathrm{pH}$ gradient

$\mathrm{kDa}$

Kilodalton

LC

Liquid chromatography

LDL

Low density lipoprotein

LDLr

Low density lipoprotein-receptor

LOD

Log of the odds

LOX

Lipoxygenase

MALDI

Matrix assisted laser desorption/ionization

MCP-1

Macrophage chemoattractant protein-1

$\mathrm{M}-\mathrm{CSF}$

Macrophage-colony stimulating factor

MMP

MRI

Matrix metalloproteinase

mRNA

MS

Magnetic resonance imaging

MS/MS

messenger Ribonucleic acid

Mass spectrometry

MTOR

Tandem mass spectrometry

Mammalian target of rapamycin

Mw

Molecular weight

NFAT

Nuclear factor of activated $T$ cells

NFKB

NO

Nuclear factor-kappa B

NOS

Nitric oxide

NSAIDs

Nitric oxide synthase

Non-steroidal anti-inflammatory drugs

oxLDL Oxidized low density lipoprotein

PAGE

PAI

PBS

PDGF

pl

PPAR

Polyacrylamide gel electrophoresis

Plasminogen activator inhibitor

Phosphate-buffered saline

Platelet-derived growth factor

Isoelectric point

Peroxisome proliferator-activated receptor

QTL

Quantitative trait locus 


$\begin{array}{ll}\text { RNA } & \text { Ribonucleic acid } \\ \text { ROS } & \text { Reactive oxygen species } \\ \text { SAA } & \text { Serum amyloid A } \\ \text { SDS } & \text { Sodium dodecyl sulphate } \\ \text { SELDI } & \text { Surface-enhanced laser desorption/ionization } \\ \text { TF } & \text { Tissue factor } \\ \text { TGF } \beta & \text { Transforming growth factor-beta } \\ \text { TIMP } & \text { Tissue inhibitor of matrix metalloproteinases } \\ \text { TNF } \alpha & \text { Tumor necrosis factor-alpha } \\ \text { TOF } & \text { Time-of-flight } \\ \text { tPA } & \text { Tissue plasminogen activator } \\ & \text { Urokinase plasminogen activator } \\ \text { UPA } & \text { Vascular cell adhesion molecule } \\ \text { VCAM } & \text { Vascular endothelial growth factor } \\ \text { VEGF } & \text { Vascular smooth muscle cells } \\ \text { VSMC } & \text { Von Willebrand factor }\end{array}$





\section{Chapter 1:}

\section{General introduction}

Majo M.P.C. Donners, Mat J.A.P. Daemen, Kity B.J.M. Cleutiens, Sylvia Hecmeman.

Based on: Intammation and restenosis: implications for therapy

Anr. Med 2003: 35: 523-537 


\section{Clinical manifestation}

Cardiovascular diseases are the leading cause of death affecting millions of people, especially in the Westem Society. In 2002, about 35\% of all deaths in the Netherlands, accounting for -50.000 individuals, were attributed to cardiovascular diseases, mainly clinically manifested as ischemic heart disease (myocardial infarction) or cerebrovascular disease (stroke) ${ }^{1}$. The main underlying pathology of cardiovascular diseases is atherosclerosis, which literally means hardening of the arteries ('sclerosis') by a build-up of lipid, cells and matrix deposits ('atheroma') in the tunica intima, the innermost layer of a blood vessel.

Atherosclerosis is a progressive disease, which starts developing already during infancy, although the early stages of the disease are clinically silent ${ }^{2}$. During progression of the disease, large lesions can develop without clinical symptoms, since the arterial wall can compensate for the luminal narrowing by active remodeling (compensatory enlargement) ${ }^{3}$. Atherosclerosis is therefore often referred to as "the silent killer" since most clinical complications are acute due to rupture of an atherosclerotic plaque, leading to thrombus formation and (partial) occlusion of the artery ${ }^{4}$.

Atherosclerosis is a complex, multifactorial disease affecting mainly large systemic arteries and is localized generally to specific sites in the vascular tree ${ }^{5}$. The highsusceptibility of these sites is determined by hemodynamic factors, usually consisting of areas of low shear stress, oscillatory flow or turbulent flow. These regions of disturbed flow are related to the geography of the vascular tree, typically occurring at branch sites or high vessel curvature (figure 1.1).

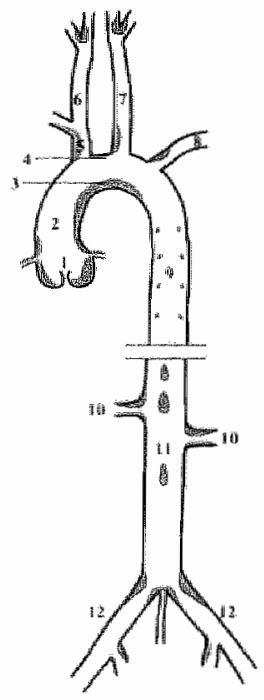

Figure 1.1

Logitudinal representation of the mouse arterial tree with the sites highly susceptible to atherosclerosis (gray). Indicated are 1, aortic sinus; 2, ascending aorta; 3, lesser curvature of the aortic arch: 4, greater curvature of the aortic arch; 5 , brachiocephalic artery; 6 , right common carotid artery; 7, lett common carotid antery; 8, left subclavian attery; 9, thoracic aorta; 10 , renal artery; 11, abdominal aorta; and 12, iliac antery. Adapted from VanderLaan et al. ${ }^{5}$. 
In humans, susceptible areas for atherosclerotic plaque development are the coronary arteries, the carotid bifurcations and the main branch points of the abdominal aorta. Besides hemodynamic factors, many factors have been described that accelerate the development of atherosclerosis. Predisposition to develop lesions is known to be genetically determined, but can be significantly influenced by environmental factors. These risk-factors include hyperlipidemia, hypertension, hyperhomocysteinemia, diabetes, obesity and life-style factors such as tobacco smoking, high fat diet, stress and physical inactivity ${ }^{6.7}$. Treatment of atherosclerotic disease is mainly aimed at reducing these riskfactors, by adjusting life-style and prescribing various types of medications, for example lipid-lowering drugs (statins) ${ }^{8}$ or anti-hypertensive drugs ( $\beta$-blockers, AngiotensinConverting Enzyme (ACE)-inhibitors) ${ }^{9}$. Severe clinical complications, however, often require surgical circumvention or removal of the culprit lesion either by arterial bypass, balloon angioplasty, stenting or atherectomy. Unfortunately, this is not always a definitive solution, since recurrence of the lesion frequently occurs (in 15-60\% of the patients), leading again to narrowing of the lumen (re-stenosis).

\section{Atherosclerotic plaque development and classification}

Histologically, several stages of atherosclerotic plaque development can be recognized and classified. Figure 1.2 shows a schematic representation of a normal artery and two types of advanced atherosclerotic plaques. Stary et al. ${ }^{10}$ described a comprehensive classification developed by the Council on Arteriosclerosis, Thrombosis and Vascular Biology of the American Heart Association (AHA), which recognized six types of atherosclerotic plaques. Lesion types I-III represent clinically silent initial lesions containing macrophages with intracellular and small extracellular lipid accumulations. Formation of a necrotic core renders advanced plaques classified as type IV lesions, or type $V$ lesions when a fibrous cap is formed by myofibroblasts and vascular smooth muscle cells (VSMC) overlying the lipid core, and extracellular matrix (ECM) deposition. According to the AHA classification, type $V$ lesions are subdivided into $V a$ (large lipid core), Vb (calcification) and Vc (fibrous) lesions. Advanced lesion types can either be stable, containing a thick fibrous cap, high VSMC/collagen content, low inflammatory cell content and a small lipid core, or the opposite unstable phenotype. The latter phenotype is vulnerable to rupture of the plaque. Ruptured plaques are classified as the type VI lesion, which is characterized by disruption of the fibrous cap and a thrombus that is in contact with the necrotic core. Thrombus formation can lead to occlusion of the vessel, which makes the type VI lesion the clinically most symptomatic lesion ${ }^{4}$.

This classification was modified by Virmani et al. ${ }^{4}$ since a number of lesions, especially the advanced plaques, were difficult to define by the AHA classification. For example, the distinction between type IV and $V$ is not always clear, particularly when a thin fibrous cap is present. Classification according to Virmani et at. distinguishes these plaques as a thin or thick fibrous cap atheroma. Lesions can further be described as fibrous or fibro-calcific. Furthermore, plaques with thrombus are not always clearly ruptured. Therefore, Virmani et al. distinguish the true ruptured plaques, in which fibrous cap disruption is discernable, from lesions showing intraplaque hemorthage or plaque erosion. 

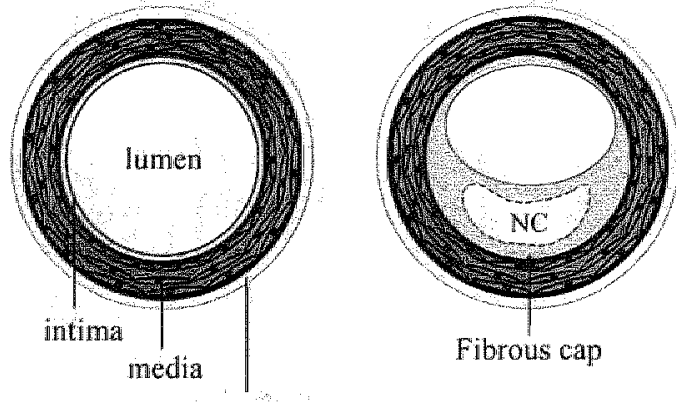

Fibrous cap

adventitia
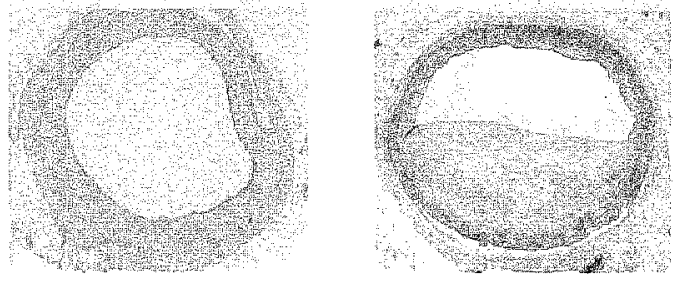

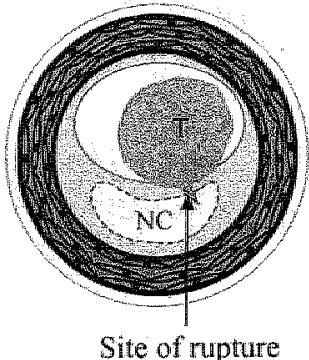

Site of rupture

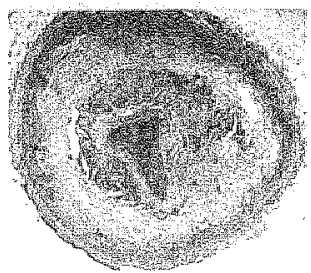

Figure 1.2

Schematic representation of human atherosclerotic plaque development (upper panel). The normal artery (left panel) consists of three layers. intima (inner layer), media (middle) and adventitia (outer laver). During atherosclerotic plaque development cells, lipid and matrix accumulate in the intima, eventually leading to the formation of a necrotic core (NC) and an overlying fibrous cap (as illustrated by the middle figure). Thinning of the fibrous cap may lead to rupture of the plaque and formation of a thrombus, which may (partially) occlude the vessel (right panel). Hematoxylin and eosin-stained sections with the corresponding plaque stage are shown in the lower panel.

\section{In vivo models of atherosiclerosis}

The development of various models of atherosclerosis is pivotal to investigate the pathogenesis of atherosclerotic disease and to evaluate the efficacy of new therapies. Since in vitro models lack the complex interplay of cell-cell interactions, several in vivo models of atherosclerosis have been developed. Before the development of transgene and knockout technology atherosclerotic research was restricted to large animals, such as primates $^{11,12}$, pigs $^{13^{\prime 14}}$ or rabbits ${ }^{15_{116}}$. Such large animal models, however, comprise several disadvantages including expensive housing, slow reproduction, limited reproducibility or ethical concerns. The availability of numerous inbred strains (i.e. genetic homogeneity) in combination with several practical advantages (small size and rapid reproduction) makes the mouse an attractive animal model. However, mice are highly resistant to the development of atherosclerosis, because of a rapid hepatic LDL clearance. Also, HDL and not LDL is the main carrier of cholesterol in mice" features of atherosclerosis, but the lesions are small and develop only when mice are fed a highly atherogenic diet containing cholic acid, which has pro-inflammatory effects ${ }^{18}$.

Transgene technology provided new mouse models with mutations in anti-atherogenic genes, rendering them highly susceptible to atherosclerotic plaque development. One of 
the commonly used atherosclerotic mouse models is the ApoE-deficient (ApoE- $/$ ) mouse ${ }^{19-21}$. Since ApoE is the lipoprotein on the surface of lipoprotein particles that is required for the clearance of lipoproteins such as low-density lipoprotein (LDL) from plasma, ApoE-/- mice exhibit high plasma cholesterol levels and spontaneously develop foam cell-rich lesions from 10 weeks of age with advanced, more fibrous lesions from 1520 weeks. Lesion development is even accelerated upon feeding an atherogenic (Western-type) diet. Another atherosclerotic mouse model is the LDL-receptor deficient (LDLr-l-) mouse, which only develops mildly raised cholesterol levels on chow diet and therefore requires an atherogenic diet ${ }^{22}$. Compared to ApoE-/- mice, LDLr-/- mice develop atherosclerosis more slowly, with the first advanced lesions found at -32 weeks, and exhibit more macrophage-rich lesions.

These atherosclerotic mouse models display several similarities to human atherosclerotic plaques. Advanced lesions in these mice often contain a fibrous cap and a necrotic lipid core, as seen in humans. Plaques consist of the same cell-types, i.e. macrophage-derived foam cells, VSMC, endothelial cells (EC), T-cells and fibroblasts. Furthermore, site specificity of atherosclerotic lesion development (as described above) is mostly similar in mice ${ }^{5}$. Nevertheless, the differences between mice and humans with respect to lipid/lipoprotein profile, hemodynamics (i.e. higher heart rate, smaller vessel dimension) and lesion progression towards an end-stage thrombotic lesion complicates the extrapolation to humans and there is certainly room for improvement in the currently available models of atherosclerosis. Recent advances towards this goal are described in chapter 2 of this thesis.

\section{Pathobiology of atherosclerosis}

As already mentioned, atherosclerosis is a complex disease characterized by the accumulation of lipids, cells and ECM in the vessel wall. Numerous studies have examined the pathogenesis of atherosclerosis and it is now generally accepted that the development of atherosclerotic lesions is a response-to-injury ${ }^{23.24}$ involving a chronic inflammatory reaction ${ }^{25-27}$. Indeed, several inflammatory serum markers such as C-reactive protein and serum amyloid $A$ have been associated with atherosclerosis ${ }^{28.29}$ and may even be produced locally by the atherosclerotic tissue ${ }^{30}$. Evidence of plaque-specific antigens, eliciting an antibody response in the serum, has prompted the possibility of vaccination against atherosclerosis ${ }^{31}$. The chronic inflammatory response is in fact involved in all stages of the disease, regulating the molecular mechanisms underlying atherosclerotic plaque progression (table 1.1).

\section{Lesion initiation}

As proposed by the response-to-injury theory, lesion initiation starts with endothelial damage leading to endothelial dysfunction. Several factors can give rise to the endothelial damage, including hemodynamic stress, oxidative stress (induced by free radicals), modified LDL and possibly infectious agents (Chlamydia pneumoniae or cytomegalovirus) ${ }^{6}$. These factors can stimulate the expression of cytokines and trigger an inflammatory response. First, EC are activated and the expression of adhesion molecules, 


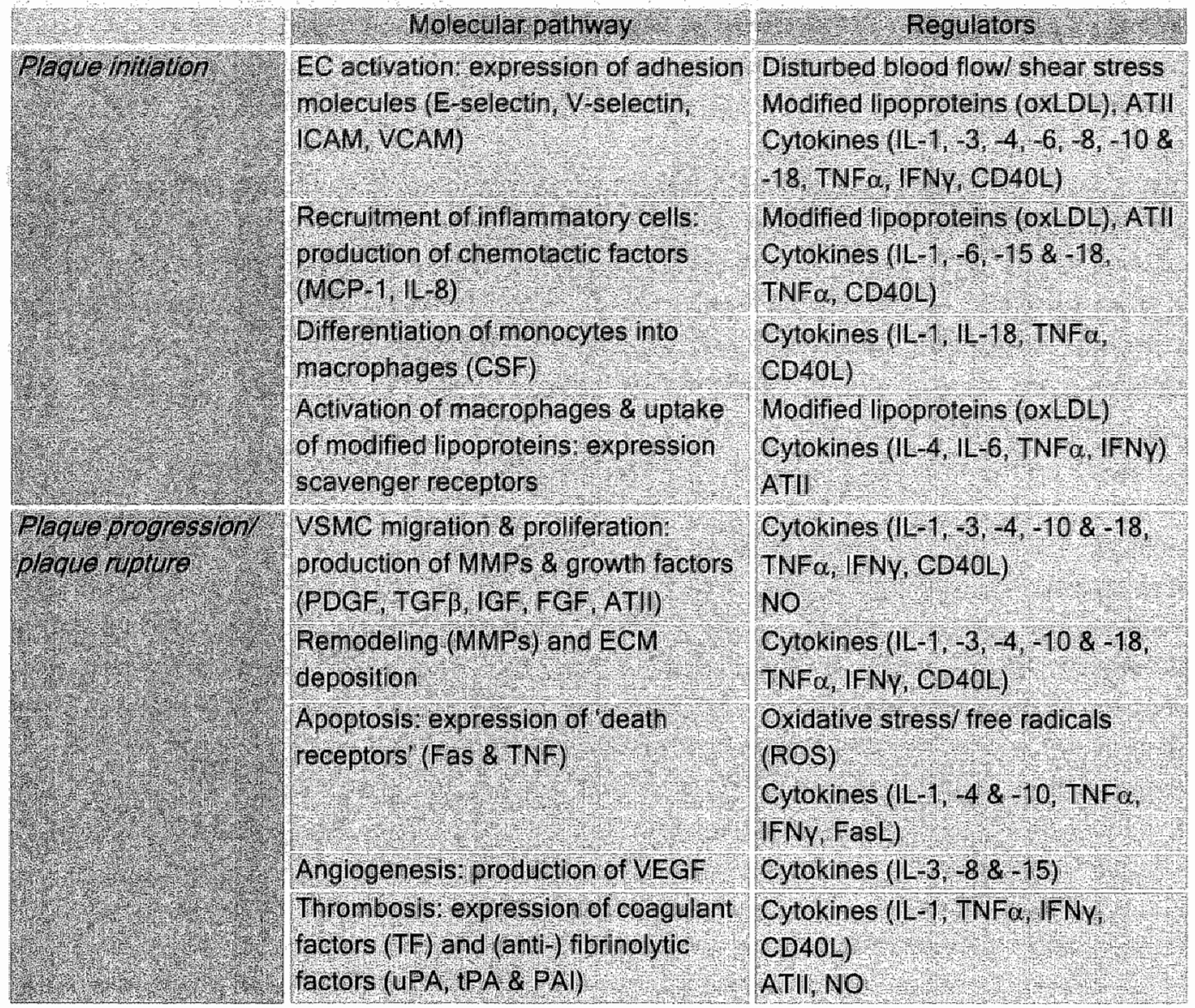

Table 1.1

Molecular mechanisms in atherosclerotic plaque development and their regulators.

such as E-selectin, P-selectin, intercellular adhesion molecule (ICAM) and vascular cell adhesion molecule (VCAM) is induced. This can be mediated either directly by disturbed blood flow ${ }^{32,33}$ and modified lipoproteins such as oxidized LDL (oxLDL) ${ }^{34,35}$ or by the induction of cytokines ${ }^{36}$. Tumor Necrosis Factor (TNF)- $\alpha$, interleukin (IL)-1 $\alpha, I L-1 \beta, I L-18$ and interferon (IFN)-y have been shown to enhance the expression of adhesion molecules, a process involving a signaling pathway through the transcription factor Nuclear Factor (NF)- $\mathrm{KB}^{37}$. This specifically recruits circulating monocytes and T-lymphocytes to the lesion site. Pro-inflammatory cytokines, such as $I L-1, I L-18$, TNF- $\alpha$ and CD $40 L$, induce the expression of Monocyte Chemotactic Protein-1 (MCP-1) and IL-8 by EC, VSMC and intimal macrophages ${ }^{38-40}$. These chemotactic factors mediate the recruitment of circulating monocytes and T-lymphocytes to the lesion site ${ }^{41}$.

In the developing atherosclerotic lesion, monocytes differentiate into macrophages under the influence of macrophage colony stimulating factor (M-CSF), a cytokine that is not only produced by macrophages, but also by stromal and vascular cells (EC, VSMC, 
fibroblasts). Macrophages then become activated by cytokines, which induce the expression of scavenger receptors for the uptake of modified lipoproteins and stimulate macrophage proliferation. IFN- $\gamma, T N F-\alpha$, and $\mathrm{IL}-6$ regulate the expression of the Scavenger Receptor (SR)- $\mathrm{A}^{42-44}, \mathrm{IL}-4$ upregulates $\mathrm{CD} 36^{45,46}$ and Transforming Growth Factor (TGF)- $\beta$ and TNF- $\alpha$ regulate the expression of the oxLDL receptor $(L O X-1)^{47.48}$.

Also the colony-stimulating factors (M-CSF and granulocyte/macrophage (GM)-CSF) can enhance the expression of macrophage scavenger receptors, probably by inducing cytokines. These scavenger receptors mediate the uptake of lipid by the macrophages, turning them into so-called foam cells. Foam cells can also produce inflammatory mediators such as ILS, TNF $\alpha$ or IFN- $\gamma$, which not only stimulate atherosclerotic plaque progression by the production of growth factors and proteolytic enzymes, but also act in an (auto)regulatory positive feedback loop by producing the cytokines, chemokines and colony stimulating factors described before. This positive feedback loop contributes to the chronic nature of the inflammatory response.

\section{Plaque progression}

Progression of an atherosclerotic plaque is characterized by the formation of a fibrous cap by VSMC migration and proliferation and the development of a necrotic core. An important process in necrotic core formation is cell death, by apoptosis or necrosis. Cytokines also play a role in the regulation of cell survival or apoptosis. IL-1 3, TNF- $\alpha$ and IFN- $y$ can aggravate the production of reactive oxygen species (ROS) leading either directly to apoptosis ${ }^{49}$ or sensitizing EC and VSMC for apoptosis by upregulation of Fasexpression $^{50}$. Furthermore, TNF- $\alpha$ and IFN- $\gamma$ can increase macrophage susceptibility to apoptosis induced by Peroxisome-Proliferator-Activated Receptor (PPAR)- $\alpha$ and $-\gamma$ ligands ${ }^{51}$. Although certain anti-inflammatory cytokines, such as $\mathrm{IL}-4$, have been shown to promote cell death ${ }^{52}$, others (such as IL-10) can promote as well as inhibit apoptosis ${ }^{53,54}$. This demonstrates that cytokines can exert ambivalent roles.

As already mentioned, lesion progression is accompanied by the formation of a fibrous cap, consisting of migrating VSMC that start to proliferate and produce ECM constituents, such as collagen and proteoglycans. Furthermore, evidence has been found that intimal VSMC can be derived from circulating vascular progenitor cells. Important growth factors for VSMC proliferation include Platelet Derived Growth Factor (PDGF), Insulin-like Growth Factor (IGF)-1 and TGF- $\beta$, which can be produced by foam cells. Furthermore, IL- 1 and TNF- $\alpha$ produced by foam cells enhance the expression of PDGF by VSMC and EC, which exerts a variety of functions including stimulation of both proliferation and migration of VSMC $^{55}$. IFN-Y (which can be induced by IL-12, -15 and/or IL-18) directly inhibits VSMC proliferation and collagen synthesis ${ }^{56,57}$.

ECM turnover is very important in the progression of atherosclerotic plaques, especially in the regulation of plaque stability. An increase in ECM deposition stabilizes the plaque, whereas an increased degradation of the ECM can lead to weakening of the fibrous cap and eventually to plaque rupture. Net matrix deposition thus depends on the balance of ECM synthesis and degradation ${ }^{58}$. Cytokines not only regulate collagen synthesis, but can 
also influence the expression of ECM degrading enzymes such as Matrix MetalloProteinases (MMPs) ${ }^{59,60}$ or cathepsins ${ }^{61}, \angle L-1 \beta$, TNF- $\alpha$ and CD40L stimulate MMP-1, -2 , $-3,-7,-8,-9,-11$ and -13 expression in EC, VSMC and macrophages/foam cells ${ }^{62,63}$. Interestingly, IFN-y attenuates both collagen synthesis and degradation, indicating again that the effects of cytokines are not always straightforward.

\section{Plaque rupture}

Weakening of the fibrous cap (by inhibition of VSMC proliferation and matrix synthesis, or increased matrix degradation) can lead to rupture of an atherosclerotic lesion and exposure of the necrotic core to the blood. The necrotic core is highly thrombogenic because of the lipid and presence of pro-coagulant factors, such as Tissue Factor (TF) ${ }^{64}$. These factors together with (anti-)fibrinolytic factors, such as plasminogen activators, urokinase-type Plasminogen Activator (UPA), tissue Plasminogen Activator (tPA) and Plasminogen Activator Inhibitor (PAl) determine the consequences of plaque rupture. Cytokines can also regulate the expression of pro-coagulant and anti-coagulant factors. IL-1, TNF- $\alpha$ and CD40L can induce TF expression in macrophages, EC and VSMC ${ }^{65,66}$. Furthermore, IL-1 $\beta$ and TNF- $\alpha$ can enhance the expression of PAI- $1^{67}$, whereas IFN- $y$ has the opposite effect ${ }^{68}$. Thus, by governing the expression of pro-coagulant, pro- or antifibrinolytic factors, cytokines may regulate the thrombogenicity of atherosclerotic plaques.

\section{Balance of pro-inflammatory and anti-inflammatory mediators}

Anti-inflammatory cytokines, such as $\mathrm{IL}-4$ and -10 can reduce the expression of adhesion molecules (ICAM and VCAM) ${ }^{69}$, chemotactic factors (IL-8) ${ }^{70}$, growth factors (through inhibition of $\mathrm{LL}-12,-15$ and -18 ), proteolytic enzymes (MMPs) ${ }^{71,72}$ and procoagulation factors (TF) ${ }^{66}$. Therefore, these cytokines can counteract the effects of proinflammatory cytokines and create a more anti-atherogenic environment. Furthermore, other mediators than cytokines can influence the inflammatory response. Angiotensin II (ATII), for example, has been shown to exert several pro-inflammatory and proatherogenic effects, such as increasing free radicals (ROS), stimulation of VSMC proliferation and expression of adhesion molecules, scavenger receptors, cytokines and chemotactic factors ${ }^{73}$.

The balance between pro-inflammatory and anti-inflammatory cytokines, chemokines and growth factors determines the net function of these mediators. An important regulatory event in this is the differentiation of $\mathrm{CD} 4^{+} \mathrm{T}$-cells into either a Th1-subtype or Th2 subtype. The Th1 response typically involves pro-inflammatory and mainly pro-atherogenic mediators, such as IFN- $\gamma$, TNF- $\alpha$ and IL-1, whereas the Th2 response favors the production of anti-inflammatory and anti-atherogenic cytokines $\| \mathrm{L}-4$ and -10 . The differentiation of $\mathrm{CD} 4^{+}$cells into Th1 or Th2 phenotypes is also regulated by cytokines ${ }^{74}$. $\mathbb{I L}-12$ induces a Th1 response, $\mathrm{IL}-10$ a Th2 response. These Th1 and Th2 cytokines are cross-regulatory, since $\mathbb{L}-10$ inhibits the Th- 1 response, whereas IFN-Y inhibits the Th2 response. It has been shown that in the atherosclerotic plaque, inflammatory mediators of the Th1 response dominate ${ }^{75}$. Pro-inflammatory $T$ cell cytokines (IL-2 and IFN- $\mathrm{V}$ ) were 
highly expressed, whereas the anti-inflammatory cytokines $1 L-4$ and -5 were rarely observed in the plaques.

In conclusion, atherosclerosis is a very complex, chronic inflammatory disease, initiated by a response to injury and mediated by a continuous interplay between (inflammatory) cells and inflammatory mediators. Cytokines play an important regulatory role in the recruitment of inflammatory cells (by modulating the expression of adhesion molecules and chemotactic factors), foam cell formation (by inducing expression of scavenging receptors), fibrous cap formation (by regulating VSMC migration, proliferation and matrix turnover), necrotic core formation (by regulating cell survival or death) and thrombogenicity of the plaques (by modulating the expression of pro-coagulant and pro- or anti-fibrinolytic factors).

\section{Pathobiology of restenosis}

Restenosis is defined as a reduction in lumen size after an intra-arterial procedure such as balloon angioplasty (reviewed by Schwartz et al.) ${ }^{76}$. This vascular response can be divided into four phases: a mechanical phase (early elastic recoil in response to the mechanical dilation of the vessell), a thrombogenic phase, a proliferative phase (neointima formation by proliferation of VSMC) and a remodeling phase (differentiation of VSMC into a synthetic phenotype and ECM deposition). The reduction in lumen size is the result of both early recoil (negative remodeling) ${ }^{77}$ and neointima formation ${ }^{78}$. The application of stents has eliminated the early recoil and thereby reduces the rate of restenosis (from 30 $40 \%$ to approximately $20 \%$ ). However, stents and the accompanying injury of the vascular wall still induce significant restenosis, mainly by neointima formation ${ }^{79}$.

Although the mechanisms underlying atherosclerosis and restenosis differ in several ways, for example in the involvement of circulating lipids and the time course of the disease $e^{80}$, both vascular diseases can be addressed as a response to injury. The initiating stimulus for restenosis is endothelial denudation and/or mechanical stretch in contrast to atherosclerosis where modified LDL, hemadynamic stress, free radicals and infectious agents induce endothelial dysfunction. Nonetheless, inflammation plays an important role in both diseases. This is already well accepted and extensively studied for atherosclerosis (as described above), whereas the role of inflammation in restenosis is not as well defined.

So far, studies of the mechanism underlying restenosis in humans are limited due to the difficulty of obtaining human restenotic tissue. However, several animal models of restenosis have been used to unravel the mechanism of restenosis ${ }^{81-83}$ and there is now increasing evidence for a role of inflammation in the development of restenosis. Several studies report an association of systemic inflammatory markers with restenosis. These markers include C-Reactive Protein (CRP), serum amyloid $A$ and fibrinogen, the same markers that are associated with the development of atherosclerosis ${ }^{84}$. Furthermore, a strong link between the presence of leukocytes and the extent of restenosis has been reported ${ }^{8586}$. Another important indication of the role of inflammation in restenosis has been recently demonstrated by the inhibitory effect of statins on the development of neointima formation after angioplasty ${ }^{87}$. Therefore, as in atherosclerosis, inflammatory 
mediators probably also regulate the molecular mechanisms underlying the development of restenosis (table 1.2).

\section{Inflammation in the early thrombogenic phase of restenosis}

Endothelial denudation by balloon angioplasty and the subsequent exposure of ECM constituents, like collagen in the subendothelial thrombogenic layer, results in the activation and adherence of platelets. Platelet adherence to collagen is mediated by von Willebrand Factor (WWF), synthesized by EC. Likewise, stents also lead to surface thrombus formation. The thrombotic cascade (activated platelets and fibrin deposits) plays a critical role in the initial recruitment of inflammatory cells ${ }^{88}$. Besides monocytes/macrophages and $T$ cells, neutrophils are also invalved in restenosis ${ }^{89}$. This leukocyte recruitment is mediated by the expression of adhesion molecules (such as Pselectin and glycoproteins Iba and IIb/llla on the platelets and ICAM on VSMC) and the expression of the chemoattractants MCP-1 and IL-8 by EC, VSMC and leukocytes in the vascular wall. Platelets and leukocytes, as well as vascular cells produce a variety of growth factors, such as PDGF, basic Fibroblast Growth factor (bFGF), TGF- $\beta^{90}$, IGF ${ }^{91}$, Vascular Endothelial Growth Factor (VEGF) and ATII/2. Platelets also produce thrombin, which is not only a potent stimulator of VSMC proliferation ${ }^{93}$, but also acts as a chemoattractant for leukocytes ${ }^{94,95}$.

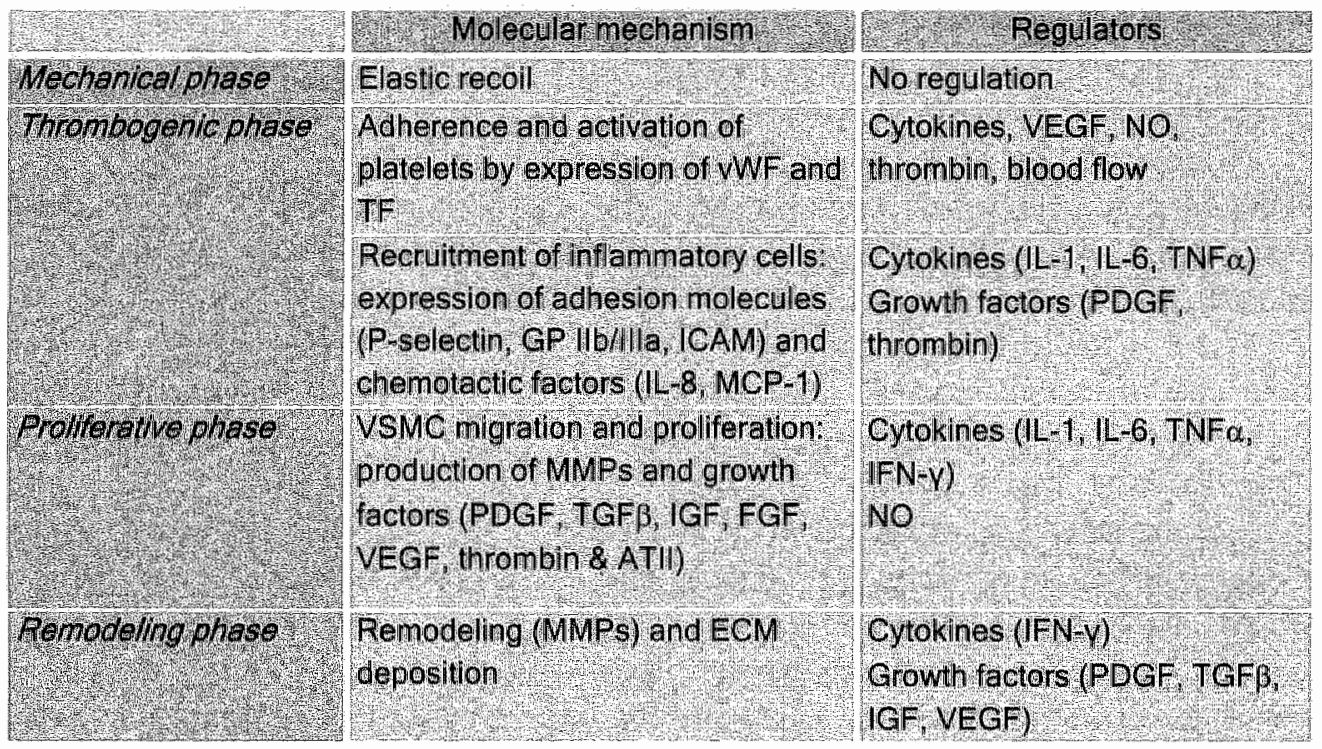

Table 1.2

Molecular mechanisms of restenosis and their regulators. NO, nitric oxide; GP I/b/lla, g/ycoprotein Mbrllla. 
The production of these growth factors is most likely mediated by several cytokines; such as $1 L-1, \| L-6$ and TNF- $\alpha$. However the exact mechanism of this induction has not been identified yet. Recently, Libby et al. ${ }^{96}$ proposed a cytokine-growth factor cascade model for the development of restenosis (figure 1.3). According to this model, mechanical injury and thrombosis first induce cytokine production by macrophages and/or VSMC in the lesion, which could invoke a secondary, self-sustaining autocrine and paracrine cytokine and growth factor expression by lesional cells. This model would include a role for neutrophils in restenosis, since neutrophils, which are not known to produce growth factors, can secrete cytokines such as $\mathrm{LL}-1, \mathbb{L}-6$ and TNF- $\alpha$, which can induce growth factor production ${ }^{97}$. The production of growth factors by VSMC, thereby sustaining VSMC proliferation, implies a potential positive feedback loop, which explains how the process of neointima formation continues even after the disappearance of the initial stimuli.

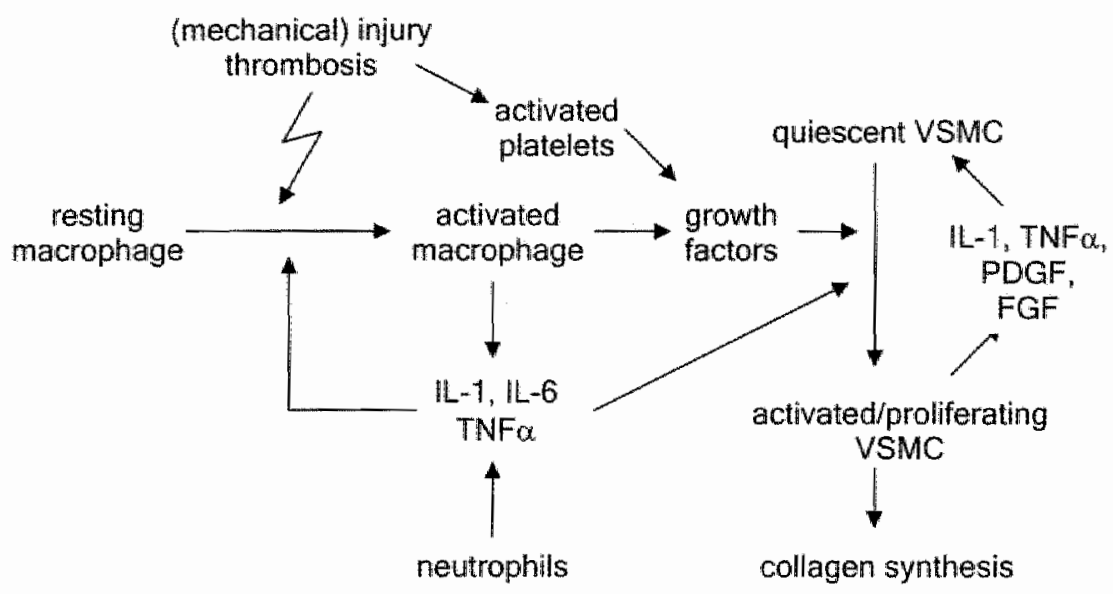

\section{Figure 1.3}

Cytokine-growth factor cascade model of restenosis as proposed by Libby et al ${ }^{96}$. In this model, a first induction of cytokine production by (mechanical) injury and/or acute thrombosis would invoke a secondary cytokine and growth factor expression by activated VSMC or macrophages. This cytokine and growth factor expression would constitute a self-sustaining, autocrine or paracrine positive feedback loop, which explains how the process of restenosis continues even after the disappearance of the intitiating stimulus.

\section{Inflammation in the proliferative and remodeling phase of restenosis}

Growth factors stimulate VSMC proliferation and migration as well as the production of ECM constituents. MMPs and their endogeneous inhibitors, called tissue inhibitors of MMPS (TIMPS), play an important role in the remodeling of the ECM. Since ECM remodeling is also necessary for cell migration, MMPs and TIMPs are often linked to the development of restenosis ${ }^{58}$. Indeed, MMP inhibitors have been demonstrated to reduce neointima formation after balloon angioplasty ${ }^{98,99}$. Cytokines and growth factors such as thrombin can (both positively and negatively) regulate MMP expression ${ }^{100}$. Furthermore, 
upregulation of plasminogen activators (UPA, TPA) or a decrease in plasminogen activator inhibitor (PAI) leads to plasmin activation, which leads to activation of the latent intracellular MMP pool ${ }^{101}$.

Once the site of injury becomes re-endothelialized, endothelial products such as nitric oxide (NO) and heparin can inhibit VSMC proliferation and neointimal growth may slow down. Recently, it has been shown that impairment of re-endothelialization is associated with increased neointima formation in New Zealand White rabbits ${ }^{102}$.

Thus, although the molecular mechanisms of restenosis are different from that of atherosclerosis, inflammation plays a critical role in both vascular diseases. It is important to realize that restenosis usually develops at a site of an atherosclerotic plaque after performing balloon angioplasty or stenting. Therefore, it may not be surprising that the (already existing) inflammation in the plaque environment participates in the development of restenosis. Nevertheless, animal studies using models of restenosis after arterial injury show that inflammation also plays a role in the absence of an atherosclerotic plaque. The differences between the development of atherosclerotic lesions and restenosis probably lie in the nature of the initiating stimulus and the time course of the disease. Atherosclerosis is mediated by several factors that induce endothelial dysfunction, whereas restenosis is induced by endothelial denudation and severe mechanical stretch. This severe type of injury leads to an acute (inflammatory) reaction involving not only monocytes/macrophages and T-cells, but also platelets and neutrophils, whereas in atherosclerosis the (inflammatory) reaction is of a more chronic nature involving mainly monocytesi macrophages and T-cells, but also lipids. Despite these differences, the inflammatory mediators regulating both processes are similar to quite an extent. Inhibition of this inflammatory response may therefore constitute an important strategy for anti-restenotic therapy.

Therapeutic potential of anti-inflammatory agents in atherosclerosis and restenosis

Several attempts have been made to use the inhibition of the inflammatory response as a therapy in both atherosclerosis and restenosis. Statins for example have not only been shown to reduce lipid levels, but also possess anti-inflammatory actions and can therefore be used to inhibit the development of both diseases ${ }^{87,103}$. Furthermore, several reports have suggested the use of inhibition of CD40/CD40L-signaling as a potential antiatherosclerotic therapy ${ }^{104,105}$. Similarly immunosuppressives such as corticosteroids, cyclosporin A (CsA), tacrolimus (FK506) and, more recently, sirolimus (rapamycin) have been examinated as anti-atherosclerotic or anti-restenotic drugs.

\section{Mechanism of action of CSA and FK506}

The immunosuppressive drugs CSA and FK506 inhibit the signaling pathway leading to the transcription of several (cytokine) genes (figure 1.4). The direct target of both CsA and

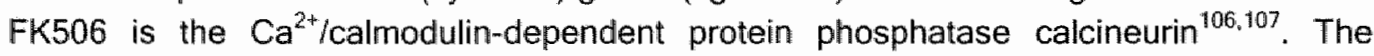
calcineurin-signaling pathway has been first described in $T$ cells, but is also prominent in vascular cell-types. Receptor activation (through antigen recognition in $T$ cells, or 


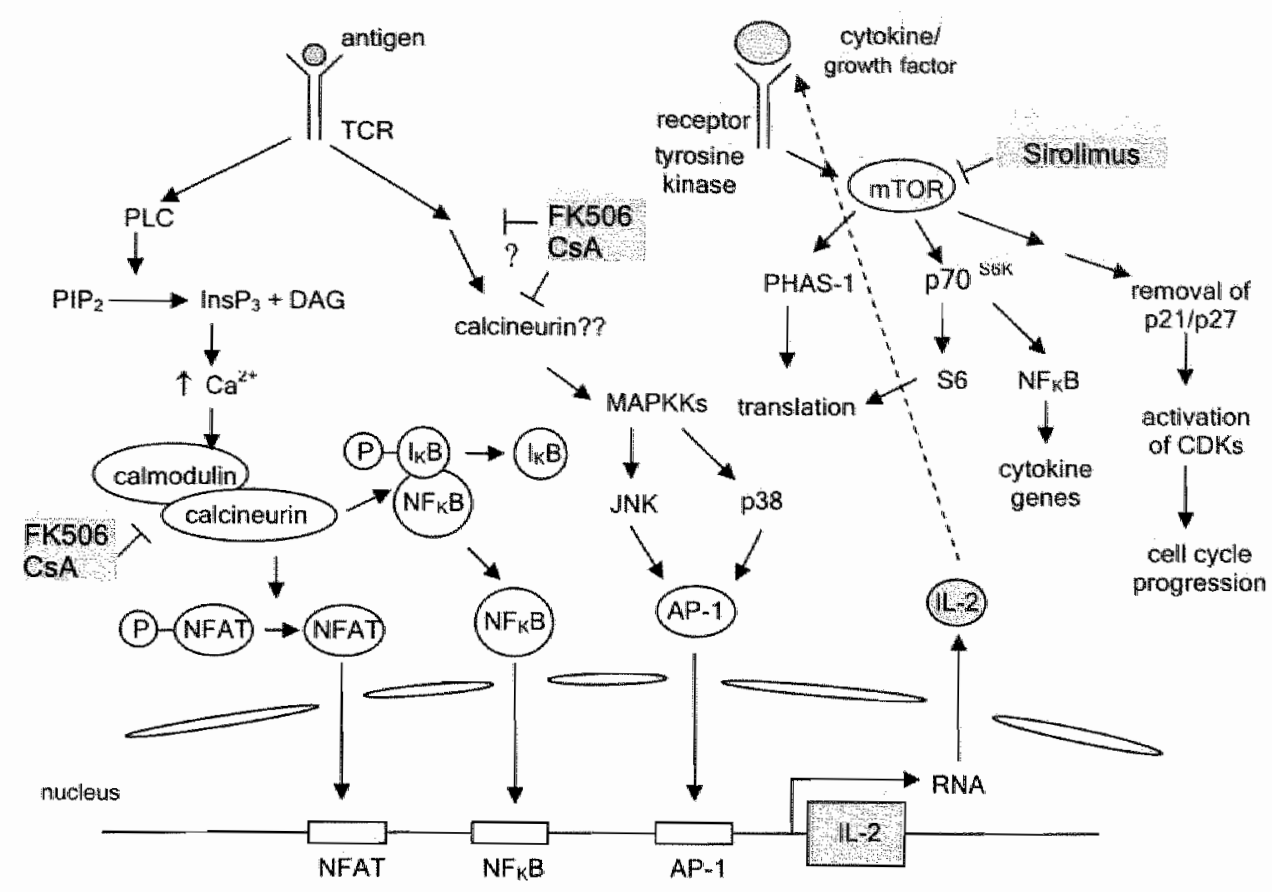

Figure 1.4

Mechanism of immumosuppressives Cyclosporin A (CSA), FK506 and sirolimus in T-cells. CsA and FK506 bind their immuophilins (cyclophilin A or FKBP12, respectively) and inhibit cytokine gene expression through a $\mathrm{Ca}^{2+} /$ calmodulin-dependent signaling cascade By inhibiting calcineurinactivation, CSA and FK506 inhibit the activation and nuclear translocation of transcription factors NFAT and NFKB, which are involved in the transcription of cytokine genes, such as $/ L-2$. Both FK506 and CSA also inhibit the p38/JNK-pathway, which suggests the involvement of calcineurin in this signaling cascade as well.

12-2 production can act in an autocrine, self-stimulatory feedback loop to stimulate T-cell proliferation. However, this can also be induced by other (paracrine) cylokines or growth factors. Receptor activation leads to autophosphorylation of mammalian target of rapamycin (mTOR) and subsequenty to cell cycle progression, initiation of mRNA translation and protein symthesis. Furthermore, cytokine gene expression is further enhanced by activating the transcription factor NFKB. By inhibiting mTOR, sirolimus in complex with FKBP12 blocks cell proliferation and the expression of cytokine genes. Sirolimus therefore inhibits the progression of the cell cycle from the $G_{1} S$ phase, whereas CSA and FK506 block the cell cycle in an earlier phase, i.e. the transition from the $G_{0}-G_{1}$ phase. TCR, $T$ cell receptor; MAPKKs, mitogen activated protein kinase (MAPK) kimases; PHAS-1, phosphorylable heat stable protein-1; CDKs, cyclin dependent kinases.

cytokine/growth factor binding in vascular cells) induces a rise in intracellular calcium and subsequent activation of calmodulin, which then interacts with and activates calcineurin. Activated calcineurin dephosphorylates and thereby activates transcription factors, such as Nuclear Factor of Activated T cells (NFAT), NFKB, myocyte enhancer factor (MEF)-2 and AP-1, leading to the transcription of several genes, including those of ILs, IFN- $\gamma$, TNF- $\alpha$, 
CSFS, CD4OL and FasL ${ }^{108}$. CSA and FK506 form a complex with immunophilins (cyclophilin $A$ and $F K$-binding protein (FKBP12), respectively), which inhibits calcineurin activity and the subsequent transcription of these genes. Interestingly, FKBP12 was found to be upregulated in human neointimal tissue retrieved by helix cutter atherectomy ${ }^{109}$. Furthermore, CsA and FK506 can also block c-jun N-terminal Kinase (JNK)/p38 signaling ${ }^{106,40}$, a pathway that is thought to be activated primarily in stress responses, such as inflammation and apoptosis. Whether this pathway also involves calcineurin remains to be established.

\section{Mechanism of action of sirolimus}

Sirolimus inhibits the signaling pathway leading to cell proliferation, which can be activated by cytokines or growth factors (figure 1.4). Sirolimus binds to the same immunophilin as FK506 (FKBP12), but has a different target. Whereas CsA/cyclophilin A and FK506/FKBP12 inhibit calcineurin-activation, the sirolimus/FKBP12-complex inhibits autophosphorylation of the kinase MTOR(Mammalian Target Of Rapamycin) ${ }^{107,111}$. Upon cytokine/growth factor stimulation, mTOR is autophosphorylated, which leads to activation of several kinases, including the p70-S6 kinase. $p 70^{\text {S6KK }}$ activates the ribosomall protein $S 6$, which is necessary for proteiln synthesis. Furthermore, $p 70^{\mathrm{S} 6 \mathrm{~K}}$ can activate the transcription factor NFKB (activating its subunit c-Rel by stimulating the degradation of $\mid K B$ ), which leads to transcription of several cytokine genes ${ }^{112}$. In addition, MTOR is involved in the initiation of mRNA translation into proteins, by phosphorylating Phosphorylable Heat Stable Protein (PHAS-1), and the progression of the cell-cycle. Upon stimulation, cyclin dependent kinase (cdk) inhibitors $\mathrm{p} 21$ and $\mathrm{p} 27^{\mathrm{kip} 1}$ are eliminated and cyclin/cdk-complexes become activated, leading to synthesis of cell-cycle proteins. Therefore, by inhibiting mTOR sirolimus inhibits the synthesis of proteins necessary for cell-cycle progression and subsequent cell proliferation.

In conclusion, CSA and FK506 block the transition of the $\mathrm{G}_{0}-\mathrm{G}_{1}$ phase of the cell-cycle and the production of cytokines through a calcineurin-dependent pathway. Sirolimus mainly blocks cell proliferation by inhibiting the transition of the $G_{1}$ to the $S$, but has also an immunosuppressive effect by inhibiting the expression of several cytokine genes.

\section{Use of immunosuppressives in vascular disease}

The use of these immunosuppressive drugs in transplant patients has often been suggested to be accompanied by the development of transplant arteriosclerosis, a process with many characteristics similar to atherosclerosis and restenosis. Initial studies indeed reported an increase of transplant arteriosclerosis, however recent studies suggested a beneficial effect of CsA or FK506 on the development of this disease ${ }^{113-115}$. This has lead to several studies on the effects of immunosuppressive drugs on the development of atherosclerosis and more recently allso restenosis. 


\section{lmmunosuppression and atherosclerosis}

Like the studies of the involvement of immunosuppressives in the development of transplant arteriosclerosis, the results from studies of the effect of immunosuppressives on atherosclerotic plaque development have been ambiguous. Drew et al. ${ }^{116}$ showed a reduction of atherosclerotic plaque development in cholesterol-fed rabbits by CsA, whereas Emeson et al. ${ }^{117}$ and Roselaar et al. ${ }^{118}$ both showed an increase in atherosclerosis after CsA treatment of hyperlipidemic mice and rabbits, respectively. FK506 has been demonstrated to increase atherosclerotic plaque development in cholesterol-fed rabbits ${ }^{119}$.

Several studies provided indirect evidence for the influence of immunosuppressive therapy on atherosclerotic plaque development by demonstrating the involvement of the calcineurin-signaling pathway or its inhibitors in several processes associated with atherosclerosis. Recently, Porter et al. showed that the signaling pathway through NFAT promotes the expression of the pro-atherogenic Th1-cytokine genes ${ }^{120}$. Furthermore, several inflammatory mediators and growth factors, such as ATII, thrombin, VEGF and PDGF have been shown to activate the calcineurin-signaling pathway and NFAT mediated transciption in vascular cells ${ }^{121-123}$. Therefore, inhibition of this pathway by CSA or FK506 can block the expression of pro-atherogenic mediators and their effects. Indeed, besides cytokines, CSA and FK506 have been shown to downregulate CD40L ${ }^{124}$, FasL ${ }^{125}$ and TF ${ }^{126,127}$ expression. Furthermore, CSA and FK506 have been shown to inhibit apoptosis $^{128-130}$ and VSMC proliferation ${ }^{131}$, although these effects are not always prominent.

Another important effect of CSA and FK506 is the upregulation of TGF $\beta^{132,133}$ and other fibrogenic factors (collagen, fibronectin, balance MMP/TIMP) ${ }^{134}$. As described before, TGF $\beta$ stimulates VSMC proliferation and ECM synthesis. In this context, it is important to note that processes like increased VSMC proliferation, ECM deposition and reduction of apoptosis can stimulate atherosclerotic plaque growth. On the other hand, these pracesses may be critical in a later stage, when the fibrous cap is thinning and the plaque is prone to rupture. Therefore, it is important to discriminate the effects on early atherosclerotic plaque development and effects on pre-existing atherosclerosis.

Since atherosclerosis is a systemic disease, immunosuppressive therapy is usually confined to systemic administration. This may be problematic in the case of immunosuppressives since side effects have been described. Cyclosporin A and FK506 have been shown to induce endothelial dysfunction ${ }^{135}$. Several reports suggested that this could be mediated by an inhibition of Nitric Oxide Synthase (NOS) and subsequent NO production. Inhibition of NO production, however, could also be beneficial since excessive amounts of NO can also cause damage to cells by the conversion of NO into peroxynitrite ${ }^{136.137}$. Recently, Kuhlencordt et al. showed a distinct role for the two types of NOS. eNOS is mainly produced by EC and a deficiency of eNOS is related to accelerated atherosclerosis ${ }^{138}$, whereas a deficiency of iNOS, which is produced in high amounts by macrophages, leads to reduced atherosclerosis ${ }^{139}$. Thus, whether the effects of CsA and FK506 on NO production are beneficial or detrimental may depend on the type of NOS affected. Other reported side effects of immunosuppressives include hypertension, 
hyperlipidemia, nephrotoxicity, neurotoxicity and diabetes. Regarding the potency of the drugs and the extent of these side effects, it is now well established that FK506 is preferred to CsA, since it is a much more potent immunosuppressive and induces less hypertension and less pronounced hyperlipidemia ${ }^{140,141}$.

Recently, sirolimus has been shown to reduce atherosclerosis in ApoE-f- mice ${ }^{142-144}$. There are no data of the effect of sirolimus on atherosclerotic plaque phenotype yet, but there are numerous reports describing the anti-proliferative effects of sirolimus. As mentioned before, inhibition of VSMC proliferation may be either beneficial in atherogenesis, whereas it is detrimental for pre-existing lesions when VSMC proliferation may contribute to plaque stabilization. Sirolimus also has immunosuppressive effects $^{107,111}$. By inhibiting the activation of cells by cytokines, such as IL-2, it inhibits autocrine stimulation and production of other cytokines ${ }^{112}$ and therefore it might inhibit the maintenance of the inflammatory response, which is in favor of plaque stabilization. It remains to be determined, however, whether immunosuppressives can be used as a (systemic) therapy for atherosclerosis.

\section{Immunosuppression and restenosis}

The development of restenosis can be divided into early elastic recoil of the vessel wall and neointima formation, mainly characterized by VSMC proliferation and ECM remodeling, initiated by a thrombotic response to the de-endothelialized vessel wall. As stents prevent the early elastic recoil, but still induce restenosis by neointima formation, most of the attempts to reduce this neointima formation focus on inhibiting thrombosis, cell proliferation or ECM remodeling. The use of anti-thrombotic agents, however, has been shown to be insufficiently effective in reducing neointima formation in humans ${ }^{145,146}$. MMPinhibitors have been shown to reduce constrictive arterial remodeling but fail to inhibit neointima formation in balloon injury models in rats and Yucatan micropigs ${ }^{98,147}$. Antiproliferative agents, especially paclitaxel ${ }^{148}$ and sirolimus ${ }^{149,150}$, appeared to be more effective. Paclitaxel (a compound of taxol) is a potent inhibitor of VSMC migration and proliferation by inducing a sustained mitotic block ${ }^{151}$, whereas sirolimus inhibits the progression of the cell cycle at the transition from $G_{1}-S$ phase. The benefit of both drugs is primarily due to their cytostatic instead of cytotoxic properties.

Systemic administration of these agents however is limited due to systemic side effects and low therapeutic doses of the drugs at the site of restenosis. Paclitaxel for example appeared to be cardiotoxic, since significant cardiovascular events, such as myocardial infarction occurred in patients treated with this drug ${ }^{152}$. Sirolimus has been reported to induce hyperlipidemia, thrombocytopenia and leukopenia ${ }^{\$ 53,154}$. The introduction of drugeluting stents has significantly improved the therapeutic potential of these drugs. Systemic drug concentration and thereby side effects are substantially lowered, whereas local drug concentration is enough to significantly inhibit restenosis. Indeed, stents coated with sirolimus or paclitaxel have been extensively studied in the last years and several clinical trials have been performed with very promising results for both drugs. Paclitaxel-eluting stents have been shown to significantly inhibit in-stent restenosis ${ }^{155,156}$ "Sirolimus-eluting 
stents also remarkably inhibit neointima formation ${ }^{157,158}$. Sirolimus was even shown to completely abolish in-stent restenosis ${ }^{157,159}$.

A possible limitation of the use of drug-eluting stents, besides their cost, is believed to be a delayed restenosis effect (catch-up). Indleed, paclitaxel-eluting stents have been reported to be effective over a limited period of time, since significant restenosis developed after 12 months ${ }^{160,161}$. Farb et al. ${ }^{162}$ therefore proposed the use of an orally effective immunosuppressive and anti-proliferative compound of the same family of sirolimus. In this study, this compound, called everolimus, was shown to significantly inhibit in-stent restenosis. This oral drug can therefore be used instead of drug-eluting stents, or as a follow-up booster when the stents are exhausted to prevent a potential neointima catch-up. For sirolimus-eluting stents a 2-year follow-up study recently reported no restenosis catch$u^{163}$. The difference with paclitaxel-eluting stents, which did show a delayed restenosis effect, might lie in the immunosuppressive actions of sirolimus ${ }^{112}$ in addition to the antiproliferative effect.

Only few studies examined the effects of other immunosuppressives on neointima formation, probably because of their limited/unequivocal anti-proliferative effect. Because there is increasing evidence for a role of inflammatory mediators (cytokines and chemokines) in the process of restenosis, immunosuppressives such as CsA and FK506 may also have an effect on neointima formation. Whereas CsA appeared to enthance neointima formation ${ }^{164}$, the effects of FK506 are rather contradictory. Some pre-clinical studies showed an inhibitory effect of FK506 on neointima formation ${ }^{165}$, but others failed to report a beneficial effect of $\mathrm{FK} 506^{164,166}$. Furthermore, these immunosuppressives may be used in combination with anti-proliferative drugs. The combination of sirolimus with FK506 has been shown to be very effective in reducing neointimal thickening in rats accompanied by a reduction in ECM deposition ${ }^{167}$.

In conclusion, drug-eluting stents have been shown to be very effective in the local inhibition of restenosis without the concerns of systemic side effects. The immunosuppressive sirolimus seems to be the most effective drug, probably because of its combination of anti-proliferative and immunosuppressive effects. No delayed restenosis has been reported after 2 years, but this remains to be further confirmed. In case of any neointimal catch-up, follow-up boosts with orally effective drugs such as everolimus may be the solution. Furthermore, a synergistic effect of other immunosuppressives such as FK506 may also be favorable. 


\section{Analysis of differential protein expression in atherosclerosis}

Many studies have been performed to unravel the underlying molecular mechanisms of atherosclerosis, however the search for molecular players modulating the development of atherosclerotic plaques, but also for markers of atherosclerosis and the accompanying clinical manifestations, continues. With the revolution in molecular biology in the last decade, genomics technique have been widely used to study (differential) gene expression profiles, in order to identify the molecular players in disease development. Indeed, this has provided a lot of valuable information, however, it has become clear that the genome is rather static and often lacks a linear correlation with protein expression ${ }^{168,169}$. Proteins eventually are responsible for maintenance of cellular functions. Since protein function is also influenced by post-translational modifications such as phosphorylation, glycosylation and proteolysis/cleavage, attention for the field of proteomics has increased the last few years.

\section{D gel electrophoresis}

One of the most common techniques used in proteomic analysis is two-dimensional (2D) gell electrophoresis, a technique developed in the 1970 s by Klose and O'Farrel ${ }^{170,177}$. 2D gell electrophoresis has a high resolution and the ability to visualize a large set of proteins in a differential display format. As its name says, $2 D$ gel electrophoresis separates proteins in 2 dimensions as depicted in figure 1.5. First, proteins are separated by their isoelectric point ( $\mathrm{pl})$, which in practice means that the proteins under the influence of an electric field migrate through a pH gradient towards the point where their net charge is zero. The $\mathrm{pH}$ gradient consists of a gradient of acidic and basic buffering groups (immobilines) incorporated into a polyacrylamide gel, constituting the immobilized pH gradient (IPG) strips. Proteins are amphoteric molecules, i.e. they carry either positive, negative or zero net charge, depending on the $\mathrm{pH}$ of their environment. Proteins are positively charged at $\mathrm{pH}$ values below and negatively charged at $\mathrm{pH}$ values above their $\mathrm{pl}$. Should a protein diffuse away from its $\mathrm{pl}$, it immediately gains charge and migrates back. Therefore the first step of 2D gel electrophoresis is called isoelectric focusing.

In the second dimension, proteins are separated by their molecular weight (Mw) using sodium dodecyl sulphate-polyacrylamide gel electrophoresis (SDS-PAGE). This separation of proteins in two dimensions generates spot patterns, in which each spot represents a specific combination of a $\mathrm{pl}$ and $\mathrm{Mw}$, which can be detected by various staining methods. The obtained spot pattern depends on the type of sample preparation, $\mathrm{pH}$-range and staining method used. For example, hydrophilic (i.e. cytosolic) proteins can be extracted (either from cells or tissue samples) using a salt-containing (Tris) lysisbuffer, whereas extraction of hydrophobic proteins (e.g. membrane proteins) need a lysisbuffer containing urea or a combination of urea/thiourea. Broad $\mathrm{pH}$ ranges can then be used for an overview of total protein distribution of a cell or tissue, whereas smaller $\mathrm{pH}$ ranges can be used to study proteins in the regions of interest in more detail. Several general protein staining methods are available, of which silverstaining or fluorescent Sypro Ruby staining are most commonly used because of their high sensitivity. Coomassie blue staining has a lower sensitivity but is more compatible with subsequent protein identification. 


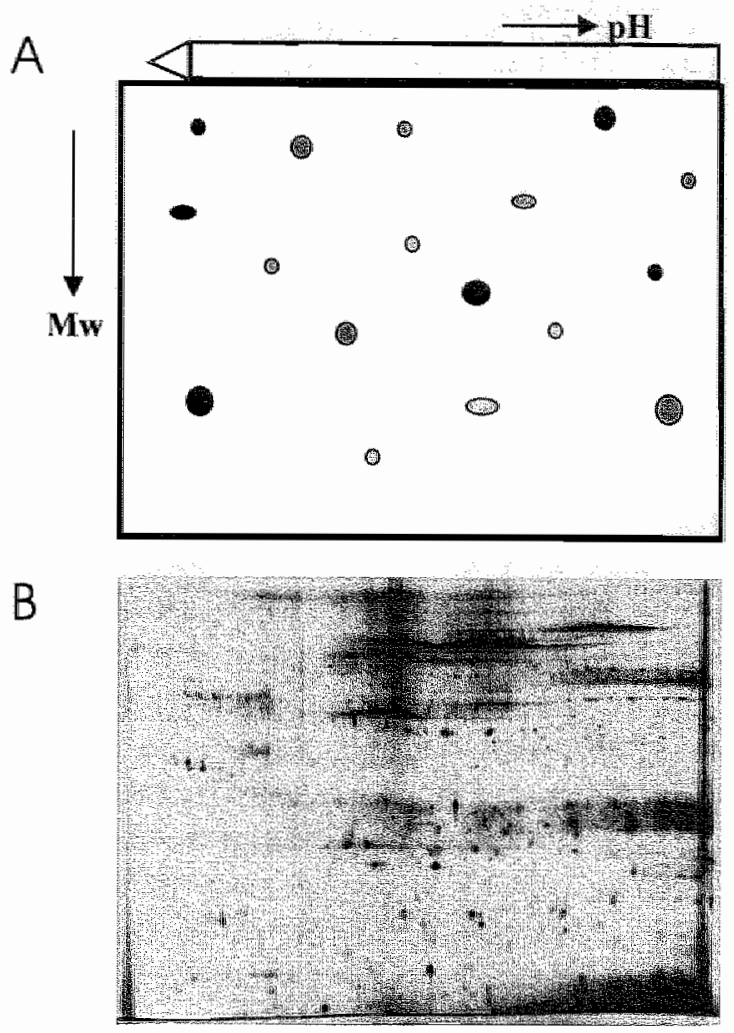

Figure 1.5

Schematic representation of $2 D$ gel electrophoresis (A). In the 7 st dimension (horizontal arrow), proteins are separated by their isoelectric point in a $\mathrm{pH}$ gradient. In the 2nd dimension (vertical arrow), proteins are separated by their molecular weight (MW). This creates a spot pattern, in which each spot represents a protein with a specific pl and $M w$. Panel $B$ shows an example of a 20 gel stained with silver staining.

The $\mathrm{pl}$ of a protein can be estimated from its focusing position along a linear $\mathrm{pH}$ gradient and also the Mw weight can be calibrated using molecular weight markers. Since each protein has a specific $\mathrm{pl}$ and $\mathrm{Mw}$, this can give some information about the identity of the proteins separated on the 2D gels. However, for more accurate protein identification, spots can be excised from the gel and subjected either directly or after digestion to protein identification techniques, usually mass spectrometry (MS). A mass spectrometer consists of three elements:

1. an ionization source, which converts the molecules into gas-phase ions

2. a mass analyzer, which separates the ions by their mass-to-charge $(\mathrm{m} / \mathrm{z})$ ratios using an electric or magnetic field or time-of-flight (TOF)

3. an ion detector, which detects the ions when they strike. 
The most commonly used ionization sources are matrix-assisted laser desorption ionization (MALDI) ${ }^{172}$ and electrospray ionization (ESI) ${ }^{173}$. In MALDI, the proteins are embedded in an energy absorbing matrix, lonized very fast by a laser and then accelerated into the analyzer. In ES:, a potential is applied to the protein sample in solution, causing it to charge and subsequently spray. The solvent evaporates and the charge associates with the protein to form an ion. MALDI is often coupled to the TOF analyzer ${ }^{74}$, which measures the time it takes for an ion to hit the detector, thereby providing accurate information about the molecular weight of the protein (peptide mass fingerprinting). Another analyzer is the quadrupole ${ }^{175,176}$, which uses an electric field with varying strength and frequency to separate ions according to their $\mathrm{m} / \mathbf{z}$ values (in a certain electric field, only ions of a particular $\mathrm{m} / \mathrm{z}$ will hit the detector, others will be deflected). The quadrupole analyzer has the ability to select one peptide for further MS analysis. This peptide is fragmented and the molecular structure (the amino-acid sequence) is analyzed in a second mass analyzer. This is called tandem mass spectrometry (MS/MS), which is often coupled to ESI. The mass spectral data are then correlated to information in databases of protein sequence, genomic sequence or expressed sequence tags (EST) to identify the protein in the $2 \mathrm{D}$ spot $^{177-179}$.

Although major improvements have been made ${ }^{180}$, the $2 \mathrm{D}$ technique has several limitations. The method is laborious, time-consuming, biased towards the higher abundant proteins and cannot resolve proteins with extremes in Mw, pl and hydrophobicity. Nevertheless, it has a high resolution to study protein expression in a differential display format. Therefore, this technique is very suitable to study disease mechanisms.

\section{SELDI}

Recently, a mass spectrometric technique has been developed which utilizes affinity chromatography combined with mass spectrometry for rapid protein expression profiling. This technique is called surface-enhanced laser desorption ionization or SELDI ${ }^{181}$. Proteins are captured on a solid-phase chip, co-crystallized with a matrix and ionized by a laser, similar to MALDI (figure 1.6). The protein chip chromatographic surfaces in SELDI are uniquely designed to retain protein from complex mixtures according to their specific properties. Typically, chemically active surfaces (i.e. hydrophobic, hydrophilic, anionic, cationic or metal ion affinity) retain whole classes of proteins, whereas biochemically active surfaces (containing immobilized antibodies, receptors, DNA, enzymes, etc.) interact specifically with a single target protein.

SELDI-MS is a highly sensitive technique, requiring only small amounts of sample and is, contrary to the 2D technique, very well suitable for low-molecular weight proteins $(<20$ kDa). The mass analyzer, however, provides only low resolution and hence low accuracy for protein identification. Therefore, the true power of SELDI is the ability to analyze crude and complex samples in a high-throughput array format, which makes this technique valuable as a diagnostic tool. By analyzing a large set of (serum) samples from healthy and diseased subjects, a specific proteomics pattern could be distinguished and the results can be used to discriminate diseases, delineate the stage of disease and/or the utility of a treatment ${ }^{182}$. 


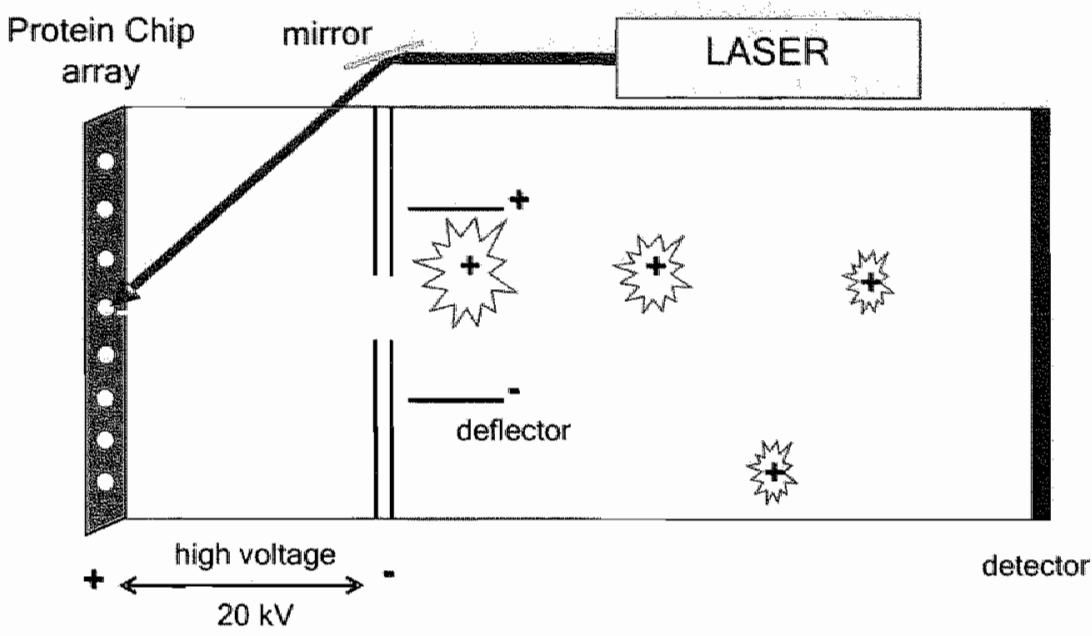

Figure 1.6

Schematic illustration of SELDI-TOF MS. Proteins are retained on the Protein Chip array, according to their affinity with the chromatographic surface. Retained proteins are mixed with energy absorbing matrix and desorbed using a nitrogen laser, which causes them to be launched as ions. A high voltage is used to accelerate the ions, which wtimately strike the detector: Very small ions are deflected since they usually arise from the energy absorbing matrix. Detected ions are displayed as peaks, whose amplitude is proportional to abundance. The time-of-flight is related to mass-to-charge $(\mathrm{m} / \mathrm{z})$ ratio of the ion.

\section{Alternative proteomics techniques}

Despite its limitations, 2D gel electrophoresis is still the cornerstone separation technique for protein mixtures. However, more sensitive, quantitative, high-throughput alternative techniques are rapidly evolving. Such methods are predominantly MS-based and aim at limiting protein purification. Peptide mixtures usually are separated by capillary electrophoresis (CE) or liquid chromatography (LC) and directly elute in the mass spectrometer. LC-MS/MS is now becoming the core technique for MS-based proteomics $^{183}$. However, mass spectrometers are inherently poor quantitative devices. Therefore, stable isotope tags can be introduced to proteins either by metabolic, enzymatic or chemical labeling. Pairs of chemically identical analytes, but with different stable-isotope composition can be differentiated owing to their mass difference, and the ratio of signal intensities indicates the abundance ratio for the two analytes. Using isotope-coded affinity tags (ICAT) ${ }^{484}$ as label, proteins can be purified by affinity chromatography in order to reduce the compllexity of the samples.

Although LC-MS/MS is a thigh-throughput technique, analysis of the large amount of data collected by this method is still time-consuming. As analytical methods and instrumentation are rapidly improving constantly, MS-based techniques will be used increasinglly to identify and quantify thousands of proteins and their post-translational modifications from complex samples. 
Another high-throughput proteomic analysis approach is constituted by protein arrays, analogous to the DNA microarrays, to study the level of protein expression and protein interactions ${ }^{185.186}$. Protein arrays consist of protein recognition molecules, usually antibodies, receptors/ligands, enzymes or aptamers (single-stranded oligonucleotides with high affinity for proteins), which have to specifically recognize their targets from a complex protein mixture. Profiting studies of disease tissue using protein arrays are beginning to emerge. Knezevic et al. used an antibody array to identify (quantitative) differences in protein expression in cancer ${ }^{167}$. Major disadvantages of such arrays, however, are the lack of comprehensive antibody collections and the fact that antibodies often cannot distinguish distinct post-translational modifications. Recently "reverse-phase protein arrays have been developed, on which the whole repertoire of tissue's proteins can be displayed ${ }^{188}$. These arrays offer the possibility to study their post-translational modifications (for example by using phosphor-specific antibodies), but still require antibodies to identify the proteins. Therefore, protein arrays currently available can not lead to the discovery of new proteins.

\section{- Hypothesis}

Since atherosclerosis is a complex disease involving a chronic inflammatory reaction, we hypothesized that the immunosuppressive drug FK506 (tacrolimus) would attenuate the development of atherosclerosis. To test this hypothesis, we first used an ApoE-1- mouse model of collar-induced atherosclerosis. In this model, atherosclerotic plaque development is accelerated (advanced plaques develop within 3-6 weeks), in contrast to the slowly progressing spontaneous atherosclerosis in ApoE-/- mice, which usually develops within several months. Therefore, we also examined the effects of FK506 on atherosclerotic plaque development in the conventional ApoE-/- mouse model. Since inflammation does not only play an important role in atherosclerosis, but also in the process of restenosis, our next hypothesis was, that FK506 would also inhibit neointima formation, a hypothesis that was tested in the mouse model of carotid artery ligation.

Most clinical complications of atherosclerosis are caused by rupture of the lesions. Although the pathophysiology of atherosclerosis has been extensively studied, the underlying molecular mechanisms of progression and rupture of atherosclerotic lesions are still not entirely elucidated. We hypothesized that lesion progression is accompanied by alterations in protein expression as well as post-translational modification of the proteins. Identification of proteins differentially expressed in distinct lesion types could provide valuable information about the molecular modulators of atherosiclerotic plaque progression, and possibly identify new targets for therapy. Furthermore protein expression profiles of the distinct atherosclerotic plaque types, but especially protein profiles of patient serum at different stages of the disease could provide an important diagnostic tool. Therefore, we studied protein expression profiles of advanced human atherosclerotic plaques using 2D gel electrophoresis, comparing 2D maps of stable plaques to those of plaques with a thrombus. Serum profiles of patients with proven advanced stable plaques were compared to those of patients with plaques with a thrombus using SELDI, to identify specific proteomic patterns. 
Outline of this thesis

In this thesis the effects of treatment with the immunosuppressive drug FK506 on the development of atherosclerosis and restenosis and the search for new biomarkers of atherosclerotic plaque rupture are described. First, in chapter 2 the latest advances in developing new models of atherosclerosis and transplant arteriosclerosis are reviewed.

The first experimental chapter (chapter 3) describes the effect of FK506 on the development and progression of atherosclerotic lesions in the ApoE-/- mouse model of collar-induced atherosclerosis. In chapter 4 , the effects of this drug on the progression of atherosclerosis in the conventional ApoE-/-model are reported. The effects of FK506 on neointima formation and arterial remodeling were examined after carotid artery ligation in C57BL/6.J mouse and the results are described in chapter 5.

The identification of proteins that are differentially expressed during the progression of human atherosclerosis in whole-mount atherosclerotic lesions using $2 \mathrm{D}$ gel electrophoresis is depicted in chapter 6. Subsequently, chapter 7 describes the use of SELDI to identify a first proteomic pattern in human serum as a possible diagnostic tool to discriminate patients with proven stable atherosclerotic plaques and lesions with a thrombus. Finally, chapter 8 discusses the results and future directions of these studies and their implications for therapeutic interventions. 


\section{References}

1. Koek H.L. VLLATM, Verschuren W.M.M., Bots M.L. Hart- en vaatziekten in Nederland 2004, cijfers over leefstijl- en risicofactoren, ziekte en sterfte. In. Den Haag: Nederlandse Hartstichting: 2004:1-17.

2. Stary HC. Macrophage foam cells in the coronary artery intima of human infants. Ann $N Y$ Acad Sci 1985;454:5-8.

3. Pasterkamp G, Wensing PJ, Post MJ, Hillen B, Mali WP, Borst C. Paradoxical arterial wall shrinkage may contributite to luminal narrowing of human atherosclerotic femoral arteries. Circulation. 1995,91:1444-9.

4. Virmani $R$, Kolodgle FD, Burke AP, Farb A, Schwartz SM. Lessons from sudden coronary death: a comprehensive morphological classification scheme for atherosclerotic lesions. Arterioscler Thromb Vasc Biol 2000;20:1262-1275.

5. VanderLaan PA, Reardon CA, Getz GS. Site specificity of atherosclerosis: site-selective responses to atherosclerotic modulators. Atterioscler Thromb Vasc Biol. 2004;24:12-22.

6. Fruchart JC, Nierman MC, Stroes ES, Kastellein JJ, Duriez P. New risk factors for atherosclerosis and patient risk assessment. Circulation. 2004;109:III15-9.

7. Tegos TJ, Kalodiki E, Sabetai MM, Nicolaides AN. The genesis of atherosclerosis and risk factors: a review. Angiology. 2001;52:89-98.

8. Rosenson RS. Statins in atherosclerosis: lipid-lowering agents with antioxidant capabilities. Atherosclerosis. 2004;173:1-12.

9. Flordellis CS, Goumenos D, Kourounis G, Tsementzis SA, Paris H, Vlachojiannis J. The shift in the "paradigm" of the pharmacology of hypertension. Curr Top Med Chem. 2004;4:487-98.

10. Stary $\mathrm{HC}_{3}$ Chandler $\mathrm{AB}$, Dinsmore RE, Fuster $\mathrm{V}$, Glagov $\mathrm{S}$, Insull W, Jr., Rosenfeld $M \mathrm{~A}_{\text {, }}$ Schwartz CJ, Wagner WD, Wissler RW. A definition of advanced types of atherosclerotic lesions and a histological classification of atherosclerosis. A report from the Committee on Vascular Lesions of the Council on Arteriosclerosis, American Heart Association. Arterioscler Thromb Vasc Biol. 1995;15:1512-31.

11. Masuda $\mathrm{d}$, Ross. R. Atherogenesis during low level hypercholesterolemia in the nonhuman primate. II. Fatty streak conversion to fibrous plaque. Arteriosclerosis. 1990;10:178-87.

12. Masuda J, Ross R. Atherogenesis during low level hypercholesterolemia in the nonhuman primate. I. Fatty streak formation. Arteriosclerosis. 1990;10:164-77.

13. Gerrity RG. The role of the monocyte in atherogenesis: I. Transition of blood-borne monocytes into foam cells in fatty lesions. Am J Pathol 1981;103:181-90.

14. Reitman JS, Mahley RW, Fry DL. Yucatan miniature swine as a model for diet-induced atherosclerosis. Atherosclerosis. 1982;43:119-32.

15. Rosenfeld ME, Tsukada $T$, Chail A, Bierman EL, Gown $A M_{1}$ Ross R. Fatty streak expansion and maturation in Watanabe Heritable Hyperlipemic and comparably hypercholesterolemic fat-fed rabbits. Arteriosclerosis. 1987;7:24-34.

16. Rosenfeld ME, Tsukada T, Gown AM, Ross R. Fatty streak initiation in Watanabe Heritable Hyperlipemic and comparably hypercholesterolemic fat-fed rabbits. Arteriosclerosis. 1987;7:9-23.

17. Paigen B, Morrow A, Holmes PA, Mitchell $D$, Williams RA. Quantitative assessment of atherosclerotic lesions in mice. Atherosclerosis. 1987;68:231-40. 
18. Paigen B, Morrow A, Brandon C, Mitchell D, Holmes P. Variation in susceptibility to atherosclerosis among inbred strains of mice. Atherosclerosis. 1985,57:65-73.

19. Plump AS, Smith JD, Hayek T, Aalto-Setala $K$, Walsh $A$, Verstuyft JG, Rubin EM, Breslow JL. Severe hypercholesterolemia and atherosclerosis in apolipoprotein E-deficient mice created by homologous recombination in ES cells. Cell. 1992;71:343-53.

20. Redidick RL, Zhang $\mathrm{SH}_{3}$ Maeda N. Atherosclerosis in mice lacking apo $\mathbb{E}$. Evaluation of lesional development and progression. Arterioscler Thromb. 1994;14:141-7.

21. Meir KS, Leitersdorf E. Atherosclerosis in the apolipoprotein E-deficient mouse: a decade of progress. Arterioscler Thromb Vasc Biol. 2004;24:1006-14.

22. Ishibashi S, Brown MS, Goldstein JL, Gerard RD, Hammer RE, Herz J. Hypercholesterolemia in low density lipoprotein receptor knockout mice and its reversal by adenovirus-mediated gene delivery. J C/in /nvest. 1993;92:883-93.

23. Rosis R, Glomset J., L. H. Response to injury and atherogenesis. Am \& Pathol. 1977;86:675-684.

24. Libby P. Inflammation in atherosclerosis. Nature. 2002;420:868-74.

25. Ross R. Atherosclerosis. An inflammatory disease. N Engl J Med. 1999;340:115-126.

26. Lusis AJ. Atherosclerosis. Nature. 2000;407:233-41.

27. Hansson GK. Immune mechanisms in atherosclerosis. Arterioscler Thromb Vasc Biol. 2001;21:1876-90.

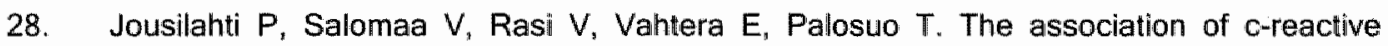
protein, serum amyloid a and fibrinogen with prevalent coronary heart disease--baseline findings of the PAIS project. Atherosclerosis. 2001;156:451-6.

29. Gattone $M$, lacoviello L, Colombo M, Castelnuowo AD, Soffiantino F, Gramoni A, Picco D, Benedetta M, Giannuzzi P. Chlamydia pneumoniae and cytomegalovirus seropositivity, inflammatory markers, and the risk of myocardial infarction at a young age. Am Heart $d$. $2001 ; 142: 633-40$.

30. Vainas T, Lubbers T., Stassen F., Herngreen S., van Dieijen-Visser M., Bruggeman $C$., Kitslaar P. J., H. SG. Serum C-reactive protein level is associated with abdominal aorta Aneurysm size and may be produced by aneurysmal tissue. Circulation. 2003;107:in press.

31. Hansson GK. Vaccination against atherosclerosis: science or fiction? Circulation. 2002;106:1599-604.

32. Topper JN, Gimbrone MA, Jr. Blood flow and vascular gene expression: fluid shear stress as a modulator of endothelial phenotype. Mol Med Today. 1999;5:40-6.

33. Chappell DC, Varner SE, Nerem RM, Medford RM, Alexander RW. Oscillatory shear stress stimulates adhesion molecule expression in cultured human endothelium. Circ Res. $1998 ; 82: 532-9$.

34. Smalley DM, Lin JH, Curtis ML, Kobari $Y$, Stemerman MB, Pritchard KA, Jir. Native LDL increases endothelial cell adhesiveness by inducing intercellular adhesion moleculle- 1 . Arterioscler Thromb Vasc Biol. 1996; 16:585-90.

35. Allen $S$, Khan S, Al-Mohanna F, Batten P, Yacoub M. Native low density lipoproteininduced calcium transients trigger VCAM-1 and E-selectin expression in cultured human vascular endothelial cells. J Clin Invest. 1998;101:1064-75.

36. Meager A. Cytakine regulation of cellular adhesion molecule expression in inflammation. Cytokine Growth Factor Rev. 1999;10:27-39.

37. Collins T, Read M.A., Neish A.S., Whitley M.Z., Thanos D., T. M. Transcriptional regulation of endothelial cell adhesion molecules: NF-kB and cytokine-inducible enhancers. FASEB J. 1995;9:899-909. 
38. Colotta F, Borre A, Wang JM, Tattanelli M, Maddalena F, Polentarutti N, Peri G, Mantovani A. Expression of a monocyte chemotactic cytokine by human mononuclear phagocytes. I Immunol. 1992;148:760-5.

39. Wang DL, Wung BS, Shyy $Y J$, Lin CF, Chao $Y J$, Usami $S$, Chien $S$. Mechanical strain induces monocyte chemotactic protein-1 gene expression in endothelial cells. Effects of mechanical strain on monocyte adhesion to endothelial cells. Circ Res. 1995;77:294-302.

40. Wang $J M$, Sica $A$, Peri $G$, Walter $S$, Padura $I M$, Libby $P$, Ceska $M$, Lindley $I_{\text {, Colota }} F$, Mantovani A. Expression of monocyte chemotactic protein and interleukin- 8 by cytokineactivated human vascular smooth muscle cells. Arterioscler Thromb. 1991;11:1166-74.

41. Terkeltaub R, Boisvert W.A., L.K. C. Chemokines and atherosclerosis. Curr Opin Lipidol. $1998: 9: 397-405$.

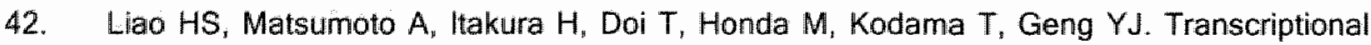
inhibition by interleukin- 6 of the class $A$ macrophage scavenger receptor in macrophages derived from human peripheral monocytes and the THP-1 monocytic cell line. Arterioscler Thromb Vasc Biol. 1999;19:1872-80.

43. Hsu HY, Nicholson AC, Hajjar DP. Inhibition of macrophage scavenger receptor activity by tumor necrosis factor-alpha is transcriptionally and post-transcriptionally regulated. $J$ Bio/ Chem. 1996;271:7767-73.

44. Geng $Y J_{1}$, Holm J, Nygren S, Bruzelius M, Stemme S, Hansson GK. Expression of the macrophage scavenger receptor in atheroma. Relationship to immune activation and the $T$ cell cytokine interferon-gamma. Arterioscler Thromb Vasc Biol. 1995;15:1995-2002.

45. Janabi M, Yamashita S, Hirano K, Sakai $N$, Hiraoka H, Matsumoto K, Zhang Z, Nozaki S, Matsuzawa $Y$. Oxidized LDL-induced NF-kappa B activation and subsequent expression of proinflammatory genes are defective in monocyte-derived macrophages from CD36deficient patients. Arterioscler Thromb Vasc Biol. 2000;20:1953-60.

46. Feng $J_{\|}$Han J, Pearce SF, Silverstein RL, Gotto AM, Jr., Hajjar DP, Nicholson AC. Induction of CD36 expression by oxidized LDL and IL-4 by a common signaling pathway dependent on protein kinase $C$ and PPAR-gamma. J Lipid Res. 2000;41:688-96.

47. Minami M, Kume N, Kataoka H, Morimoto M, Hayashida $K$, Sawamura T, Masaki T, Kita T. Transforming growth factor-beta(1) increases the expression of lectin-like oxidized lowdensity lipoprotein receptor-1. Biochem Biophys Res Commun. 2000;272:357-61.

48. Kume $N$, Moriwaki $H$, Kataoka $H$, Minami M, Murase $T$, Sawamura $T$, Masaki T, Kita $T$. Inducible expression of LOX-1, a novel receptor for oxidized LDL, in macrophages and vascular smooth muscle cells. Ann N Y Acad Sci. 2000;902:323-7.

49. Li PF, Maasch $C$, Haller $H$, Dietz $R$, won Harsdorf $R$. Requirement for protein kinase $C$ in reactive oxygen species-induced apoptosis of vascular smooth muscle cells. Circulation. 1999;100:967-73.

50. Geng $Y J$, Henderson LE, Levesque EB, Muszynski M, Libby P. Fas is expressed in human atherosclerotic intima and promotes apoptosis of cytokine-primed human vascular smaoth muscle cells. Anterioscler Thromb Vasc Biol. 1997;17:2200-8.

51. Chinetti G, Griglio S, Antonucci M, Torra IP, Delerive P, Majd Z, Fruchart JC, Chapman J, Najib J, Staels B. Activation of proliferator-activated receptors alpha and gamma induces apoptosis of human monocyte-derived macrophages. J Biol Chem. 1998;273:25573-80.

52. Lee $Y W$, Kuhn $H$, Hennig B, Toborek M. IL-4 induces apoptosis of endothelial cells through the caspase-3-dependent pathway. FEBS Lett. 2000;485:122-6. 
53. Lindner $H$, Holler E, Erti B, Multhoff $G$, Schreglimann M, Klauke I, Schultz-Hector S, Eissner G. Peripheral blood mononuclear cells induce programmed cell death in human endothelial cells and may prevent repair: role of cytokines. Blood. 1997,89:1931-8.

54. Oshima $K$, Sen $L$, Cui $G_{*}$ Tung $T$, Sacks BM, Arellano-Kruse $A$; Laks $H_{\text {. Localized }}$ interleukin-10 gene transfer induces apoptosis of alloreactive $T$ cells via FASIFASL pathway, improves function, and prolongs survival of cardiac allograft. Transplantation. 2002; 73:1019-26.

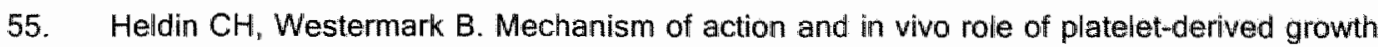
factor. Physiol Rev. 1999; 79:1283-316.

56. Hansson GK, Jonasson L, Holm J, Clowes MM, Clowes AW. Gamma-interferon regulates vascular smooth muscle proliferation and la antigen expression in vivo and in vitro. Circ Res. 1988;63:712-9.

57. Harrop AR, Ghahary A, Scott PG, Forsyth N, Uji-Friedland A, Tredget EE. Regulation of collagen synthesis and mRNA expression in normal and hypertrophic scar fibroblasts in vitro by interferon-gamma. / Surg Res. 1995:58:471-7.

58. Galis ZS, Khatri JJ. Matrix metalloproteinases in vascular remodeling and atherogenesis: the good, the bad, and the ugly. Circ Res. 2002;90:251-62.

59. Amento EP, Ehsani N, Palmer H, Libby P. Cytokines and growth factors positively and negatively regulate interstitial collagen gene expression in human vascular smaoth muscle cells. Aiterioscler Thromb. 1991;11:1223-30.

60. Schonbeck U, Mach F, Sukhova GK, Murphy C, Bonnefoy JY, Fabunmi RP, Libby P. Regulation of matrix metalloproteinase expression in human vascular smooth muscle cells by T lymphocytes: a role for CD40 signaling in plaque rupture? Circ Res. 1997;81:448-54.

61. Liu J, Sukhova GK, Sun JS, Xu WH, Libby P, Shi GP. Lysosomal Cysteine Proteases in Atherosclerosis. Arterioscler Thromb Vasc Biol 2004.

62. Galis ZS, Muszynski M, Sukhova GK, Simon-Morrissey E, Libby P. Enhanced expression of vascular matrix metalloproteinases induced in vitro by cytokines and in regions of human atherosclerotic lesions. Ann $N$ Y Acad Sci. 1995;748:501-7.

63. Galis ZS, Muszynski M, Sukhova GK, Simon-Morrissey E, Unemori EN, Lark MW, Amento E. Libby P. Cytokine-stimulated human vascular smooth muscle cells synthesize a complement of enzymes required for extracellular matrix digestion. Circ Res. 1994:75:1819.

64. Taubman MB, Fallon JT, Schecter AD, Giesen P, Mendlowitz M, Fyfe BS, Marmur JD, Nemerson $Y$. Tissue factor in the pathogenesis of atherosclerosis. Thromb Haemost. 1997:78:200-4.

65. Taubman MB. Tissue factor regulation in vascular smooth muscle: a summary of studies performed using in vivo and in vitro models. Am J Cardid. 1993:72:55C-60C.

66. Osnes LT, Westvik AB, Joo GB, Okkenhaug $C$. Kierulf $P$. Inhibition of IL-1 induced tissue factor (TF) synthesis and procoagulant activity (PCA) in purified human monocytes by IL-4, $\| L-10$ and IL-13. Cytokine 1996;8:822-7.

67. Zoellner $H$, Wojta J, Gallicchio $M_{n}$ McGrath $K$, Hamilton JA, Cytokine regulation of the synthesis of plasminogen activator inhibitor-2 by human vascular endothelial cells. Comparison with plasminogen activator inhibitor-1 synthesis. Thromb Haemost. $1993 ; 69: 135-40$.

68. Gallicchio $M$, Hufnagl P, Wojta $J_{n}$ Tipping P. IFN-gamma inhibits thrombin- and endotoxininduced plasminogen activator inhibitor type 1 in human endothelial cells. I /mmunol. $1996 ; 157: 2610-7$. 
69. Krakauer T. $\mathbb{L}-10$ inihibits the adhesion of leukocytic cells to $\mathbb{L}-1$-activated human endothelial cells. Immuno/ Lett. 1995;45:61-5.

70. Van Der Meeren $A_{s}$ Squiban $C_{s}$ Gourmelon P, Lafont $H_{s}$ Gaugler MH. Differential regulation by $I L-4$ and $I L-10$ of radiationinduced $L L-6$ and $I L-8$ production and ICAM- 1 expression by human endotheliall cells. Cylokine. 1999;11:831-8.

71. Mastafa Mtairag E, Chollet-Martin S, Oudghiri M, Laquay N, Jacob MP, Michel JB, Feldman LJ. Effects of interleukin-10 on monocyte/endothelial cell adhesion and MMP-9/TIMP-1 secretion. Cardiovasc Res. 2001;49:882-90.

72. Lacraz $S$, Nicod L, Galve-de Rochemonteï B, Baumberger $C$, Dayer JM, Welgus $H G$. Suppression of metalloproteinase biosynthesis in human alveolar macrophages by interleukin-4. J Clin Invest. 1992;90:382-8.

73. Braster AR, Recinos $A, 3$ rd, Eledrisi MS. Vascular inflammation and the renin-angiotensin system. Arterioscler Thromb Vasc Biol. 2002;22:1257-66.

74. Seder RA, Paul WE. Acquisition of lymphokine-producing phenotype by CD4+T cells. Annu Rev Immunol 1994;12:635-73.

75. Frostegard J, Ulfgren A., Nyberg P., Hedin U.. Swedenborg J., Andersson U., K. HG. Cytokine expression in advanced human atherosclerotic plaques: dominance of prom inflammatory (Th1) and macrophage-stimulating cytokines. Atheroscterosis. 1999;145:3343 .

76. Schwartz RS, Henry TD. Pathophysiology of coronary artery restenosis. Rev CardiovasC Med. 2002;3:S4-9.

77. Mintz GS, Kent KM, Pichard AD, Satler LF, Popma JJ, Leon MB. Contribution of inadequate arteriall remodeling to the development of focal coronary artery stenoses. An intravascular ultrasound study. Circulation. 1997;95:1791-8.

78. Bennett MR, O"Sullivan M. Mechanisms of angioplasty and stent restenosis: implications for design of rational therapy. Pharmaco/ Ther. 2001;91:149-66.

79. Haude $M$, Erbel $R$, Issa $H$, Meyer J. Quantitative analysis of elastic recoil after balloon angioplasty and after intracoronary implantation of balloon-expandable Palmaz-Schatz stents. I Am Coll Cardiol. 1993;21:26-34.

80. Orford $\mathrm{JL}$, Selwyn AP, Ganz P, Popma JJ, Rogers C. The comparative pathobiology of atherosclerosis and restenosis. Am J Cardiol. $2000 ; 86: 6 \mathrm{H}-11 \mathrm{H}$.

81. Clowes AW, Reidy MA, Clowes MM. Mechanisms of stenosis after arterial injury. Lab Invest. 1983;49:208-15.

82. Steele PM, Chesebro JH, Stanson AW, Holmes DR, Jir., Dewanjee MK, Badimon L, Fuster $\mathrm{V}$. Balloon angioplasty. Natural history of the pathophysiological response to injury in a pig model. Circ Res. 1985;57:105-12.

83. Scheinowitz $M$, Shou $M$, Banai $S$, Gertz SD, Lazarous DF, Unger EF. Neointimal proliferation in canine coronary arteries. A model of restenosis permitting local and continuous drug delivery. Lab /nvest. 1994;71:813-9.

84. Schillinger $M$, Exner $M$, Mlekusch $W$, Rumpold $H$, Ahmadi $R$, Sabeti S, Haumer $M$, Wagner $O$, Minar $E$. Vascullar inflammation and percutaneous transluminal angioplasty of the femoropopliteal artery: association with restenosis. Radiology. 2002;225:21-6.

85. Kornowski $R$, Hong $M K$, Tio FO, Bramwell $O$, Wu $H$, Leon MB. In-stent restenosis: contributions of inflammatory responses and arterial injury to neointimal hyperplasia. $J$ Am Coll Cardiol 1998;31:224-30. 
86. Miller DD, Karim MA, Edwards WD, Schwartz RS. Relationship of vascular thrombosis and inflammatory leukocyte infiltration to neointimal growth following porcine coronary antery stent placement. Atherosclerosis. 1996;124:145-55.

87. Chen Z, Fukutomi T, Zago AC, Ehlers R, Detmers PA, Wright SD, Rogers C, Simon DI: Simvastatin reduces neointimal thickening in low-density lipoprotein receptor-deficient mice after experimental angioplasty without changing plasma lipids. Circulation. 2002;106:20-3.

88. Lee MS, David EM, Makkar RR, Wilentz JR. Molecular and cellular basis of restenosis after percutaneous coronary intervention: the intertwining roles of platelets, leukocytes, and the coagulation-fibrinolysis system. I Patho/ 2004:203:861-70.

89. Welt FG, Edelman ER, Simon DI, Rogers C. Neutrophil not macrophage infiltration precedes neointimal thickening in balloon-injured arteries. Arterioscler Thromb Vasc Biol. 2000;20:2553-8.

90. Chamberlain J. Transforming growth factor-beta: a promising target for anti-stenosis therapy. Cardiovasc Drug Rev, 2001;19:329-44.

91. Bayes-Genis A, Conover CA, Schwartz RS. The insulin-like growth factor axis: A review of atherosclerosis and restenosis. Circ Res. 2000;86:125-30.

92. Daemen MJ, Lombardi DM, Bosman FT, Schwartz SM. Angiotensin II induces smooth muscle cell proliferation in the normal and injured rat arterial wall. Circ Res. 1991;68:450-6.

93. McNamara CA, Sarembock IJ, Bachhuber BG, Stouffer GA, Ragosta M, Barry W, Gimple LW, Powers ER, Owens GK. Thrombin and vascullar smooth muscle cell proliferation: implications for atherosclerosis and restenosis. Semin Thromb Hemost. 1996:22:139-44.

94. Narayanan S. Multifunctional roles of thrombin. Ann Clin Lab Sci. 1999;29:275-80.

95. Naldini A, Sower L, Bocci $V$, Meyers B, Carney DH. Thrombin receptor expression and responsiveness of human monocytic cells to thrombin is linked to interferon-induced cellular differentiation. J Cell Physiol. 1998;177:76-84.

96. Libby $P$, Schwartz D, Brogi $E$, Tanaka $H$, Clinton SK. A cascade model for restenosis. A special case of atherosclerosis progression. Circulation. 1992;86:11/47-52.

97. Lloyd $\mathrm{AR}_{\mathrm{v}}$ Oppenheim JJ. Poly's lament: the neglected role of the polymorphonuclear neutrophil in the afferent limb of the immune response. Immuno/ Today. 1992;13:169-72.

98. de Smet BJ, de Kleijn D, Hanemaaijer R, Verheijen JH, Robertus L, van Der Helm YJ, Borst C. Post MJ. Metalloproteinase inhibition reduces constrictive arterial remodeling after balloon angioplasty: a study in the atherosclerotic Yucatan micropig. Circulation. 2000; 101:2962-7.

99. Furman $C$, Luo Z, Walsh K, Duverger N, Copin C, Fruchart JC, Rouis M. Systemic tissue inhibitor of metalloproteinase-1 gene delivery reduces neointimal hyperplasia in ballooninjured rat carotid artery. FEBS Lett. 2002;531:122-6.

100. Galis $Z S_{n}$ Kranzhofer $R_{n}$ Fenton $J W, 2 n d$, Libby $P$. Thrombin promotes activation of matrix metalloproteinase-2 produced by cultured vascular smooth muscle cells. Arterioscler Thromb Vasc Biol. 1997; 17:483-9.

101. Lijnen HR. Plasmin and matrix metalloproteinases in vascular remodeling. Thromb Haemost. 2001;86:324-33.

102. Gennaro G, Menard C, Michaud SE, Rivard A. Age-dependent impairment of reendothelialization after arterial injury: role of vascular endothelial growth factor. Circulation. 2003;107:230-3.

103. Sukhova GK, Williams JK, Libby $P$. Statins reduce inflammation in atheroma of nonhuman primates independent of effects on serum cholesterol. Arterioscler Thromb Vasc Biol. $2002 ; 22: 1452-8$. 


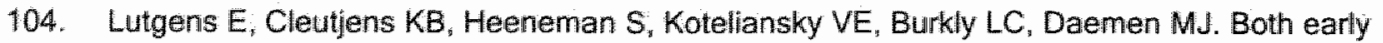
and delayed anti-CD40L antibody treatment induces a stable plaque phenotype. Proc Nat' Acad SCI U S A. 2000:97:7464-9.

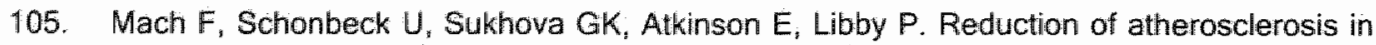
mice by inhibition of CD40 signalling. Nature. 1998;394:200-3.

"06. Matsuda $S$, Koyasu S. Mechanisms of action of cyclosporine. Immunopharmacology. $2000 ; 47: 119-25$.

107. Baumann G. Molecular mechanism of immunosuppressive agents. Transplant Prac. 1992:24:4-7.

108. Rao $A_{1}$, Luo $C_{i}$ Hogan $P G$. Transcription factors of the NFAT family: regulation and function. Anru Rev Immunol. 1997; 15:707-47.

109. Zohilnhofer D, Klein CA, Richter T, Brandl R, Murr A, Nuhrenberg T, Schomig A, Baeuerle $P A_{11}$ Neumann FJ. Gene expression profiling of human stent-induced neointima by" CDNA array analysis of microscopic specimens retrieved by helix cutter atherectomy: Detection of FK506-binding prolein 12 upregulation. Circulation. 2001;103:1396-402.

110. Matsuda S, Shibasaki F, Takehana K, Mori H, Nishida E, Koyasu S. Two distinct action mechanisms of immunophilin-ligand complexes for the blockade of T-cell activation. EMBO Rep. 2000;1:428-34.

111. Sehgal SN. Rapamune (RAPA, rapamycin, sirolimus): mechanism of action immunosuppressive effect results from blockade of signal transduction and inhibition of cell cycle progression. Clin Biochem. 1998;31:335-40.

112. Suzuki T, Kopia G, Hayashi S, Bailey LR, Llanos G, Wilensky R, Klugherz BD Papandreou $G$, Narayan P, Leon MB, Yeung AC, Tio F, Tsao PS, Falotico R, Carter AJ. Stent-based delivery of sirolimus reduces neointimal formation in a porcine coronary model. Circulation. 2001;104:1188-93.

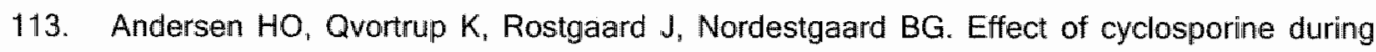
initiation of transplant arteriosclerosis. An ultrastructural study in the aorta-transplanted rabbit. Atherosclerosis. 1997;133:171-81.

114. Cramer DV, Chapman FA, Wu GD, Harnaha JB, Qian SQ, Makowka L. Cardiac transplantation in the rat. 11. Alteration of the severity of donor graft arteriosclerosus by modulation of the host immune response. Transplantation. 1990;50:554-8.

115. Wu GD, Cramer DV, Chapman FA, Cajulis E, Wang HK, StarZl TE, Makowka L. FK 506 inhibits the development of transplant arteriosclerosis. Transplant Proc. 1991;23:3272-4.

116. Drew AF. Tipping PG. Cyclosporine treatment reduces early atherosclerosis in the chollesterol-fed rabbit. Atherosclerosis. 1995;116:181-9.

117. Emeson EE, Shen ML. Accelerated atherosclerosis in hyperlipidemic C57BL/6 mice treated with cyclosporin A. Am J Pathol. 1993;142:1906-15.

118. Roselaar SE, Schonfeld G. Daugherty A. Enhanced development of atherosclerosis in cholesterol-fed rabbits by suppression of cell-mediated immunity. $J$ Clin Invest. 1995;96:1389-94.

119. Matsumoto T, Saito E, Watanabe H, Fujjioka T, Yamada T, Takahashi $Y$, Ueno T, Tochihara $T$, Kanmatsuse $K$. Influence of FK506 on experimental atherosclerosis in cholesterol-fed rabbits. Atherosclerosis. 1998;139:95-106.

120. Porter CM, N.A. C. Sustained NFAT signaling promotes a Th1-like pattern of gene expression in primary murine CD4+ cells. J. Immuno/ 2002;168:4936-4945. 
121. Liang $H_{4}$ Venema $V J$, Wang $X$, Ju H, Venema $R C$, Marrero MB. Regulation of angiotensin Il-induced phosphorylation of STAT3 in vascular smooth muscle cells. I Biol Chem. 1999:274:19846-51.

122. Boss $\mathrm{V}$, Abbott KL, Wang XF, Pavlath GK, Murphy TJ. The cyclosporin A-sensitive nuclear factor of activated T cells (NFAT) proteins are expressed in vascular smooth muscle cells. Differential localization of NFAT isoforms and induction of NFAT-mediated transcription by phospholipase C-coupled cell surface receptors. J Bio/ Chem. 1998;273:19664-71.

123. Hernandez GL, Volpert OV, Iniguez MA, Lorenzo E, Martinez-Martinez S, Grau R, Fresno M. Redondo JM. Selective inhibition of vascular endothelial growth factor-mediated angiogenesis by cyclosporin $A$ : roles of the nuclear factor of activated $T$ cells and cyclooxygenase 2. J Exp Med. 2001;193:607-20.

124. Fuleihan R, Ramesh N, Horner A, Ahern D, Belshaw PJ, Alberg DG, Stamenkovic I, Harmon W, Geha RS. Cyclosporin A inhibits CD40 ligand expression in T lymphocytes. A Clin Invest. 1994;93:1315-20.

125. Sata M, Walsh K. Cyclosporine downregulates Fas ligand expression on vascular endothelial cells: implication for accelerated vasculopathy by immunosuppressive therapy. Biochem Biophys Res Commun. 1999;263:430-2.

126. Holschermann $H$, Durfeld F, Maus U, Bierhaus A, Heidinger K Lohmeyer J, Nawroth PP, Tillmanns $H$, Haberbosch $W$. Cyclosporine a inhibits tissue factor expression in monocytes/macrophages. Blood. 1996;88:3837-45.

127. Zaman AK. Effects of tacrolimus hydrate (FK-506) on the expression of tissue factor in THP-1 human monocyte cell line. Hokkaido Igaku Zasshi. 2000;75:179-86.

128. Walter DH, Haendeler J, Galle J, Zeiher AM, Dimmeler S. Cyclosporin A inhibits apoptosis of human endothelial cells by preventing release of cytochrome $\mathrm{C}$ from mitochondria. Circulation. 1998:98:1153-7.

129. De Windt LJ, Lim HW, Taigen T, Wencker D, Condorelli G, Dorn GW, 2nd, Kitsis RN, Molkentin JD. Calcineurin-mediated hypertrophy protects cardiomyocytes from apoptosis in vitro and in vivo: An apoptosis-independent model of dilated heart failure. Circ Res. 2000;86:255-63.

130. Nottingham S, Knapp P, Springer $₫$. FK506 treatment inhibits caspase-3 activation and promotes oligodendroglial survival following traumatic spinal cord injury. Exp Neurol. 2002;177:242-51.

131. Mohacsi PJ, Tuller D, Hulliger $B$; Wijngaard PL. Different inhibitory effects of immunosuppressive drugs on thuman and rat aortic smooth muscle and endothelial cell proliferation stimulated by platelet-derived growth factor or endothelial cell growth factor. $J$ Heart Lung Transplant. 1997;16:484-92.

132. Prashar $Y$, Khanna $A$, Sehajpal $P$, Sharma VK, Suthanthiran M. Stimulation of transforming growth factor-beta 1 transcription by cyclosporine. FEBS Lett. 1995;358:109-12.

133. Mohamed MA, Robertson $H$, Booth TA, Balupuri $S$, Kirby JA, Talbot D. TGF-beta expression in renal transplant biopsies: a comparative study between cyclosporin-A and tacrolimus. Transplantation. 2000;69:1002-5.

134. Khanna AK, Hosenpud JS, Plummer MS, Hosenpud JD. Analysis of transforming growth factor-beta and profibrogenic molecules in a rat cardiac allograft model treated with cyclosporine. Transplantation. 2002;73:1543-9.

135. Ovuworie CA, Fox ER, Chow CM, Pascual M, Shih VE, Picard MH, Tolkoff-Rubin NE. Vascular endothelial function in cyclosporine and tacrolimus treated renal transplant recipients. Transplantation. 2001;72:1385-8. 
136. Hortelano $S$, Lopez-Collazo $E$, Bosica $\mathbb{L}$. Protective effect of cyclosporin $A$ and $F K 506$ from nitric oxide-dependent apoptosis in activated macrophages. $\mathrm{Br} J$ Pharmacol. $1999 ; 126: 113946$.

137. Dusting GJ, Macdonald PS. Endogenous nitric oxide in cardiovascular disease and transplantation. Ann Med. 1995;27:395-406.

138. Kuhlencordt PJ; Gyurko $R$, Han F, Scherrer-Crosbie M, Aretz TH, Hajjar $R$, Picard MH, Huang PL. Accelerated atherosclerosis, aortic aneurysm formation, and ischemic heart disease in apolipoprotein Elendothelial nitric oxide synthase double-knockout mice. Circulation. 2001;104:448-54.

139. Kuhlencordt $P J$, Chen J, Han F, Astern J, Huang $P L$. Genetic deficiency of inducible nitric oxide synthase reduces atherosclerosis and lowers plasma lipid peroxides in apolipoprotein E-knockout mice. Circulation. 2001;103:3099-104.

140. Vanrenterghem YF. Which calcineurin inhibitor is preferred in renal transplantation: tacrolimus or cyclosporine? Curr Opin Nephrol Hypertens. 1999;8:669-74.

141. Hohage $H$, Arlt M, Bruckner D, Dietl KH, Zidek W, Spieker C. Effects of cyciosporin A and FK 506 on lipid metabolism and fibrinogen in kidney transplant recipients. C/in Transplant. 1997:11:225-30.

142. Basso MD, Nambi P, Adelman SJ. Effect of sirolimus on the cholesterol content of aortic arch in ApoE knockout mice. Transplant Proc. 2003;35:3136-8.

143. Elloso MM, Azrolan N, Sehgal SN, Hsu PL, Phiel KL, Kopec CA, Basso MD, Adelman S.J. Protective effect of the immunosuppressant sirolimus against aortic atherosclerosis in apo E-deficient mice. Am J Transplant 2003:3:562-9.

144. Castro C, Campistol JM, Sancho D, Sanchez-Madrid F, Casals E, Andres V. Rapamycin attenuates atherosclerosis induced by dietary cholesterol in apolipoprotein-deficient mice through a p27 Kip1-independent pathway. Atherosclerosis, 2004;172:31-8.

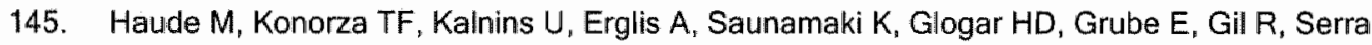
A, Richardit $H G$, Sick P, Erbel R. Heparin-coated stent placement for the treatment of stenoses in small coronary arteries of symptomatic patients. Circulation. 2003;107:1265-70.

146. Park SW, Lee CW, Kim HS, Lee NH, Nah DY, Hong MK, Kim JJ, Park SJ. Effects of cilostazol on angiographic restenosis after coronary stent placement. Am \& Cardiol. 2000;86:499-503.

147. Bendeck MP, Irvin $C$, Reidy MA. Inhibition of matrix metalloproteinase activity inhibits smooth muscle cell migration but not neointimal thickening after arterial injury. Circ Res. 1996:78:38-43.

148. Sollott SJ, Cheng L, Pauly RR, Jenkins GM, Monticone RE, Kuzuya M, Froehlich JP, Crow MT, Lakatta EG, Rowinsky EK, et al. Taxol inhibits neointimal smooth muscle cell accumulation after angioplasty in the rat. $/$ Clin /nvest. 1995;95:1869-76.

149. Poon M, Marx SO, Gallo R, Badimon JJ, Taubman MB, Marks AR. Rapamycin inhibits vascular smooth muscle cell migration. J Clin Invest. 1996;98:2277-83.

150. Gallo R, Padurean A, Jayaraman T, Marx S, Roque M, Adelman S, Chesebro J, Fallon J, Fuster $V$, Marks $A$, Badimon JJ. Inhibition of intimal thickening after balloon angioplasty in porcine coronary arteries by targeting regulators of the cell cycle. Circulation. 1999;99:2164-70.

151. Schiff PB, Horwitz SB. Taxol stabilizes microtubules in mouse fibroblast cells. Proc Nat/ Acad SciUS A. 1980;77:1561-5.

152. Rowinsky EK, Eisenhauer EA, Chaurdhry V, Arbuck SG, Donehower RC. Clinical toxicities encountered with paclitaxel (Taxol). Semin Oncol. 1993;20:1-15. 
153. Meier-Kriesche HU, Kaplan B. Toxicity and efficacy of sirolimus: relationship to whole-blood concentrations. Clin Ther 2000;22:B93-100.

154. Quesniaux VF, Wehrli $S$, Steiner $C$, Joergensen $J$, Schuurman $H J$, Herman $P$, Schreier $M H$, Schuler $W$. The immunosuppressant rapamycin blocks in vitro responses to hematopoietic cytokines and inhibits recovering but not steady-state hematopolesis in vivo. Blood. 1994;84:1543-52.

155. Hong MK, Mintz GS, Lee $C_{\text {, Song } J M}$, Han KH, Kang DH, Song JK $\mathrm{NJ}_{\text {" Feamot NE}}$. Park SW" Park SJ. Paclitaxel Coating Reduces In-Stent Intimal Hyperplasia in Human Coronary Arteries: A Serial Volumetric Intravascular Ultrasound Analysis From the ASian Paclitaxel-Eluting Stent Clinical Trial (ASPECT). Circulation. 2003; 107:517-20.

156. Tanabe K, Serruys PW, Grube E, Smits PC, Selbach G, Van Der Giessen WJ, Staberock M, De Feyter P, Muller R, Regar E, Degertekin M, Ligthart JM, Disco C, Backx B, Russell ME. TAXUS III Trial: In-Stent Restenosis Treated With Stent-Based Delivery of Paclitaxel Incorporated in a Slow-Release Polymer Formulation. Circulation. 2003; 107:559-64.

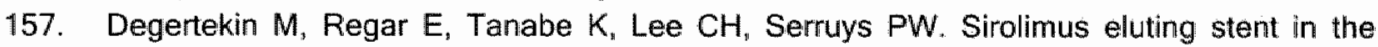
Ireatment of atherosclerosis coronary artery disease. Minerva Cardioangiol. 2002;50:40518.

158. Sousa JE, Costa MA, Abizaid A, Abizaid AS, Feres F, Pinto IM, Seixas AC, Staico R, Mattos LA, Sousa AG, Falotico R, Jaeger J, Popma JJ, Serruys PW. Lack of Neointimal Proliferation After Implantation of Sirolimus-Coated Stents in Human Coronary Arteries : A Quantitative Coronary Angiography and Three-Dimensional Intravascular Ultrasound Study. Circulation. 2001;103:192-195.

159. Regar $E$, Serruys PW, Bode C, Holubarsch $C$, Guermonprez JL, Wijns W, Bartorelli A, Constantini $C$, Degertekin M, Tanabe K, Disco C, Wuelfert E, Morice MC. Angiographic findings of the multicenter Randomized Study With the Sirolimus-Eluting Bx. Velocity Balloon-Expandable Stent (RAVEL): sirolimus-eluting stents inhibit restenosis irrespective of the vessel size. Circulation. 2002;106:1949-56.

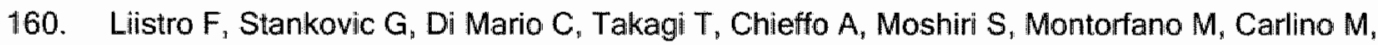
Briguori $C$, Pagnotta $P$, Albiero R, Corvaja $N$, Colombo A. First clinical experience with a paclitaxel derivate-eluting polymer stent system implantation for in-stent restenosis: immediate and long-term clinical and angiographic outcome. Circulation. 2002;105:1883-6.

161. Farb A, Heller PF, Shroff S, Cheng L, Kolodgie FD, Carter AJ, Scott DS, Froehlich J, Virmani R. Pathological analysis of local delivery of paclitaxel via a polymer-coated stent. Circulation. 2001;104:473-9.

162. Farb $A$, John $M$, Acampado $E_{1}$ Kolodgie FD, Prescott MF, Virmani R. Oral everolimus inhibits in-stent neointimal growth. Circulation. 2002;106:2379-84.

163. Sousa JE, Costa MA, Sousa AG, Abizaid AC, Seixas AC, Abizaid AS, Feres F, Mattos LA, Falotica R, Jaeger J, Popma JJ, Serruys PW. Two-year angiographic and intravascular ultrasound follow-up after implantation of sirolimus-eluting stents in human coronary arteries. Circulation 2003;107:381-3.

164. Waller JR, Brook NR, Bicknell GR, Nicholsan ML. Differential effects of modem immunosuppressive agents on the development of intimal hyperplasia. Transpl /nt. $2004 ; 17: 9-14$.

165. Wieneke H, Dirsch O, Sawitowski T, Gu YL, Brauer H, Dahmen U, Fischer A, Whendt $S$, Erbel $\mathbb{R}$. Synergistic effects of a novel nanoporous stent coating and tacrolimus on intima proliferation in rabbits. Catheter Cardiovasc Interw. 2003;60:399-407. 
166. Grube $E$, Gerckens $U$, Muller $R$, Bullesfeld $L$. Drug eluting stents: initial experiences. $Z$ Kardiol. 2002;91 Suppl 3:44-8.

167. Waller JR, Murphy GJ, Bicknell GR, Toomey D, Nicholson ML. Effects of the combination of rapamycin with tacrolimus or cyclosporin on experimental intimal hyperplasia. $B r J S u r g$. 2002;89:1390-5.

168. Graveley BR. Alternative splicing: increasing diversity in the proteomic world. Trends Genet. $2001 ; 17: 100-7$.

169. Santucci $A$, Trabalzini $L$, Bovalini $L$, Ferro E, Neri $P$, Martelli $P$. Differences between predicted and observed sequences in Saccharomyces cerevisiae. Electrophoresis. 2000;21:3717-23.

170. Klose J. Protein mapping by combined isoelectric focusing and electrophoresis of mouse tissues. A novel approach to testing for induced point mutations in mammals. Humangenetik. 1975;26:231-43.

171. O'Farrell $\mathrm{PH}$. High-resolution two-dimensional electrophoresis of proteins. J.Biol.Chem. 1975;250:4007-4021.

172. Shevchenko A, Wilm M, Vorm O, Mann M. Mass spectrometric sequencing of proteins from silver-stained polyacrylamide gels. Anal. Chem. 1996;68:850-858.

173. Smith RD, Loo JA, Edmonds CG, Barinaga Cd, Udseth HR. New developments in biochemical mass spectrometry: electrospray ionization. Anal Chem. 1990;62:882-99.

174. Yip TT, Hutchens TW. Mapping and sequence-specific identification of phosphopeptides in unfractionated protein digest mixtures by matrix-assisted laser desorption/ionization timeof-flight mass spectrometry. FEBS Lett. 1992;308:149-53.

175. Grant ER, Cooks RG. Mass spectrometry and its use in tandem with laser spectroscopy. Science. 1990;250:61-8.

176. Chernushevich IV, Loboda AV, Thomson BA. An introduction to quadrupole-time-of-flight mass spectrometry. J Mass Spectrom. 2001;36:849-65.

177. Mann $M$, Wilm M. Error-tolerant identification of peptides in sequence databases by peptide sequence tags. Anal Chem. 1994;66:4390-9.

178. Yates JR, Eng JK, McCormack AL, Schieltz D. Method to correlate tandem mass spectra of

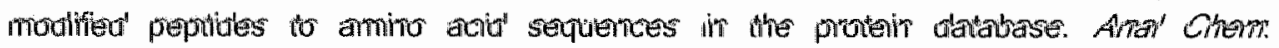
$1995 ; 67: 1426-36$.

179. Hoogland $C$, Sanchez JC, Walther D, Baujard V, Baujard O, Tonella L, Hochstrasser DF。 Appel RD. Two-dimensional electrophoresis resources available from ExPASy. Electrophoresis. 1999;20:3568-71.

180. Gorg $A_{\text {s }}$ Postel W, Gunther $S$. The current state of two-dimensional electrophoresis with immobilized pH gradients. Electrophoresis. 1988;9:531-46.

181. Issaq HJ, Conrads TP, Prieto DA, Tirumalai R, Veenstra TD. SELDI-TOF MS for diagnostic proteomics. Anal Chem. 2003; 75:148A-155A.

182. Petricoin EF, Liotta LA. SELDI-TOF-based serum proteomic pattern diagnostics for early delection of cancer. Curr Opir Biotechnol. 2004;15:24-30.

183. Hunt DF, Henderson RA, Shabanowitz J, Sakaguchi K, Michel H, Sevilir N, Cox AL, Appella E. Engelhard $\mathrm{VH}$. Characterization of peptides bound to the class I MHC molecule HLAA2.1 by mass spectrometry. Science. 1992;255:1261-3.

184. Gygi SP, Rist B, Gerber SA, Turecek F, Gelb MH, Aebersold R. Quantitative analysis of complex protein mixtures using isotope-coded affinity tags. Nat Biotechnol 1999;17:994-9. 
185. Liotta LA, Espina $V$, Mehta Al, Calvert $V$, Rosenblatt $K$, Geho D, Munson PJ, Young $L$, Wulfkuhle J, Petricoin EF, 3rd. Protein microarrays: meeting analytical challenges for clinical applications. Cancer Cell. 2003;3:317-25.

186. MacBeath G. Protein microarrays and proteomics. Nat Genet 2002,32 Suppl:526-32.

187. Knezevic V, Leethanakul C, Bichsel VE, Worth JM, Prabhu VV, Gutkind JS, Liotta LA, Munson PJ, Petricoin EF, 3rd, Krizman DB. Proteomic profiling of the cancer microenvironment by antibody arrays. Proteomics. 2001;1:1271-8.

188. Paweletz CP, Charboneau L, Bichsel VE, Simone NL, Chen T, Gillespie JW, Emmert-Buck $M R$, Roth $M J$, Petricoin IE, Liotta LA. Reverse phase protein microarrays which capture disease progression show activation of pro-survival pathways at the cancer invasion front. Oncogene. 2001:20:1981-9. 



\section{Chapter 2:}

\section{Models of atherosclerosis and transplant arteriosclerosis the quest for the best}

Marjo M.P.C. Donners, Sylvia Heeneman. Mat A.P. Daenen.

Drug Discovery Today 2004; 1(3):257-263. 


\section{- Abstract}

The pathobiology of atherosclerosis and transplant arteriosclerosis has been extensively studied using both in vitro and in vivo models. This review describes the latest advances in this highly dynamic field of research, including the quest for animal models of atherosclerotic plaque rupture, the search for new modifier genes using (in silico) quantitative trait locus analysis and the determination of the role of progenitor cells in the development of these wide-spread diseases. 
Atherosclerosis is a complex, chronic disease of the large systemic arteries and the leading cause of death in the western world. This multifactorial disease is characterized by the accumulation of lipids, cells and extracellular matrix in the vessel wall. It is now generally accepted that the development of atherosclerotic lesions is a response-to-injury and involves a chronic inflammatory reaction ${ }^{1}$.

Transplant arteriosclerosis is the single leading cause of late graft loss in organ transplants and vascular reconstructions. Similar to atherosclerosis, transplant arteriosclerosis develops as a response-to-injury. It is characterized by prominent vascular smooth muscle cell (VSMC) proliferation (neointima formation), but also involves an immunologic component ${ }^{2}$.

Several in vitro and in vivo models have been developed to unravel the underlying molecular mechanisms of these diseases and to examine the effects of therapeutic interventions. In this review we will describe the latest developments in this dynamic field of research.

\section{In vitro models}

Since atherosclerosis and transplant arteriosclerosis are such complex diseases, in vitro models are mostly used to study distinct (sub)cellular processes involved in these diseases. These include assays of proliferation, apoptosis, adhesion and (trans)migration of vascular or hemopoietic cells such as VSMC, endothelial cells (EC), monocytes/macrophages and T-lymphocytes. Recently , in vitro models have been developed to study endothelial dysfunction induced by the immunosuppressive drug cyclosporine A (relevant for transplant arteriosclerosis) or by glucose (associated with atherosclerosis in diabetics) ${ }^{3,4}$. Since in the in vivo situation interactions between cells is extremely important, new in vitro models use co-cultures, arterial segments and wholemount lesions in culture ${ }^{5}$. Because of the complexity of interactions in an intact organism, in vitro studies alone are generally insufficient.

\section{In vivo models}

For over a decade now, the most widely used animal models of primary atherosclerosis are genetically engineered mice lacking genes involved in lipid metabolism like apolipoprotein $E$ (ApoE-/-) and the low-density lipoprotein-receptor ( $\mathrm{LDLF}-/-)^{6}$. These model mice develop widespread atherosclerotic lesions reproducibly within 4 months (or faster when fed a high-fat diet). The extent of atherosclerosis development and lesion morphology is also determined by the genetic background of the mice. C5BL/6J mice compared to FVB/NJ mice, for example, develop larger and more advanced lesions, showing large lipid cores and fibrous caps ${ }^{7}$. Atherosclerotic lesions can be quantified using en face analysis, in which the aorta is pinned out and stained for lipid, or cross-sectional analysis of the aortic sinus/arch, which provides also information on lesion morphology ${ }^{8,9}$. Three years ago, Von der Thusen et al. ${ }^{10}$ developed a mouse-model of accelerated 
atherosclerosis, in which placement of a silastic collar around the common carotid artery induced development of advanced heterogeneous atherosclerotic plaques within 6 weeks.

Recently several papers have reviewed the available models of plaque instability, a very important clinical complication of atherosclerotic disease ${ }^{11,12}$. Reddick et al. ${ }^{13}$ reported thrombus formation in mouse aortas that were injured by squeezing with a forceps, whereas von der Thusen et al. ${ }^{1 / 4}$ used adenoviral p53-overexpression in ApoE-/- mice to induce fibrous cap thinning and treatment with phenylephrine, a vasoconstrictor, to induce intraplaque hemorrhage. In addition, features of plaque instability have been reported in the brachiocephalic artery of ApoE-\% mice on a prolonged high-fat diet. Aneurysm formation also includes some characteristics of plaque vulnerability, although it may involve a different mechanism. Mouse models of abdominal aortic aneurysm have recently been reviewed by Daugherty et al ${ }^{15}$.

Larger animals in atherosclerotic research may more accurately resemble human atherosclerosis, but their use is still limited. Pigs develop plasma cholesterol levels and atherosclerotic lesions similar to humans, but their maintenance is more difficult and expensive than smaller animals. Cholesterol-fed rabbits are often used as a model to reflect the human condition, but develop extremely high cholesterol levels and more fatty, macrophage-rich lesions than humans ${ }^{16}$. The recent development of transgenic rabbits ${ }^{17}$, however, could make this model more attractive. Furthermore, some studies have reported evidence of plaque instability in rabbits. Although most studies needed some kind of mechanical or chemical intervention to induce plaque rupture with thrombus formation, recently a new strain of Watanabe heritable hyperlipidemic (WHHL) rabbits has been reported that displays spontaneous myocardial infarction, which was attributed to large occlusive coronary atherosclerotic lesions with intraplaque hemorrhage ${ }^{18}$.

Larger animals can also be used in (molecular) imaging studies of cardiovascular disease, in which disease development and efficacy of (novel) therapies can be monitored objectively and non-invasively. Imaging may also enable early disease diagnosis or prognosis. Imaging studies in atherosclerosis have focused on the detection of atherosclerotic plaques and the determination of plaque composition by using several imaging modalities, such as (intravascular) ultrasound, computed tomography or magnetic resonance imaging (MRI). Molecular imaging focuses on detecting high-risk, vulnerable plaques by displaying and quantifying cellular or molecular targets such as lipid (oxidized LDL), protease activity, activated endothellium or macrophages (reviewed by Jaffer and Weissleder ${ }^{19}$ ). Targeting fibrin or other thrombus-related proteins may facilitate the detection of plaque rupture. Although the majority of imaging studies still use larger animals, such as rabbits or pigs, it is possible to image atherosclerotic lesions in the mouse.

Studies of transplant arteriosclerosis have also often used larger animals (rat, rabbit, dog, pig) because of the technical challenge of performing vascular transplantations in small animals. Models using allografting (transplantation between different strains) resemble arteriosclerosis accompanying organ transplantation, whereas models using autologous grafting of vein segments into arteries (within the same animal strain) resemble transplant arteriosclerosis due to altered flow environment accompanying venous bypass 
grafting. A reproducible vein graft model using rabbits was published last year by Jiang et al. ${ }^{20}$. In this study various vascular reconstructions were used to study vein graft adaptation under conditions of low and high shear stress, leading to enhanced intimal thickening or outward remodeling, respectively. Dietrich et al. ${ }^{27}$ developed a mouse model of transplant arteriosclerosis in which vascular segments were implanted between 2 ends of the carotid artery by sleeving the arterial ends over a nylon cuff, which simplifies the operative procedure and reduces traumatic and ischemic injury to the grafts. On the other hand, $L u$ et al. developed a rat model, in which the synergistic effects of ischemic/reperfusion injury and the immune reaction accelerates transplant arteriosclerosis ${ }^{22}$.

These animal models have not only been used to study the effect of interventions on disease development, they are also extensively used to dissect the molecular mechanisms involved. One of these mechanisms is the origin of the neointimal VSMC that was generally believed to originate locally from the medial layer. Recently increasing evidence has been found that bone marrow cells have the potential to give rise to vascular progenitor cells, which can home to sites of vascular injury. These vascular progenitor cells can locally differentiate into EC or VSMC, thereby contributing to vascular repair or lesion formation. Convincing evidence for the contribution of vascular progenitor cells to lesion formation emerged from studies using mice ubiquitously expressing green fluorescent protein (GFP) or LacZ (ROSA26 mice) (reviewed by Sata ${ }^{23}$ ). These studies using transplantation of hearts or vascular segments showed a substantial contribution of recipient cells to neointima formation. Transplantation of wild-type hearts into ROSA26 mice yielded coronary neointimal lesions expressing LacZ in contrast to the LacZ-negative medial layer. Vice versa, when hearts of ROSA26 mice were transplanted into wild-type mice, LacZ-negative neointimal lesions developed on the LacZ-positive coronary artery media. To identify the source of these neointimal cells in the coronary arteries of (wildtype) transplanted hearts, bone marrow transplantation (BMT) was used. Wild-type mice with bone marrow of ROSA26 or GFP mice, developed transplant arteriosclerotic lesions with neointimal cells mainly expressing LacZ or GFP, indicating they were derived from the donor bone marrow.

Similarly, in studies of atherosclerotic lesions, BMT was performed from mice expressing either GFP or LacZ to ApoE-/- mice. After several weeks on an atherogenic diet, GFP/LacZ-positive cells accumulated in atherosclerotic lesions developing in the recipient mice. These cells expressed markers for VSMC ( $\alpha$-smooth muscle actin) or macrophages, indicating that bone-marrow derived cells (from GFP/LacZ-expressing donor mice) homed to the site of atherosclerotic lesion development and differentiated into vascular cells. These findings may provide the basis for development of new therapeutic strategies for vascular disease, targeting mobilization, homing, proliferation and differentiation of circulating vascular progenitor cells. 
Although the models described above have been used extensively to study the pathobiology of atherosclerosis and transplant arteriosclerosis and to test the role of candidate genes in these diseases, the underlying molecular mechanisms are still not fully elucidated and the search for new "modifier genes' perseveres. Quantitative trait locus (QTL)-analysis is a genetic approach to examine correlations between genotypes and phenotypes and to identify (new) genes underlying polygenic traits (figure 2. 1). Again, mice are the preferred model for this genetic approach because of the availability of numerous inbred strains (which are genetically homogeneous), the ease of genetic manipulation, the high degree of genetic knowledge and, particularly for atherosclerosis, the availability of different mouse models. QTL-analysis uses 100-200 strain-specific polymorphic markers that span the mouse genome at small intervals (20-10 centimorgan) thereby defining chromosomal map loci. Correlations between genotype and phenotype can then be defined using special QTL software, such as Map Manager QTX or R/qut (http://mapmgr.roswellpark.org/mmQTX.html or http.//www.biostat.jhsph.edu/ kbroman/qtl, respectively). The output is expressed as a likelihood ratio statistic or as a log of the odds ratio (LOD) score.

After this initial mapping, secondary congenic lines are created by repeated intercrossing of inbred strains that differ significantly in the measured phenotype(s) to isolate the QTL locus from one strain onto the genetic background of another strain. By selecting for recombinants in the interval, the QTL locus can be narrowed-down to identify strainspecific polymorphisms and functional or expression differences in specific genes. The recent completion of the draft mouse genome ${ }^{24}$ will assist the definitive identification of the quantitative trait loci, although minimal QTL intervals often contain several genes or numerous DNA sequence variants. Consequently, each nucleotide variant or gene must be tested functionally.

Several QTL-analysis studies have been studying atherosclerosis susceptibility and so far approximately 10-15 loci, of which some may overlap ${ }^{25}$, have been reported to be associated with atherosclerotic lesion size (reviewed by Smith et al. ${ }^{26}$ ). However, the definitive identification and functional testing of these candidate genes is still in progress. Both physiologic and behavioral parameters for phenotypic characterization can be found in the Mouse Phenome Database (http://www.jax.org/phenome).

This phenotype-driven, 'reverse genomics' approach probably also leads to the development of new (mouse) models (available at http://pga.jax.org/) to examine genes underlying complex diseases such as atherosclerosis and transplant arteriosclerosis (reviewed by Svenson et al.) ${ }^{27}$. Besides using existing genetic variation between the hundreds of distinct inbred mouse strains, also whole-genome intervention (chemical mutagenesis by $\mathrm{N}$-ethyl- $\mathrm{N}$-nitrosurea (ENU)) followed by phenotypic characterization can be utilized to establish new mouse models and to expand our understanding of the disease mechanisms. 


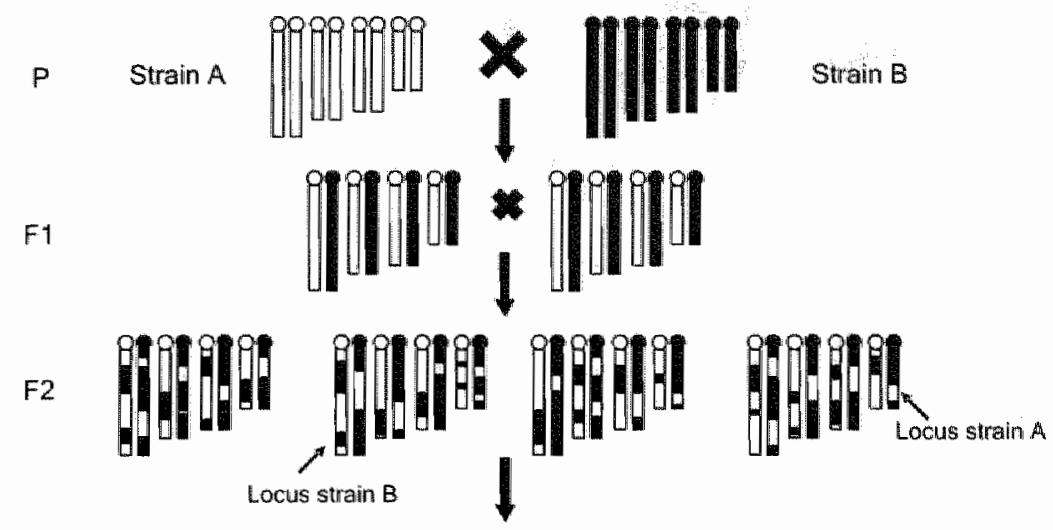

Genome scans and linkage analysis
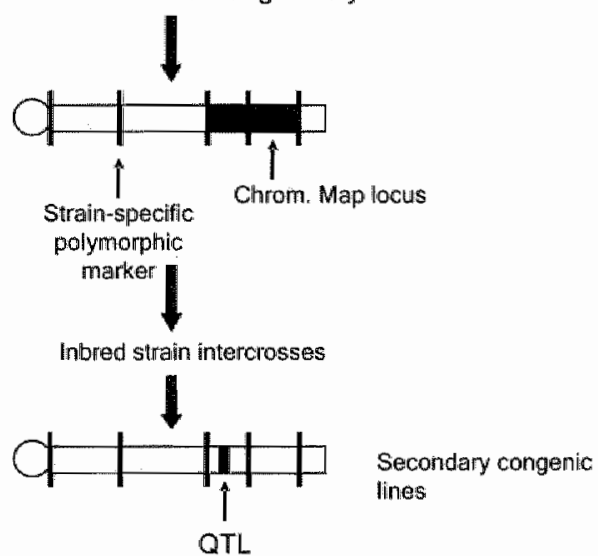

\section{Figure 2.1}

QTL analysis uses two (mouse) strains displaying distinct phenotypes ( $A$ and $B$ ) and intercrosses of their offspring. Genome scans are performed to determine the genotype of F2 mice. Chromosomal map loci are defined by strain-specific polymorphic markers that span the genome at small intervals (10-20 cM). Special QTL sofware can then be used to correlate genotype and phenotype of individual mice. Subsequently, secondary congenic limes are created by repeated intercrosses and used to isolate the QTL locus from one strain onto the genetic background of the other strain.

\section{In silico models}

QTL-analysis is a laborious technique, requiring various intercrosses and determination of genotypes and phenotypes of hundreds or thousands of mice, which can easily take years of analysis. A few years ago, Grupe et al. ${ }^{28}$ developed an in silico QTL method, using a computer algorithm and a mouse single nucleotide polymorphism (SNP) database containing allele information of 15 inbred mouse strains (avallable at http://mousesnp.roche.com). After entering phenotype data on the particular trait, the algorithm searches for SNP patterns that are similar among strains with similar phenotypes, but different among strains with different phenotypes. Although further 
- Map Manager QTX QTL software is available at:

http:/mapmgr roswellpark.org/mmQTX.html

- R/qtI QTL software is avallable at:

http:/www biostat.jhsph.edu/ $/ \mathrm{kbroman/qut/}$

- The Mouse Phenome database can be found at:

hittp:/www.jax.org/phenome

- Information on newly developed (mouse) models can be found at:

http://pga.jax.org/

- The mouse single nucleotide polymorphism database is available at:

http.//mousesnp.roche.com

Box 2.1

List of links to related websites

analysis is needed to pinpoint the gene and the mutations within the QTL, this in silico method highly accelerates the process not only by circumventing strain intercrosses, but also by comparing multiple strains instead of two as ün traditional QTL.

Using this in silico QTLL-analysis, Smith et al. ${ }^{29}$ defined 5 genetic loci that are associated with atherosclerosis in ApoE-/- mice on 6 inbred genetic backgrounds. Four of these 5 loci have been previously implicated in atherosclerosis by traditional QTL-analysis, whereas other atherosclerosis susceptibility loci identified by traditional QTL-analysis were not observed in in silico QTL. A list of related websites and the most relevant articles is shown in boxes 2.1 and 2.2 respectively.

- Cullen "P. et al. (2003) Rupture of the atherosclerotic plaque: does a good animal model exist? Arterioscler Thromb Vasc Bio/ 23 (4), 535-542.

- Jaffer, F.A. et al. (2004) Seeing within: molecular imaging of the cardiovascular system. Circ Res 94 (4), 433-445.

- Sata, M. (2003) Circulating vascular progenitor cells contribute to vascular repair, remodeling, and lesion formation. Trends Cardiovasc Med 13 (6), 249-253.

- Smith, J. (2003) Quantitative trait locus mapping for atherosclerosis susceptibility. Curr Opin Lipidol 14 (5), 499-504.

- Daugherty, A. and Cassis, L.A. (2004) Mouse models of abdominal aortic aneurysms. Anterioscler Thromb Vasc Bio/24 (3), 429-434

Bax 2.2

List of most relevant articles 


\section{Model comparison}

The previous section describes several models or approaches to study underlying molecular mechanisms of atherosclerosis and transplant arteriosclerosis or to examine the effects of interventions on the development of these complex diseases. Table 2.1 summarizes the advantages and disadvantages of these models. Although in vitro models can never completely mimic in vivo situations, in vitro systems using co-cultures or wholemount arterial segments/lesions (partially) retain the interplay of cellular and humoral factors.

In wivo models also use increasingly more complex interventions, such as BMT or double-knockout mice, to specify the contribution of distinct cell-types to lesion formation and the effect of manipulation of specific targets on disease development. Because of the availability of numerous inbred strains and the relative ease of genetic manipulation, mouse models have been widiely used for in vivo studies. However, there is still a need for larger animal models, which may more closely resemble human lesion formation. Larger animals are also very suitable for (molecular) imaging studies, although the focus is now being directed to mice because of their benefit of genetic modification. In this perspective, transgenic rabbits could become a very interesting model. Local gene transfer to the vessel wall also provides a way to genetically modify the development of atherosclerosis or transplant arteriosclerosis in (large) animal models.

Several models have been described recently that show some features of plaque instability, but the quest for animal models of true plaque rupture remains. Models using mechanical/chemical interventions display time-controlled features of plaque instability, but for studies of spontaneous plaque rupture such models are not very suitable.

Besides these models of atherosclerosis and transplant arteriosclerosis, 'reversegenomics' approaches are used to identify (modifier) genes associated with these complex diseases, such as in vivo QTL-analysis. However, this is a laborious and time-consuming technique, using a large amount of mice, whereas the in silico method highly accelerates the analysis and reduces the amount of animals needed. Questions regarding these outstanding issues are summarized in Box 2.3.

- Will future developments lead to a good animal model of atherosclerotic plaque ruplure?

- Will the use of new techniques such as BMT or molecular imaging lead to novel mechanistic insights and new therapies?

- Will the trend of the use of larger animal models persist?

- Will phenotype-driven reverse-genomics approaches lead to the development of new (mouse) models of atherosclerasis or transplant arteriosclerosis?

Box 2.3

Outstanding questions regarding atherosclerotic/transplant arteriosclerotic research 


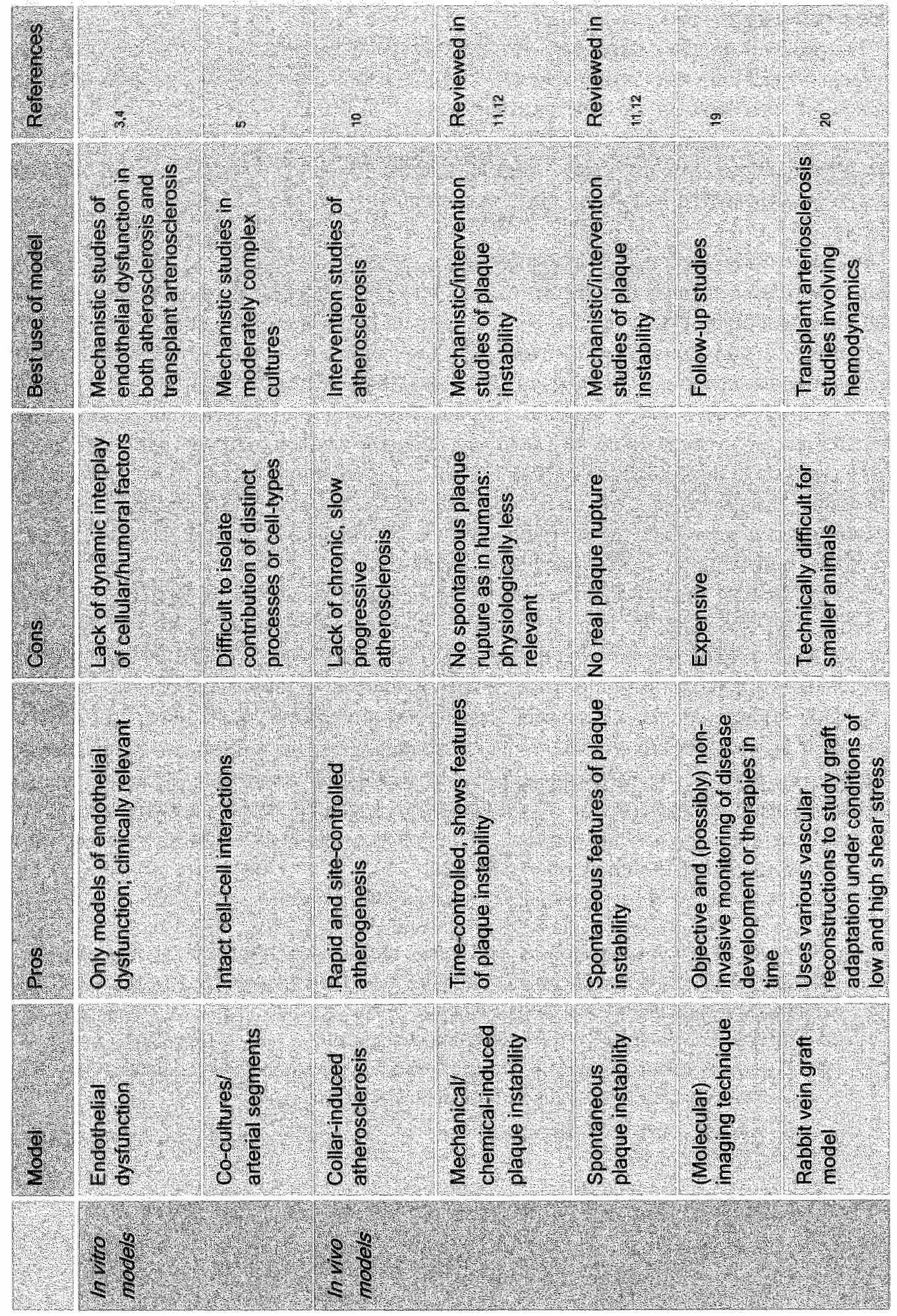




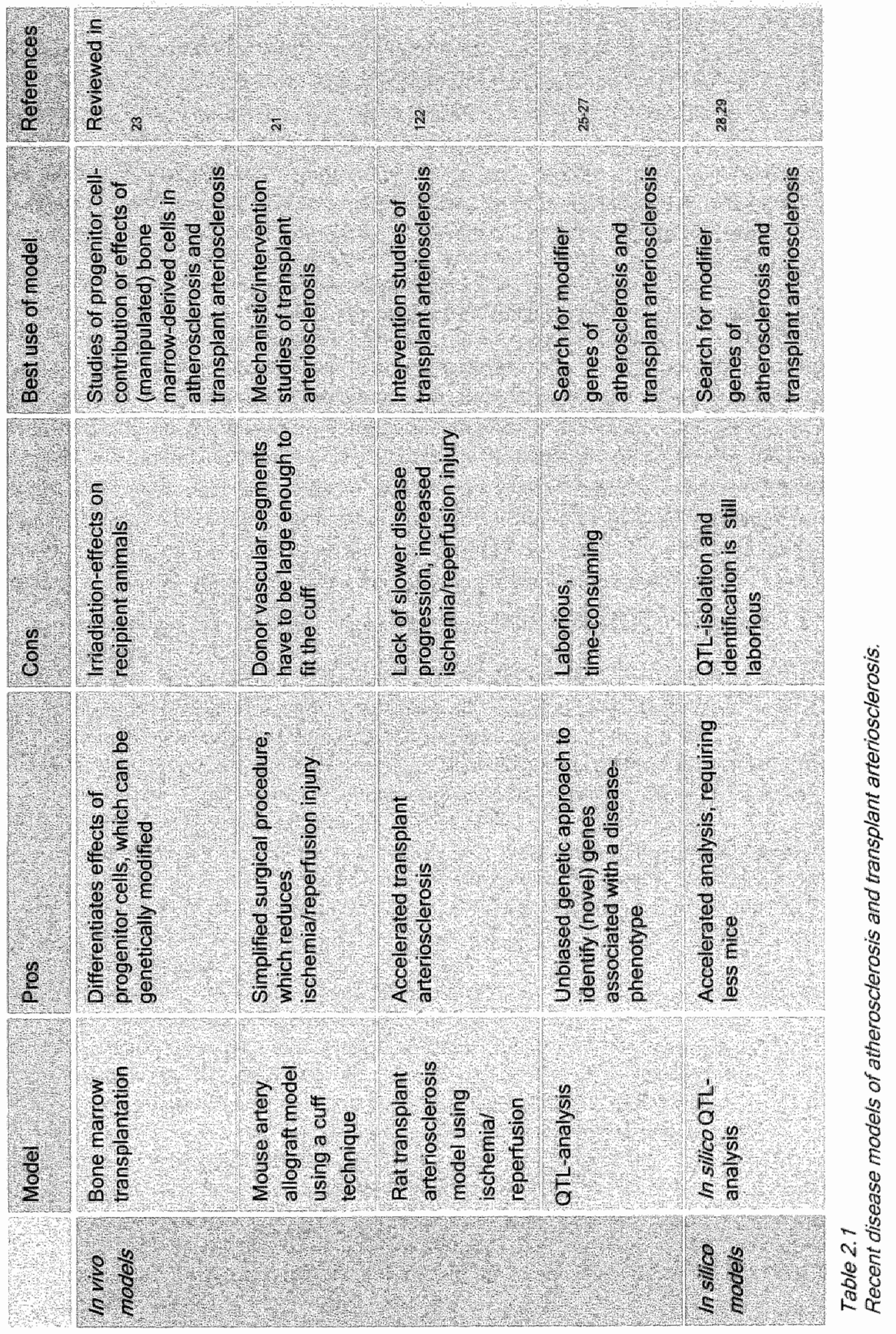


Model translation to humans

Considering the different models described above, the larger animal models may more closely resemble human situations of atherosclerosis and transplant arteriosclerosis, but the benefits of genetically modified inbred mice remains, especially in QTL-analysis studies. The major limitation of atherosclerotic research, however, is the lack of animal models of human-like plaque rupture, characterized by fibrous cap disruption and luminal thrombus formation. The development of a model to reproduce the complex process of human atherosclerotic plaque rupture would probably require multiple interventions, most likely using larger animal models.

\section{Conclusions}

Although the pathobiology of atherosclerosis and transplant arteriosclerosis has been extensively studied, the underlying molecular mechanisms are not fully elucidated. QTLanalysis can significantly contribute to the identification of genes underlying these complex diseases. Furthermore, the quest for new models, especially animal models of atherosclerotic plaque rupture, perseveres. These models are essential to elucidate disease mechanisms, as evidenced by the studies indicating a role for progenitor cells in lesion development in both diseases. This knowledge can then lead to development of new therapies. Finally, (molecular) imaging can be used to enable early diagnosis, monitor disease development or (novel) therapies. 


\section{References}

1. Lusiis AJ. Atherosclerosis. Nature. 2000;407:233-41.

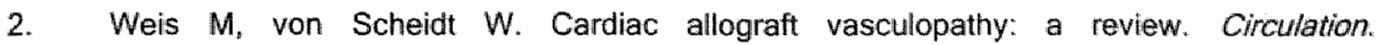
1997;96:2069-77.

3. Wilasrusmee $C_{n}, D a$ Silva $M$, Singh $B$, Kittur $S$, Siddiqui J, Bruch $D$, Wilasrusmee $S$, Kittur DS. A new in vitro model to study endothelial injury. J Surg Res. 2002;104:131-6.

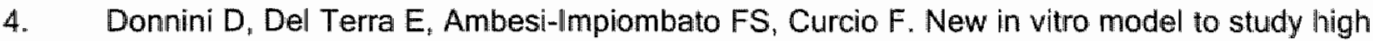
glucose-dependent endothelial dysfunctions. Biochimie. 2003;85:701-5.

5. Constantinescu $E$, Alexandru $D$, Alexandru $V$. An ex vivo model to study the monocyteendothelial cell interaction in the prelesional stage of experimentally-induced atherogenesis in hamster. I Submicrasc Cytol Pathol. 2002;34:115-24.

6. Smith JD, Breslow JL. The emergence of mouse models of atherosclerosis and their relevance to clinical research. J Intern Med. 1997;242:99-109.

7. Dansky HM, Charlton SA, Sikes JL, Heath SC, Simantov $R$, Levin LF, Shu $P$, Moore KJ, Breslow JL, Smith JD. Genetic background determines the extent of atherosclerosis in ApoE-deficient mice. Arterioscler Thromb Vasc Biol. 1999;19:1960-8.

8. Lutgens $E_{x}$ Daemen $M$, Kockx $M$, Doevendans $P$, Hofker $M$, Havekes $L$, Wellens $H_{v}$ de Muinck ED. Atherosclerosis in APOE*3-Leiden transgenic mice: from proliferative to atheromatous stage. Circulation. 1999;99:276-83.

9. Daugherty A, Whitman SC. Quantification of atherosclerosis in mice. Methods Mol Biol. 2003;209:293-309.

10. von der Thusen JH, van Berkell T.J.C., E.A.L. B. Induction of rapid atherogenesis by perivascular carotid collar placement in apolipoprotein E-deficient and low-density lipoprotein receptor-deficient mice. Circulation. 2001;103:1164-1170.

11. Lutgens $E$, van Suylen RJ, Faber BC, Gijbels MJ, Eurlings PM, Bijnens AP, Cleutjens KB, Heeneman S, Daemen MJ. Atherosclerotic plaque rupture: local or systemic process? Arterioscler Thromb Vasc Biol. 2003;23:2123-30.

12. Cullen $P$, Baetta $R$, Bellosta $S$, Bernini $F$, Chinetti $G$, Cignarella $A$, von Eckardstein $A$, Exley A, Goddard M, Hofker M. Hurt-Camejo E, Kanters E, Kovanen P, Lorkowski S, McPheat W, Pentikainen M, Rauterberg J, Ritchie A Staels B, Weitkamp B, de Winther M. Rupture of the atherosclerotic plaque: does a good animal model exist? Arterioscler Thromb Wasc Biol. 2003;23:535-42.

13. Reddick RL, Zhang SH, Maeda $N$. Aortic atherosclerotic plaque injury in apolipoprotein $E$ deficient mice. Atherasclerosis. 1998;140;297-305.

14. von der Thusen $\mathrm{JH}$, van Vlijmen BJ, Hoeben RC, Kockx MM, Havekes LM, van Berkel TJ, Biessen EA. Induction of atherosclerotic plaque rupture in apolipoprotein E-\%-mice after adenovirus-mediated transfer of p53. Circulation. 2002;105:2064-70.

15. Daugherty A, Cassis LA. Mouse models of abdominal aortic aneurysms. Arterioscler Thromb Vasc Biol. 2004;24:429-34.

16. Badimon L. Atherosclerosis and thrombosis: lessons from animal models. Thromb Haemost. 2001;86:356-65.

17. Bosze $Z$, Hiripi $L$, Carnwath JW, Niemann $H$. The transgenic rabbit as model for human diseases and as a source of biologically active recombinant proteins. Transgenic Res. $2003 ; 12: 541-53$. 
18. Shiomi $M$, tho $T$, Yamada $S$, Kawashima $S$, Fan J. Development of an animal model for spontaneous myocardial infiarction (WHHLMI rabbit). Arterioscler Thromb Vasc Biol. $2003 ; 23: 1239-44$.

19. Jaffer FA, Weissleder R. Seeing within: molecular imaging of the cardiovascular system. Circ Res. 2004;94:433-45.

20. Jiang Z, Wu L, Miller BL, Goldman DR, Fernandez CM, Abouhamze ZS, Ozaki CK, Bercell SA. A novel vein graft model: adaptation to differential flow environments. Am J Physiol Heart Circ Physial 2004;286:H240-5.

21. Dietrich $H, H u Y$, Zou $Y$, Dirnhofer $S$, Kleindienst $R$, Wick $G, X u Q$. Mouse model of transplant arteriosclerosis: role of intercellular adhesion molecule-1. Arterioscler Thromb Vasc Biol. 2000;20:343-52.

22. Lu YP, Chen WG, Wang I, Li YP. A new rat model of transplant arteriosclerosis accelerated by ischemia/reperfusion injury. Transplant Proc: 2003;35:184-6.

23. Sata $M$. Circulating vascular progenitor cells contribute to vascular repair, remodeling, and lesion formation. Trends Cardiovasc Med. 2003;13:249-53.

24. Okazaki $Y$, et al. Analysis of the mouse transcriptome based on functional annotation of 60,770 full-length cDNAs. Nature. 2002;420:563-73.

25. Ishimori N, Li R, Kelmenson PM, Korstanje R, Walsh KA, Churchill GA Forsman-Semb $K_{*}$ Paigen B. Quantitative trait loci analysis for plasma HDL-cholesterol concentrations and atherosclerosis susceptibility between inbred mouse strains C57BL/6J and 129S1/Sv/mJ. Arterioscler Thromb Vasc Biol. 2004;24:161-6.

26. Smith J. Quantitative trait locus mapping for atherosclerosis susceptibility. Curr Opin Lipidol. 2003;14:499-504.

27. Svenson KL, Bogue MA, Peters LL. Invited review: Identifying new mouse models of cardiovascular disease: a review of high-throughput screens of mutagenized and inbred strains. J App/ Physiol. 2003;94:1650-9; discussion 1673.

28. Grupe A, Germer S, Usuka J, Aud D , Belknap JK, Klein RF, Ahluwalia MK, Higuchi R, Peltz G. In silico mapping of complex disease-related traits in mice. Science. 2001;292:1915-8.

29. Smith JD, James D, Dansky HM, Wittkowski KM, Moore KJ, Breslow JL. In silico quantitative trait locus map for atherosclerosis susceptibility in apolipoprotein E-deficient mice. Arterioscler Thromb Vasc Biol. 2003:23:117-22. 



\section{Chapter 3:}

\section{Low dose FK506 blocks collar-induced atherosclerotic plaque development and stabilizes plaques in ApoE-/- mice}

Marjo M.P.C. Donners, Ilze Bot, Leon J. De Windt, Theo J.C. Wan Berkel, Mat J.A.P. Daemen, Erik A.L. Biessen, Sylvia Heeneman.

American Jounal of Transplantation, in press. 


\section{Abstract}

Since atherosclerosis is a chronic inflammatory disease, we tested the hypothesis that calcineurin-inhibition by the immunosuppressive drug FK506 (tacrolimus) would attenuate the development and progression of atherosclerosis using a mouse model of collarinduced atherosclerosis. ApoE-f- mice were treated for 4 weeks with the immunosuppressive drug FK506 ( $0.05 \mathrm{mg} / \mathrm{kg} /$ day), yielding sustained blood levels $(\sim 0.2$ $\mathrm{ng} / \mathrm{ml}$ ) without systemic side-effects. Atherosclerotic plaque development of mice treated with FK506 was significantly reduced $(63 \%)$ while cell density of plaques was increased by $52 \%$ compared to controls.

Importantly, FK506 also blocked progression of pre-existing atherosclerotic plaques. Plaque area of pre-existing plaques was $35 \%$ reduced by FK506. Cell density (35\%) and collagen content $(51 \%)$ were significantly increased, whereas necrotic core content was decreased $(42 \%)$, indicating that FK506-treatment induced a more stable plaque morphology. Flow-cytometric analysis showed no peripheral effects on blood cell count or T-cell activation after FK506-treatment. In vitro, FK506 decreased vascular smooth muscle cell (VSMC) apoptosis and inhibited nuclear factor of activated T-cells (NFAT)-luciferase reporter activity at concentrations in the range of the in vivo concentration.

Calcineurin-inhibition by low dose FK506 inhibits collar-induced atherosclerotic plaque development and progression and induces more stable plaque phenotypes in ApoE-/- mice without any peripheral side-effects. 


\section{Introduction}

Atherosclerosis is a chronic inflammatory disease, involving several inflammatory cells such as macrophages and T-lymphocytes, and often complicates transplant biology. Immunosuppressives such as Cyclosporin A (CsA) and FK506 (tacrolimus) suppress inflammation by inhibiting the activation of calcineurin, a calcium/calmodulin-dependent serine/threonine protein phosphatase. Upon activation calcineurin dephosphorylates the transcription factor NFAT (nuclear factor of activated T cells), which then translocates to the nucleus and regulates the expression of several cytokines such as interleukin-2, interferon-gamma, tumor necrosis factor-alpha and CD40Ligand".

CsA and FK506 are often used to suppress host-versus-graft disease after transplantation. However, it is not clear whether the use of these immunosuppressives either inhibits or ameliorates the development of (transplant) atherosclerosis. Previous studies on the effect of FK506 and CsA, on transplant arteriosclerosis ${ }^{2,3}$ and de novo atherosclerosis in hyperlipidemic animals ${ }^{4-6}$ were contradictory. Drew et al. ${ }^{4}$ showed a reduction in atherosclerosis in cholesterol-fed rabbits after CsA treatment, whereas others showed an increase in atherosclerosis in cholesterol-fed rabbits treated with either CsA or FK506 5 ,

In this study, we tested the effect of FK506 on de novo atherosclerosis and progression of established atheroscleratic plaques in ApoE-1- mice. In view of reported side-effects we used a low dose of FK506 (0.05 mg/kg/day). Rapid atherogenesis was induced by perivascular collar-placement which generated complex heterogeneous, lipid-rich lesions ${ }^{7}$. Treatment with FK506 blocked initial atheroscleratic plaque development as well as progression of pre-existing lesions. Our results suggest an important role for calcineurin in the initiation and progression of murine atherasclerosis and show that calcineurin-inhibition by a low dose of the immunosuppressive FK506 has a favorable effect on the development of this wide-spread disease.

\section{Materials and Methods}

\section{Animals and surgery}

Male ApoE-/- mice (10-12 weeks of age) were obtained from TNO-PG (Leiden, the Netherlands) and fed a Western-type diet throughout the experiment. Carotid atherosclerotic lesions were induced by bilateral perivascular collar-placement as described by von der Thüsen et al. ${ }^{7}$ (figure 3.1A).

To asses the effect of FK506 on lesion initiation, one week after collar-placement osmotic minipumps (Alzet type 2004, Durect Corporation, Cupertino, USA) containing either $0.17 \mu \mathrm{g} / \mu \mathrm{l}(20 \mathrm{mM})$ FK506 (Fujisawa Holland) in PBS $(0.05 \mathrm{mg} / \mathrm{kg} / \mathrm{day}, \mathrm{n}=9)$ or PBS alone $(n=8)$, were placed subcutaneously on the back of the mice (figure $3.1 B$ ). To determine the effect of FK506-treatment on lesion progression, identical osmotic minipumps containing FK506 ( $0.05 \mathrm{mg} / \mathrm{kg} /$ day, $\mathrm{n}=15)$ or PBS $(\mathrm{n}=9)$ were inserted 5 weeks 
A

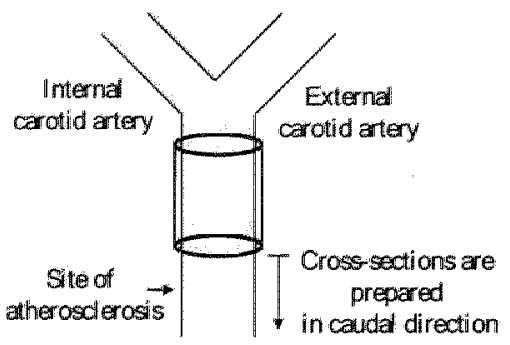

Common carotid atery

B time

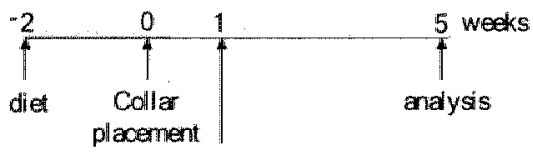

Start FK 506

treatment

(C) thine

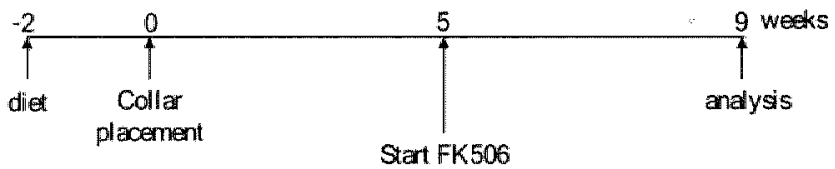

Start FK506

treatment

Figure 3.1

(A) Schematic representation of the collar-model. Atheroscleratic lesions develop caudal to the collar, therefore cross-sections were made of the common carotid antery in a caudal direction from the collar and collected in a parallel series of slides.

(B) Time schedule of the experiment to situdy the effect of calcineurin-inhibition on de novo atherosclerotic plaque development.

(C) Time schedule of the experiment to study the effect of calcineurin-inhibition on pre-existing atherosclerotic lesions.

after collar placement (figure 3.1C). In both treatment protocols, mice were treated with FK506 for 4 weeks.

\section{Cholesterol and triglyceride assay}

Blood samples $(100 \mu l)$ were taken weekly by tail-cut and plasma was obtained by centrifugation at $8000 \mathrm{rpm}$ for $10 \mathrm{~min}$. Levels of total plasma cholesterol and triglycerides were measured spectrophotometrically using enzymatic procedures (Roche Diagnostics, Almere, the Netherlands).

\section{Tissue harvesting and analysis}

Five or nine weeks after collar-placement, mice were subjected to in situ perfusionfixation through the left cardiac ventricle, cryosections were prepared and stained with hematoxylin and eosin (HE). Cross-sections with maximal stenosis were used for morphometric analysis using a Leica system, as described previously ${ }^{8}$. (lmmuno)histochemical stainings were performed to detect macrophages (MOMA-2), 
VSMC ( $\alpha$-smooth muscle actin (ASMA)), lipid (Oil red O), T-cells (CD3) and collagen (picrosirius red) as described previously ${ }^{8}$.

For macrophages, cell numbers (by counting MOMA-positive cells in one cross-section, expressed as a percentage of total cell numbers) as well as MOMA-positive cell area (expressed as a percentage of plaque area) were assessed. For VSMC and collagen, the area of ASMA-positive cells and picrosirius red staining, respectively, was measured and expressed as a percentage of total plaque area. Analysis was performed by one blinded investigator (MMPCD) with an intra-observer variability of $<10 \%$.

\section{Assessment of FK506 blood concentration}

Whole blood samples, taken after 4 weeks of FK506-treatment were hemolyzed, deproteinized and analyzed using an on-line solid-phase extraction combined with liquid chromatography-tandem mass spectrometry (LC-MS/MS) as described by vogeser et al. ${ }^{9}$.

\section{Fluorescence-activated cell sorting (FACS)-analysis}

ApoE- $\%$ mice ( $n=10$ per group) were treated with FK506 or PBS as described above. After 4 weeks, mice were sacrificed and peripheral blood was obtained from the inferior vena cava. Spleen and lymph nodes (superficial and deep cervical nodes, brachial nodes and mesenteric nodes) were isolated and used to make single-cell suspensions. Erythrocytes in peripheral blood and spleen were removed by hypotonic lysis with $\mathrm{NH}_{4} \mathrm{Cl}$. Blood cells $\left(2^{*} 10^{5}\right.$ cells/sample), spleen and lymph node cells $\left(1^{*} 10^{6}\right.$ cells/sample) were stained with anti-CD3-FITC (17A2, 1:100 diluted), anti-CD8 $\alpha-P E(53-6.7,1: 20$ diluted) and anti-CD4-Cyc (RM4-5, 1:10 diluted), with anti-CD25-PE (PC61, 1:40 diluted) and anti-CD4Cyc or with anti-CD69-PE (H1.2F3, 1:20 diluted) and anti-CD3-FITC (all antibodies from $\mathrm{BD}-$ Biosciences Pharmingen, San Diego, California). Blood cells $\left(2^{*} 10^{5}\right.$ cells/ sample) were also stained with anti-CD3-FITC and anti-B220-PE (RA3-6B2, 1:300 diluted) or with anti-Gr1-FITC (RB6-8C5, 1:375 diluted) and anti-Mac1-PE (M1/70, 1:300 diluted). FACSanalysis was performed on a FACS-Calibur and analyzed with the CellQuest software (BDScience, San Jose, California). Data of $1^{*} 10^{4} \mathrm{CD}^{*}$ cells were collected when stained with anti-CD3-FITC/anti-CD8 $\alpha-P E / a n t i-C D 4-C y c$, with anti-CD3-FITC/anti-CD69-PE or with anti-CD3-FITC/anti-B220-PE, of $1^{*} 10^{4} \mathrm{CD} 4^{*}$ cells when stained with anti-CD25-PE/antiCD4-Cyc or of $1{ }^{*} 10^{4}$ Gr1 ${ }^{*}$ cells when stained with anti-Gr1-FITC/anti-Mac1-PE.

\section{In vitro analysis}

The murine macrophage cell-line RAW 264.7 and VSMC, isolated from thoracic aortas of male C57Bl/6 mice, were used for proliferation and apoptosis assays as described previously ${ }^{8}$. In brief, proliferation of both cell types was determined by [ $\left.{ }^{3} \mathrm{H}\right]$-thymidine incorporation, while apoptosis was assessed by measuring DNA-fragmentation using FACS-analysis. 


\section{Luciferase reponter assay}

VSMC and RAW 264.7 were seeded at a density of $10^{5} \mathrm{cells} / \mathrm{cm}^{2}$ and allowed to attach for 24 hours. Cells were transfected with $1 \mu \mathrm{g}$ pNFKB-luciferase reporter plasmid containing the p65/p65 and p50/p65 responsive HIV $k B$ enhancer and TATA box (kindly provided by Dr O.C. Meijer, LACDR, Leiden, Netherlands) or pNFAT-luciferase reporter plasmid (kindly provided by Dr L.J. de Windt, Hubrecht Laboratory, Utrecht, Netherlands) and $0.1 \mu \mathrm{g}$ phRL (Renilla Luciformis)-luciferase reference plasmid (Promega) using Exgen 500 in vitro transfection reagent (Fermentas). After 24 hours, cells were pretreated with 0$2000 \mathrm{ng} / \mathrm{ml}$ FK506 in medium for 2 hours followed by stimulation with $20 \mathrm{ng} / \mathrm{ml}$ PMA and 1 $\mu \mathrm{M}$ ionomycin for 5 hours. Cells were lysed with Passive Lysis Buffer and luciferaseactivity was measured with a luminometer according to the manufacturer's protocol (Dual Luciferase Reporter Assay System; Promega).

Statistical Analysis

Values are expressed as mean \pm SEM and Mann-Whitney-U-test or one-way ANOVA were used to compare individual groups of animals or in vitro experiments, respectively. Probability values of $<0.05$ were considered significant. 


\section{Results}

Steady-state FK506 concentrations in the blood of mice after subcutaneous infusion for 4 weeks with $0.05 \mathrm{mg} / \mathrm{kg} /$ day were $0.2 \pm 0.04 \mathrm{ng} / \mathrm{ml}(-25 \mathrm{nM})$. FK506-treatment did not affect body weight, hematocrit, total cholesterol and triglyceride levels of the mice (table 3.1). No nephrotoxicity, the most frequently documented side-effect of FK506, was found in treated mice (data not shown).
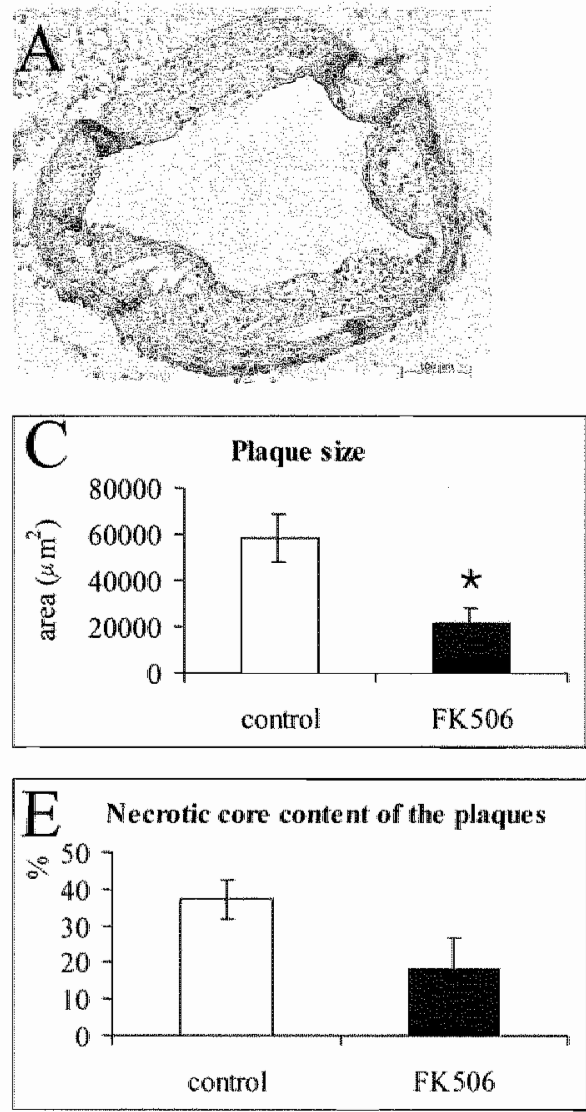
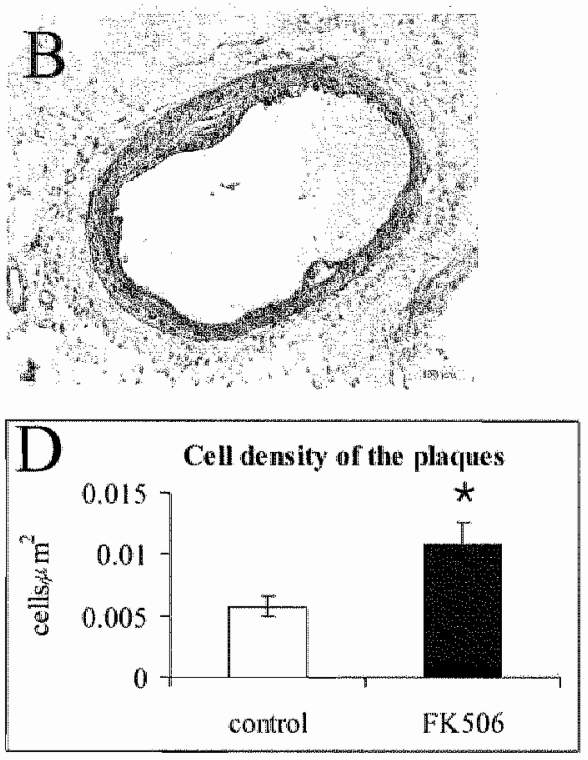

Figure 3.2

Morphological and morphometric analysis of the effect of FK506-treatment on collar-induced atherosclerotic plaque development in common carotid anteries of ApoE-1- mice. Panel $A$ and $B$ show representative $H E$ stained cross-sections of control vs FK506-treated mice, respectively. Panel $C$ : plaque size, panel $D$ : cell density and panel E: necrotic core area relative to plaque area. 


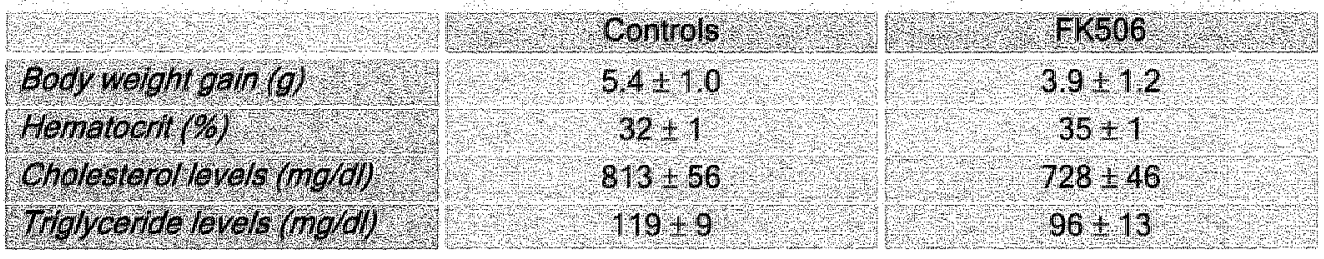

\section{Table 3.1}

Effects of FK506-treatment (0.05 $\mathrm{mg} / \mathrm{kg} / \mathrm{day}$ ) on (gain of) body weight, hematocrit, cholesterol and triglyceride levels of mice.

\section{Morphometric analysis}

Plaque size of FK506-treated mice 5 weeks after collar-placement was significantly lower ( $63 \%, p=0.01$ ) compared to controls (figures $3.2 \mathrm{~A}, \mathrm{~B}$ and $\mathrm{C}$ ). Intima/lumen ratio of FK506-treated mice was also significantly reduced $(56 \%, \mathrm{p}=0.01)$, as was the medial area. Lumen size was larger in the FK506-treated mice compared to controls. No significant differences were found in intima/media ratio (table 3.2).

\begin{tabular}{|c|c|c|c|c|}
\hline & \multicolumn{2}{|c|}{ de novo atherosclerosis } & \multicolumn{2}{|c|}{ pre existing lesions } \\
\hline & Controls $(n=8)$ & $1 \times 506(n=9)$ & Gontrols $(n=9)$ & Ex $506(n=15)$ \\
\hline Plaque size $\left(10^{3} u^{2}\right)$ & $58.5 \pm 10.6$ & $21.4+6.6$ & $76.7=98$ & $49.7 \pm 76$ \\
\hline Medial area $\left(10^{3} \mathrm{~m}^{\prime}\right)$ & $33.8+2.6$ & $233+18^{*}$ & $50.2+121$ & $420-6.2$ \\
\hline IntimalMedia ratio & $1.8=0.4$ & $0.94 \pm 0.3$ & $1.9 \pm 0.3$ & $12+02$ \\
\hline Intima/ umen ratio & 0.710 .1 & $0.3+0.1 \%$ & $0.9+0.1$ & $0.6=0.1 \%$ \\
\hline Lumen size $\left(10^{3} \mathrm{um}^{2}\right)$ & $246 \pm 5.8$ & $44.1 \pm 5.3$ & $75+22$ & $305+4.1 \%$ \\
\hline
\end{tabular}

\section{Table 3.2}

Effect of calcineurin-inhibition by FK506 (0.05 mg/kg/day) on plaque morphometry. Results are strown for both the effects of Calcineurin-inhibition on de novo atherosclerosis and pre-existing lesions. 
To study the effect of calcineurin-inhibition on pre-existing lesions, ApoE-1-mice were treated with FK506 for 4 weeks, beginning 5 weeks after collar-placement (figure 3.1C). Plaque size of FK506-treated mice was significantly lower $(35 \%, p=0.02)$ compared to controls (figures $3.4 \mathrm{~A}, \mathrm{~B}$ and $\mathrm{C}$ ) as was the intima/lumen ratio. Lumen size was markedly increased $(75 \%, p<0.001)$ in FK506-treated mice compared to controls. Medial area, intima/media ratio and total vessel area (outward remodeling) did not differ between groups (table 3.2 ).

Remarkably, plaque size of pre-existing lesions of FK506-treated mice (at 9 weeks) was comparable to that of control mice at 5 weeks after collar-placement $\left(49665 \pm 7597 \mu \mathrm{m}^{2} \mathrm{vs}\right.$ $58499 \pm 10627 \mu^{2}$ respectively), suggesting that FK506 completely blocked lesion progression.
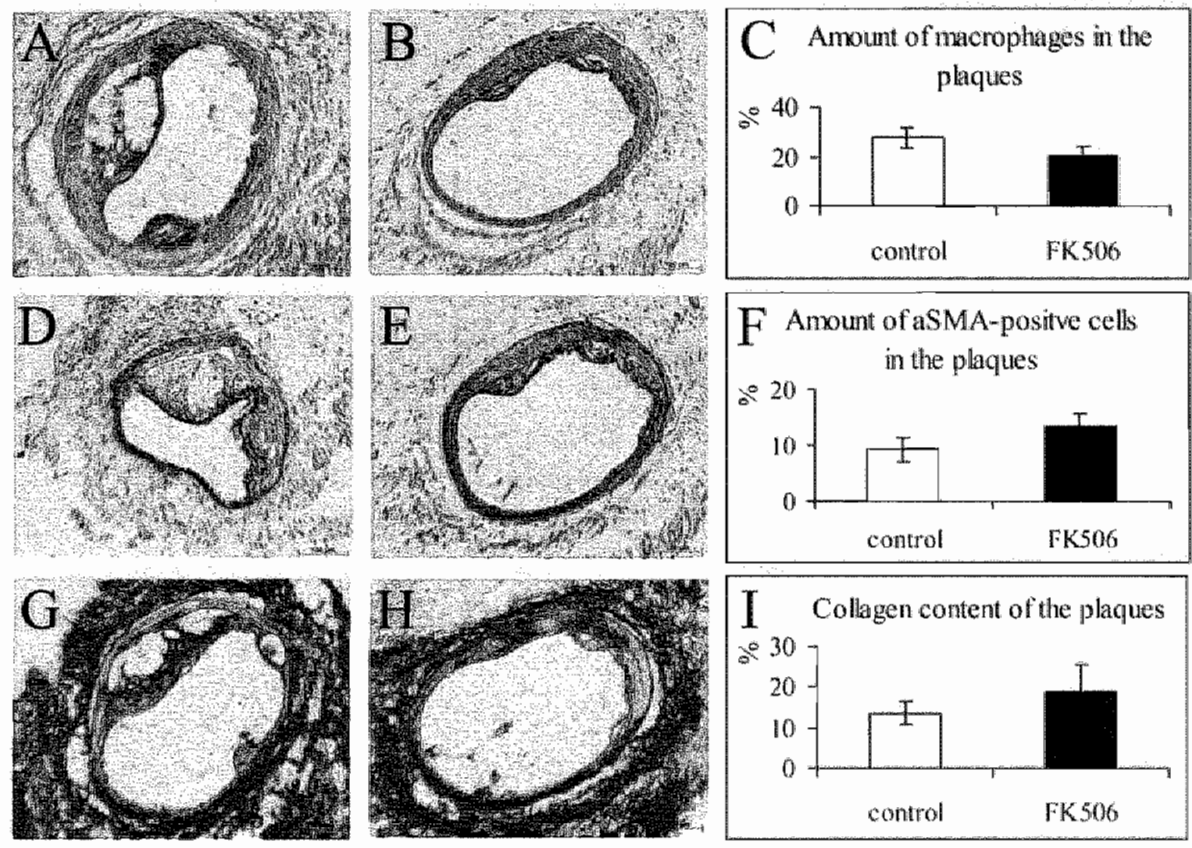

Figure 3.3

Analysis of the effect of FK506-treatment on plaque morphology. Panel A-C: macrophage specific MOMA-staining, panel D-F: VSMC-specific ASMA-staining and panel G-l: sirius red staining for collagen content of plaques of FK506-treated mice $(B, E$ and $H)$ compared to controls $(A, D$ and $G)$. 


\section{Plaque morphology}

Figures 3.2-3.5 show representative examples of cross-sections stained with hematoxylin and eosin (HE), MOMA (macrophages), ASMA ( $\alpha$-smooth muscle actincontaining VSMC), and picrosirius red (collagen). Since plaque area of FK506-treated mice was signifficantly reduced compared to controls, the amount of cells, necrotic core area and collagen content of the plaques are expressed relative to the total amount of cells in the plaque or to total plaque area.

Cell density of the plaques at 5 weeks after collar-placement was significantly increased in FK506-treated mice compared to controls (figure 3.2D). However, no significant differences were found in either relative amount (figure 3.3C) or relative area of macrophages ( $35.7 \pm 4.8 \%$ for controls ws $27.5 \pm 6.8 \%$ for FK506-treated mice, $\mathrm{p}=0.396$ ). Furthermore, no differences were found in the relative area of ASMA-stained VSMC (figures 3.3F) and in collagen content of the plaques (figure 3.31). Necrotic core area in FK506-treated mice tended to be decreased $(p=0.08$, figure $3.2 E$ ). No differences in the (relative) amount of T-cells were found between FK506-treated mice and controls, albeit that the T-cell content of carotid artery plaques was too low to draw firm conclusions (data not showin).

The effect of calcineurin-inhibition on the morphology of pre-existing lesions was even more pronounced. FK506-treatment of pre-existing plaques resulted in more stable plaque phenotypes compared to plaques of control mice. Cell density of the plaques was significantly increased in FK506-treated mice (figure 3.4D) as was the relative amount of collagen in the plaques (figure 3.5l). The relative area of ASMA-positive VSMC tended to be increased, but this was not significant $(p=0.1$, figures $3.5 F$ ). The relative necrotic core area of FK506-treated mice was significantly decreased compared to controls (figure $3.4 \mathrm{E}$ ). No differences were observed in the relative macrophage number (figure $3.5 \mathrm{C}$ ) or area $(10.7 \pm 1.7 \%$ vs $11.4 \pm 1.8 \%$ for FK506 and control group, respectively, $p=0.751)$ while the (relative) amount of T-cells in FK506-treated mice and controls was similar, albeit that the T-cell content of carotid artery plaques was too low to draw firm conclusions (data not shown). Furthermore, lipid content of the plaques (Oil red $O$ ), was not affected by FK506-treatment $(0.61 \pm 0.06$ for FK506-treated mice vs $0.62 \pm 0.07$ for the controls, $\mathrm{p}=0.86$ ). 

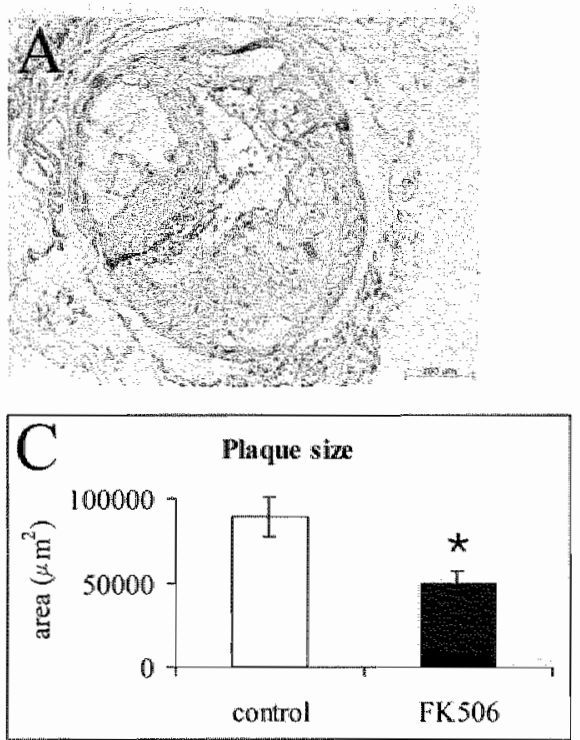

E Necrotic core content of the plaques

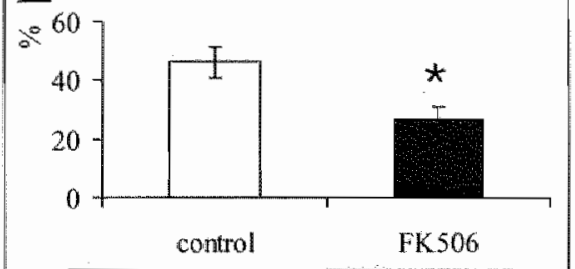

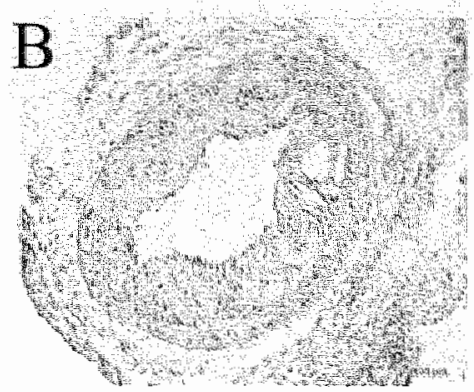

D Cell density of the plaques

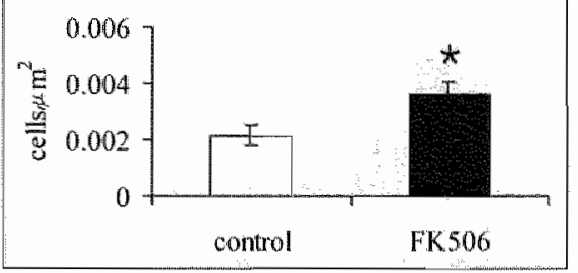

Figure 3.4

Morphological and morphometric analysis of the effect of FKS06-treatment on the development of pre-existing atherosclerotic plaques in common carotid arteries of ApoE $-/ \sim$ mice. Panel $A$ and $B$ show representative HE stained cross-sections of control ws FK506-treared mice, respectively. Panel C: plaque size, panel D: cell density and panel E: necrotic core area relative to plaque area. 

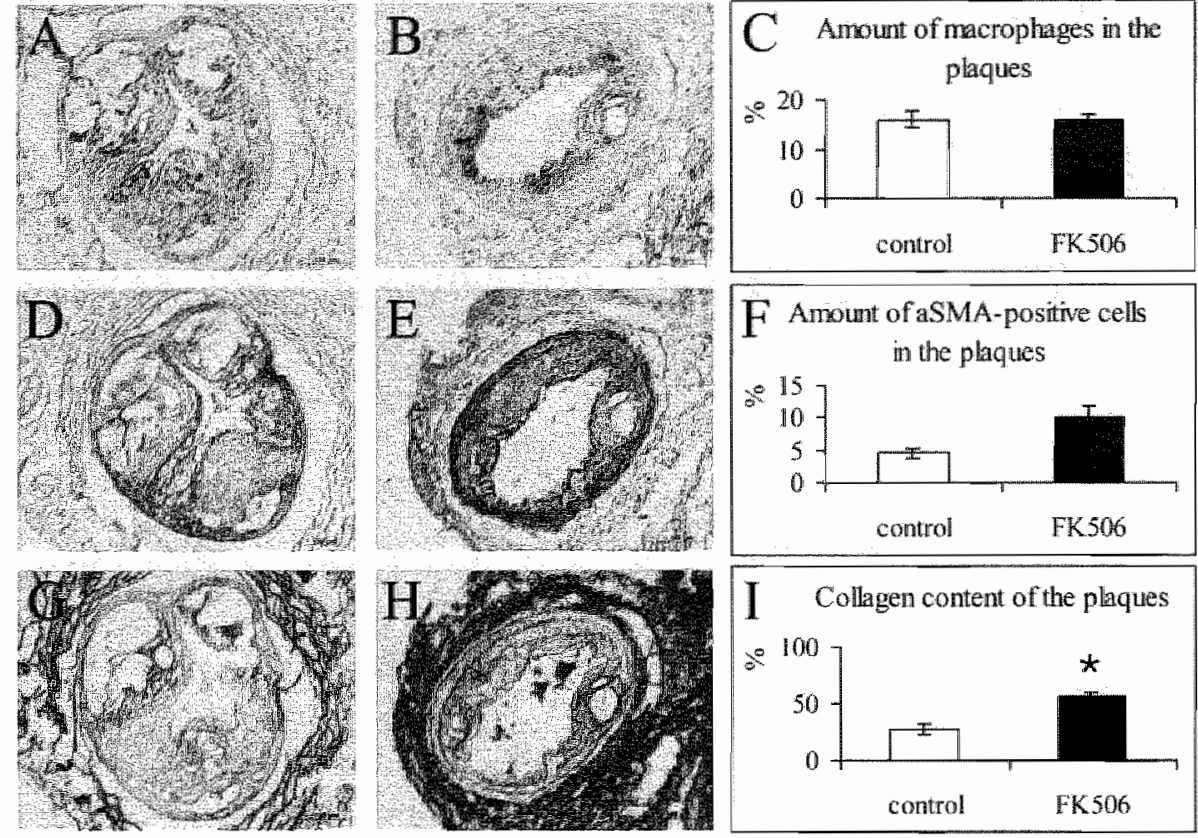

\section{Figure 3.5}

Analysis of the effect of FK506-treatment on morphology of pre-existing atherosclerotic plaques in FK506-treated mice ( $B, E$ and $H$ ) compared to controls ( $A, D$ and $G$ ). Panel $A-C$ : macrophage specific MOMA-staining, panel D-F: VSMC-specific ASMA-staining and panel G-l: sirius red staining for collagen content.

\section{FACS-analysis}

To investigate whether FK506 affects lesion formation indirectly via modulating peripheral immunity, we have analyzed the relative abundancy of various leukocytes and the amount of activated T-cells by flow-cytometric analysis using single-cell solutions of blood, spleen and lymph nodes. No differences in amount of B-cells (B220+), granulocytes $(\mathrm{Gr} 1+)$ and macrophages (Mac1+) were found between FK506-treated mice and controls (data not shown). Furthermore, CD3+ T-cell numbers, CD4/CD8 ratio (ratio of T-helper to cytotoxic T-cells) or activated T-cell numbers (CD25+ or CD69+) were not affected by FK506-treatment (figure 3.6). 

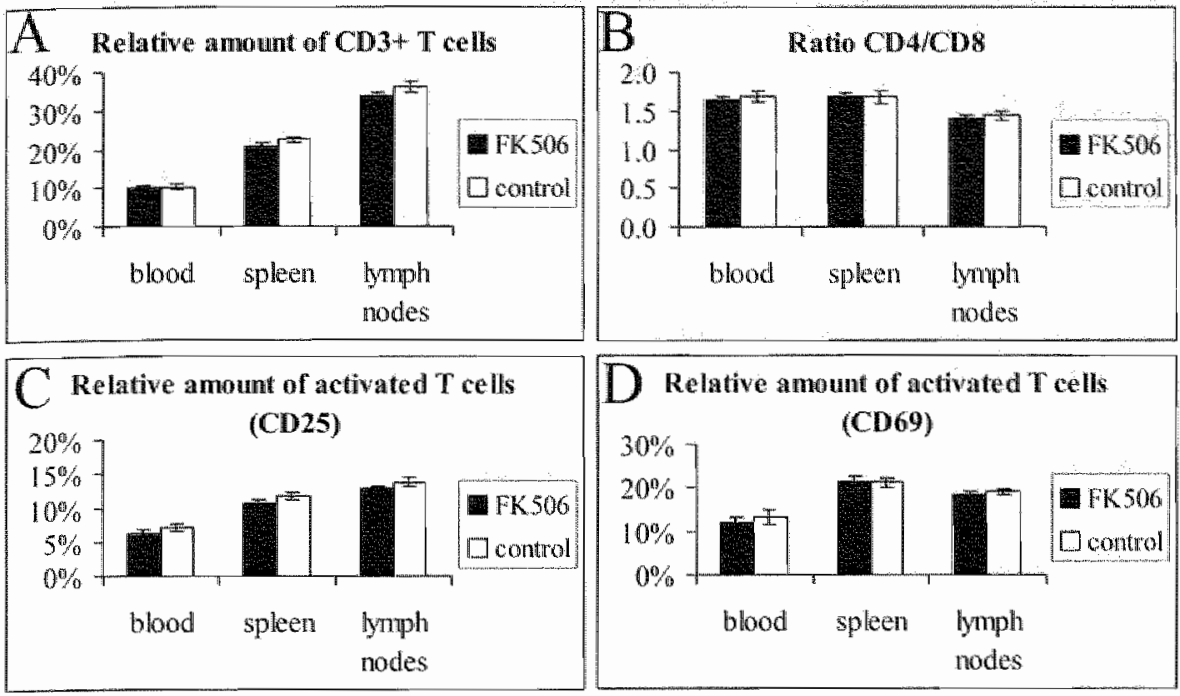

\section{Figure 3.6}

Flow-cytometric analysis of the effect of in vivo FK506-treatment on the relative amount of CD3* $T$. cells (A), the ratio $C D 4+/ C D 8+T-C e / / s$ (B) and the amount of activated T-cells (C: CD25*; $D$ : CD69+) in blood, spleen and Iymph nodes of control vs FK506-treated mice.

In vitro experiments

To address the effects of calcineurin-inhibition by FK506 on plaque cellularity in vivo, we investigated the effect of FK506 on cell proliferation and apoptosis in vitro. Our data clearly show that FK506 did not affect VSMC or macrophage proliferation at concentrations up to $42 \mathrm{ng} / \mathrm{ml}$ (figure 3.7A and B), nor did it influence the rate of macrophage apoptosis (figure 3.7D). Conversely, FK506-treatment markedly decreased the extent of VSMC apoptosis $(p=0.002$, figure $3.7 C)$.

Effects of FK506 on transcriptional activation of downstream calcineurin-responsive transcription factors were alssessed via luciferase-reporter assays. FK506 significantly and dose-dependently inhibited NFAT-activation in VSMC ( $p=0.02$ at $2 \mathrm{ng} / \mathrm{ml})$. For RAW, NFAT-activation was significantly inhibited even at concentrations as low as $0.2 \mathrm{ng} / \mathrm{mll}$, which corresponds with FK506-concentrations in viva $(p=0.03$, figure 3.8B). FK506 did not affect NFKB-activation in RAWs at concentrations of up to $2000 \mathrm{ng} / \mathrm{ml}$ (Figure 3.8C). 

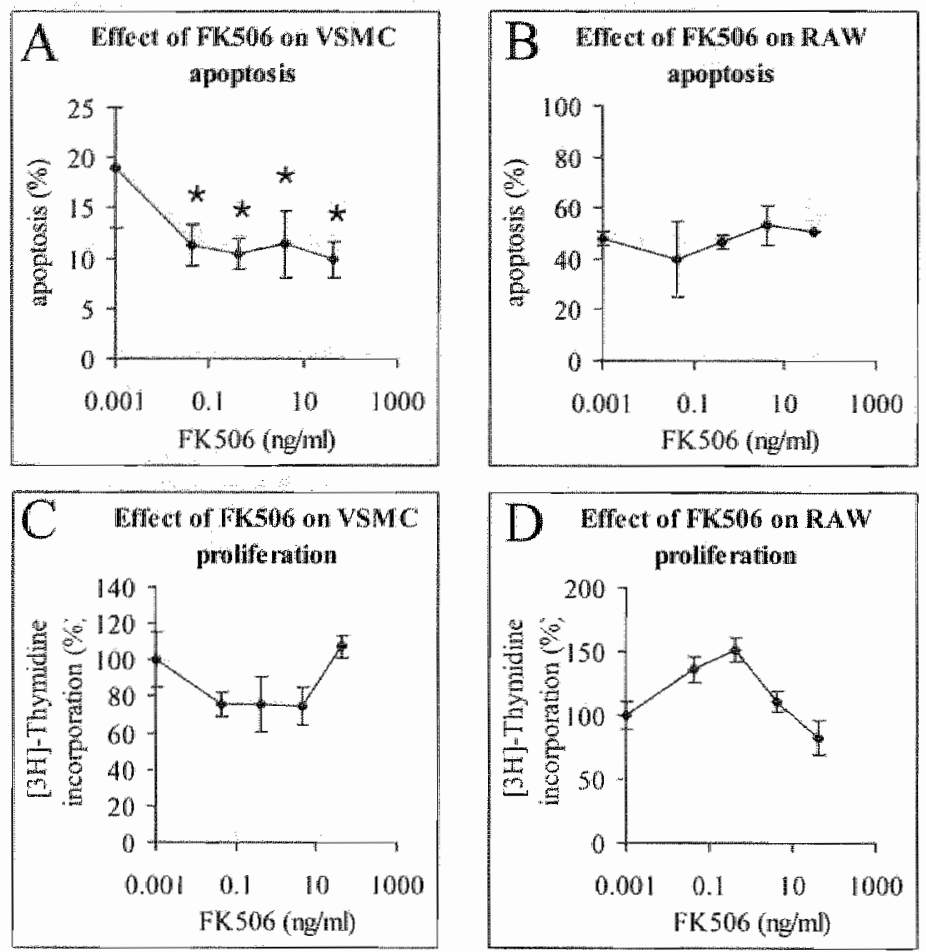

\section{Figure 3.7}

Effect of FKSOG on VSMC proliferation (A), RAW proliferation (B) and VSMC apoptosis (C) and RAW apoptosis (D) in vitro. Results are expressed as percentage of the amount of apoptosis or [3H]-thymidine incorporation of controls (without FK506).
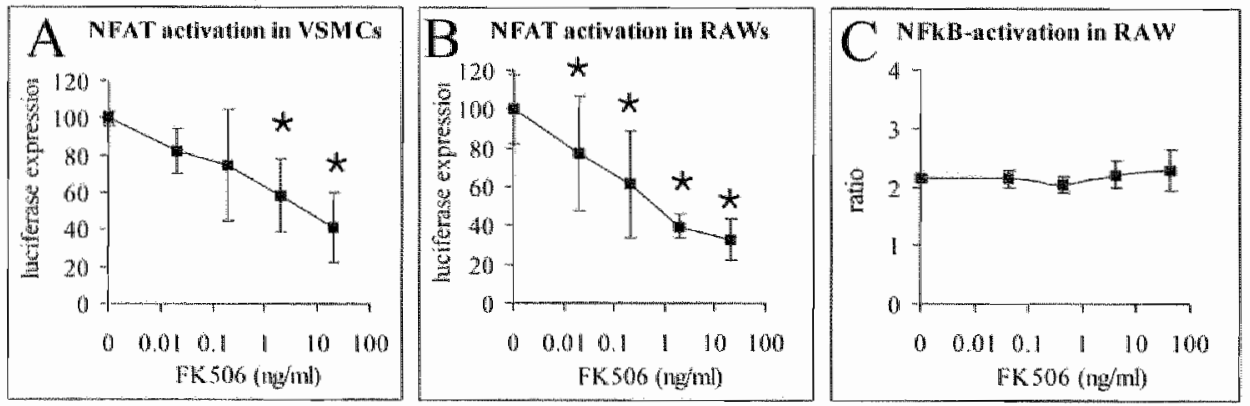

Figure 3.8

Effect of FK506 on PNFAT-fuciferase or PNFKB-luciferase reporter activity in VSMCs and RAW cells. Luciferase-activity was expressed relative to Renilla Luciformis luciferase-activity fused as an internal control). 


\section{- Discussion}

Immunosuppressives such as CsA and FK506 (tacrolimus) are often used to suppress host-versus-graft disease after transplantation. However, it is not clear whether the use of these immunosuppressives either inhibits or ameliorates the development of (transplant) atherosclerosis. Both CSA and FK506 exert their immunosuppressive function by inhibition of the calcineurin pathway, which is a major signaling pathway involved in the inflammatory response, especially in T cell activation and the regulation of cytokine gene expression in a variety of cell types". Besides T cells, calcineurin and downstream transcription factors are also expressed in several other vascular cells such as endothelial cells (EC), VSMC and macrophages ${ }^{10-12}$. Furthermore, calcineurin has been described in several other processes involved in atherosclerosis such as apoptosis ${ }^{13,14}$ and angiogenesis ${ }^{11}$.

Since atherosclerosis is a chronic inflammatory disease, we tested the hypothesis that the immunosuppressive FK506, by inhibiting calcineurin signaling, would attenuate atherosclerotic plaque development in an ApoE-/- mouse model of collar-induced atherosclerosis. Similar to transplant arteriosclerosis, this is a model of rapid atherogenesis and therefore it may also be very suitable to compare the effects of FK506 on the development of de novo atherosclerosis to the development of transplant arteriosclerosis.

This is the first study to report an atheroprotective effect of calcineurin-inhibition by FK506 in mice. Previously the immunosuppressive CSA has been shown to accelerate fatty streak formation in cholesterol-diet fed C57B//6 mice ${ }^{15}$. However, the use of CsA has been shown to be associated with hyperlipidemia ${ }^{16}$, increased oxidizability of $\mathrm{LDL}^{17}$ and hypertension ${ }^{18}$, which are all risk factors for development of atherosclerosis that are much less affected by FK506.

In view of the side-effects of these immunosuppressives, we decided to evaluate a low dose regimen of FK506 (0.05 mg/kg/day), which was subcutaneously administered by osmotic minipumps to yield blood concentrations of $0.2 \mathrm{ng} / \mathrm{ml}$. This dose had no adverse effects on body weight, cholesterol and triglyceride levels, hematocrit or renal morphology nor did FK506 affect systemic T-cell numbers or T-cell activation as assessed by FACSanalysis. The administered dose was also well below the $0.5 \mathrm{mg} / \mathrm{kg} /$ day recently described by Ellis et al. as the upper limit for sub-immunosuppressive effects of FK506-administration in mice ${ }^{19}$. In addition, there is strong evidence that local FK506 responses are dictated by the relative expression profile of immunophilin isoforms (such as FKBP12) in a particular tissue $^{20}$, implicating that identical doses of FK506 could differentially affect diverse celltypes. Interestingly, FKBP12 was found to be upregulated in human neointimal tissue retrieved by helix-cutter atherectomy, suggesting that the diseased human vascular wall may be more sensitive to $F K 506^{21}$. Combined, data from literature and our own data suggest that calcineurin-inhibition by FK506 exerts its regulatory actions on plaque phenotype at the level of the plaque itself and not primarily via a systemic immunosuppressive effect. 
This study shows that calcineurin-inhibition by FK506 significantly inhibited development of collar-induced atherosclerosis and blocked plaque-progression, even at a very low dose of FK506. Furthermore, FK506 induced a more stable plaque phenotype by reducing necrotic core content and increasing cell density and collagen content, which was most evident in plaque progression. In vitro data showed FK506 to be a potent inhibitor of VSMC apoptosis which concurs with earlier studies ${ }^{13}$. FK506-mediated inhibition of VSMC apoptosis may at least in part explain the increased plaque cell density of FK506-treated mice. FK506 did not affect macrophage apoptosis consistent with the in vivo finding that the number of plaque macrophages was not affected by FK506-treatment. The expression of several cytokine genes (MCP-1, IL-10 or IFN- $\gamma$ ) in the arterial segment containing the plaque was not significantly different after 4 weeks of treatment with low dose FK506 (data not shown). However, cytokine gene expression could be affected at an earlier time point, for example in the first week(s) when atherosclerotic plaques start to develop.

At first glance, results of several studies using FK506 to examine its effects on atherosclerosis seem rather contradictory. Wu et al. ${ }^{3}$ and Cramer et al. ${ }^{22}$ showed an inhibitory effect of FK506 on post-transplant arteriosclerosis in rats, whereas Matsumoto et al. ${ }^{5}$ showed a minor stimulation of atherosclerosis in cholesterol-fed rabbits. While the former study involves a different pathobiology, the latter has applied higher doses of FK506. Therefore, the contradictory results may have arisen from differences in experimental set-up or the dose of FK506 used. In contrast to its activating effect in T-cells, calcineurin has been shown to induce an anti-inflammatory effect in macrophages by suppressing the expression of various inflammatory cytokines ${ }^{12}$. In macrophages, calcineurin-inhibition was found to activate the transcription factor NFKB, leading to enhanced expression of cytokine genes, whereas it suppresses cytokine gene expression in T-cells. Interestingly, the FK506-concentration required for activation of NFKB and effector-gene expression in macrophages is much higher than required for inhibition of NFAT-activation and cytokine gene expression in T-cells. Indeed, our luciferase-reporter assays showed inhibition of NFAT-activation by FK506 even at a very low dose $(0.2$

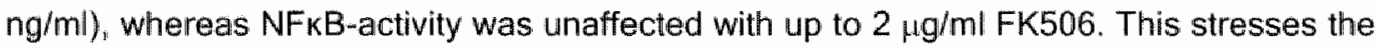
importance of the low dose of FK506 used and might explain the differences on the effect of FK506 on the development of atherosclerosis. In comparison, blood concentrations achieved in transplant patients are in the range $5-10 \mathrm{ng} / \mathrm{ml}^{23}$. The relatively high doses of FK506 used in transplantation might therefore stimulate development of atherosclerosis in these patients. Indeed, arteriosclerotic disease is still a major cause of morbidity and mortality in transplant patients.

Although FK506 and CsA mediate their effects primarily through calcineurin-inhibition, these drugs can also have calcineurin-independent effects. However, prior research on effects of these drugs in the attenuation of cardiac hypertrophy has shown that interventions in the calcineurin-pathway (e.g transgene and knock-out intervention studies) demonstrated the same phenotype as after the use of either FK506 or $\operatorname{CsA} \mathrm{A}^{24,25}$. These studies and our in vitro NFAT-reporter assay indicate that the results were mainly calcineurin-dependent. 
In conclusion, calcineurin-inhibition by a low dose of the immunosuppressive agent FK506 reduced the development of collar-induced atherosclerosis in ApoE-1- mice and blocked progression of pre-existing lesions. Furthermore, it induced more stable plaque phenotypes by increasing cell density and collagen content while decreasing necrotic core content of plaques. These surprising findings may have important implications for the clinical use of (a low dose of) FK506.

\section{- Acknowledgements}

The authors want to thank Karin Hoogtanders (Clinical Pharmacology, Academic Hospital of Maastricht, the Netherlands) for measuring FK506 blood concentrations and Dr. C. Peutz (Dept. of Pathology, Academic Hospital of Maastricht the Netherlands) for histological analysis of the kidneys. 


\section{References}

1. Rao A, Luo C, Hogan PG. Transcription factors of the NFAT family: regulation and function. Annu Rev Immunol. 1997;15:707-47.

2. Andersen $H O$, Qwortrup $K$, Rostgaard $J$, Nordestgaard BG. Effect of cyclosporine during initiation of transplant arteriosclerosis. An ultrastructural study in the aorta-transplanted rabbit. Atherosclerosis. 1997;133:171-81.

3. Wu GD, Cramer DV, Chapman FA, Cajulis E, Wang HK, Starzl TE, Makowka L. FK 506 inhibits the development of transplant arteriosclerosis. Transplant Proc 1991;23:3272-4.

4. Drew $\mathrm{AF}_{1}$. Tipping $\mathrm{PG}$. Cyclosporine treatment reduces early atherosclerosis in the cholesterol-fed rabbit. Atherosclerosis. 1995;116:181-9.

5. Matsumoto $T$, Saito $E$, Watanabe $H$, Fujioka $T$, Yamada $T$, Takahashi $Y$, Ueno $T$, Tochihara T. Kanmatsuse $\mathrm{K}$. Influence of FK506 on experimental atherosclerosis in cholesterol-fed rabbits. Atherosclerosis. 1998;139:95-106.

6. Roselear SE, Schonfeld G. Daugherty A. Enhanced development of atherosclerosis in cholesterol-fed rabbits by suppression of cell-mediated immunity. $\mathcal{J}$ Clin Invest. 1995;96:1389-94.

7. von der Thusen JH, van Berkel T.J.C., E.A.L. B. Induction of rapid atherogenesis by perivascular carotid collar placement in apolipoprotein E-deficient and low-density lipoprotein receptor-deficient mice. Circulation. 2001;103:1164-1170.

8. Bot I, von der Thusen JH, Donners MM, Lucas A. Fekkes ML, de Jager SC, Kuiper J, Daemen $M J$, wan Berkel $T J$, Heeneman $S$, Biessen EA. Serine protease inhibitor Serp-1 strongly impairs atherosclerotic lesion formation and induces a stable plaque phenotype in ApoE-/-mice. Circ Res. 2003;93:464-71.

9. Vogeser M, Fleischer C, Meiser B, Groetzner J, Spohrer U, Seidel D. Quantification of sirolimus by liquid chromatography-tandern mass spectrometry using on-line solid-phase extraction. Clin Chem Lab Med. 2002;40:40-5.

10. Boss $\mathrm{V}$, Abbott $K L$, Wang XF, Pavlath GK, Murphy TJ. The cyclosporin A-sensitive nuclear factor of activated T cells (NFAT) proteins are expressed in vascular smooth muscle cells. Differential localization of NFAT isoforms and induction of NFAT-mediated transcription by phospholipase C-coupled cell surface receptors. J Bio/ Chem. 1998;273:19664-71.

11. Hernandez GL, Volpert OV, Iniguez MA, Lorenzo E, Martinez-Martinez S, Grau R, Fresno M. Redondo JM. Selective inhibition of vascular endothelial growth factor-mediated angiogenesis by cyclosporin $A$ : roles of the nuclear factor of activated $T$ cells and cyclooxygenase 2. JExp Med. 2001;193:607-20.

12. Conboy IM, Manoli D, Mhaiskar $V$, Jones PP. Calcineurin and vacuolar-type H+-ATPase modulate macrophage effector functions. Proc Nat Acad Sci U S A. 1999;96:6324-9.

13. De Windt LJ, Lim HW. Taigen $T$, Wencker $D$, Condorelli $G$, Dorn GW, 2nd, Kitsis RN, Molkentin JD. Calcineurin-mediated hypertrophy protects cardiomyocytes from apoptosis in vitro and in vivo: An apoptosis-independent model of dilated heart failure. Circ Res. 2000;86:255-63.

14. Kim MJ, Jo DG, Hong GS, Kim BJ, Lai M, Cho DH, Kim KW, Bandyopadhyay A, Hong YM, Kim do H, Cho C, Liu JO, Snyder SH, Jung YK. Calpain-dependent cleavage of cain/cabin 1 activates calcineurin to mediate calcium-triggered cell death. Proc Natl Acad Sci $U S A$. $2002 ; 99: 9870-5$. 
15. Emeson EE, Shen ML. Accelerated atherosclerosis in hyperlipidemic C57BL/6 mice treated with cyclosporin A. Am J Pathol. 1993;142:1906-15.

16. Hohage $H$, Arlt M, Bruckner D, Dietl KH, Zidek W, Spieker C. Effects of cyclosporin A and FK 506 on lipid metabolism and fibrinogen in kidney transplant recipients. Chn Transplam. 1997; $11: 225-30$.

17. Apanay DC, Neylan JF, Ragab MS, Sgoutas DS. Cyclosporine increases the oxidizability of low-density lipoproteins in renal transplant recipients. Transplantation. 1994;58:663-9.

18. Avdonin PV, Cottet-Maire F, Afanasjeva GV, Loktionova SA, Lhote P. Ruegg UT. Cyclosporine A up-regulates angiotensin 11 receptors and calcium responses in human vascular smooth muscle cells. Kioney int. 1999;55:2407-14.

19. Ellis RA, Brenner MJ, Mackinnon SE, Myckatyn TM, Hunter DA. Use of mixed lymphocyte reaction to identify subimmunosuppressive FK-506 levels in mice. Microsurgery. 2003;23:276-82.

20. Kung L, Halloran PF. Immunophilins may limit calcineurin inhibition by cyclosporine and tacrolimus at high drug concentrations. Transplantation. 2000;70:327-35.

21. Zohinhofer D, Klein CA, Richter T, Brandl R, Murr A, Nuhrenberg T, Schomig A, Baeuerle PA, Neumann FJ. Gene expression profiling of human stent-induced neointima by cDNA array analysis of microscopic specimens retrieved by helix cutter atherectomy: Detection of FK506-binding protein 12 upregulation. Circulation. 2001;103:1396-402.

22. Cramer DV, Chapman FA, Wu GD. Harnaha JB, Qian SQ, Makowka L. Cardiac transplantation in the rat. II. Alteration of the severity of donor graft arteriosclerosis by modulation of the host immune response. Transplantation. 1990;50:554-8.

23. Pirsch JD, Miller J, Deierhoi MH, Vincenti F, Filo RS. A comparison of tacrolimus (FK506) and cyclosporine for immunosuppression after cadaveric renal transplantation. FK506 Kidney Transplant Study Group. Transplantation. 1997;63:977-83.

24. Bueno OF, Wilkins BJ "Tymitz KM, Glascock BJ, Kimball TF, Lorenz JN, Molkentin JD. Impaired cardiac hypertrophic response in Calcineurin Abeta -deficient mice. Proc Natl Acad Sci U S A. 2002;99:4586-91.

25. Leinwand LA. Calcineurin inhibition and cardlac hypertrophy: a matter of balance. Proc Nat/ Acad SciU S A. 2001;98:2947-9. 


\section{Chapter 4:}

\section{Low dose FK506 inhibits atherosclerotic plaque development in the ApoE-/- mouse model of spontaneous atherosclerosis}

Marjo M.P.C. Donners, Mat JA.P. Daemen, Sylvia Heeneman.

Parts of this chapter are to be puthished in the American Jounal of Transplantation 


\section{Abstract}

In this study we examined the effects of a low dose of the immunosuppressive drug FK506 (tacrolimus) on the spontaneous development of atherosclerosis in the ApoE-/mouse model. ApoE- $/$ - mice ( $n=10$ per group, 17 weeks of age) were treated for 8 weeks by continuous infusion of FK506 $(0.05 \mathrm{mg} / \mathrm{kg} / \mathrm{day})$. Atherosclerotic plaques in the main branch points of the aortic arch, i.e. the brachiocephalic trunk, left carotid artery and left subclavian artery, were analyzed and subdivided into initial or advanced plaques. Plaque size of initial lesions in FK506-treated mice was significantly reduced (54\%) compared to control mice. The relative area of alpha-smooth muscle actin (ASMA)-positive vascular smooth muscle cells (VSMC) of initial plaques in the left subclavian artery was significantly increased by $89 \%$, whereas the relative amount of T-cells of initial lesions in the brachiocephalic trunk were $68 \%$ reduced in FK506-treated mice compared to the control group. No effects were found on lipid levels and nephrotoxicity.

In conclusion, this study shows that low dose FK506 inhibits spontaneous atherosclerotic plaque development in ApoE-l- mice. Furthermore, treatment with low dose FK506 may increase plaque stability by increasing the relative ASMA-positive VSMC content and reducing the relative $T$ cell content of the plaques. 


\section{Introduction}

The use of immunosuppressive drugs such as Cyclosporine $A(\mathrm{CsA})$ or tacrolimus (FK506) to suppress host-versus-graft disease in patients that underwent organ transplantation has often been associated with the development of transplant arteriosclerosis. Several studies have therefore examined the effect of these drugs on atherosclerotic plaque development. However, the results of such studies were rather contradictory. Drew et al. showed a reduction in atherosclerosis in cholesterol-fed rabbits after CsA treatment ${ }^{1}$, whereas others showed an increase in atherosclerosis in cholesterolfed rabbits treated with either CSA or FK506 $6^{2,3}$.

In a previous study, we showed a protective effect of FK506 using a low dose of FK506 $(0.05 \mathrm{mg} / \mathrm{kg} / \mathrm{day}$, by continuous subcutaneous infusion) in an ApoE-/- mouse model of collar-induced accelerated atherosclerosis (chapter 3 ). In this model rapid atherogenesis was induced by collar placement around the common carotid artery. Low dose FK506 inhibited the development and progression of atherosclerotic plaques and induced a more stable plaque phenotype by decreasing lipid core content, and increasing the amount of collagen and cell density of the plaques, while no systemic effects were found.

This model of accelerated atherosclerotic plaque development may be very suitable to compare the effects of FK506 on the development of atherosclerosis to the development of transplant arteriosclerosis, which also involves a rapid progression. It is not known, however, how low dose FK506 affects the more delayed, spontaneous atherogenesis in the ApoE-1- mouse. Therefore, in this studly, we examined the effects of the same low dose FK506 on atherosclerotic plaque progression in the ApoE-l-mouse model.

We showed that FK506 also inhibits this slow progressing type of atherosclerosis. The effect of FK506 on lesion morphology was less evident in this model compared to the model of accelerated atherosclerosis, but again we found evidence that low dose FK506 induces a more stable plaque phenotype.

\section{Materials and Methods}

\section{Animals and treatment}

Male ApoE- $/$ mice (17 weeks of age, $n=10$ per group) obtained from Charles River Laboratories (Maastricht, the Netherlands) were treated with FK506 $(0.05 \mathrm{mg} / \mathrm{kg} / \mathrm{day}$, Fujisawa Holland) or phosphate-buffered saline (PBS, controls) for 8 weeks by placing osmotic minipumps (Alzet type 2004, Durect Corporation, Cupertino, USA) subcutaneously on the back of the mice. The osmotic minipumps were replaced after 4 weeks. Mice were fed a normal chow throughout the experiment.

Tissue harvesting and histological analysis

After 8 weeks of treatment, mice were sacrificed and blood was obtained from the inferior caval vein to assess lipid profiles. The arterial tree was perfused through a catheter inserted into the left cardiac ventricle with PBS containing $0.1 \mathrm{mg} / \mathrm{ml}$ nitroprusside (Sigma) 
and subsequently with $1 \%$ paraformaldehyde. The aortic arch including its main branch points (brachiocephalic trunk/right common carotid artery, left common carotid artery and left subclavian artery) was removed, fixed overnight in $1 \%$ paraformaldehyde and embedded longitudinally in paraffin. The entire aortic arch was cut into approximately 40 sections ( $4 \mu \mathrm{m}$ thick), of which 20 consecutive sections, representing the central area of the arch with an intact morphology of the complete arch, were used for analysis as described previously ${ }^{4}$.

Four sections (20 $\mu \mathrm{m}$ apart) were stained with hematoxylin and eosin (HE) and were used for morphometric measurement of plaque area, lipid core area (expressed as percentage of total plaque area) and cell density. Sections stained for picrosirius red were used to measure the relative collagen content (expressed as percentage of plaque area). Atherosclerotic plaques were divided into initial lesions, constituted mainly by macrophage-derived foam cells, and advanced plaques containing a lipid core and/or a fibrous cap.

Sections were stained with $\alpha$-smooth muscle actin (ASMA ${ }^{\text {FITC }}, 1: 3000$, Sigma) as a marker for vascular smooth muscle cells (VSMC), with MAC3 (1:30, Pharmingen) for macrophages or CD3 (1:80, Lab Vision) for T-cells. For VSMC and macrophages, the area of ASMA-positive cells or MAC3-positive cells, respectively, was measured and expressed as percentage of plaque area. For T-cells, the amount of CD3-positive cells were counted and expressed as percentage of total cell numbers in the plaque. Analysis was performed by one blinded investigator (MMPCD) with an intra-observer variability of $<10 \%$.

\section{Assessment of FK506 blood concentration}

Whole blood samples, taken after 8 weeks of FK506-treatment were hemolyzed, deproteinized and analyzed using an on-line solid-phase extraction combined with liquid chromatography-tandem mass spectrometry (LC-MS/MS) as described by Vogeser et al. ${ }^{5}$.

\section{Lipid profile}

Levels of total plasma cholesterol and triglycerides were measured after 8 weeks of treatment using standard enzymatic techniques, automated on the Cobas Fara centrifugal analyzer (Hoffmann-La Roche). Total plasma cholesterol was measured using kit no. 0736635 (Hoffmann-La Roche), total glycerol was measured using kit no. 337-40A/33710B (Sigma) and free glycerol was measured using kit no. 0148270 (Hoffmann-La Roche). Triglyceride levels were calculated by subtracting free glycerol from total glycerol levels. Standardized serum (Precipath) was used as an internal standard.

\section{Statistical Analysis}

Values are expressed as mean \pm SEM and a Mann-Whitney-U non-parametrical test was used to compare individual groups. Probability values of $<0.05$ were considered significant. 


\section{Results}

Steady-state FK506 concentrations in whole blood of the mice treated for 8 weeks with low dose FK506 (0.05 mg/kg/day, subcutaneously) were $0.11 \pm 0.01 \mathrm{ng} / \mathrm{ml}$. Body weight, plasma total cholesterol and triglyceride levels were not affected by FK506 treatment (table 4.1). No signs of nephrotoxicity were found in FK506 treated mice.

\begin{tabular}{|c|c|c|}
\hline & Controls & 17606 \\
\hline Bovy wergh gah $(g)$ & $30.8 \pm 02$ & $3.5+0.3$ \\
\hline Total Cholesterol $(\mathrm{mg} / \mathrm{ll}$ ) & $375 \pm 27$ & $387+19$ \\
\hline Ihglvoendes (mglal) & $57=9$ & $69+7$ \\
\hline
\end{tabular}

\section{Table 4.1}

Effects of FKS06-treatment (0.05 mg/kg/day) on (gain of) body weight and the plasma lipid profile of mice.

\section{Plaque morphometry}

Plaque area was measured of the atherosclerotic lesions in the brachiocephalic trunk, the left carotid artery and the left subclavian artery. For the analysis, lesions were divided into either initial or advanced plaques. No differences were found in the number of initial and advanced plaques between FK506-treated and control mice. Total plaque burden (sum of all plaque areas in the aortic arch) of FK506-treated mice was 30\% decreased compared to control mice $\left(119621 \pm 33323 \mu \mathrm{m}^{2}\right.$ vs $169868 \pm 31495 \mu \mathrm{m}^{2}$, respectively, $p=0.06)$.

Mean individual plaque area of all initial lesions in FK506-treated mice was decreased $54 \%$ compared to control mice $\left(17422 \pm 3897 \mu^{2}\right.$ vs $37905 \pm 7320 \mu \mathrm{m}^{2}$, respectively, $p=0.009$ ), whereas no significant differences in mean plaque size were found for advanced plaques (figure 4.1). Lesions in the three main branch points of the aortic arch were diverse in size or phenotype (figure 4.1A), i.e. lesions in the brachiocephalic trunk were generally large and often advanced lesions, whereas plaques developed in the left common carotid artery were mainly initial lesions. Plaques in the left subclavian artery were usually large, but often show an initial phenotype. Therefore, we also calculated the mean plaque area of the distinct branch points. Since the number of advanced lesions was too small for statistical analysis, we focused on initial lesions. Plaque size of initial lesions was significantly reduced $(64 \%)$ in both the brachiocephalic trunk $\left(30409 \pm 5088 \mu \mathrm{m}^{2}\right.$ vs $\left.85532 \pm 5762 \mu \mathrm{m}^{2}, p=0.034\right)$ and the left subclavian artery $\left(8632 \pm 2716 \mu \mathrm{m}^{2}\right.$ vs $24223 \pm$ $\left.4908 \mu \mathrm{m}^{2}, \mathrm{p}=0.025\right)$ in FK506-treated mice compared to the controls. Results are summarized in table 4.2 . 


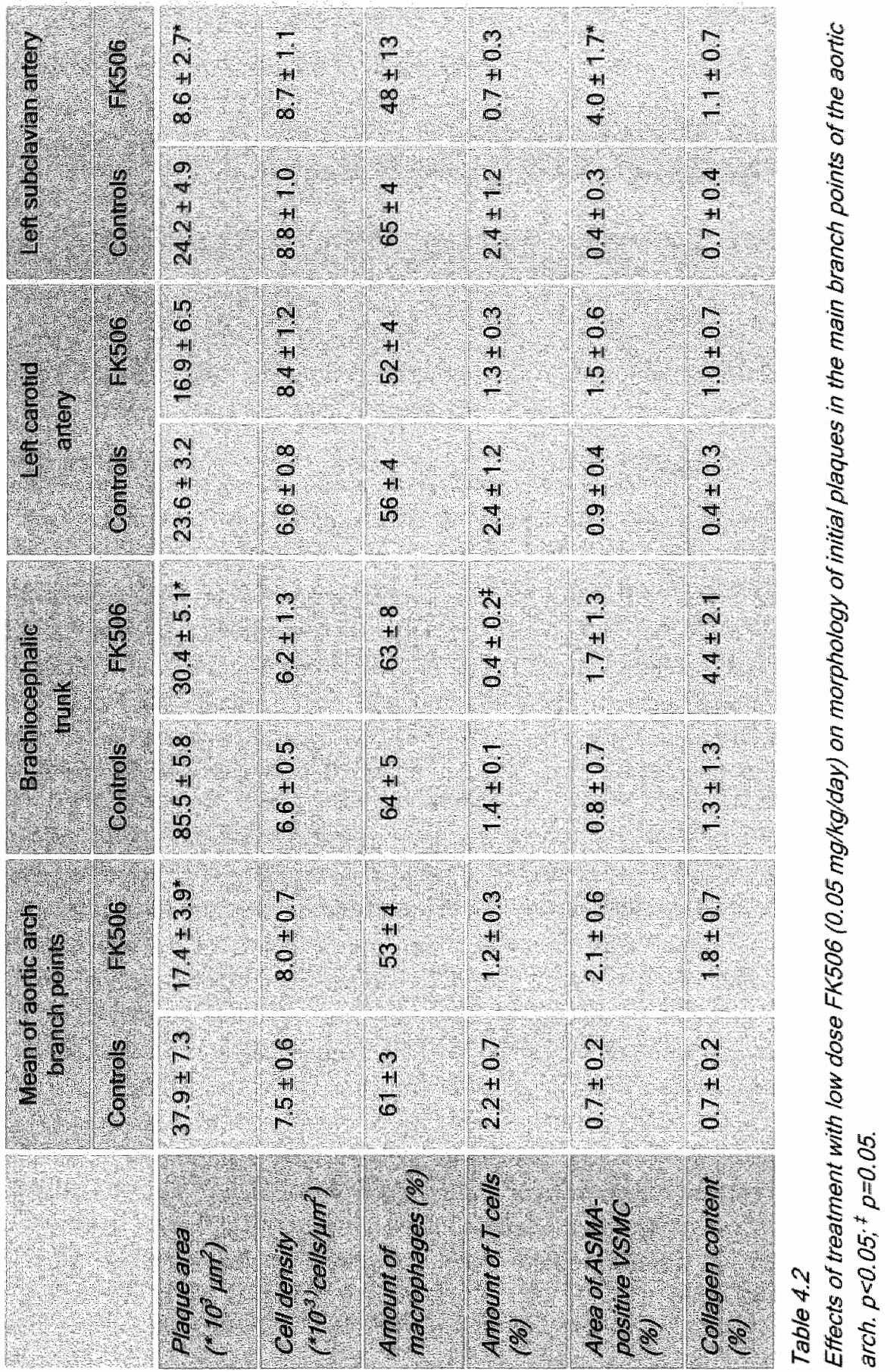



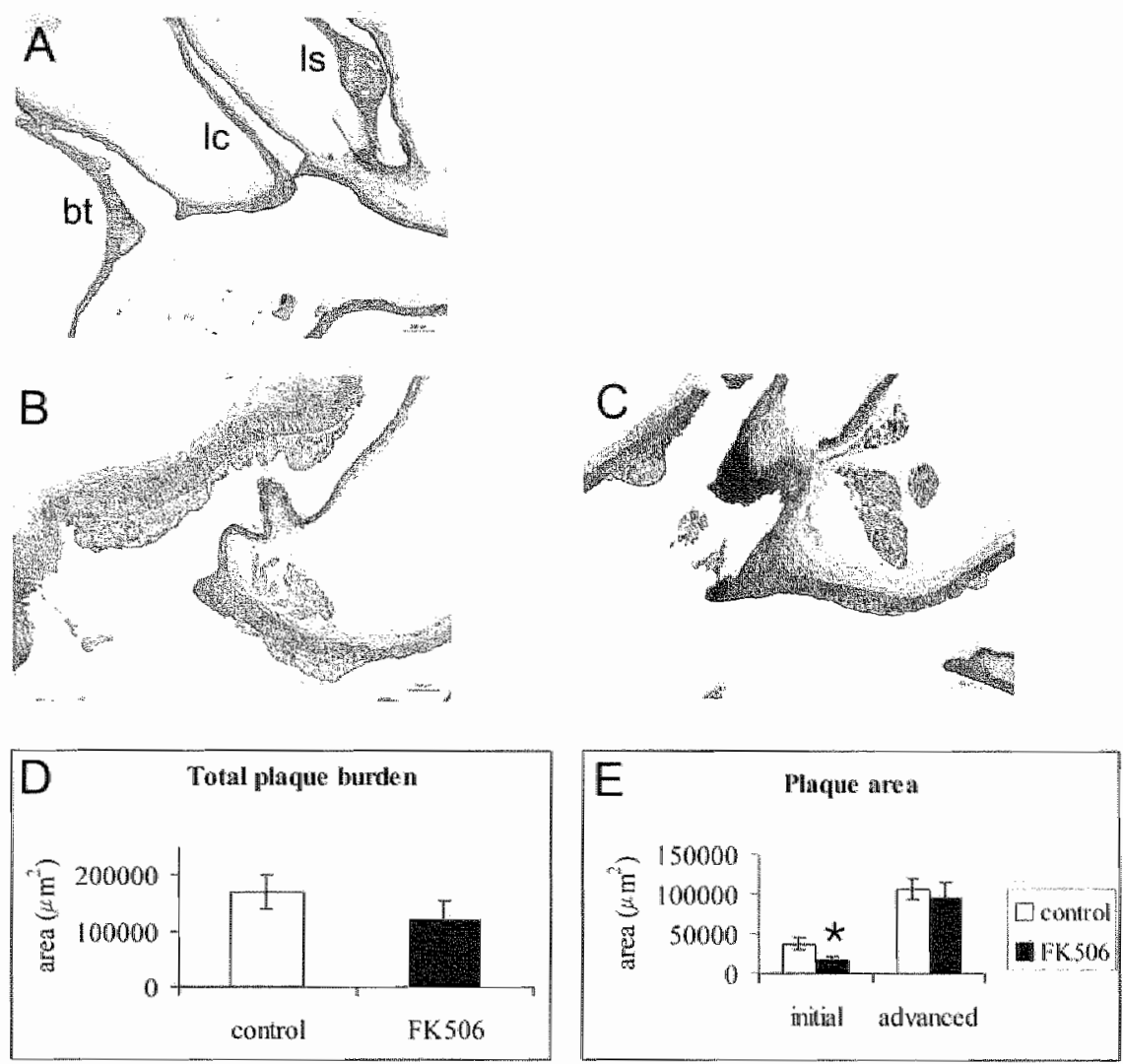

Figure 4.1

Morphometric analysis of atherosclerotic plaque development in the three main branch points of the aortic arch, i.e. the brachiocephalic trunk (bt), the left carotid antery (lc) and left subclavian artery (15). Parrel A shows the lesions in the main branch points of the aortic arch, which can be diverse in size and phenotype. Panels $B$ and $C$ show representative examples of initial lesions in the brachiocephalic trunk of control and FK506-treated mice, respectively. Total plaque burden was calculated by combining plaque sizes of lesions in all the branch points and tended to be decreased in FK506-treated mice ( $p=0.06$, panef D). Individual plaque size of initial lesions was significantly decreased in FK506-treated mice compared to controls ( $\rho=0.009$, panel E).

\section{Plaque morphology}

Besides the effects on plaque size, we also examined the effects of FK506-treatment on lesion composition (figure 4,2). Plaque cell density (amount of cells relative to plaque area) of FK506-treated mice was slightly increased, but not significantly different from that of control mice for both initial and advanced plaques. No significant differences in the relative amount of macrophages or T-cells were found. The area of ASMA-positive VSMC relative to plaque area was increased, although this was not significant when all the plaques of the three branch points were combined. The area of ASMA-positive VSMC, however, was significantly increased $(89 \%)$ in initial lesions of the left subclavian artery in FK506-treated 
mice vs controls $(3.97 \pm 1.67 \%$ vs $0.37 \pm 0.25 \%$, respectively, $p=0.028)$. No significant differences in the area of ASMA-positive VSMC were found in the left carotid artery and the brachiocephalic trunk. In initial plaques of the brachiocephalic trunk, the amount of Tcells (relative to the total amount of plaque cells) was $68 \%$ decreased in FK506-treated mice $(0.44 \pm 0.22 \%$ vs $1.38 \pm 0.07 \%$ for the controls), albeit borderline significant $(p=0.05)$. The relative amount of T cells in plaques of the left carotid and subclavian artery was not significantly different between FK506-treated mice and controls. No significant differences were found in advanced plaques, although the number of advanced plaques in the left carotid and subclavian artery was too small for an adequate comparison $(n=1$ or $n=2$ for both groups, respectively). The relative collagen content of both initial and advanced plaques did not significantly differ between FK506-treated mice and controls. Lipid core content (advanced plaques only) was also not different in the FK506-treated group.
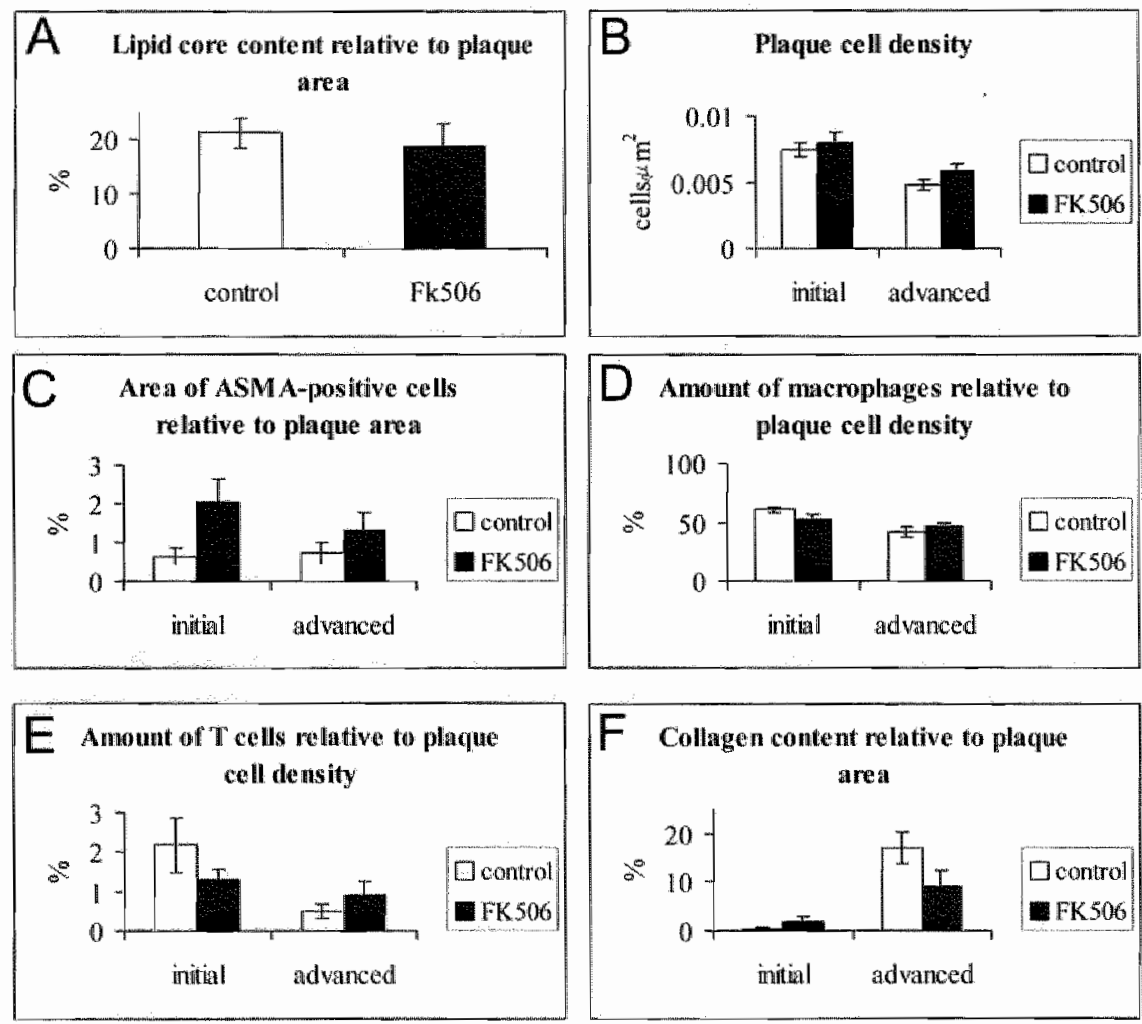

\section{Figure 4.2}

Analysis of plaque morphology of FK506-treated mice ws controls. No significant differences were found in lesion composition, when no distinction was made between plaques in the distinct branch points of the aortic arch. However, the relative area of ASMA-positive VSMC was significantly increased $(p=0.028)$ in initial plaques of the left subclavian artery, whereas the $T$ cell content of initial lesions in the brachiocephalic trunk was decreased $(p=0.05)$ in FK506-treated mice compared to controls. 


\section{Discussion}

in a previous study (described in chapter 3) we examined the effects of low dose FK506 on atherosclerotic plaque development and progression using an ApoE-/- mouse model of accelerated atherogenesis. We showed that low dose FK506 reduced plaque size and enhanced plaque stability by increasing cell density and collagen content and decreasing lipid core content of the plaques. The present study extends these data by showing similar effects of low dose FK506 on atherosclerotic plaque development in the conventional ApoE- $/$ - mouse model of atherosclerosis ${ }^{6}$. Treatment of the mice with $0.05 \mathrm{mg} / \mathrm{kg} / \mathrm{day}$ FK506 for 8 weeks by continuous infusion using osmotic minipumps resulted in reduced plaque size of initial lesions, reduced amounts of $T$ cells in initial lesions of the brachiocephalic artery and increased ASMA-positive VSMC content of initial lesions of the left subclavian artery. This again indicates that low dose FK506 not only reduces the extent of atherosclerosis, but may also stabilize the lesions. However, no significant differences were found in cell density, collagen or lipid core content, all of which were affected by FK506 in the previous study. These differences may be explained by divergence of the two models. In contrast to the model of collar-induced atherosclerosis, which uses an atherogenic diet, ApoE-/- mice on a normal chow develop atherosclerosis more slowly. Acceleration of atherogenesis might intensify the processes contributing to the plaque development and therefore augment the effects of an intervention.

The differences in atherosclerotic plaque development in the distinct branch points of the aortic arch may also complicate the interpretation of the results. Plaques of the brachiocephalic trunk, left carotid artery and left subclavian artery, the three main branch points of the aortic arch, can differ substantially in lesion size, which can obscure significant differences when calculating the mean of all plaques of these branch points. Therefore, we also evaluated the effects of FK506-treatment on atherosclerotic plaque development for each location individually. In this approach, however, especially when plaques are subdivided into initial and advanced lesions, the number of plaques is often too small to perform a statistical analysis. Nevertheless, we showed that low dose FK506, besides its beneficiall effects on the accelerated type of atherosclerosis, also inhibits the slow progressing type of atherosclerosis. The conventional ApoE $/$ - mouse model may more accurately reflect the de novo atherosclerosis in humans, in which plaque development also encompasses several decades of life, whereas the modell of accelerated atherosclerosis might be more suitable to compare with the type of atherosclerosis developing rapidly in grafts of patients after transplantation.

Paradoxically, transplant arteriosclerosis is a major complication of transplantation and often believed to be attributed to the use of immunosuppressive drugs. Indeed, immunosuppressive drugs such as CsA have been shown to be associated with several cardiovascular risk factors, such as hyperlipidemia ${ }^{7}$, hypertension ${ }^{8}$, and increased oxidizability of $\mathrm{LDL}^{9}$. Whereas these factors are much less affected by FK506, the major cardiovascular concern of FK506 is posttransplant diabetes ${ }^{10}$. In view of these adverse side-effects, we used a low dose of FK506 yielding blood concentrations $(\sim 0.1 \mathrm{ng} / \mathrm{ml})$ that 
was significantly below those achieved in transplant patients $(5-10 \mathrm{ng} / \mathrm{ml})^{11}$. FK506 inhibits the protein phosphatase calcineurin, which upon stimulation activates the transcription factor Nuclear Factor of Activated T-cells (NFAT). In T-cells, activation of the calcineurin/NFAT- signalling pathway results in the expression of inflammatory cytokine genes $^{12}$. By inhibiting this pathway, FK506 exerts its anti-inflammatory, immunosuppressive effects ${ }^{13}$. Contrary, in macrophages inhibition of calcineurin was found to enhance inflammatory cytokine gene expression by activating the transcription factor NFKB. Interestingly, the FK506-concentration required for inhibition of NFKB-activation and subsequent cytokine production in macrophages is much higher than required for inhibition of NFAT-activation and cytakine gene-expression in T-cells ${ }^{14}$. This may suggest that a higher dose of FK506 could enhance atherosclerosis by inducing pro-inflammatory cytokine expression in plaque macrophages, whereas a low dose of FK506 reduces atherosclerotic plaque development.

In conclusion, this study shows that low dose FK506 inhibits the spontaneous, slow developing type of atherosclerosis using the conventional ApoE-1- mouse model. Furthermore, we found low dose FK506 to have a beneficial effect on plaque stability, although this was not as prominent as the effects on the accelerated type of atherosclerosis.

\section{Acknowledgements}

The authors want to thank Karin Hoogtanders (Clinical Pharmacology, Academic Hospital of Maastricht, the Netherlands) for measuring FK506 blood concentrations and Dr. C. Peutz (Dept. of Pathology, Academic Hospital of Maastricht, the Netherlands) for histological analysis of the kidneys. 


\section{References}

1. Drew $A F$, Tipping $P G$. Cyclosporine treatment reduces early atherosclerosis in the cholesterol-fed rabbit. Atherosclerosis. 1995;116:181-9.

2. Matsumoto $T$, Saito $E$, Watanabe $H$, Fujioka $T$, Yamada $T$, Takahashi $Y$, Ueno $T$, Tochihara $T$, Kanmatsuse K. Influence of FK506 on experimental atherosclerosis in cholesterol-fed rabbits. Atherosclerosis. 1998;139:95-106.

3. Roselaar SE, Schonfeld G, Daugherty A. Enhanced development of atherosclerosis in cholesterol-fed rabbits by suppression of cell-mediated immunity. $J$ clin lnvest. 1995;96:1389-94.

4. Lutgens E, Gorelik L, Daemen MJ, de Muinck ED, Grewal IS, Koteliansky VE, Flavell RA. Requirement for CD154 in the progression of atherosclerasis. Nat Med 1999;5:1313-6.

5. Vogeser M, Fleischer C, Meiser B, Groetzner J, Spohrer U, Seidel D. Quantification of sirolimus by liquid chromatography-tandem mass spectrometry using on-line solid-phase extraction. Clin Chem Lab Med. 2002;40:40-5.

6. Reddick RL, Zhang SH, Maeda $N$. Atherosclerosis in mice lacking apo E. Evaluation of lesionall development and progression. Arterioscler Thromb. 1994;14:141-7.

7. Hohage H, Arlt M, Bruckner D, Dietl KH, Zidek W, Spieker C. Effects of cyclosporin A and FK 506 on lipid metabolism and fibrinogen in kidney transplant recipients. Clin Transplant. 1997;11:225-30.

8. Avdonin PV, Cottet-Maire F, Afanasjeva GV, Loktionova SA, Lhote P. Ruegg UT. Cyclosporine A up-regulates angiotensin $\|$ receptors and calcium responses in human vascullar smooth muscle cells. Kidney /nt. 1999;55:2407-14.

9. Apanay DC, Neylan JF, Ragab MS, Sgoutas DS. Cyclosporine increases the oxidizability of low-density lipoproteins in renal transplant recipients. Transplantation. 1994;58:663-9.

10. Weir M. Impact of immunosuppressive regïmes on posttransplant diabetes mellitus. Transplant Proc. 2001;33:23S-26S.

11. Pirsch JD, Miller J, Deierhoi MH, Vincenti F, Filo RS. A comparison of tacrolimus (FK506) and cyclosporine for immunosuppression after cadaveric renal transplantation. FK506 Kidney Transplant Study Group. Transplantation. 1997;63:977-83.

12. Rao A, Luo C, Hogan PG. Transcription factors of the NFAT family; regulation and function. Annu Rev Immunol. 1997;15:707-47.

13. Flanagan WM, Corthesy B, Bram RJ, Crabtree GR. Nuclear association of a T-cell transcription factor blocked by FK-506 and cyclosporin A. Nature. 1991;352:803-7.

14. Conboy IM, Manoli D, Mhaiskar V, Jones PP. Calcineurin and vacuolar-type H+-ATPase modullate macrophage effector functions. Proc Natt Acad Sci U S A. 1999;96:6324-9. 


\section{Chapter 5:}

Effects of low dose FK506 on neointima formation and arterial remodeling in a mouse model of carotid artery ligation

Mario M.P.C.Donners, Mat J.A.P. Daemen, Sylvia Heeneman.

inpreparaton. 


\section{Abstract}

Restenosis is the process of luminal narrowing after an intra-arterial procedure and is characterized by proliferation of vascular smooth muscle cells (VSMC) and extracellular matrix (ECM) accumulation. Since inflammatory processes are increasingly implicated in the pathological mechanism underlying restenosis, we hypothesized that the immunosuppressive drug tacrolimus (FK506) would inhibit the development of neointima formation. To test this hypothesis, we used a mouse model of carotid artery ligation.

Male C57BL/6J mice $(n=14)$ were treated for 4 weeks, starting immediately after ligation of the common carotid artery, with low dose FK506 (0.05 mg/kg/day) by continuous subcutaneous infusion. No significant effects were found on mean neointimal area, neointimal thickness, or intima/media ratio. At individual levels, neointimal thickness was decreased (46\%) in FK506 treated mice in the area close to the ligation, but only at one level.

FK506 affected arterial remodeling, since mean lumen size $(37 \%)$ and medial area $(17 \%)$ was increased in FK506-treated mice compared to the controls. Immunohistochemical staining for CD45 showed the presence of inflammatory cells in the neointimal lesions, but no significant differences were found in the amount of CD45+ cells between FK506-treated and control groups. Cell density of the neointima was also not significantly different.

In conclusion, treatment with low dose FK506 only minimally affected neointima formation whereas effects of low dose FK506 on arterial remodeling involved an increase in mean lumen size and medial area. 


\section{Introduction}

Restenosis is the major complication of an intra-arterial intervention in the treatment of atherosclerotic disease, involving both (negative) remodeling of the vessel wall and the formation of a neointima. Neointima formation is characterized by migration and proliferation of vascular smooth muscle cells (VSMC) and extracellular matrix (ECM) accumulation. The last few years, it has become increasingly apparent that inflammatory processes play a substantial role in the development of a neointima ${ }^{1}$. Several studies reported a strong association between the presence of leucocytes or inflammatory serum markers, such as C-reactive protein, and the extent of restenosis ${ }^{2-4}$. Recently, the implementation of the immunosuppressive drug sirolimus (rapamycin) in drugmeluting stents successfully reduced neointima formation ${ }^{5,6}$. Studies of the effects of tacrolimus (FK506) on neointima formation have showed controversial results. A preclinical study by Wieneke et al. ${ }^{7}$ showed inhibition of neointima formation and a reduction in inflammatory cell infiltration using FK506-eluting stents in New Zealand rabbits, whereas Waller et al. showed no significant effects of FK506 on neointima formation in response to vascular injury by balloon angioplasty in rats ${ }^{8}$. Preliminary clinical trials using FK506-eluting stents did not show a beneficial effect of FK506 on in-stent restenosis, although variation in stent designs may cause differences in patient outcome ${ }^{9}$.

In this study we examined the effect of FK506 on both neointima formation and arterial remodeling after carotid artery ligation in the mouse. We found a minimal effect on neointima formation, with a reduction in neointimal thickness only in the area close to the ligation. Lumen and medial area was significantly increased in FK506-treated mice, indicating an effect of FK506 on arterial remodeling.

\section{Materials and Methods}

Animals and Surgery

Male C57BL/6J mice (12-14 weeks of age, $n=14$ ) were obtained from Charles River (Maastricht, the Netherlands) and fed a normal chow throughout the experiment. Mice were anesthetized with $2.5 \%$ isofluorane and the right common carotid artery was ligated with a silk suture (5-0) near the carotid bifurcation as described by Kumar et al. ${ }^{10}$. Mice were treated for 4 weeks by continuous infusion of a low dose of FK506 $(0.05 \mathrm{mg} / \mathrm{kg} / \mathrm{day}$, Fujisawa Holland) or PBS (control group) using osmotic minipumps (Alzet type 2004, Durect Corporation, Cupertino, USA) placed subcutaneously on the back of the mice. 
Tissue harvesting and histological analysis

After 4 weeks, mice were sacrificed and blood was obtained from the inferior caval vein for determination of FK506-concentration. The arterial tree was perfused through a catheter inserted into the left cardiac ventricle with PBS containing $0.1 \mathrm{mg} / \mathrm{ml}$ nitroprusside (Sigma) and subsequently with $1 \%$ paraformaldehyde. The carotid arteries were removed, fixed overnight in $1 \%$ paraformaldehyde and embedded in paraffin. Cross-sections $(4 \mu \mathrm{m}$ thick) were cut at $200 \mu \mathrm{m}$ intervals throughout the common carotid artery. For each level, a cross-section was stained with Elastica-von-Giesson staining (EvG) and hematoxylin and eosin (HE). EvG-stained cross-sections were used for morphometric analysis of the lumen area, intimal area (the area within the internal elastic lamina (IEL) minus the lumen area), medial area (defined as the area within the external elastic lamina (EEL) minus the area within the IEL) and total vessel area (area encompassed by the EEL). Furthermore, Intima/Media (I/M) thickness and neointimal thickness (which corrects for vessel size by dividing the neointimal area by the length of the $(E L)$ were calculated.

Sections were stained with anti-CD45 (1:50, Pharmingen) for analysis of inflammatory cell infiltration.

\section{Assessment of FK506 blood concentration}

Whole blood samples, taken after 4 weeks of FK506-treatment were hemolyzed, deproteinized and analyzed using an on-line solid-phase extraction combined with liquid chromatography-tandem mass spectrometry (LC-MS/MS) as described previously ${ }^{11}$.

\section{Statistical Analysis}

Values are expressed as mean \pm SEM and a Mann-Whitney-U non-parametrical test was used to compare individual groups of animals. Probability values of $<0.05$ were considered significant. 


\section{Results}

Steady-state concentrations of FK506 in whole blood of C57BL/6J mice treated for 4 weeks by continuous subcutaneous infusion with $0.05 \mathrm{mg} / \mathrm{kg} / \mathrm{day}$ FK506 were $0.08 \pm 0.009$ $\mathrm{ng} / \mathrm{ml}$. No effects were found on body weight gain $(1.3 \pm 0.5 \mathrm{~g}$ for the controls vs $1.5 \pm 0.6$ $\mathrm{g}$ for FK506-treated mice). No signs of nephrotoxicity were observed.

\section{Morphometric analysis}

In response to the ligation, neointimal lesions developed in the common carotid artery until $-2-2.5 \mathrm{~mm}$ from the point of ligation. The first 10 cross-sections (with intervals of 200 $\mu \mathrm{m}$ ) were used for the analysis. We calculated both the mean of the measurements of these 10 cross-sections, as well as the mean for each individual section. Figures $5.1 \mathrm{~A}$ and $B$ show representative cross-sections of the ligated common carotid artery with a neointimal lesion of control and FK506-treated mice. No significant differences were found in the mean neointimal area, neointimal thickness or $1 / \mathrm{M}$ thickness of these $10 \mathrm{cross}$ sections (figure 5.1C). However, neointima formation in the area close to the ligation was decreased in FK506-treated mice, which was only significant for neointimal thickness at the second level $(22.4 \pm 2.1 \mu \mathrm{m}$ for FK506-treated mice vs $41.6 \pm 10.1 \mu \mathrm{m}$ for the controls, $p=0.04$, figure 5.2A). More distant from the ligation, neointima formation was not significantly different from control mice.

The mean lumen area was significantly larger (37\%) in FK506-treated mice compared to the controls $\left(23146 \pm 1898 \mu \mathrm{m}^{2}\right.$ vs $14481 \pm 1974 \mu \mathrm{m}^{2}$ for FK506-treated mice and controls, respectively, $p=0.01$, figure $5.1 \mathrm{D})$. Lumen area was larger in all sections, although in the individual sections significance was reached at only two levels (figure 5.2B). The mean medial area was $17 \%$ increased in FK506-treated mice (37473 $\pm 1958 \mu \mathrm{m}^{2}$ vs $31112 \pm$ $1209 \mu \mathrm{m}^{2}$ for the controls, $p=0.03$, figure 5.1E). Also in the individual cross-sections the increase in medial area was significant at several levels (figure 5.2C). No significant differences were found in mean total vessel area (figure 5.1F), although total vessel area in FK506-treated mice expanded as the intimal area increased (figure 5.2D).

\section{Histological analysis}

Immunohistochemical staining for CD45 confirmed the presence of inflammatory cells in the neointimal layer of the ligated caratid artery (figure 5.3A). No differences were found in the amount of CD45+ positive cells in the neointima of FK506-treated mice compared to control mice $(2.7 \pm 0.6 \%$ vs $2.5 \pm 0.5 \%$, respectively, figure $5.3 \mathrm{~B})$. Furthermore, cell density of the neointimal lesions did not significantly differ between treated and control groups $\left(4.3 \pm 0.45^{\star} 10^{3}\right.$ vs $5.7 \pm 1.0^{*} 10^{3}$ cells/ $\mu \mathrm{m}^{2}$, respectively, figure $\left.5.3 \mathrm{C}\right)$. 
A
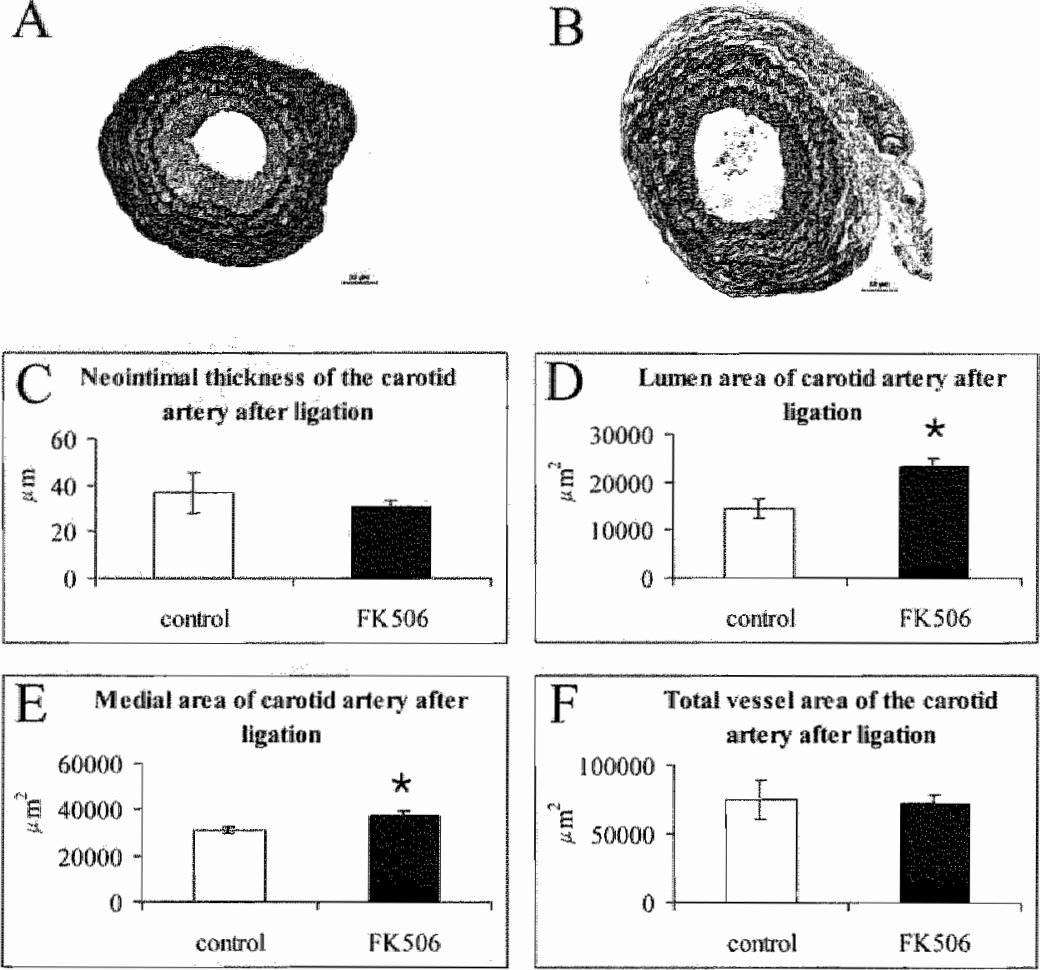

\section{Figure 5.1}

Morphometric analysis of neointima formation and arterial remodeling 4 weeks after ligation of the right common carotid artery. Panel $A$ and $B$ show representative (Elastica von Giesson stained) cross-sections of control mice and FK506-treated mice, respectively. Mean neointimal thickness (C), lumen area (D), medial area (E) and total vessel area (F) of 10 equally spaced cross-sections was measured. Mean lumen size and medial area were significantly increased in FK506-treated mice compared to controls, with no significant differences in mean neointimal thickness and mean total vessel area. 

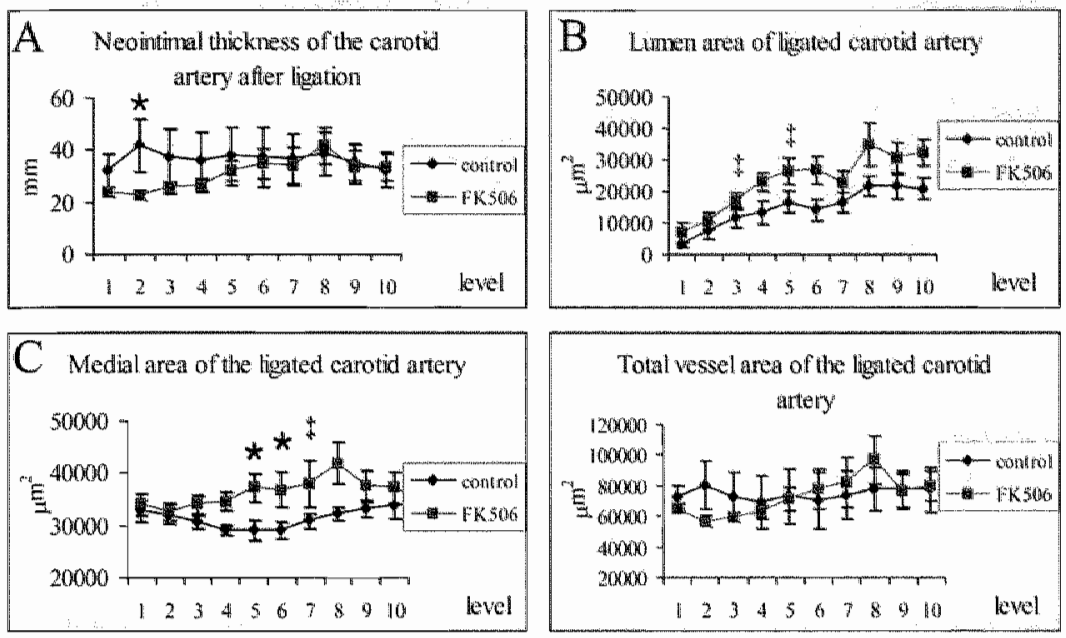

\section{Figure 5.2}

Morphometric analysis of neointima formation and arterial remodeling in the individual levels of the carotid artery from the point of ligation (section 1) towards the aortic arch. In FK506-ireated mice, neointimal thickness was significantly decreased in the area close to the ligation (panel A). Lumen area was larger in all sections in the FK506-treated group, but was only nearly significant in sections 4 and 6 (panel B). FK506-treatment also significantly increased medial area in section 4-6 (panel C). Differences in total vessel area were not significant (pane/ D). ${ }^{*} p<0.05, \$ p=0.075$.
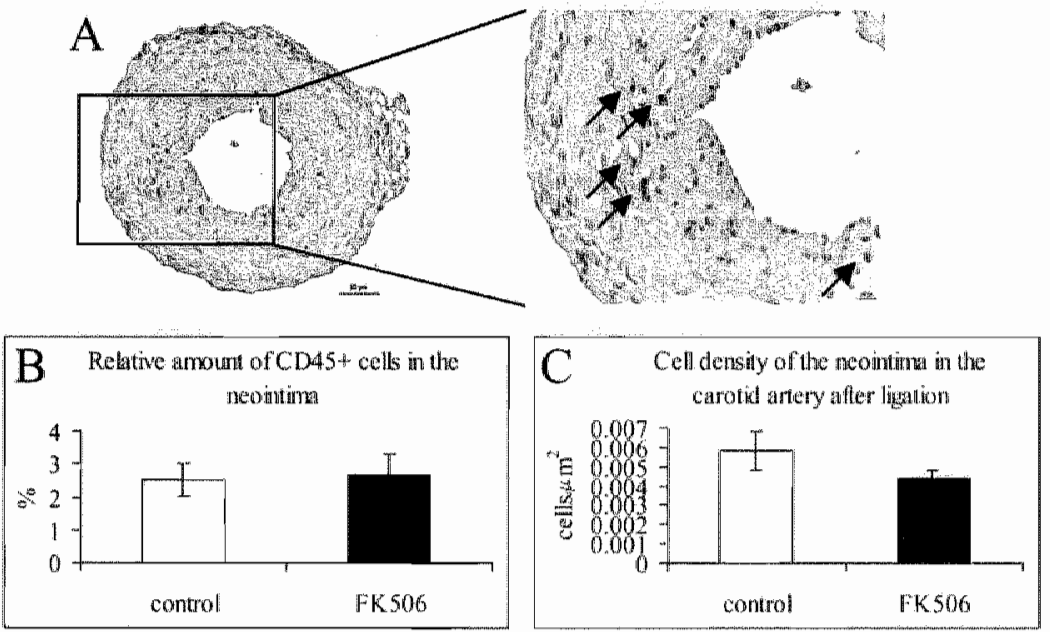

Figure 5.3

(Immunolhistological analysis of neointimal lesions 4 weeks after carotid antery ligation. Panel A shows a cross-section stained for CD45+ cells showing the presence of inflammatory cells in the neointima. No significant differences were found in the total amount of $\mathrm{CD} 45+$ cells relative to the total amount of cells in the neointima $(B)$ or the cell density of the neointimal lesions (C) affer FK506-treatment. 


\section{- Discussion}

Recently, the application of anti-inflammatory or immunosuppressive drugs, especially in drug-eluting stents, has proven to be very promising for the treatment of restenosis. The distinct immunosuppressive drugs, however, have been shown to differ in effectiveness of reducing neointima formation. Whereas sirolimus is now generally believed to be a very potent inhibitor of neointima formation ${ }^{12}$, cyclosporin A was shown to increase neointimal thickening $^{8}$. The results for FK506 so far are inconclusive. Preclinical studies ${ }^{7.13}$ reported reduced neointima formation by FK506 accompanied by a reduction in inflammatory cell content, whereas others failed to show an effect of FK506 on neointima formation ${ }^{8,9}$.

In this study we examined the effects of low dose FK506 on neointima formation and arterial remodeling after carotid artery ligation in the mouse. We showed that treatment with low dose FK506 did not significantly affect neointima formation, whereas lumen size and medial area were significantly increased. Low dose FK506 tended to reduce neointima formation only in the area close to the ligation, but this was only significant at one level. Neointima formation in the area more distant from the ligation was not affected by FK506treatment.

The reduction in neointima formation by FK506 was not as pronounced as is described for sirolimus. The concentration of FK506 required for inhibition of VSMC proliferation may be higher than the concentrations achieved in this study. Indeed, in vitro VSMC proliferation was not affected by FK506 concentrations up to $42 \mathrm{ng} / \mathrm{ml}$ (chapter 3 ). Another possible explanation may be the different mechanism of action of both immunosuppressives. Besides its immunosuppressive actions, sirolimus has been shown to be a potent anti-proliferative drug. By forming a complex with the immunophilin FKBP12, sirolimus inhibits mammalian target of rapamycin (mTOR), thereby inhibiting cell cycle progression and subsequently cell proliferation ${ }^{14}$. FKBP12 has been suggested to be a regulator of cell cycle, since FKBP12-1- mice have been shown to manifest cell cycle arrest mediated by a significant upregulation of $\mathrm{p} 21^{15}$. This hypothesis may be supported by the fact that FKBP12 has been found to be upregulated in neointimal tissue ${ }^{16}$. FK506 also forms a complex with FKBP12, but inhibits calcineurin-activity rather than MTOR, which leads to inhibition of the transcription factor NFAT (nuclear factor of activated T cells) and subsequent cytokine gene expression. Although FK506 has been shown to be able to also induce p21 expression ${ }^{17}$ and to inhibit human VSMC proliferation ${ }^{18}$, its actions are considered to be mostly anti-inflammatory. Although FK506-treatment in our study did not lead to a reduction in the total amount of inflammatory cells, low dose FK506 may influence the amount of various inflammatory cell-types, their activation status or the production of cytokines by both inflammatory and other vascular cells.

In previous studies (chapters 3 and 4), we showed low dose FK506 to significantly inhibit atherosclerotic plaque development and to induce a more stable plaque phenotype by increasing cell density, collagen content or alpha-smooth muscle actin-positive VSMC content and decreasing lipid core content or T-cell content of the plaques. The effects of low dose FK506 on atherosclerosis are clearly more prominent than for restenosis-related 
processes. Although both diseases share some common features, their respective underlying mechanism also have unique features ${ }^{19}$. Although inflammatory processes play a role in both diseases, restenosis is mainly characterized by a proliferative response of the VSMC, most likely in response to an acute inflammationy reaction caused by severe injury of the vessel wall. Contrary, in addition to the accumulation of lipid, cells and ECM, the process of atherosclerosis involves a chronic inflammatory response, mainly constituted by macrophages and T-cells. Indeed, the inflammatory cell content of atherosclerotic lesions is considerably larger than that of the neointima. Furthermore, the model of carotid artery ligation does not include endothelial damage, which probably also limits the extent of the inflammatory response. This may explain the fact that FK506 is more effective in reducing atherosclerotic plaque development than neointima formation.

In this study, we found low dose FK506 to affect arterial remodeling. Lumen size and medial area were increased in FK506-treated mice, although at the individual levels this was only significant to a limited extent. These effects were also observed in the model of collar-induced atherosclerosis (chapter 3). Arterial remodeling is an active process involving reconstruction of the ECM, which requires matrix-degrading proteins such as matrix metalloproteinases (MMPs). There is little information on the effect of FK506 on MMP expression or activity, but it has been shown to induce transforming growth factor (TGF)- $\beta$ expression ${ }^{20,21}$. TGF- $\beta$ is a multifunctional cytokine with anti-inflammatory and pro-fibrogenic activities. It is known to regulate ECM turnover, usually by stimulating collagen synthesis and inhibiting degradation of ECM constituents by proteinases ${ }^{22}$, but it has also been shown to stimulate MMP-expression ${ }^{23,24}$. In a study of flow-induced arterial remodeling, Sho et al. showed TGF- $\beta$, MMP-2, MMP-9 and membrane-type (MT-) MMPs to be highly upregulated early in the process of arterial enlargement ${ }^{25}$. Thus, by inducing TGF- $\beta$ expression, FK506 may regulate ECM turnover thereby enabling the vessel to remodel.

In conclusion, this study shows that low dose FK506 did not significantly inhibit neointima formation in the mouse carotid artery ligation model. FK506 tended to reduce neointimal thickness, but only in the area close to the ligation. Treatment of low dose FK506 also affected arterial remodeling by an increase in lumen size and medial area. The effects of low dose FK506 on neointima formation were not as evident as its effects on atherosclerosis, probably due to differences in underlying disease mechanism and the nature of the inflammatory response. 


\section{Acknowledgements}

The authors want to thank Karin Hoogtanders (Clinical Pharmacology, Academic Hospital of Maastricht, the Netherlands) for measuring FK506 blood concentrations and Dr. C. Peutz (Dept. of Pathology, Academic Hospital of Maastricht, the Netherlands) for histological analysis of the kidneys. 


\section{References}

1. Welt FG, Rogers C. Inflammation and restenosis in the stent era. Arterioscler Thromb Vasc Biol. 2002;22:1769-76.

2. Schillinger $M$, Exner $M_{s}$ Mlekusch $W$, Rumpold $H$, Ahmadi $R_{\text {in }}$ Sabeti $S$, Haumer $M_{\text {" Wagner }}$ $O$. Minar E. Vascular inflammation and percutaneous transluminal angioplasty of the femoropopliteal artery: association with restenosis. Radiology, 2002;225:21-6.

3. Farb A, Weber DK, Kolodgie FD, Burke AP, Virmani R. Morphological predictors of restenosis after coronary stenting in humans. Circulation. 2002;105:2974-80.

4. Kornowski R, Hong MK, Tio FO, Bramwell $O$, Wu $H$, Leon MB. In-stent restenosis: contributions of inflammatory responses and arterial injury to neointimal hyperplasia. I Am Coll Cardiol. 1998;31:224-30.

5. Sousa JE, Costa MA , Abizaid A Abizaid AS, Feres F, Pinto IM, Seixas AC, Staico $R$ Mattos LA, Sousa AG, Falotico R, Jaeger J, Popma JJ, Serruys. PW. Lack of Neointimal Proliferation After Implantation of Sirolimus-Coated Stents in Human Coronary Arteries : A Quantitative Coronary Angiography and Three-Dimensional Intravascular Ultrasound Study. Circulation. 2001;103:192-195.

6. Regar E, Serruys PW, Bodle C, Holubarsch C, Guermonprez JL, Wijns W, Bartorelli A, Constantini C, Degertekin M. Tanabe K, Disco C. Wuelfert E, Morice MC. Angiographic findings of the multicenter Randomized Study With the Sirolimus-Eluting $B x$ Velocity Balloon-Expandable Stent (RAVEL): sirolimus-eluting stents inhibit restenosis irrespective of the vessel size. Circulation. 2002;106:1949-56.

7. Wieneke H, Dirsch O, Sawitowski T, Gu YL, Brauer H, Dahmen U, Fischer A, Wnendt S, Erbel R. Synergistic effects of a novel nanoporous stent coating and tacrolimus on intima proliferation in rabbits. Catheter Cardiovasc Inter. 2003;60:399-407.

8. Waller JR, Brook NR, Bicknell GR, Nicholson ML. Differential effects of modern immunosuppressive agents on the development of intimal hyperplasia. Transp/ int. 2004;17:9-14.

9. Grube $E_{1}$ Gerckens U, Muller R, Bullesfeld L. Drug eluting stents: initial experiences. Z Kardiol. 2002;91 Suppl 3:44-8.

10. Kumar $A$, Lindner $V$. Remodeling with neointima formation in the mouse carotid artery after cessation of blood flow. Anterioscler Thromb Vasc Biol 1997:17:2238-44.

11. Vogeser M, Fleischer C, Meiser B, Groetzner J, Spohrer U, Seidel D. Quantification of sirolimus by liquid chromatography-tandem mass spectrometry using on-line solid-phase extraction. Clin Chem Lab Med. 2002;40:40-5.

12. Cheng-Lai A, Frishman WH. Sirolimus-eluting coronary stents: novel devices for the management of coronary artery disease. Am J Ther. 2004:11:218-28.

13. Bartorelli AL, Trabattoni $D$, Fabbiocchi $F$, Montorsi $P$, de Martini $S$, Calligaris $G$, Teruzzi $G$, Galli S, Ravagnani $P$. Synergy of passive coating and targeted drug delivery: the tacrolimus-eluting Janus CarboStent. J interv Cardiol 2003;16:499-505.

14. Sehgal SN. Rapamune (RAPA, rapamycin, sirolimus): mechanism of action immunosuppressive effect results from blockade of signal transduction and inhibition of cell cycle progression. Clin Biochem. 1998:31:335-40.

15. Aghdasi $B$, Ye K, Resnick A, Huang $A, H a ~ H C$, Guo X, Dawson TM, Dawson VL, Snyder SH. FKBP12, the 12-kDa FK506-binding protein, is a physiologic regulator of the celf cycle. Proc Natt Acad Sci U S A. 2001;98:2425-30. 
16. Zohlnhofer D, Klein CA, Richter T, Brandl R, Murr A Nuhrenberg T, Schomig A, Baeuerle $P A$, Neumann FJ. Gene expression profiling of human stent-induced neointima by cDNA. array analysis of microscopic specimens retrieved by helix cutter atherectomy: Detection of FK506-binding protein 12 upregulation. Circulation. 2001:103:1396-402.

17. Khanna AK. The immunosuppressive agent tacrolimus induces p21WAF/CIP1WAF1/CIP1 via TGF-beta secretion. Biochem Biophys Res Commun. 2003;303:266-72.

18. Mohacsi PJ, Tuller D, Hulliger B, Wijngard PL. Different inhibitory effects of immunosuppressive drugs on human and rat aortic smooth muscle and endothelial cell prolfferation stimulated by platelet-derived growth factor or endothelial cell growth factor. $J$ Heart Lung Transplant. 1997;16:484-92.

19. Orford JL, Selwyn AP, Ganz P, Popma JJ, Rogers C. The comparative pathobiology of atherosclerosis and restenosis. Am J Cardiol. $2000 ; 86: 6 \mathrm{H}-11 \mathrm{H}$.

20. Khanna A. Cairns $V$, Hosenpud JD. Tacrolimus induces increased expression of transforming growth factor-beta1 in mammalian lymphoid as well as nonlymphoid cells. Transplantation. 1999;67:614-9.

21. Khanna A, Plummer M, Bromberek C. Bresnahan B. Hariharan S. Expression of TGF-beta and fibrogenic genes in transplant recipients with tacrolimus and cyclosporine nephrotoxicity, Kidney /nt. 2002;62:2257-63.

22. Massague J. The transforming growth factor-beta family. Ann Rev Cell Biol. 1990;6:597641.

23. Marti HP, Lee L, Kashgarian M, Lovett DH. Transforming growth factor-beta 1 stimulates glomerular mesangial cell synthesis of the $72-\mathrm{kd}$ type IV collagenase. Am J Pathol. 1994; 144:82-94.

24. Puyraimond $A$, Weitzman JB, Babiole $E$, Menashi S. Examining the relationship between the gelatinolytic balance and the invasive capacity of endothelial cells. J Ce// Scr. 1999;112 (PI 9):1283-90.

25. Sho $\mathbb{E}$, Sho $M$, Singh $T M$, Nanjo $H$, Komatsu $M$, Xu $C$, Masuda $H$, Zarins $C K$. Arterial enlargement in response to high flow requires early expression of matrix metalloproteinases to degrade extracellular matrix. Exp Mo/ Pathol 2002;73:142-53. 



\section{Chapter 6:}

\section{Proteomic analysis of differential protein expression in human atherosclerotic plaque progression}

Marjo M.P.C. Donners, Monque J. Verluyen, Freek G. Bouwman, Edwin C M. Mariman. Bart Devreese, Frank Vanrobaeys, Jozef van Beeumen, Luc H.J.M. van den Akker, Mat J.A.P. Daemen, Syvia Heeneman. 


\section{Abstract}

In this study, differential protein expression was assessed during human atherosclerotic plaque progression. A multifaceted approach was used in which differential protein expression was studied by two-dimensional (2D) gel electrophoresis and validated in individual patients using Western blotting and immunohistochemistry.

The reproducibility of the $2 D$ technique was determined using replicate gels of one sample and was found to be highly reproducible $(81 \%$ of the $2 \mathrm{D}$ spots was present in at least 4 out of 7 replicate gels). Then, 2D profiles of whole-mount advanced stable lesions were compared to those of plaques containing a thrombus. Mass spectrometry analysis identified vinexin- $\beta$ and alpha- 1 antitrypsin (AAT) in the same spot, which was differentially expressed in plaques with a thrombus. Immunohistochemistry and Western blotting showed limited expression of both vinexin- $\beta$ and AAT in early lesions, whereas high expression of both proteins was found in advanced lesions. Differential expression of vinexin- $\beta$ in lesions with a thrombus compared to stable plaques could not be confirmed, indicating the importance of validation of the results of the proteomic analyses. For AAT, Western blotting of 2D gels revealed expression of 6 isoforms in advanced plaques, one of which was confirmed to be solely expressed in plaques with a thrombus.

In conclusion, although 2D gelelectrophoresis is a reproducible technique to identify differential protein expression in complex samples such as whole-mount atherosclerotic tissue, it may reveal false-positives and requires validation of the results. This is the first study that identified vinexin- $\beta$ to be expressed in advanced human atherosclerotic plaques, but the differential expression of this protein in stable plaques vs lesions with a thrombus could not be confirmed. Furthermore, this analysis revealed the expression of six isoforms of AAT in advanced plaques, one of which was uniquely expressed in plaques with a thrombus. 


\section{- Introduction}

Rupture of an atherosclerotic plaque is the predominant cause of acute coronary syndromes and peripheral vascular disease ${ }^{1-3}$. The underlying molecular mechanisms of plaque rupture have been extensively studied, but are still not fully known. Gene expression studies have identified many genes to be either upregulated or downregulated in human atherosclerosis ${ }^{4-7}$. However, protein expression patterns do not always reflect differential gene expression patterns ${ }^{8,9}$. Furthermore protein functions can also be influenced by post-translational modifications, such as phosphorylation, glycosylation or proteolysis $^{10}$.

Proteomic technology is a powerful tool to describe changes on the level of protein expression and modification. The most commonly used technique for proteomics is the 2 Dimensional (2D) gel electrophoresis, originally described by Klose ${ }^{11}$ and O'Farrell ${ }^{12}$. The $2 \mathrm{D}$ technique allows a broad-base screening of protein expression patterns at various stages of atherosclerosis and identification of unknown proteins involved in this process. It has already been used to study disease mechanisms, such as cancer, cardiac failure and infectious diseases, and to identify new diagnostic markers and therapeutic targets ${ }^{13,14}$. Recently, You et al. reported a proteomics study to identify proteins associated with the development of coronary artery disease $\mathrm{e}^{15}$. In their study, protein expression profiles of diseased coronary arteries were compared to normal coronary arteries and one protein (ferritin light chain) was shown to be differentially expressed. However, to date no proteomics study to investigate the underlying molecular mechanism of atherosclerotic plaque rupture has been reported.

In the present study, 2D gelelectrophoresis was used to examine the differences between advanced, but stable human atherosclerotic plaques and plaques containing a thrombus. Our results show that the technique is able to identify proteins from wholemount human atherosclerotic plaques that are differentially expressed during progression from a stable plaque to a lesion with a thrombus, but that additional validation is necessary. We found vinexin- $\beta$ to be highly expressed in advanced human atherosclerotic plaques, although its differential expression in stable lesions vs plaques with a thrombus could not be confirmed. Expression of six isoforms of alpha- 1 antitrypsin (AAT) was revealed in advanced plaques, one of which was shown to be unique for plaques containing a thrombus, suggesting a possible role of AAT in human atherosclerotic plaque rupture. 


\section{Materials and Methods}

Tissue harvesting and sample preparation

Human carotid plaque specimens were obtained from patients undergoing endarterectomy (Department of Vascular Surgery, Maasland Hospital, Sittard). The plaques were divided immediately on ice into $3 \mathrm{~mm}$ thick parallel slices, which were either fixed in 10\% phosphate-buffered formalin $(\mathrm{pH} \mathrm{7.4)}$ for histological analysis or snap-frozen in liquid nitrogen for protein isolation. After crushing the tissue in liquid nitrogen with a mortar, proteins were extracted with $40 \mathrm{mM}$ Tris-lysisbuffer containing protease-inhibitors (1 mmol/L sodium orthovanadate; $1 \mathrm{mmol} / \mathrm{L}$ dithiothreitol (DTT); $10 \mathrm{mmol} / \mathrm{L}$ soytrypsin inhibitor; $2 \mathrm{mmol} / \mathrm{L}$ benzamidine hydrochloride; $10 \mathrm{mmol} / L$ leupeptin; $10 \mathrm{~mol} / \mathrm{L}$. DNAse and 10 mol/L RNAse). Formalin-fixed specimens were routinely processed, embedded in paraffin and cut into $4 \mu \mathrm{m}$ cross-sections. After staining with hematoxylin and eosin, plaques were classified according to Virmani et.al. ${ }^{16}$. Stable lesions were characterized by an intact fibrous cap containing either a well-formed necrotic core, calcification or fibrous tissue. Lesions containing a thrombus included ruptured plaques or those with intraplaque hemorrhage.

\section{Two-dimensional gelelectrophoresis}

Protein samples were separated first by their isoelectric point (pl) by means of isoelectric focusing (IEF) ${ }^{17}$. Therefore, $300 \mu \mathrm{g}$ of protein was loaded per $24 \mathrm{~cm}$ Immobiline $\mathrm{pH}$ gradient (IPG)-strip with a linear $\mathrm{pH}$-range of 4-7 by in-gel rehydration under low voltage (30V) overnight at $20^{\circ} \mathrm{C}$ on the IPG-Phor (Amersham Biosciences). The voltage was then raised step-wise and proteins were focused for $15 \mathrm{hrs}$ at $8000 \mathrm{~V}$.

After equilibration, proteins in the strips were transferred to large 12\% SDS-PAGE gels for separation by their molecular weight (Mw). The gels were run simultaneously in the Ettan-DALT (Amersham Biosciences) and fixed overnight with methanol/acetic acid. Subsequently, the gels were stained using a silver-staining protocol adapted from Shevchenko et. al ${ }^{18}$ or with Sypro ${ }^{16}$ Ruby Protein gel stain (Bio-Rad). Subsequently, image analysis was performed using the PDQuest 2-D Gel Analysis Software version 6.2.0 (BioRad).

\section{In-gel digestion}

Differential spots were excised from the gel either manually for silverstained spots or automatically using the Spot Cutter (Bio-Rad) for Sypro Ruby stained spots. Excised spots were then processed on a MassPREP digestion robot (Waters), according to the following protocol: A solution of $50 \mathrm{mmol} / \mathrm{L}$ ammonium bicarbonate/ $50 \%$ acetonitrile was used for the destaining of Sypro Ruby stained spots. For sillver stained spots $15 \mathrm{mmol} / \mathrm{L}$ potassium ferricyanide/ $50 \mathrm{mmol} / \mathrm{L}$ sodium thiosulphate was used. Cysteines were reduced with 10 mmol/L DTT in $100 \mathrm{mmol} / \mathrm{L}$ ammonium bicarconate for 30 minutes followed by alkylation with $55 \mathrm{mmol} / \mathrm{L}$ iodoacetamide in $100 \mathrm{mmol} / \mathrm{L}$ ammonium bicarbonate for 20 minutes. Spots where washed with $100 \mathrm{mmol} / \mathrm{L}$ ammonium bicarbonate to remove excess reagents 
and dehydrated with $100 \%$ acetonitrile. Porcine sequencing-grade modified trypsin ( 6 $\mathrm{ng} / \mathrm{ul}$, Promega) in $50 \mathrm{mmol} / \mathrm{L}$ ammonium bicarbonate was added to the gel plug and incubated at $37{ }^{\circ} \mathrm{C}$ for 5 hours. The peptides were extracted with $1 \%$ formic acid / $2 \%$ acetonitrile ${ }^{18}$.

\section{Mass spectrometry}

For matrix-assisted laser desorption ionization time-of-flight (MALDL-TOF) mass spectrometry $1.5 \mu \mathrm{l}$ of each peptide mixture was mixed with matrix $(10 \mathrm{mg} / \mathrm{ml} \alpha$-cyano-4hydroxycinnamic acid in $50 \%$ acetonitrile/ $0.1 \%$ trifluoroacetic acid) and spotted on a target plate. The spots were allowed to air dry for homogeneous crystallization. Spectra were obtained using a MALDI-Linear Reflectron mass spectrometer (Waters). The instrument was operated in positive reflector mode. Acquisition mass range was 900-3000 $\mathrm{Da}$. The instrument was calibrated on 6-8 reference masses from a tryptic digest of alcohol dehydrogenase. In addition, a nearpoint lockmass correction for each sample spot was performed using adrenocorticotropic hormone fragment 18-39 $(\mathrm{MH}+2465.199)$ to achieve maximum mass accuracy. A peptide mass list was generated for subsequent database search.

Proteins were further identified by MALDI-TOF/TOF (4700 Proteomics Analyzer, Applied Biosystems) and nano Liquid Chromatography (LC)-MS/MS on a Q-Trap LC-MS/MS analyzer (Applied Biosystems). For MALDI-TOF/TOF analysis, $1 \mu \mathrm{l}$ of the tryptic digest was mixed with matrix ( $\alpha$-cyano-4- hydroxycinnamic acid) and spotted on the target. After abtaining a fingerprint, the five largest peaks were selected for fragmentation, for which the collision gas cell was filled with ambient air. For nano LC-MS/MS, peptide mixtures were separated on an Ultimate nanoLC system (LC-Packings Dionex) as described by Devreese et al. ${ }^{19}$. The Q-Trap mass spectrometer is a hybrid quadrupole linear ion trap instrument. Typically, 3 scan functions were used to characterize the peptides: an enhanced MS scan (full scan using linear ion trap at 4000 arbitrary mass units (amu)/sec), an enhanced resolution scan around the 2 major peaks from the enhanced MS scan (1000 amu/sec) and an MS/MS spectrum of these peptides when their charged state was $\geq 2$. The collision gas used was nitrogen. Database searches were established using Mascot (www.matrixscience.com) and the NCBI protein database.

\section{Western Blotting}

Twenty micrograms of proteins were separated on 12\% SDS-PAGE gels. For Western blotting of 2D gels, $100 \mu \mathrm{g}$ of proteins was loaded on $24 \mathrm{~cm}$ IPG-strips (pH 4-7). After transfer to nitrocellulose, membranes were blocked overnight with $3 \%$ marvel/ $0.1 \%$ PBSTween, and incubated with primary antibody for $2 \mathrm{hrs}$, at room temperature (polyclonal goat-anti-AAT or goat-anti-vinexin- $\beta$, diluted 1:100, Santa Cruz, USA). After washing with $0.1 \%$ PBS-Tween, the membranes were incubated for 2 hrs at room temperature with secondary antibody (Rabbit-anti-goat, horse radish peroxidase-labeled diluted 1:5000, Pierce, Perbio Science, Netherlands). Blots were washed again with $0.1 \%$ PBS-Tween 
and incubated with WestPico (Pierce, Perbio Science, Netherlands) for visualization. After scanning, densitometric analysis was performed using Quantity One software (Bio-Rad).

\section{Immunohistochemistry}

After deparaffinization, cross-sections were pre-treated with trypsin and incubated with a polyclonal rabbit-anti-human-AAT (1:5000, DAKO, Denmark). Swine-anti-rabbit secondary antibody (1:1000, biotin-labeled, DAKO, Denmark) and ABC-alkaline phosphatase were used for visualization.

For immunostaining of vinexin- $\beta$, cross-sections were pre-treated with pepsin and incubated with polyclonal goat-anti-human vinexin- $\beta$ (1:20, Santa Cruz, USA). Secondary rabbit-anti-goat (1:200, biotin-labeled, DAKO, Denmark) and ABC-alkaline-phosphatase were used for visualization.

\section{Statistical analysis}

Data are expressed as mean \pm SEM. Protein expression between lesion types was compared using a non-parametric Mann-Whitney-U test. Probability values of $<0.05$ were considered significant. 


\section{Results}

Reproducibility of 2D gel electrophoresis

To test the reproducibility of the technique, a single protein sample (Trismextract of a human atherosclerotic plaque) was used to create 7 replicate 2D-gels, which were silverstained. The IPG-strips and SDS-PAGE gels were run in parallel in order to keep the variation due to differences in running conditions to the minimum. An area containing -500 spots was selected for testing the reproducibility of the technique. The selected areas of the 7 replicate gels were matched (figure 6.1) and the presence of the spots on the gels was assessed. Of the 477 spots that were analyzed, $388(81 \%)$ were present on at least 4 out of 7 replicate gels, whereas $359(75 \%)$ spots were detected on 5 of the 7 gels. This indicates that the $2 \mathrm{D}$ technique is highly reproducible.

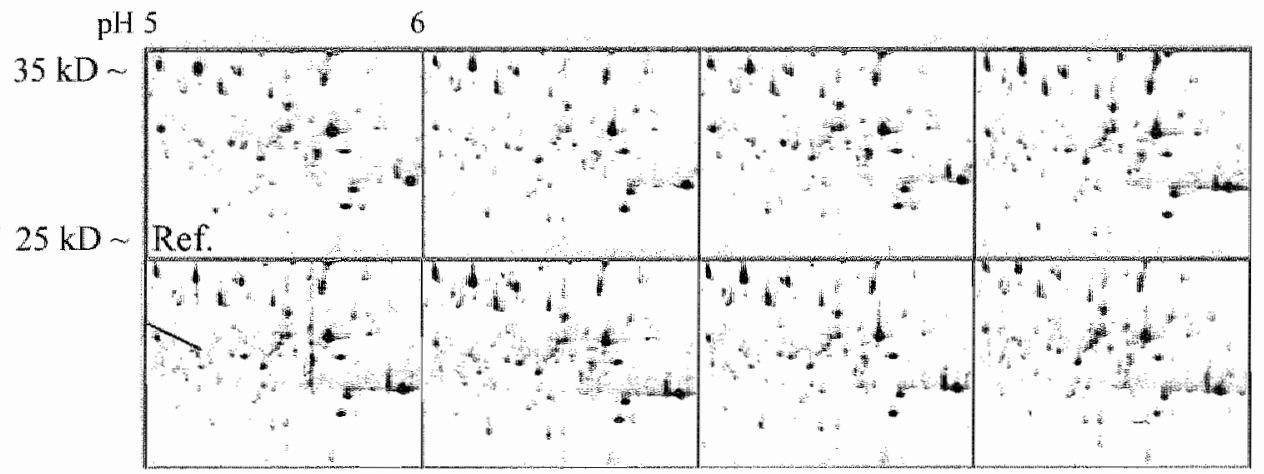

Figure 6.1

Reproducibility test of the 20 get electrophoresis technique. Filtered images of a selected area (ranging fram $\rho H 15-6$, containing $\sim 500$ spots) of 7 replicate 20 gels of a sample of human atherosclerotic plaques are shown, with the reference gel in the upper left panel. Of the 477 spots, $75 \%$ of the spots were present in at least 5 of the 7 replicate gels; $81 \%$ of the spots in at least 4 of these gels.

Differential protein expression in human atherosclerosis

To study the differential protein expression during the development of human atherosclerosis, proteins were isolated from atherosclerotic plaques. Since plaque rupture is the predominant cause of clinical syndromes, protein expression profiles of advanced but stable plaques were compared to lesions with a thrombus. We compared two methods for the analysis of differential protein expression. In the first experimental set-up we used pooled samples: a pool of 3 stable plaques and a pool of 3 lesions containing a thrombus were created (male patients 64-81 years of age). For each pool, 5 replicate 2D-gels were run and processed in parallel. Using silverstaining, we detected around 1000 spots in the pH-range 4-7. The 5 replicate gels of each pool were compared to each other and a reference gel was created, which contained all the spots that were present on at least 4 of 
A

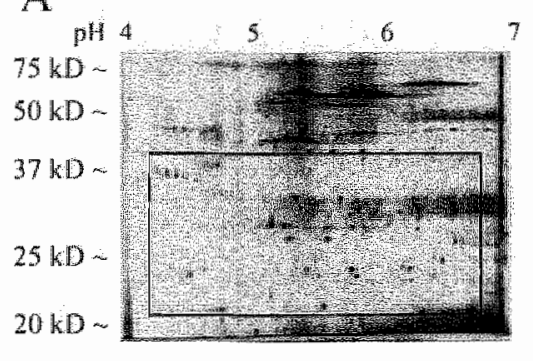

B

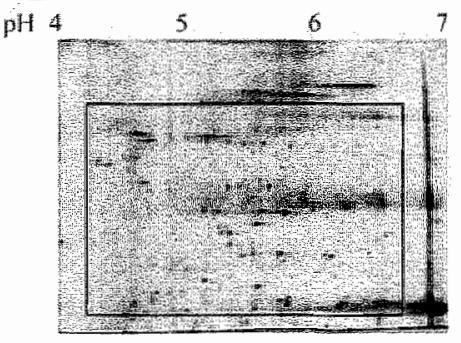

Stable plaques

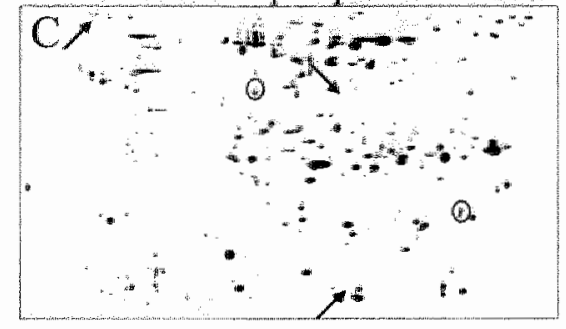

Plaques with a thrombus

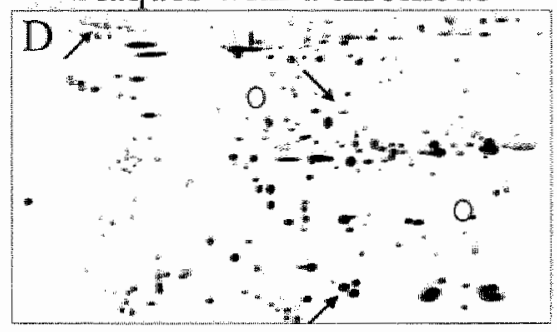

\section{Figure 6.2}

I/Iustration of a $2 D$ gel of human atherosclerotic plaques with a thrombus stained with silverstaining (A) or Sypro Ruby (B). The box indicates the area that we analyzed. Panels $C$ and $D$ show the reference gels of advanced, stable plaques vs lesions with a thrombus, respectively, containing all the spots present in at least 3 of 5 stable plaques or 4 of 6 plaques with a thrombus. Arrows indicate some spots unique for lesions with a thrombus, circles indicate some spots only expressed in stable plaques. The upper left arrow indicates the spot identified by MS to contain both vinexin- $\beta$ and $A A T$.

the 5 replicate gels. Subsequently, the two reference gels were compared. In the area of interest (shown in figure $6.2 \mathrm{~A}$ ), which contained -400 spots, we found 89 spots to be unique to the pool of stable plaques, whereas 67 spots were only expressed in thrombuscontaining lesions. In the second experimental set-up, the differential protein expression was studied using individual plaques instead of pools. Extracts of 5 stable plaques and 6 lesions with a thrombus (all male patients $49-78$ years of age) were used each sample in triplicate. Samples were again processed in parallel and the gels were stained with fluorescent Sypro Ruby staining. In the pH-range of $4-7$, a total of $\sim 800$ spots could be detected. Figure 6.2 ( $A$ and $B$ ) shows an example of a Sypro Ruby stained gel next to a silver-stained gel of the plaques containing a thrombus. The spot patterns are comparable, as expected, since Sypro Ruby has a similar sensitivity and specificity as the silverstaining ${ }^{20}$.

The same area of interest (figure 6.2B), which contained 300-350 spots, was used for image analysis. First, the 3 replicate gels of each lesion were compared to create a reference gel, which contained all the spots present in at least 2 of the 3 replicate gels. Subsequently, the reference gels of the patients with the same lesion types were 
compared to create a master reference gel for the stable plaques and a master reference gel for the lesions with a thrombus. These master reference gels contained all the spots that were present in at least 3 of the 5 stable lesions or in at least 4 of the 6 plaques with a thrombus. Finally, the master reference gel of the stable lesions was compared to the master reference gel of the thrombus-containing lesions. This revealed 71 unique spots for the stable plaques and 29 unique spots for plaques with a thrombus. Figures $6.2 \mathrm{C}$ and $\mathrm{D}$ show the master reference gels of the stable lesions and the lesions with a thrombus, with some differential spots marked by circles (for the spots unique to stable lesions) or by arrows (for the spots unique to lesions with a thrombus).

\begin{tabular}{|c|c|c|c|c|}
\hline NW & 1) & Staining & Expression & MS Mdentification \\
\hline$-25 \mathrm{kD}$ & +5.5 & Siverstaining & $\begin{array}{l}\text { Bothadvanced stable } \\
\text { lesions and plaques with } \\
\text { quronmbus }\end{array}$ & Thioredoxin peroxida \\
\hline$-50 \mathrm{kD}$ & -74.4 & Sypro Ruby & Lesions with a thrombus & MAT \\
\hline$-50 \mathrm{kD}$ & -55 & Sypro Ruby & Advanced stable & $\begin{array}{l}\text { Anglotensinl } \\
\text { Lactoferin } \\
\text { Lipocalin-1 } \\
\text { Prolline-tich lacrimal } \\
\text { protem }\end{array}$ \\
\hline$-33 k 0$ & -5.4 & Sypro Ruby & Lesions with a thrombus & Unknown \\
\hline$-28 \mathrm{~kb}$ & -5.5 & Sypro Ruty & Advanced stable & Unknown \\
\hline$-25 \times$ & -57 & Sypro Ruby & Lesions with a thrembus & Unkrowi \\
\hline$-19 \mathrm{kB}$ & -4.8 & Syproputgy & Advanced stable & Unknown \\
\hline$-15 \mathrm{kD}$ & -5.9 & Sypro Ruby & Lesions with a thrombus & Unkrown \\
\hline
\end{tabular}

Table 61

fdentification of $2 D$ spots by MALDH-TOF MS and MSMS. Molecular weight (MW) and isoelectric point (pll are derved from the 20 gels. Spots depicted as unknown are eiher proteins that could not be unequivocally identifed or are just not known in the databases.

\section{Protein identification}

Differential spots were selected for protein identification by MALDI-TOF MS and MSMS. However, for the silverstained spats, only very large spots could be identified. One example of a siverstained spot, which was identified by MALDL-TOF MS, is thioredoxin peroxidase-1 (table 6.1). However, these large spots were not differentially expressed and therefore we proceeded with Sypro Ruby thorescent staining of the gels, which is more compatible with MS than siverstaining ${ }^{20}$. Sypro Ruby is also suitable for quantitative analysis, but we only selected the spots that were unique for either of the plaque types. 
A. Stable plaques

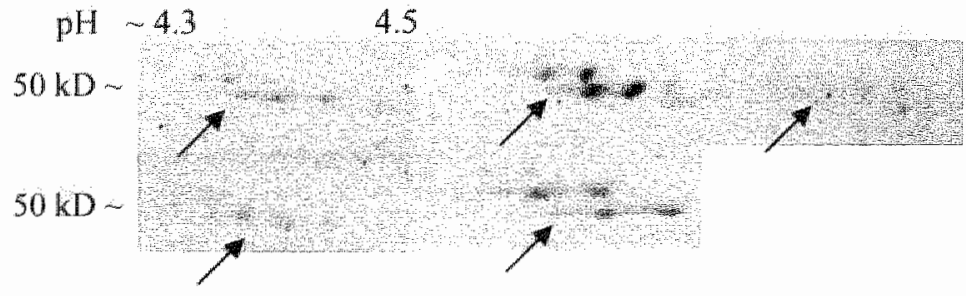

B Lesions with a thrombus

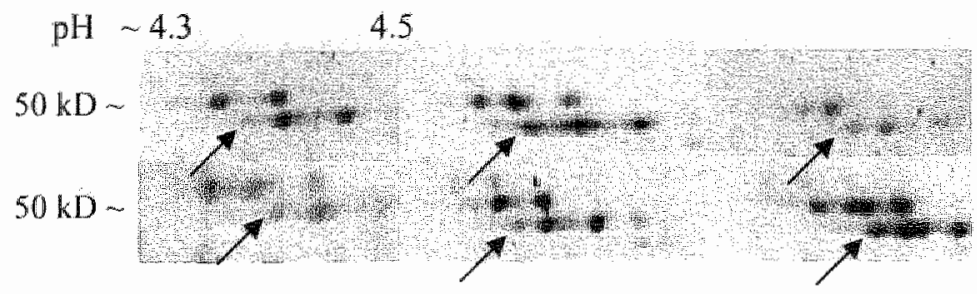

$\mathrm{C}$

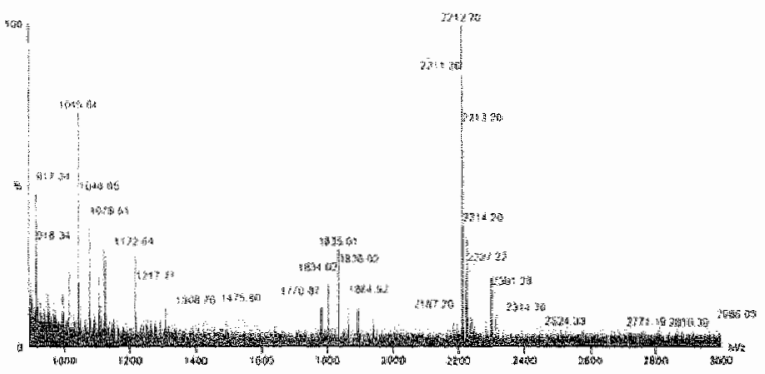

D

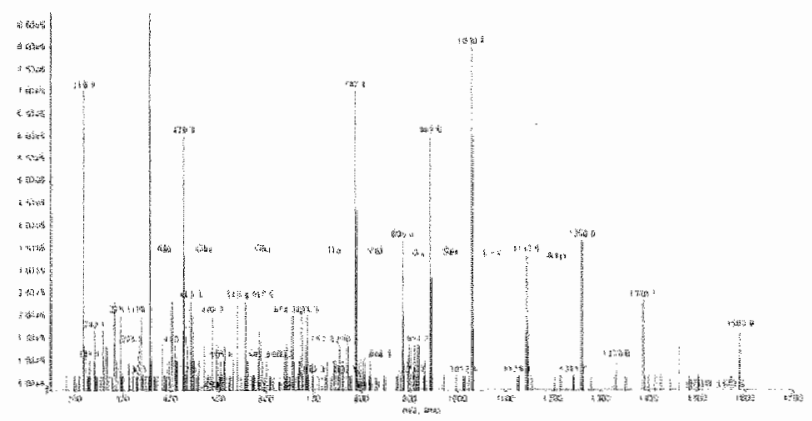

Figure 6.3

Entargements of Sypro Ruby stained $2 D$ gels showing differential expression of a $2 D$ spot (indicated by arrows) upregulated in advanced stable human atherosclerotic plaques (A) compared to lesions with a thrombus (B). Panels $C$ and D show MS and MSMS spectra, respectively, of this differentially expressed spot. Using the peptide/ion masses in the spectra and the NCBI database, this spot was identified to contain both vinexin- $\beta(C)$ and $A A T(D)$. 
MALDI-TOF MS and MS/MS analysis of Sypro Ruby stained spots identified vinexin- $\beta$ and alpha-1 antitrypsin (AAT) to be present in a spot unique for plaques with a thrombus (figure 6.3). Both proteins were detected in the same spot. Another Sypro Ruby stained differential spot, which was unique for stable plaques, contained three different proteins, identified as angiotensin I, lactoferrin and a proline-rich lacrimal protein (table 6.1). Other differential spots yielded good MS spectra, but could not be unequivocally identified.

\section{Expression of vinexin- $\beta$ in human atherosclerotic plaques}

Differential expression of vinexin- $\beta$ in advanced stable atherosclerotic plaques vs lesions with a thrombus could not be confirmed by Western blotting (figure 6.4A and $\mathrm{B}$ ). Immunohistochemistry of human atherosclerotic plaques showed almost no expression of vinexin- $\beta$ in early lesions (figure $6.4 \mathrm{C}$ ). In advanced stable plaques and lesions with a thrombus, vinexin- $\beta$ was expressed by macrophages, vascular smooth muscle cells (VSMC) and endothelium, although no differences were found between these lesion types (figure 6.4D and E).

\section{Expression of AAT in human atherosclerotic plaques}

Western blotting of a 2D gel confirmed the presence of AAT in the specific spot and showed the expression of 6 isoforms of AAT in human atherosclerotic plaques (figure 6.5A). Western blotting of 1D SDS-PAGE gels of advanced, stable plaques vs lesions with a thrombus showed an increased expression of the lower isoforms of AAT (relative to the isoforms of higher molecular weight) in plaques with a thrombus compared to stable lesions, although not significantly $(p=0.068)$. The antibody used cannot discriminate between the several isoforms (figure $6.5 \mathrm{~B}$ and $\mathrm{C}$ ). However Western blotting of $2 \mathrm{D}$ gels of individual human atherosclerotic plaques could confirm the differential expression of one specific isoform of AAT (figure 6.5A).

To further examine the expression of AAT (all isoforms) in human atherosclerotic plaques, immunohistochemistry was performed on cross-sections of various stages of human atherosclerotic plaques. AAT protein expression was shown to be nearly absent in early stages of atherosclerosis and was highly expressed in advanced stable plaques and lesions with a trhrombus (figure $6.5 \mathrm{D}, \mathrm{E}$ and $\mathrm{F}$ ). AAT was found to be expressed by several (but not all) macrophages and some endothelial cells (figure 6.5G and $\mathrm{H}$ ). Furthermore, AAT expression was found in neutrophils as described in literature (figure 6.51). 
A

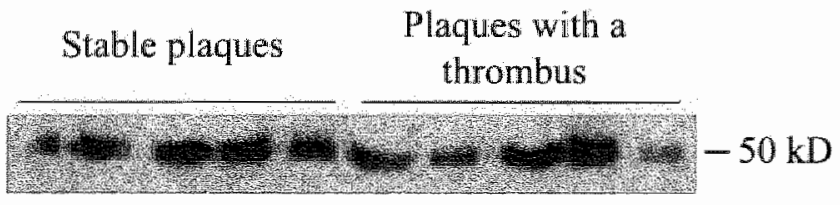

B
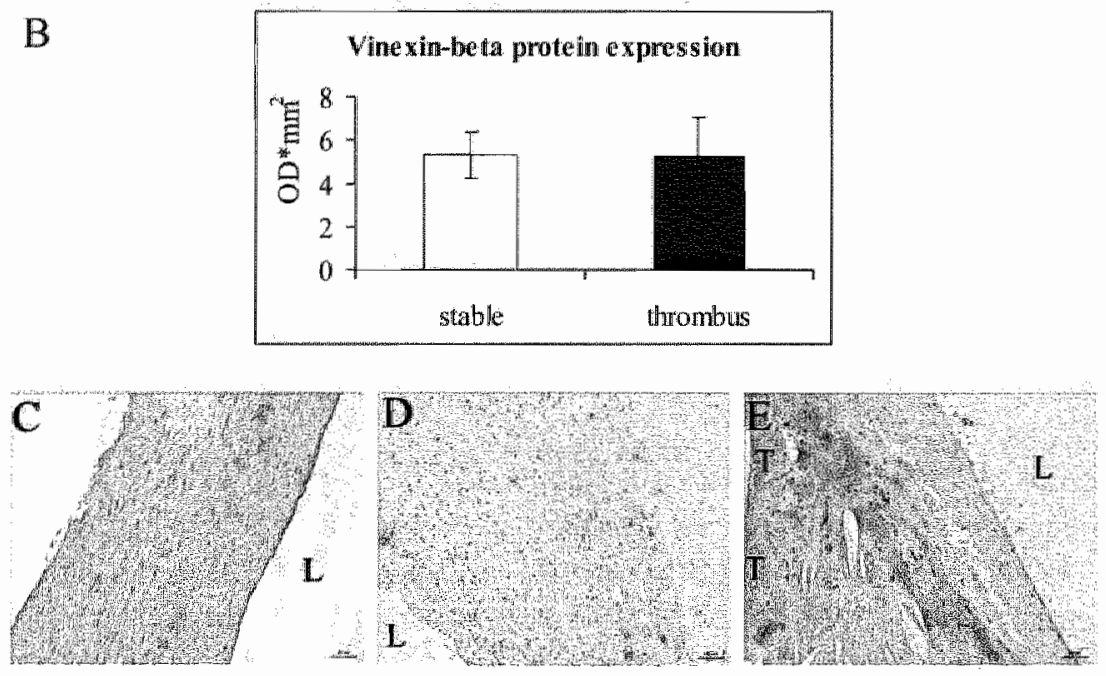

\section{Figure 6.4}

Vinexin- $\beta$ protein expression in individual advanced human atherosclerotic plaques (A). Densitometric analysis of this Western Blot could not confirm differential expression of vinexin- $\beta$ in atherosclerotic plaques with a thrombus compared to advanced stable plaques (B). Immunohistochemical staining of vinexin- $\beta$ protein expression in human atherosclerotic plaques shows low vinexin- $\beta$ expression in early plaques $(C)$, whereas expression in advanced stable plaques (D) and lesions with a thrombus (E) was high, especially in inflammatory regions. Vinexin$\beta$ expression was found in macrophages, VSMC and endothelial cells. $L$ indicates the lumen of the carotid artery, T marks the thrombus. 
A

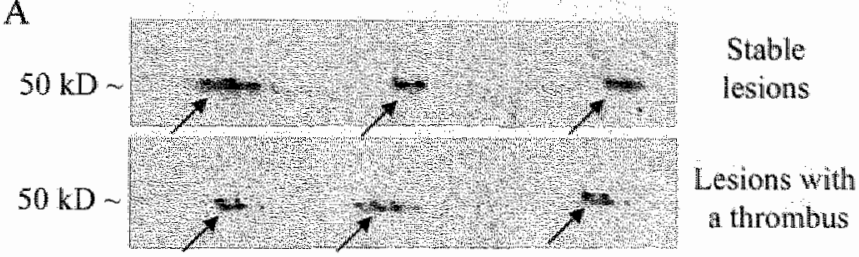

B

Stable Plaques with a

plaques

thrombus

$50 \mathrm{kD}$

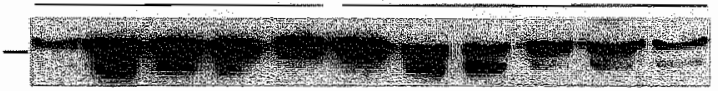

C
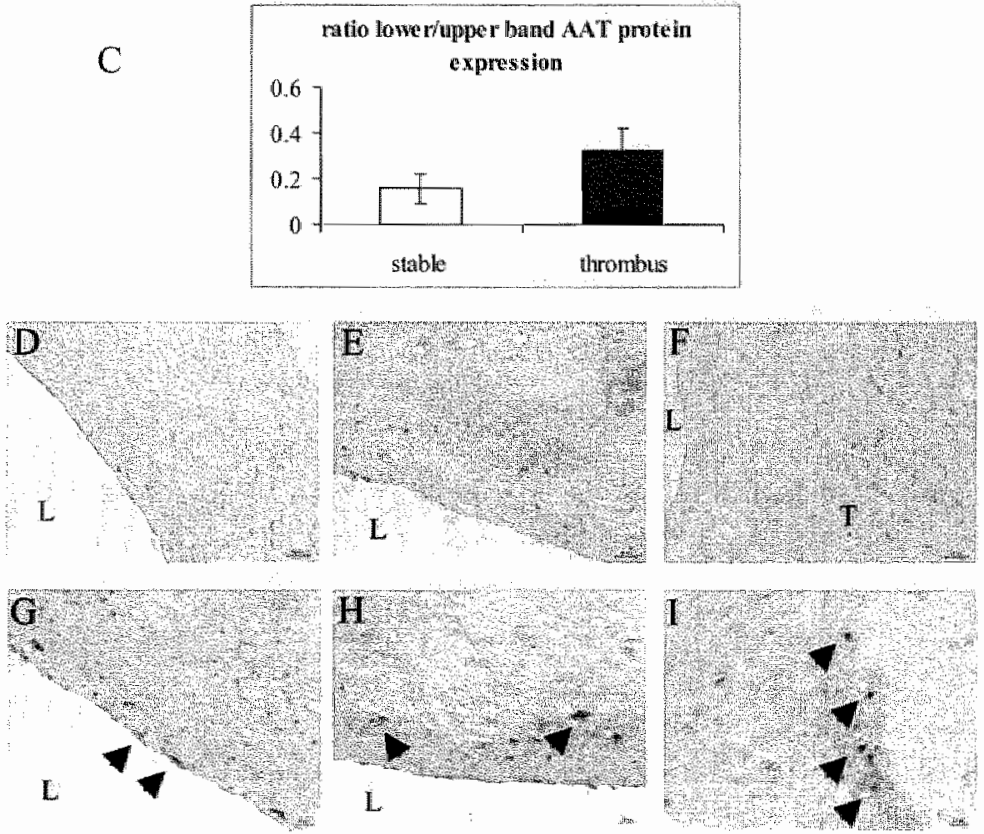

Figure 6.5

20 blots of human advanced stable plaques ws lesions with a thrombus (A) showing several isoforms of AAT. Arrows indicate the spot differentially expressed in atherosclerotic plaques with a thrombus. Panel $B$ shows a 10 blot of 5 lesions with a thrombus vs 5 stable plaques. In plaques containing a thrombus, expression of the smaller isoforms is increased relatively to the larger isoforms ( $C)$, although not significantly $(p=0.068)$. The antibody, however, does not discriminate the specific isoforms. The lower panel shows immunohistochemical staining of AAT protein expression in human atherosclerotic plaques. Immunohistochemsistry showed low expression of A.AT in early plaques (D), whereas in advanced stable plaques (E) and lesions with a thrombus $(F)$, AAT was highly expressed, especially by macrophages. Figures $G$, $H$ and / show AAT expression in endothelial cells, macrophages and neutrophils respectively, marked by arrows. $L$ indicates the Iumen. T marks the site of the thrombus. 


\section{Discussion}

In this study, we used 2D gel electrophoresis to explore protein expression profiles of whole-mount human atherosclerotic tissue during the progression from advanced stable plaques to ruptured lesions. We have chosen to study differential protein expression instead of gene expression, since mRNA expression does not always reflect protein expression levels. In yeast, for example, it was shown that some protein levels varied by more than 20-fold, whereas the mRNA levels were invariant. Conversely, mRNA levels may vary as much as 30 fold, where protein levels stay the same ${ }^{21}$. Furthermore, proteins may carry dynamic, post-translational modifications (i.e. phosphorylation, glycosylation or proteolysis) that may not be apparent from genomic information but can influence the function of the protein significantly ${ }^{10}$. Therefore, a study of the protein expression and modification patterns by a proteomics approach can give more (direct) information about the regulatory mechanism of atherosclerotic plaque development.

First we determined the reproducibility of the 2D technique. Only a few studies report on this issue. Voss et al. showed pair-wise matching efficiencies of $89 \%$ and a decreasing reproducibility when using large amounts of $2 \mathrm{D}$ gels $^{22}$. We tested the reproducibility of spots in a selected area (containing $\sim 500$ spots) of 7 replicate gels and found $81 \%$ of the spots to be matched in at least four of these gels.

We used 2 different approaches to compare expression patterns of advanced stable plaques to lesions with a thrombus. Using pools of samples we found more differential expressed spots compared to using individual plaque samples. This shows that the use of individual plaques instead of pools probably selectively excludes patient-specific differentially expressed spots. It also indicates that the use of pools requires validation of differential expression in individual patients.

Using MALDI-TOF MS and MS/MS analysis we were able to identify spots that were (differentially) expressed in human atherosclerotic plaques (table 6.1). Identification of silverstained spots was only possible for very large spots, which were (usually) not differentially expressed. Sypro Ruby fluorescent staining is more compatible with MS and using this staining we identified some differentially expressed proteins. Noteworthy, we also found several proteins present in the same spot. For example, we found two proteins in the same differential spot unique for thrombus-containing plaques. Another spot, unique for advanced stable plaques, contained four different proteins. This indicates co-migration of proteins of approximately the same $\mathrm{Mw}$ and $\mathrm{pl}$ on the $2 \mathrm{D}$ gel, a phenomenon also described in literature ${ }^{23}$. The possibility of co-migration of proteins in $2 \mathrm{D}$ gels might explain the difficulties of protein identification by MS analysis of 2D spots when using complex protein samples such as whole-mount atherosclerotic plaques. Furthermore, it emphasizes again the importance of validation of the results of $2 D$ gelelectrophoresis by additional methods.

This is the first study that identifies vinexin- $\beta$ as a protein expressed in advanced atherosclerotic plaques, albeit at equal levels in stable lesions and plaques with a thrombus. Vinexin is a recently discovered vinculin-binding protein present in focal 
adhesions $^{24}$. Although vinexin- $\beta$ has been shown to enhance activation of the junkinase/stress-activated protein kinase, a signaling pathway described in atherosclerosis and involved in cell migration, proliferation and apoptosis ${ }^{25,26}$, vinexin $\beta$ itself has not been described in atherosclerosis. We found vinexin- $\beta$ expression in advanced (but not early) human atheroscterotic lesions, especially in macrophages, VSMC and endothelium. However, no differences in vinexin- $\beta$ expression were found between stable plaques and lesions with a thrombus using Western blotting and immunohistochemistry. Validation of the differential protein expression in thrombus-containing lesions compared to stable lesions therefore revealed differential expression of vinexin- $\beta$ to be a false-positive result. due to overlap with another protein in the same spot.

This protein was identified as alpha- 1 antitrypsin (AAT) and its expression appeared to be associated with rupture of human atherosclerotic plaques. AAT is an acute phase protein expressed by the liver during inflammation. AAT is a serine protease inhibitor (serpin) and the endogenous inhibitor of neutrophil elastase, which has recently been found to be expressed in advanced human atherosclerosis ${ }^{27}$. Stastny et al. also showed AAT expression in human fibro-fatty lesions ${ }^{28}$. Both neutrophil elastase and AAT have been shown to be expressed by macrophages and neutrophils ${ }^{29}$. We confirmed this expression in the same cell types in advanced human atherosclerotic plaques (figure 6.5).

The presence of AAT in atherosclerotic plaques was suggested to enhance fibrosis by its inhibitory effects on collagenases and elastases ${ }^{30}$. Upregulation of AAT in lesions with a thrombus could therefore act as a counter-regulatory mechanism. On the other hand, the anti-elastase activity of AAT could provide a mechanism by which AAT may protect against atherosclerosis, possibly by prohibiting the invasion of inflammatory cells. Western blotting of $2 \mathrm{D}$ gels showed 6 isoforms of AAT, and anly one of these isoforms was upregulated in atherosclerotic plaques containing a thrombus. It is known that AAT can be modiffed, giving rise to several non-inhibitory forms of $\mathrm{AAT}^{31}$. Lack of the anti-elastase activity of AAT may promote the invasion and subsequently the accumulation of inflammatory cells, rendering the plaque more vulnerable to rupture. Indeed, cleavage of AAT yields a carboxyll terminal fragment, which has been described in human atherosclerotic plaques and which can regulate inflammatory transcription factors and lipid accumulation in monocytes $^{32}$. Furthermore, AAT is known to be a glycosylated protein and this glycosylation can affect the stabillty, secretion and perhaps inhibitory function of AAT. Variations in AAT glycosylation have indeed been associated with some (inflammatory) diseases such as arthritis and Crohn's disease ${ }^{33,34}$. Using a fluorescent glycoprotein detection kit (GlycoProfile II., Sigma-Aldrich, USA) we confirmed that the 6 AAT isoforms expressed in advanced human atherosclerotic plaques indeed were glycosylated forms (data not shown). However, the exact type of glycosylation variant of AAT in lesions with a thrombus and its implications in human atherosclerotic plaque rupture remains to be determined.

In conclusion, we used a multifaceted approach to identify and validate differential expressed proteins in human atherosclerotic plaque progression. Although $2 \mathrm{D}$ gel electrophoresis by itself is highly reproducible, it may lead to false-positive results and therefore requires validation. Vinexin- $\beta$ was shown to be such a false-positive result, 
probably because of co-migration of proteins. One of the proteins that proved to be differentially expressed in human atherosclerotic plaque progression was alpha-1 antitrypsin, which was validated by western blotting and immunohistochemistry. We showed expression of 6 isoforms in advanced atherosclerotic plaques, one of which was unique for lesions with a thrombus.

\section{Acknowledgements}

J.V.B. is indebted to the Flemish Fund for Scientific Research-Flanders (FWOVlaanderen) for the grant providing the mass spectrometric instrumentation. 


\section{References}

1. Libby $P$, Ridker $P M$, Maseri $A$. Inflammation and atherosclerosis. Circulation. 2002;105:1135-43.

2. Lusis AJ. Atherosclerosis. Nature. 2000:407:233-41.

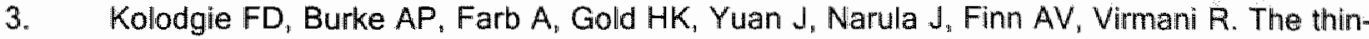
cap fibroatheroma: a type of vulnerable plaque: the major precursor lesion to acute coronary syndromes. Curr Opin Cardiol. 2001:16:285-92.

4. Faber BC, Cleutjens KB, Niessen RL, Aarts PL, Boon W, Greenberg AS, Kitslaair PJ, Tordoir" $\mathrm{JH}$, Daemen $\mathrm{MJ}$. Identification of genes potentially involved in rupture of human atherosclerotic plaques. Circ Res. 2001;89:547-54.

5. Monajemi $H$, Arkenbout EK, Pannekoek H. Gene expression in atherogenesis. Thromb Haemost. 2001;86:404-12.

6. Libby $P$, Galis ZS. Cytokines regulate genes involved in atherogenesis. Ann N Y Acad Scd. 1995; 748:158-68; discussion $168-70$.

7. Hiltunen MO, Tuomisto T.T., Niemi M, Brasen J.H., Rissanen T.T., Toronen P., Vajanto I., Yla-Herttuala $S$. Changes in gene expression in atherosclerotic plaques analyzed using DNA array. Atherosclerosis. 2002; 165:23-32.

8. Abbott A. A post-genomic challenge: learning to read patterns of protein synthesis. Nature. 1999;402:715-20.

9. Graveley BR. Alternative splicing: increasing diversity in the proteomic world. Trends Genet. 2001;17:100-7.

10. Moore BR, Free SJ. Protein modification and its biological role. Int J Biochem. 1985;17:2839.

11. Klose J. Protein mapping by combined isoelectric focusing and electrophoresis of mouse tissues. A novel approach to testing for induced point mutations in mammals. Humangenetik. 1975;26:231-43.

12. O'Farrell PH. High-resolution twa-dimensional electrophoresis of proteins. J.Biol.Chem. 1975;250:4007-4021

13. Chambers G, Lawrie L, Cash P. Murray Gl. Proteomics: a new approach to the study of disease. J Pathol. 2000;192:280-8.

14. Bichsel VE, Liotta LA, Petricoin EF, 3rd. Cancer proteomics: from biomarker discovery to signal pathway profiling. Cancer J. 2001;7:69-78.

15. You SA, Archacki SR, Angheloiu G, Moravec CS, Rao S, Kinter M, Topol EJ, Wang Q. Proteomic approach to coronary atherosclerosis shows ferritin light chain as a significant marker: evidence consistent with iron hypothesis in atherosclerosis. Physiol Genomics. $2003 ; 13: 25-30$.

16. Virmani $R$, Kolodgie FD, Burke AP, Farb A, Schwartz SM. Lessons from sudden coronary death: a comprehensive morphological classification scheme for atherosclerotic lesions. Arterioscler Thromb Vasc Biol. 2000;20:1262-1275.

17. Gorg A, Obermaier $C$, Boguth $G$, Harder A, Scheibe B, Wildgruber R, Weiss W. The current state of two-dimensional electrophoresis with immobilized pH gradients. Electrophoresis. 2000;21:1037-53

18. Shevchenko A, Wilm M, Vorm $O$, Mann M. Mass spectrometric sequencing of proteins from silver-stained polyacrylamide gels. Anal. Chem. 1996;68:850-858. 
19. Devreese $B$, Janssen KP, Vanrobaeys $F$, Van Herp $F$, Martens $G J$, Van Beeumen J. Automated nanoflow liquid chromatography-tandem mass spectrometry for a differential display proteomic study on Xenopus laevis neuroendocrine cells. I Chromatogr $A$. $2002 ; 976: 113-21$.

20. Lopez MF, Berggren $K$, Chernokalskaya $E_{\text {s }}$ Lazarev $A$, Robinson $M$, Patton WF. $A$ comparison of silver stain and SYPRO Ruby Protein Gel Stain with respect to protein detection in two-dimensional gels and identification by peptide mass profiling. Electrophoresis. 2000:21:3673-83.

21. Gygi SP, Rochon $Y$, Franza BR, Aebersold R. Correlation between protein and mRNA abundance in yeast. Mo/ Cell Biol. 1999;19:1720-30.

22. Voss $T$, Haberl $P$. Observations on the reproducibility and matching efficiency of twodimensional electrophoresis gels: consequences for comprehensive data analysis. Electrophoresis. 2000;21:3345-50.

23. Pietrogrande MC, Marchetti N, Dondi F, Righetti PG. Spot overlapping in two-dimensional polyacrylamide gel electrophoresis maps: relevance to proteomics. Electrophoresis. 2003;24:217-24.

24. Kioka N, Sakata S, Kawauchi T, Amachi T, Akiyama SK, Okazaki K, Yaen C, Yamada KM, Aota S. Vinexin: a novel vinculin-binding protein with multiple SH3 domains enhances actin cytoskeletal organization. J Cell Biol 1999;144:59-69.

25. Akamatsu M, Aota S, Suwa A, Ueda $K$, Amachi $T$, Yamada KM, Akiyama SK, Kioka $N$. Vinexin forms a signaling complex with $S o s$ and modulates epidermal growth factorinduced $\mathrm{c}$-Jun N-terminal kinase/stress-activated protein kinase activities. I Bio/ Chem. 1999;274:35933-7.

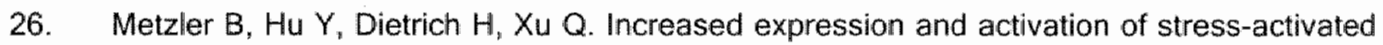
protein kinases/c-Jun $\mathrm{NH}(2)$-terminal protein kinases in atherosclerotic lesions coincide with p53. Am I Pathal. 2000; 156:1875-86.

27. Dollery CM, Owen CA, Sukhova GK Krettek A, Shapiro SD, Libby P. Neutrophil elastase in human atherosclerotic plaques: production by macrophages. Circulation. 2003;107:282936.

28. Stastny JJ, Fosslien E. Quantitative alteration of some aortic intima proteins in fatty streaks and fibro-fatty lesions. Exp Mol Pathol 1992;57:205-14.

29. Hafeez W, Ciliberto G, Perlmutter DH. Constitutive and modulated expression of the human alpha $\mathbb{1}$ antitrypsin gene. Different transcriptional initiation sites used in three different cell types. $J$ Clin Invest. 1992;89:1214-22.

30. Hollander W, Colombo MA, Kirkpatrick B, Paddock J. Soluble proteins in the human atherosclerotic plaque. With spectral reference to immunoglobulins, C3-complement compoment, alpha 1-antitrypsin and alpha 2-macroglobulin. Atherosclerosis. 1979;34:391405.

31. Janciauskiene S. Conformational properties of serine proteinase inhibitors (serpins) confer multiple pathophysiological roles. Biochim Biophys Acta. 2001;1535:221-35.

32. Dichtl $W$, Moraga $F$, Ares MP, Crisby M, Nilsson $J$, Lindgren $S$, Janciauskiene $S$. The carboxyl-terminal fragment of alpha1-antitrypsin is present in atherosclerotic plaques and regulates inflammatory transcription factors in primary human monocytes. Mo/ Cell Biol Res Commun. 2000;4:50-61.

33. Mizon $C$, el Yamani J, Colombel JF, Maes $P$, Balduyck $M$, Laine A, Cortot A, Tartar A, Mizon J. Deglycosylation of alpha 1-proteinase inhibitor is impaired in the faeces of patients with active inflammatory bowel disease (Crohn's disease). Clin Sci (Lond). 1991;80:517-23. 
34. Hrycaj $P$, Nayyar $S$, Stanworth DR, Muller W. Microheterogeneity of alpha 1-antitrypsin in relation to the concentration of its complex with immunoglobulin $A$ in the sera of patients with rheumatoid arthritis. Clin Exp Rheumatol 1996;14:119-23. 


\section{Chapter 7:}

\section{Preliminary analysis of serum proteomic profiles to discriminate atherosclerotic plaque rupture using SELDI- TOF mass spectrometry}

Marjo M.P.C. Donners, Elenne C.H. M. Midisen, Wil K. N.H Wodzig, Peter J.E.H.M. Kislaar, Mat J.A.P. Daemen, Sylvia Heeneman, Marja P. Van Dieijen-Visser. 


\section{Abstract}

Atherosclerosis is a complex, systemic disease of the arteries involving a chronic inflammatory process and accumulation of cells, lipids and extracellular matrix in the vascular wall. Although several circulating (inflammatory) biomarkers such as $\mathrm{C}$-reactive protein (CRP) or Serum Amyloid A (SAA) have been associated with atherosclerosis, none of these markers has been found to be specific and sensitive enough for a diagnostic test. In this study we used Surface-Enhanced Laser Desorption/lonization time-of-flight mass spectrometry (SELDI-TOF MS) analysis to identify a serum proteomic profile of biomarkers for atherosclerotic plaque rupture.

Using metal-binding (IMAC30-Cu ${ }^{2+}$ ) ProteinChip ${ }^{\text {rth }}$ arrays and only a few microliters of serum sample we compared SELDI-TOF MS spectra of patients with a stable atherosclerotic plaque $(n=10)$ with those from patients with a lesion containing a thrombus $(n=11)$. Eight peaks were found to differ significantly $(p<0.05)$ in intensity between both groups. Further analysis is required to validate the results and to determine the diagnostic value of these differences in pattern.

In conclusion, we found eight protein peaks to discriminate between patients with a stable atherosclerotic plaque and those with a plaque containing a thrombus. The distinct serum profiles might provide a base for a novel diagnostic test to detect atherosclerotic plaque rupture. 


\section{Introduction}

Atherosclerosis is the leading cause of death in Western society, mainly due to clinical complications such as myocardial infarction or stroke. It is a chronic, progressive disease of the arterial wall that can lead to the development of large lesions even without any clinical symptoms, which are usually caused by rupture of an atherosclerotic plaque".

Circulating biomarkers reflecting disease state are essential for appropriate diagnosis and treatment. Several systemic (inflammatory) markers such as CRP, fibrinogen, oxidized low-density lipoprotein (OxLDL), heat shock proteins (HSP) or acute-phase reactants, e.g. SAA, have been correlated with atherosclerosis, but lack the specificity required for an accurate diagnostic test ${ }^{2}$. A pattern of multiple markers may be more accurate and more specific than a single biomarker, particularly for a complex multistage disease as atherosclerosis. Recently. Petricoin et al. combined SELDI-TOF MS analysis with a bioinformatics tool to identify a proteomics serum pattern of biomarkers for the detection of ovarian cancer ${ }^{3}$. This study is considered the first proof of concept for the use of SELDITOF MS in clinical diagnostics.

SELDI-TOF MS is a high-throughput protein profiling technique, in which proteins from complex samples such as serum are bound selectively to chemically modified affinity surfaces on the ProteinChip ${ }^{\text {tw }}$ array (Ciphergen Biosystems), co-crystallized with energy absorbing molecules and analyzed by TOF-MS. The technique is highly sensitive, requires only a small amount of sample and is also suitable for profiling low molecular weight proteins $(<20 \mathrm{kDa})^{4}$.

Several studies have used SELDI-TOF MS to identify serum proteomic patterns for cancer diagnostics ${ }^{5,6}$. Allard et al. recently identified Apolipoprotein C-I and C-III as plasma markers to distinguish between ischemic and hemorrhagic stroke using SELDI-TOF MS followed by LC-MS/MS technology ${ }^{7}$. However, reports of the application of SELDI-TOF MS in cardiovascular research are limited.

In this study we used SELDI-TOF MS to identify a serum proteomic profile for atherosclerotic plaque rupture. Preliminary results show eight protein peaks with different intensities to discriminate patients with a stable atherosclerotic lesion from patients with a plaque containing a thrombus. 


\section{Materials and Methods}

\section{Study population}

Serum samples were obtained after written informed consent from patients that undenwent carotid endarterectomy or femoral artery bypass, centrifuged at $4000 \mathrm{rpm}$ for 15 min and stored at $-20^{\circ} \mathrm{C}$ until further use. The plaque specimens were divided into $3 \mathrm{~mm}$ thick slices, which were formalin-fixed, processed for histological analysis and classified according to Virmani et al. ${ }^{1}$. Using this classification, patients containing either stable plaques or lesions with a thrombus were selected for the analysis (data on patients are given in table 7.1). All slices of the plaques were required to have an intact fibrous cap containing either a well-formed necrotic core, fibrous tissue or calcification to select a patient with a stable plaque. In case at least one of the segments contained a thrombus, intra-plaque hemorrhage or plaque erosion, patients were classified to contain a lesion with a thrombus.

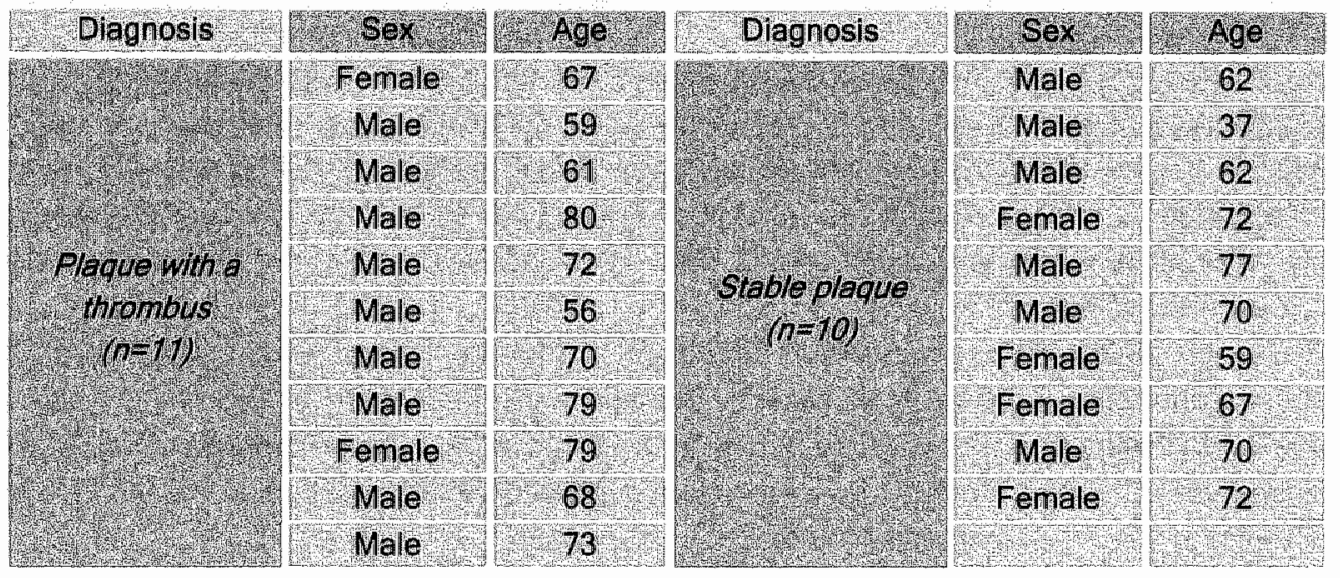

\section{Table 7.1}

Clinical data of the patients used in SELDI-TOF MS analysis to identify a serum proteomic profile which can discriminate patients with a stable carotid artery lesions from those with a carotio artery lesion containing a thrombus.

\section{SELDI-TOF MS analysis}

Serum samples were denatured by diluting $10 \mu \mathrm{l}$ in $90 \mu \mathrm{l} 9 \mathrm{M}$ urea with $2 \%$ CHAPS (3(3-(Cholamidopropyl)-dimethylammonio)-1-propanesulfonate). Each sample was applied in duplo on the ProteinChip ${ }^{\mathrm{TM}}$ arrays (Ciphergen Biosystems). Optimal conditions were determined using different combinations of array types and binding buffers. We used combinations of cation exchange arrays (CM10) with a binding buffer of $\mathrm{pH} 4,5(50 \mathrm{mM}$ sodium acetate) or 7 (50 $\mathrm{mM}$ sodium phosphate); anion exchange arrays (Q10) with a binding buffer of $\mathrm{pH} 5,7$ or $9(50 \mathrm{mM}$ Tris-HCl); hydrophobic arrays $(\mathrm{H} 50)$ with a $0.1 \mathrm{M}$ sodium phosphate binding buffer containing $10 \%$ acetonitrile with or without $0.5 \mathrm{M} \mathrm{NaCl}$ and metal-affinity (IMAC30-Cu ${ }^{2+}$ ) arrays with $0.1 \mathrm{M}$ sodium phosphate binding buffer with 
or without $50 \mathrm{mM} \mathrm{NaCl}$. Since higher laser intensities are required for ionization of proteins of higher molecular weight, both low and high laser intensities were tested.

For identification of a proteomic serum pattern, IMAC30- $\mathrm{Cu}^{2+}$ arrays and $0.1 \mathrm{M}$ sodium phosphate binding buffer of $\mathrm{pH} 7.0$ were used. After activation of the IMAC30-surface with $50 \mu 0.1 \mathrm{M} \mathrm{CuSO}_{4}$ according to the manufacturer's instructions (Ciphergen Biosystems), $10 \mu \mathrm{l}$ denatured sample was diluted in $90 \mu \mathrm{l}$ binding buffer, applied to the spots in a bioprocessor and incubated for 45 minutes on a shaker. Spots were washed three times 5 minutes with $150 \mu \mathrm{L}$ binding buffer, rinsed quickly with $200 \mu \mathrm{L} 50 \mathrm{mM}$ HEPES buffer $\mathrm{pH} 7.0$ and allowed to air-dry. Subsequently, $1 \mu$ of a saturated sinapinic acid solution ( $5 \mathrm{mg}$ SPA in $200 \mu \mathrm{l}$ acetonitrile $+200 \mu \mathrm{l} 1 \%$ trifluoroacetic acid) was applied to the spots twice followed by air-drying each time.

ProteinChip ${ }^{\text {TM }}$ arrays were analyzed using the PBS-llc mass spectrometer (Ciphergen Biosystems) with a laser intensity of 170 , detector sensitivity of 6 and selected mass range of 0-200 kDa. Peak analysis, baseline substraction, total ion current normalization, peak alignment and statistical analysis (Mann-Whitney- $U$ non-parametric test) were performed using ProteinChip ${ }^{\text {TM }}$ Software version 3.2 and Ciphergen Express Software version 2.1. For peak clustering the following parameters were used: first pass $\mathrm{S} / \mathrm{N}$ ratio of 5 , minimal peak threshold $50 \%$, cluster mass window $0.3 \%$ of mass, second pass $S / N$ ratio of 2 and $\mathrm{m} / \mathrm{z}$ range of $2-200 \mathrm{kDa}$. 


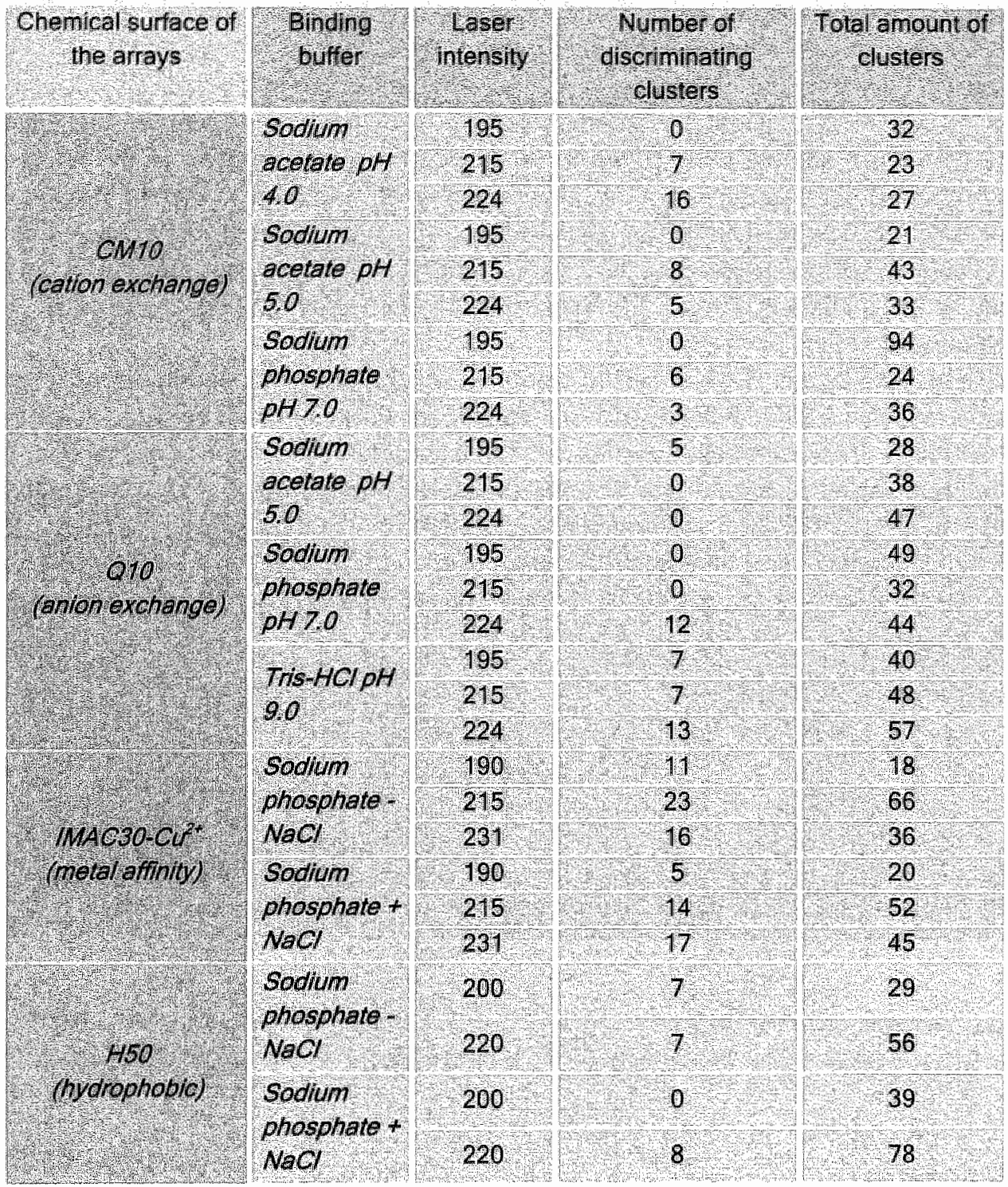

Table 7.2

Analysis of optimal conditions to discriminate serum profiles of patients with stable atherosclerotic plaques from patients with a lesion containing a thrombus. SELDI-TOF MS spectra were generated using different combinations of chemical array-surfaces, binding buffers and laser intensity. The MAC30. $\mathrm{Cu}^{2+}$ array combined with a $0.1 \mathrm{M}$ sodium phosphate binding buffer generated the highest amount of clusters and discriminating peaks(indicated by the box) and was used for further analysis. 


\section{Results}

Evaluation of optimal screening conditions

As various chemical array surfaces will capture different subsets of proteins and provide different protein profiles, we first determined the conditions that yielded the best results to discriminate patients with stable atherosclerotic plaques from those with lesions with a thrombus. Optimal conditions were tested by analyzing serum samples of stable plaques $(n=2)$ vs lesions with a thrombus $(n=3)$ using different combinations of array types, binding buffers and laser intensities. SELDI-TOF MS spectra were generated by averaging 130 laser shots. After alignment and clustering of the peaks, the total amount of clusters was assessed as well as the relative amount of discriminating clusters (i.e. clusters with a significant difference in peak intensity between samples of stable plaques and lesions with a thrombus). Results are listed in table 7.2. The $1 \mathrm{MAC} 30-\mathrm{Cu}^{2+}$ array combined with $0.1 \mathrm{M}$ sodium phosphate binding buffer without $\mathrm{NaCl}$ achieved the best results by yielding a high amount of clusters with a relatively high amount of discriminating clusters. Therefore, this condition was used for further analysis. The inter-spot and inter-array variation was assessed by applying one patient sample on 24 spots of $3 \| M_{M A C} 30-\mathrm{Cu}^{2+}$ arrays, calculating the variation in peak intensity of 25 random peaks. The inter-spot coefficient of variation (CV) was $15.5 \%, 22.0 \%$ and $20.7 \%$ for the 3 arrays, respectively. The inter-array CV was $20.1 \%$.

\begin{tabular}{|c|c|c|}
\hline - m/z & PValue & Peak intensíty \\
\hline 4302.7 & 0.006 & $S>T$ \\
\hline 4284.8 & 0.006 & $S>T$ \\
\hline 3975.5 & 0.007 & $S>T$ \\
\hline 3276.7 & 0020 & $S>T$ \\
\hline 31456 & 0.024 & $S>T$ \\
\hline 4468.9 & 0.035 & $T>S$ \\
\hline 3958.5 & 0.049 & $S>T$ \\
\hline 8936.3 & 0049 & $T>S$ \\
\hline
\end{tabular}

\section{Table 7.3}

Average mass (mass-to-charge $(\mathrm{m} / \mathrm{z})$ ratio) of the clusters discriminating patients with a stable atherosclerotic plaque from patients with a lesion containing a thrombus. The right panel indicates whether the protein is more abundant in serum of patients with a stable plaque (S) compared with those with a plaque containing a thrombus (T) or vice versa. 


\section{SELDI-TOF MS serum protein profiling}

To identify a discriminating serum proteomic profile for atherosclerotic plaque rupture, we compared serum profiles of 10 patients with stable plaques with serum profiles of 11 patients with lesions containing a thrombus. Samples were analyzed in duplo, which were considered as paired measurements, using IMAC-C ${ }^{2+}$ arrays. SELDI-TOF MS spectra were generated by averaging 130 laser shots. Eight clusters were found to differ significantly $(p<0.05)$ in intensity between both groups and could therefore aid to discriminate patients with stable atherosclerotic lesions from patients with a plaque with a thrombus. The average masses of these discriminating clusters are listed in table 7.3. Six of these peaks have an increased intensity in patients with a stable plaque compared to those with a plaque containing a thrombus, whereas two protein peaks are more abundant in serum of patients with a lesion with a thrombus.

Figure 7.1A shows representative SELDI-TOF MS spectra of 5 patients with a stable plaque vs 5 patients with a plaque containing a thrombus (shown in gel view). The peak at $4303 \mathrm{Da}$ is the most significant discriminator between both groups. This potential biomarker is significantly more abundant in serum of patients with a stable plaque compared to patients with a lesion containing a thrombus as is shown in the Box-andWhisker plot in figure 7.1B $(p=0.006)$. 


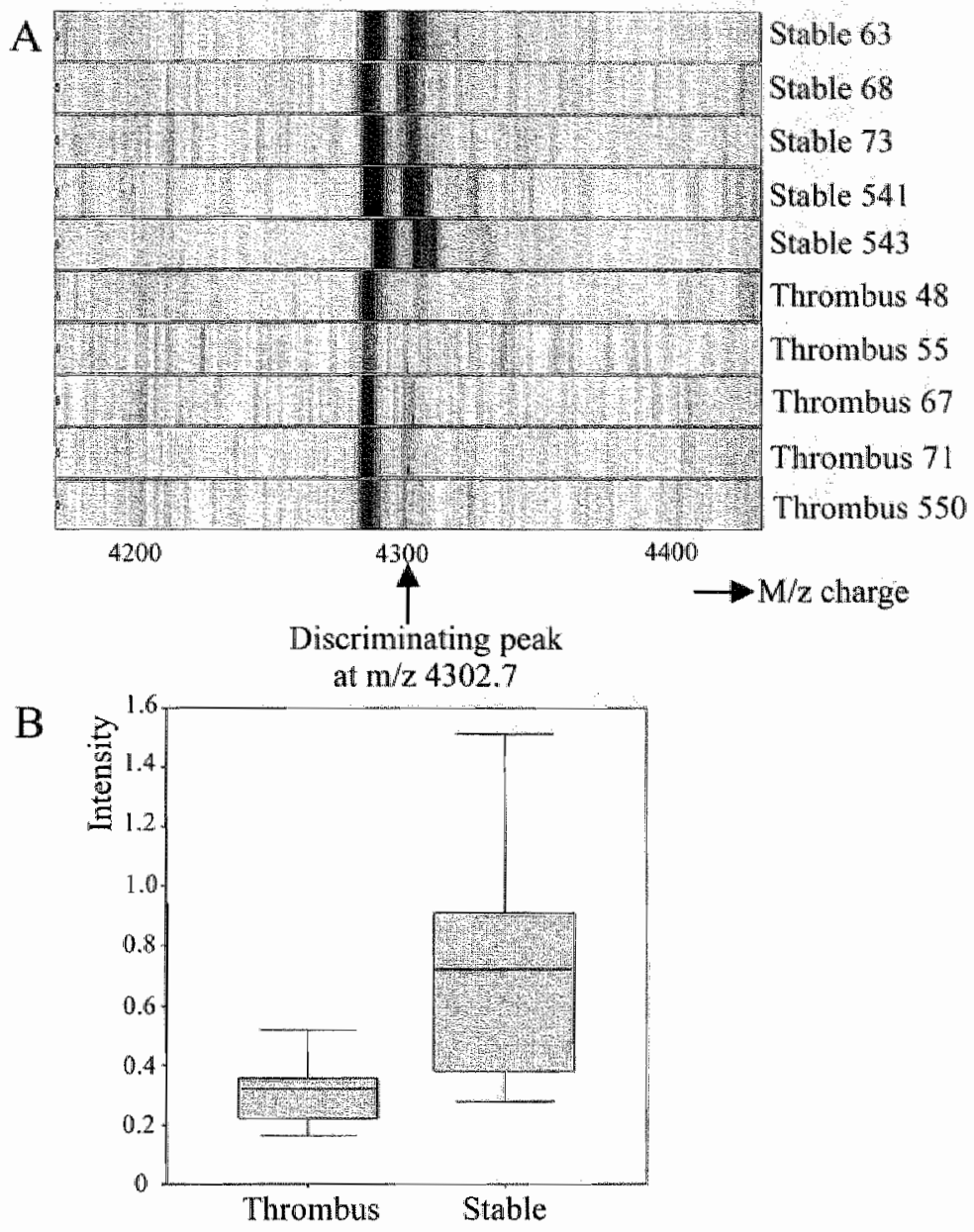

Figure 7.1

Representative examples of the serum proteomic profile of 5 patients with a stable plaque and 5 patients with a plaque containing a thrombus are shown in ge/-view (A) indicating a significant. increase in peak intensity at $4302.7 \mathrm{Da}$ for patients with a stable plaque compared to those with a plaque with a thrombus (pane/ $B, p=0.006$ ). 


\section{Discussion}

SELDI-TOF MS has become an attractive technology since it was shown to be effective in the determination of a serum biomarker pattern for the early detection of cancer ${ }^{3}$. Indeed, the technique has several advantages that make it very suitable as a diagnostic tool. It is a fast, high-throughput technique which only requires a very small amount (a few. microliters) of sample. Serum samples can be easily obtained from patients, since no surgery or biopsy is required. Furthermore, the technique is sensitive and especially suitable for profiling of low molecular weight proteins, which are often regulatory proteins.

In this study we used SELDI-TOF MS to identify a proteomics pattern for atherosclerotic plaque rupture in serum of patients. We compared SELDI-TOF MS spectra of patients with a stable plaque to those of patients with a plaque containing a thrombus and found eight clusters with a significant difference in peak intensity to discriminate between both groups of patients. Furthermore, the reproducibility of the SELDI-TOF MS spectra was assessed using one patient sample, showing inter-spot $\mathrm{CV}$ of $15.5-22.0 \%$ and an inter-array $\mathrm{CV}$ of $20.1 \%$ for peak intensity. For use of the SELDI-TOF technique as a diagnostic tool, the reproducibility needs to be improved $(\mathrm{CV}<10 \%)$. Recently, some concerns have emerged regarding the reproducibility between experiments. Baggerly et al. for example compared SELDI-TOF MS profiles for discriminating ovarian cancer from normal tissue of three experiments by the same group and found the results not reproducible across the experiments, which could be due to artifacts in sample processing ${ }^{8}$. Selection of the proper set of patients or control groups and standardization of sample preparation and processing is therefore essential. We only used a small set of patients for this first analysis. The groups need to be and will be expanded ( $n=30$ per group) for generating a model proteomic profile. Subsequently, this model will be validated using a masked set of patients ( $n>30$ patients, whose disease state is unknown) to determine the sensitivity and specificity of the diagnostic pattern of potential biomarkers.

The identity of the potential biomarkers to distinguish plaque rupture has not been established (yet). For use of the proteomic profile as a diagnostic tool, this is not necessarily required. Identification of the proteins using MS/MS, however, may be worthwhile to validate the potential biomarker to provide valuable information on the relevance of the discriminating peaks. To obtain a highly specific diagnostic tool, the discriminating peaks should be specific for atherosclerotic plaque progression and not be associated with other (for example inflammatory) diseases or epiphenomena of the disease. It is therefore essential to use an appropriate study population and control groups. in our study, both groups consisted of atherosclerotic patients, thereby minimizing the risk of detecting non-specific biomarkers. To validate the specificity of the diagnostic pattern , it would also be desirable to use healthy controls, a set of patients that manifests only early atherosclerotic lesions and a group of patients with other diseases, such as cancer or arthritis, in the masked validation step.

SELDI-TOF MS is a sensitive, high throughput technique to identify biomarker patterns in complex protein mixtures such as serum. The complexity of the samples, however, 
decreases the resolution of the technique and may complicate the detection of low abundant proteins. Therefore, it could be helpful to pre-fractionate the serum sample or to remove high abundant proteins such as albumin. However, albumin acts as a carrier protein for lower abundant, low molecular weight proteins that can be removed simultaneously ${ }^{9}$.

Whereas SELDI-TOF MS technology has been widely used in cancer research ${ }^{5,6}$, its application in cardiovascular disease is still limited. Dayal et al. used the SELDI-TOF MS technique for profiling the expression levels of apolipoprotein A in plasma of atherosclerotic patients ${ }^{10}$. Recently, Allard et al. applied SELDI-TOF MS profiling to distinguish patients with ischemic and hemorrhagic stroke and identified a panel of potential plasma markers, including Apolipoprotein C-I and C-III, using LC-MS/MS ${ }^{7}$.

This is the first report of the application of SELDI-TOF MS to identify a serum proteomic profile for atherosclerotic plaque progression. Although the results need to be confirmed, we found eight protein peaks to discriminate patients with a stable atherosclerotic plaque from those with a plaque containing a thrombus. Further analysis will be performed to identify and validate the definitive serum proteomic profile and to determine the sensitivity and specificity of this profile as a diagnostic test for atherosclerotic plaque rupture. 


\section{References}

1. Virmani $R$, Kolodgie FD, Burke AP, Farb A, Schwartz SM. Lessons from sudden coronary death: a comprehensive morphological classification scheme for atherosclerotic lesions. Arterioscler Thromb Vasc Biol. 2000;20:1262-1275.

2. Lind $\mathrm{L}$. Circulating markers of inflammation and atherosclerosis. Atherosclerosis. 2003,169:203-14

3. Petricoin EF "Ardekani AM, Hitt BA, Levine PJ, Fusaro VA, Steinberg SM, Mills GB, Simone C. Fishman DA, Kohn EC, Liotta LA. Use of proteomic patterns in serum to identify ovarian cancer. Lancet 2002;359:572-7.

4. Issaq HJ, Conrads TP, Prieto DA, Tirumalai $R$, Veenstra TD. SELDI-TOF MS for diagnostic proteomics. Anal Chem 2003;75:148A-155A.

5. Wiesner A. Detection of tumor markers with ProteinChip technology. Curr Pharm Biotechinol. 2004;5:45-67.

6. Soltys SG, Le QT, Shi G, Tibshirani R, Giaccia AJ, Koong AC. The use of plasma surfaceenhanced laser desorption/ionization time-of-flight mass spectrometry proteomic patterns for detection of head and neck squamous cell cancers. Clin Cancer Res. 2004;10:4806-12.

7. Allard L, Lescuyer $P$, Burgess $J$, Leung $K Y$, Ward $M$, Walter $N$, Burkhard PR, Corthals G, Hochstrasser DF, Sanchez JC. ApoC-I and ApoC-III as potential plasmatic markers to distinguish between ischemic and hemorrhagic stroke. Proteomics. 2004;4:2242-51.

8. Baggerly KA, Morris JS, Coombes KR. Reproducibility of SELDI-TOF protein patterns in serum: comparing datasets from different experiments. Bioinformatics. 2004;20:777-85.

9. Mehta Al, Ross S, Lowenthal MS, Fusaro V, Fishman DA, Petricoin EF, $3^{\text {rd }}$, Liotta LA. Biomarker amplification by serum carrier protein binding. Dis Markers. 2003;19:1-10.

10. Dayal B, Ertel NH. ProteinChip technology: a new and facile method for the identification and measurement of high-density lipoproteins apoA-1 and apoA-ll and their glycosylated products in patients with diabetes and cardiovascular disease. I Proteome Res. $2002 ; 1: 375-80$. 
Chapter 8:

General Discussion 
This thesis describes the evaluation of the therapeutic potential of low dose FK506 immunosuppression in vascular pathology and the quest for new therapeutic targets or diagnostic tools for atherosclerotic plaque rupture using proteomics technology. Since inflammation plays a role in the development of both atherosclerosis and restenosis (chapter 1), we hypothesized that the immunosuppressive drug FK506 would inthibit lesion development in both vascular pathologies. Therefore we investigated the effects of low dose FK506 immunosuppression on collar-induced and spontaneous development of atherosclerosis in ApoE-f- mice, as well as the effects of low dose FK506 on neointima formation and arterial remodeling in a mouse caratid artery ligation model. The main findings of these studies are that:

- Low dose FK506 inhibits the development and progression of collar-induced atherosclerosis in ApoE-/- mice (chapter 3)

- Low dose FK506 also reduces spontaneous development of atherosclerosis in ApoE-/- mice (chapter 4)

- Low dose FK506 induces a more stable plaque phenotype by increasing collagen content, the amount of ASMA-positive cells and cell density and decreasing lipid core content and T-cell content of the plaque (chapters 3 and 4)

- Effects of low dose FK506 on neointima formation and vascular remodeling after carotid artery ligation are less evident; neointima formation is minimally affected, but FK506 affects arterial remodeling, including an increase in lumen size and medial area (chapter 5).

Although gene expression studies have been widely used to investigate the molecular mechanisms underlying atherosclerotic plaque development and progression these mechanisms are still not fully clarified. We hypothesized that alterations in protein expression or post-translational modifications of proteins would accompany atherosclerotic lesion progression. Analysis of these alterations could provide valuable information about the molecular players modulating atherosclerotic lesion progression and possibly reveal new targets for therapy. Besides protein expression in the atherosclerotic lesions itself, serum protein profiles may reflect the progression of lesions and could therefore serve as a new diagnostic tool. To identify new therapeutic targets for atherosclerotic plaque rupture, we used 2D gel electrophoresis to study differential protein expression in whole-mount atherosclerotic plaques. SELDI-TOF MS technology was used to compare serum protein profiles of patients with a stable plaque with those containing a lesion with a thrombus. The main findings of these studies are that:

- $2 \mathrm{D}$ gel electrophoresis is a sensitive and reproducible, though low-throughput technique to study alterations in protein expression in tissue samples. However, especially for complex tissue samples such as whole-mount atheroscierotic plaques, protein identification by MS-technology remains difficult (chapter 6).

- Alpha-1 antitrypsin (AAT) was differentially expressed in human atherosclerotic lesions. We found several AAT isoforms expressed in advanced atherosclerotic plaques, with one isoform uniquely expressed in plaques with a thrombus (chapter 6). 
- Preliminary analysis by SELDI-TOF MS technology showed serum proteomic profiles containing eight peaks that could discriminate patients with a stable plaque from those with a plaque containing a thrombus (chapter 7).

Therapeutic potential of immunosuppression in atherosclerosis and restenosis

In chapters 3-5, we describe the effects of low dose FK506 treatment on the development of collar-induced atherosclerosis, on the spontaneous development of atherosclerosis and on neointima formation and arterial remodeling, processes associated with restenosis (summarized in table 8.1 ). We found a significant reduction in plaque size in both collar-induced atherosclerosis (63\% reduction) and spontaneous development of atherosclerosis ( $54 \%$ reduction) in ApoE- $/$ - mice, whereas effects on neointima formation after carotid artery ligation were minimal.

The pathophysiological mechanisms of atherosclerosis and restenosis may be comparable in several ways, nevertheless they remain substantially distinct ${ }^{1}$. Although inflammation plays an important (regulatory) role in both vascular diseases (chapter 1), the chronic nature of the inflammatory reactions in atherosclerosis is more dominant than the acute inflammatory response in restenosis. The inflammatory cell content of atherosclerotic plaques (especially consisting of macrophages and $T$ cells) is also significantly higher than that of meointimal lesions $(-30 \%$ for atherosclerotic lesions compared to $2 \%$ for neointimal lesions). This may explain our findings (chapter 3-5) that low dose FK506 markedly reduces atherosclerosis, while neointima formation, a process mainly characterized by VSMC proliferation, was only minimally inhibited. In vitro, we (chapter 3) and others ${ }^{2,3}$ showed no effects of FK506 on VSMC proliferation. This is in contrast to sirolimus, which is a potent inhibitor of VSMC proliferation and highly effective in reducing neointima formation ${ }^{4,5}$. Inhibition of neointima formation apparently requires some anti-proliferative actions to be sufficiently effective, although the effects of sirolimus may be augmented by its immunosuppressive effects. Combination of the anti-proliferative actions of sirolimus and anti-inflammatory actions of FK506 may be more effective in reducing neointima formation than the use of an anti-proliferative drug alone. Indeed, Waller et al. studied the effects of sirolimus and FK506 together on neointima formation in balloon injured rats and showed a significant reduction in intimal thickening ${ }^{6}$. Recently, sirolimus has also been shown to reduce atherosclerosis in ApoE $/$ - mice ${ }^{7,8}$. Castro et al. showed a reduced expression of pro-inflammatory mediators (MCP-1, IFN-Y and IL12) in atherosclerotic lesions after sirolimus treatment ${ }^{9}$. Considering the significance of the (chronic) inflammatory response in atherosclerotic plaque development, these antiinflammatory actions of sirolimus could play a critical role in its effectiveness as an antiatherogenic drug.

It becomes increasingly evident that most anti-atherogenic drugs at least to a certain extent contain (systemic) anti-inflammatory properties. Statins for example originally have been implicated in anti-atherosclerotic therapy because of their capacity to lower LDLcholesterol levels ${ }^{10}$. The last few years, however, it has been recognized that in addition to the lipid-lowering effects, statins also exert anti-oxidant and anti-inflammatory actions by 


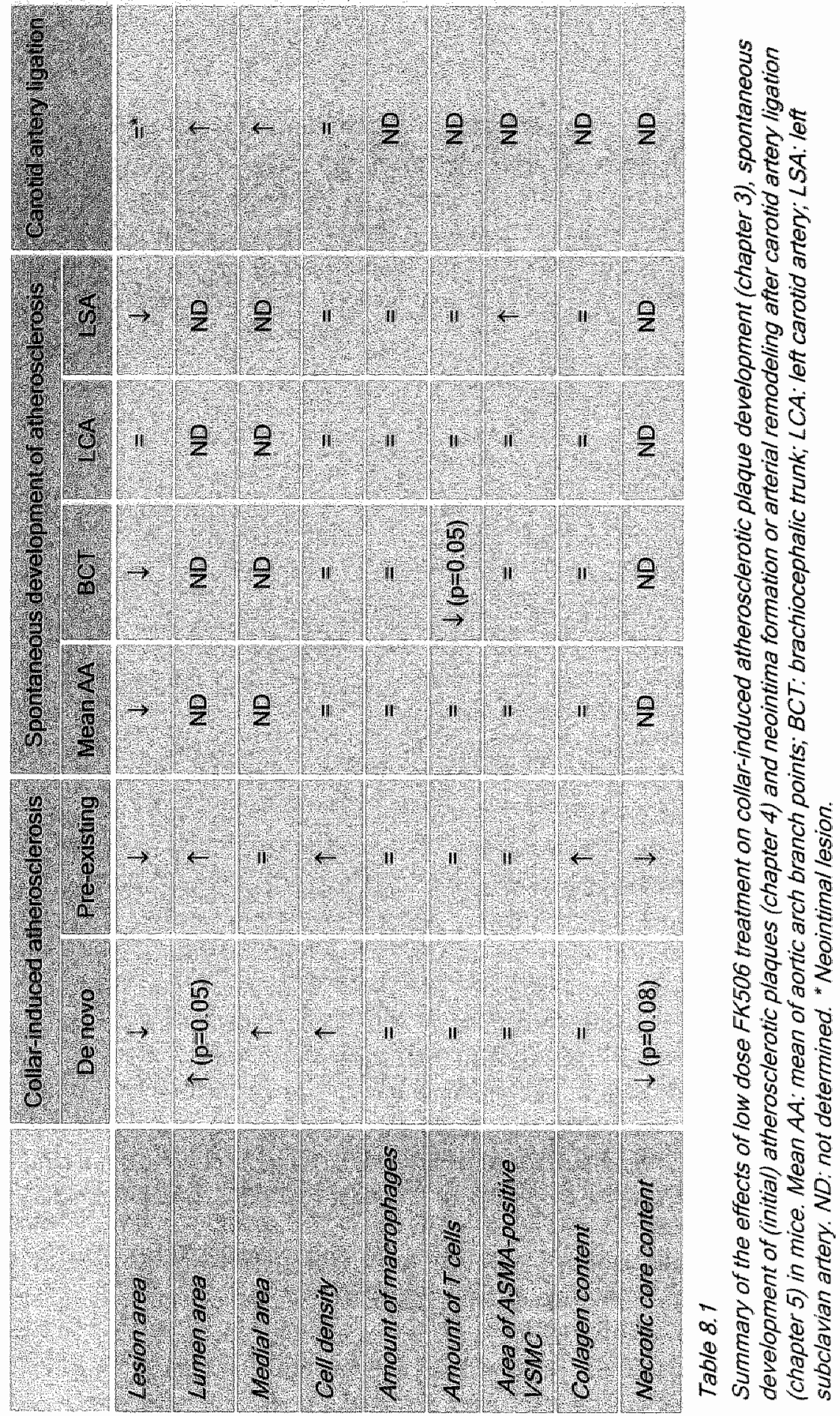


reducing the expression of reactive oxygen species (ROS), cytokines, chemokines, adhesion molecules and acute phase reactants such as (high-sensitivity) C.Reactive Protein (CRP) ${ }^{11,12}$.

A myriad of other drugs with anti-inflammatory actions have been investigated for their therapeutic potential in cardiovascular disease (table 8.2). LKe statins, PPARy agonists (Thiazolidinediones) not only affect lipid metabolism, but also inhibit a variety of inflammatory actions ${ }^{13}$. Angiotensin Converting Enzyme (ACE)-inhibitors are widely used as anti-hypertensive drugs, but are now also acknowledged to have anti-mflammatory properties that contribute to the inhibition of atherosclerotic disease ${ }^{14,15}$. Non-steroidal antfinflammatory drugs, such as aspirin or ibuprofen, inhibit the enzymes involved in prostaglandin synthesis (cyclooxygenase (COX)-1 and COX-2), thereby acting as both anti-thrombotic and anti-inflammatory drugs that are able to reduce atherosclerosis ${ }^{*}$. For aspirin, however, effects on the prevention of atherosclerotic events are inconciusive, especially for long-term treatment ${ }^{17}$. Furthermore, it is not clear whether the effects of aspirin in atherosclerotic disease are attributable to its anti-thrombotic or anti-inflammatory actions. Nevertheless, the effects of several anti-inflammatory drugs are comparable to our findings with FK506 in ApoE- - mice, suggesting an atheroprotective effect of antiinflammatory therapy in general.

Since atherosclerotic plaque rupture is the main cause of clinical complications of atherosclerotic disease, plaque stabilization is an important aim of anti-atherosclerotic therapy. Anti-inflammatory therapy has been shown to promote plaque stabilization. The combination of the lipid-lowering and anti-inflammatory effects of statins, also make them highly effective in stabilizing atherosclerotic plaques ${ }^{18}$. Clinical trials demonstrated more than $30 \%$ reduction of acute coronary events in patients treated with statins ${ }^{19.20}$. Nonsteroidal anti-inflammatory drugs (aspirin) and selective COX-2 inhibitors have also been shown to reduce the risk of cardiovascular events, although recently some selective COX2 inhibitors have been shown to increase the risk of thrombotic cardiovascular events ${ }^{21,22}$. Several animal studies have reported increased plaque stability after direct inhibition of major inflammatory mediators, such as $\mathrm{CD} 4 \mathrm{~L}^{23,24}$ or IFN- $\gamma^{25}$. Such interventions, however, have not yet been employed in clinical studies.

An important limitation of a general anti-inflammatory therapy is a non-specific inhibition of the immune response, which is also necessary in protection against infections. In this perspective, using a low dose of anti-inflammatory or immunosuppressive drugs becomes very interesting. Aspirin has been shown to inhibit vascular inflammation even at a low dose, resulting in a reduction of atherosclerotic plaque development and an increase in plaque stability in LDLr-/- mice ${ }^{26}$. However, in ApoE- $/$ - mice aspirin failed to affect lesion composition and prolonged aspirin-treatment even resulted in an increase of atherosclerosis ${ }^{27}$. This suggests that aspirin may not be suitable for chronic treatment of atherosclerosis. A pilot study by Brown et al. showed that subantimicrobial doses of the antibiotic drug doxycyline were also effective in reducing inflammation and promoting plaque stability ${ }^{28}$. 


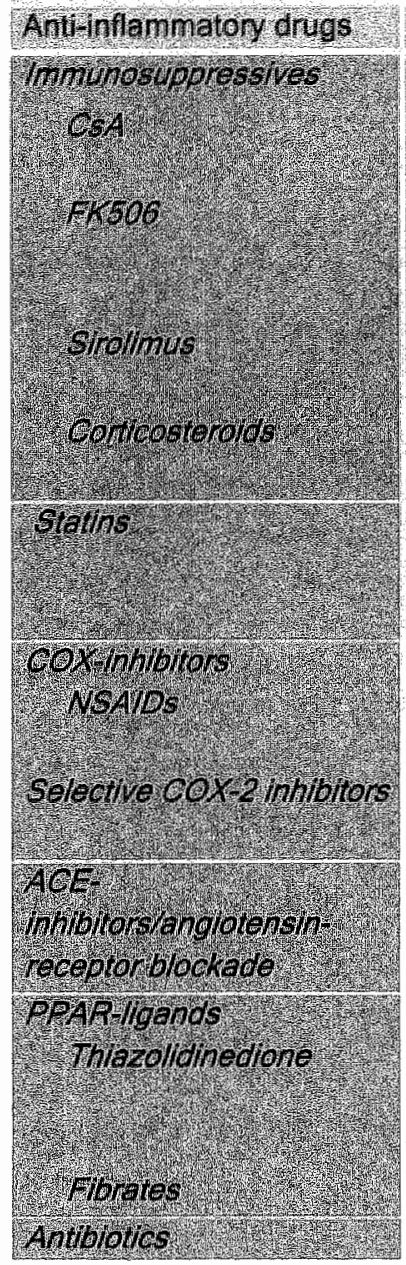

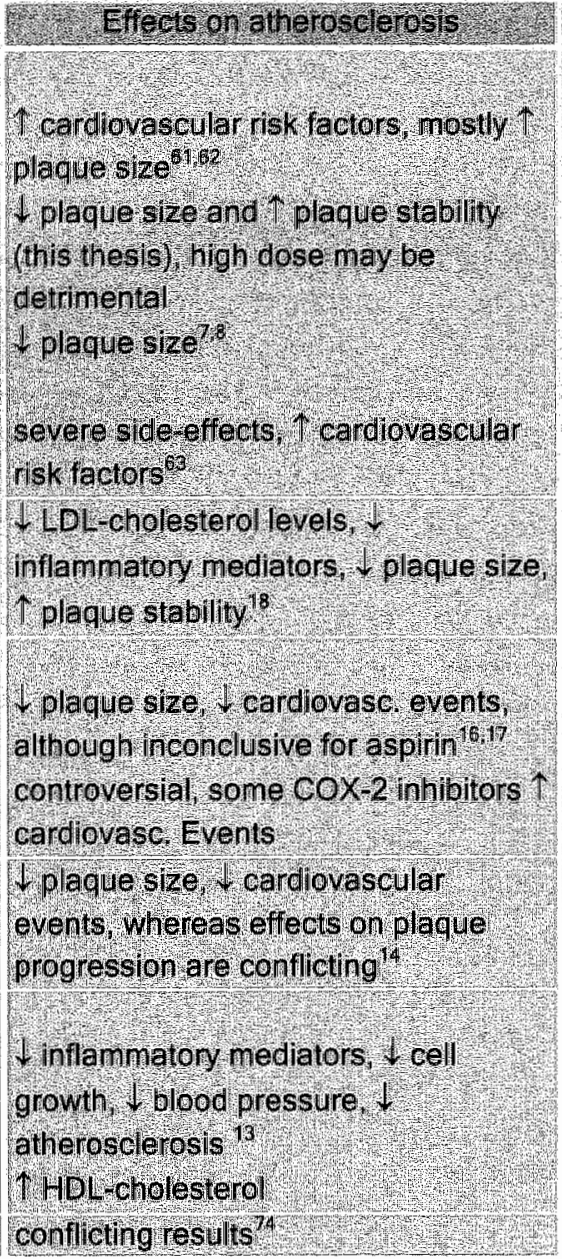

\section{Efects on ostenosis}

No effects 64 or 1 neointima tormation 65 :

Minmal effect on neointima formaton (this thesis)

Wheointima formation, VSMC Proliferation? controversial results 6667 4 nedintima in animals 68 :69 controversial results in humans?

NSMC proliferation? ho data avallable Controversial results?

4 VSMC proliferation \& migration,

1. Weointima formation ${ }^{3}$ ne data avalable no data available

\section{Table 8.2}

Effects of anti-inflammatory drugs on atherosclerosis and restenosis. CsA: Cyclosporin A, COX: cyclooxygenase, NSAID: non-steroidal anti-inflammatory drug. ACE: angiotensin-converting enzyme PPAR: peroxisome proliferators-activated receptor, WSMC: vascular smooth muscle cells.

In chapters 3 and 4 we showed that low dose FK506 (0.05 $\mathrm{mg} / \mathrm{kg} / \mathrm{day})$ reduced the extent of atherosclerotic plaque development and induced a more stable plaque phenotype, without systemic effects on immunocompetent cells. Based on our findings, we conclude that low dose FK506-treatment could serve as an effective anti-atherosclerotic therapy. 
Proteomic analysis of new therapeutic targets/diagnostic tools for plaque rupture

Although it has been recognized that inflammatory reactions play an important role in atherosclerotic plaque rupture, the underlying molecular mechanisms remain to be elucidated. Studies of alterations in gene and protein expression during disease progression are required to dissect the molecular pathways involved in the induction of plaque development and modulation of plaque stability.

Severall years ago, particularly since the introduction of mass spectrometry (MS) technology in the 1990s, proteomic analysis (with $2 \mathrm{D}$ gel electrophoresis as the cornerstone technique) emerged as a promising methodology to study disease mechanisms. Application of this so-called 'differential-display' proteomics, however, has been hampered by technical limitations. Especially for complex protein samples, such as crude extracts from whole-mount tissue, protein identification appears problematic, with a high incidence of false-positive identification ${ }^{29}$. In chapter 6 , we used $2 \mathrm{D}$ gel electrophoresis and showed differential expression of 100 (SyproRuby stained) -150 (silver-stained) protein spots. Most of these spots contained insufficient amounts of protein for identification. The spots that could be identified appeared to contain multiple proteins, which led to a false-positive identification. Prefractionation of complex samples and isoelectric focusing (IEF) using Immobiline $\mathrm{pH}$ gradient (IPG) strips with small $\mathrm{pH}$ ranges loaded with high amounts of proteins (i.e. micropreparative 2D gels) might solve these problems $^{30}$. Prefractionation indeed has been shown to enhance the resolution of protein separation by $2 \mathrm{D}$ gel electrophoresi $\mathrm{s}^{31}$ and increase the amount of proteins that can be identified ${ }^{32}$. Comparison of $2 \mathrm{D}$ gels is an arduous task, which is susceptible to errors. These problems can be circumvented by Difference Gel Electrophoresis (DIGE), a technique in which 2 different samples are tagged with distinct fluorescent dyes and run simultaneously in one $2 \mathrm{D}$ gel ${ }^{33}$. Using DIGE, Friedman et al. ${ }^{34}$ identified 52 proteins (including alpha-1 antitrypsin) that differed in abundance between human tumor and normal colon tissue. Without this technique and the use of a sample mixture internal standard, 42 of these proteins would have been overlooked.

The strength of $2 \mathrm{D}$ gel electrophoresis lies in its separation power and the possibility of directly visualizing post-translational modifications. Indeed, we found expression of 6 alpha-1 antitrypsin isoforms in advanced human atherosclerotic plaques, one of which was differentially expressed in plaques containing a thrombus compared to stable plaques (chapter 6). In this perspective, 2D gel electrophoresis remains a valuable separation technique.

2D gel electrophoresis, however, is a laborious and therefore low-throughput technique. High-throughput MS-based techniques are now rapidly evolving ${ }^{35}$. Instead of protein separation in 2D gels, samples are fractionated for example by capillary electrophoresis (CE) or liquid chromatography (LC) and then directly eluted into a mass spectrometer ${ }^{36,37}$. Such high-throughput MS-based proteomic techniques generate huge amounts of data, the analysis of which may be a time-consuming process, which makes it less suitable for daily clinical practice ${ }^{38}$. Surface-Enhanced Laser Desorption/lonization (SELDI)-MS combines affinity chromatography with MS and uses bioinformatic algorithms for pattern recognition. SELDI-TOF MS is the most promising technique for diagnostic proteomic 


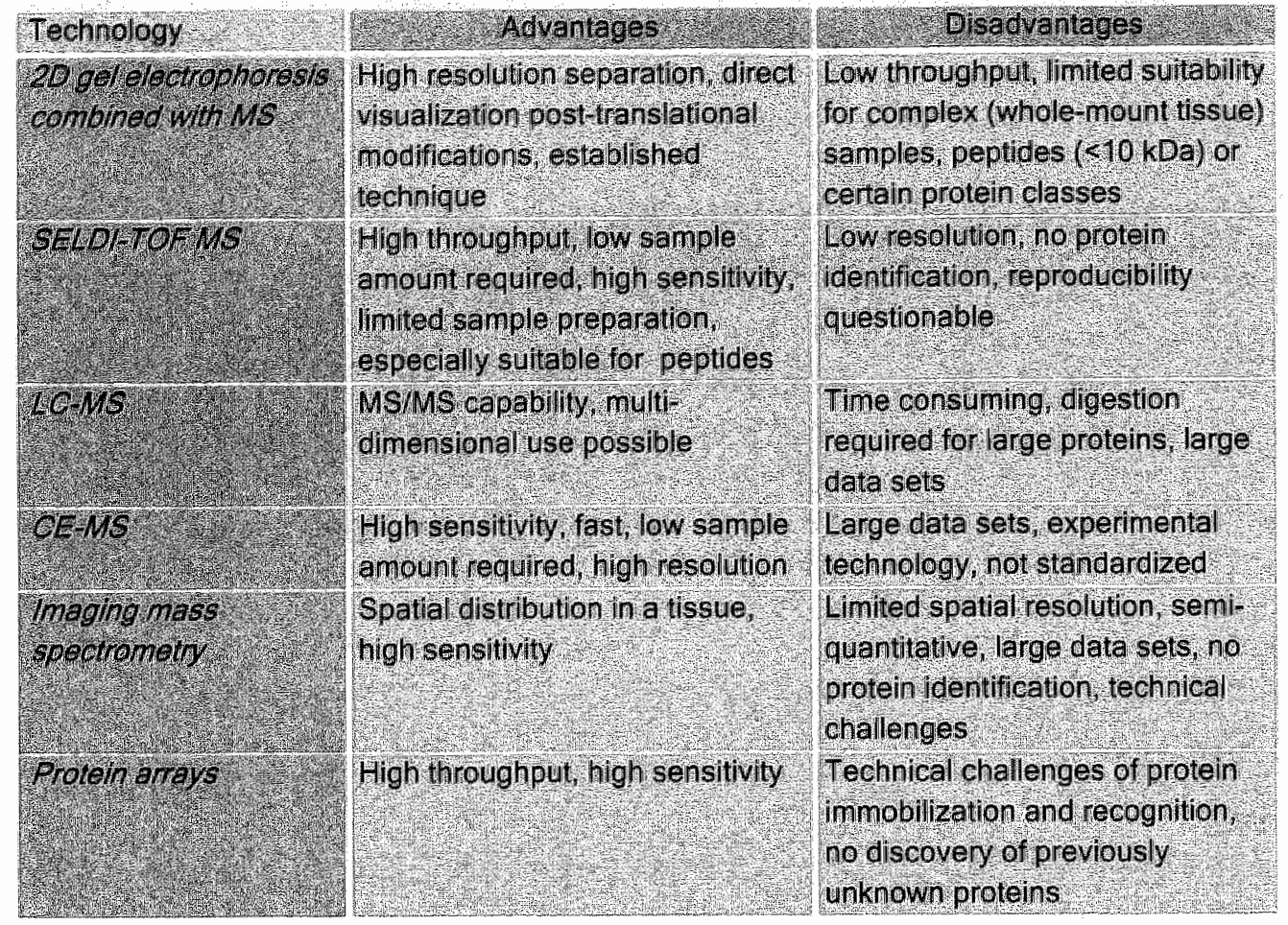

\section{Table 8.3}

Comparison of several proteomic technologies for protein separation and identification. SELDITOF MS: Surface Enhanced Laser Desorption/lonization-Time-Of-Flight Mass Spectrometry, LCMS: Liquid Chromatography- Mass Spectrometry. CE-MS: Capillary Electrophoresis Mass Spectromety.

profiling, because it is a figh-throughput, sensitive technique which requires only a small amount of sample and limited sample preparation. Table 8.3 summarizes the advantages and disadvantages of these proteomics techniques.

Since the introduction as a proteomic profiling technique by Petricoin et al. ${ }^{39}$, SELDITOF MS has been widely used, especially in cancer diagnostics. In chapter 7 we describe a first evaluation of the application of SELDI-TOF-MS in serum samples of atherosclerotic patients and the detection of eight markers that discriminate patients with a stable plaque from those with a plaque containing a thrombus. Prefractionation of the serum samples might increase the sensitivity of the technique even further, especially for the detection of low abundant proteins. Other concerns regarding SELDI-TOF MS include its low resolution and reproducibility ${ }^{40}$. The resolution of SELDI-MS spectra is rather low, but could be increased by using a high-resolution mass spectrometer ${ }^{41}$. Regarding reproducibility, standard operating procedures should be used for sample collection and handling, whereas a pooled reference standard sample (which can be obtained for example from the National Institute of Standards and Technology (NIST); http://www. nist.gov) could be used as a quality control for sample preparation and mass spectrometer ${ }^{42}$. Although alternative 
MS technology and bioinformatic tools are rapidly evolving, SELDI-TOF MS is a very promising proteomic profiling technique, which is suitable for inclusion in daily clinical research.

Recently, imaging mass spectrometry (IMS) has been introduced as a technology to display spatial distribution of proteins in a tissue ${ }^{43}$. This technique generates molecular profiles of proteins directly from frozen tissue sections. However, the technique is semiquantitative, has a limited capacity for tandem mass spectrometry (i.e. protein identification) and spatial resolution is limited (5-100 $\mu \mathrm{m})^{44}$.

Another high-throughput screening technique for differential display proteomics uses protein microarrays, analogous to DNA microarrays ${ }^{45}$. Immobilization of proteins, however, is much more challenging than DNA immobilization, due to the complex tertiary and quaternary structures of proteins that are crucial for protein recognition (e.g. for antibodies) or interaction (for example receptor-ligand interactions) ${ }^{46}$. Furthermore, such arrays use known antibodies, receptors or ligands and can therefore not lead to the discovery of new proteins.

Based on our preliminary evaluation of SELDI-TOF MS described in chapter 7, we conclude that this is indeed a powerful technique for serum proteomic profiling and we will continue to identify a biomarker pattern to discriminate patients with a plaque containing a thrombus from patients with a stable atherosclerotic plaque. $2 \mathrm{D}$ gel electrophoresis is a low-throughput technique, but remains a valuable technique for visualizing posttranslational modifications (chapter 6).

\section{Concluding remarks and future perspectives}

This thesis describes the evaluation of the therapeutic potential of low dose FK506 immunosuppression in vascular pathologies and the application of proteomic techniques to identify new therapeutic targets or diagnostic tools for atherosclerotic plaque rupture.

Chapters 3-5 show that low dose FK506 inhibits both collar-induced and spontaneous atherosclerotic plaque development in mice, accompanied by an increase in plaque stability, whereas effects on neointima formation and vascular remodeling are marginal. Considering the significance of the (chronic) inflammatory response in atherosclerotic plaque development, inhibition of atherosclerosis and the induction of a more stable plaque phenotype most likely require anti-inflammatory actions. FK506 acts by inhibition of calcineurin and its signaling pathway, which plays an important role in the inflammatory response ${ }^{47,48}$. Recently, calcineurin has been shown to promote MCP-1 expression in VSMC, mediating macrophage infiltration in neointimal lesions ${ }^{49}$. Furthermore, activation of the calcineurin-transcription factor NFAT induces the expression of pro-inflammatory cytokines and promotes the Th1-response ${ }^{50}$, which also dominates in atherosclerotic plaques $^{51}$. In vitro, we showed that FK506 inhibits NFAT-activation even at low doses (chapter 3), suggesting that the effects of low dose FK506 on atherosclerosis are mediated by calcineurin-inhibition. Higher concentrations of FK506, however, may have opposing effects on macrophages, inducing activation of NFKB leading to increased cytokine gene expression instead of inhibition of NFAT-activation and reduction of cytokine expression 
(chapter 3). Therefore, it will be interesting to test our hypothesis that higher doses of FK506 can be detrimental to atherosclerotic plaque development.

Whether the beneficial effects of low dose FK506 are indeed calcineurin-dependent remains to be established. The role of calcineurin in the development of vascular pathologies can be further investigated using calcineurin-specific inhibitors ${ }^{52,53}$ or targeting endogenous inhibitors (MCIP, Cain/Cabin1, calcipressin) ${ }^{54.56}$ Furthermore, it would be interesting to examine the role of calcineurin in modulating plaque stability and explore the potential of specific calcineurin-inhibition to prevent plaque rupture. The lack of a suitable animal model for atherosclerotic plaque rupture (as already discussed in chapter 2) however limits the evaluation of the capacity of low dose FK506 to prevent plaque rupture. Nevertheless, we showed an increase in histological features of plaque stability after low dose FK506-treatment (chapters 3 and 4).

Since the mechanism of atherosclerotic plaque rupture is still not fully elucidated, we used 2D gel electrophoresis to identify possible molecular regulators of atherosclerotic plaque rupture in humans (chapter 6). Identification of such molecular regulators, however, was limited by the complexity of the whole-mount plaque samples. SELDI-TOF MS analysis was used to identify a proteomic serum biomarker profile and a preliminary analysis depicted 8 peaks that could discriminate patients with a stable plaque from those with a plaque containing a thrombus. Thus, SELDI-TOF MS is a promising technique to identify a new biomarker profile as a diagnostic tool for plaque rupture (chapter 7). Although rupture of an atherosclerotic plaque is a local process, it has been shown that $80 \%$ of patients with acute coronary syndromes contain at least 1 extra plaque rupture, distinct and separate from the 'culprit' plaque rupture ${ }^{57}$. This enhances the possibility of detecting biomarkers for plaque rupture in serum. Recently, Naghavi et al. proposed the introduction of the 'vulnerable patient', a term that not only includes high-risk, culprit lesions, but also accounts for vulnerable blood (prone to thrombosis) and vulnerable myocardium (prone to fatal arrythmia) ${ }^{58,59}$. Not only true plaque rupture, but also high-risk plaques containing intra-plaque hemorrhage or plaque erosion are considered as culprit lesions $^{60}$. For this reason, we selected patients with a lesion containing a thrombus (representing all these distinct types of culprit lesions) for our proteomic analysis of human atherosclerotic plaque rupture. 
In summary, we evaluated the therapeutic potential of the immunosuppressive drug FK506 in vascular pathologies. Whereas low dose FK506 was less effective in attenuating neointima formation after carotid artery ligation, it reduced the development and progression of atherosclerosis accompanied by an increase in plaque stability features. This may have important implications for the clinical use of FK506, especially since high doses might be detrimental to atherosclerotic plaque development. The mechanism of this atheroprotective effect of low dose FK506, as well as the role of calcineurin as a new therapeutic target in atherosclerosis, remains to be established.

$2 \mathrm{D}$ gel electrophoresis was successfully applied to study differential protein expression in advanced stable atherosclerotic plaques compared to plaques with a thrombus. 2D gel electrophoresis proved to be a sensitive and reproducible technique. The search for new (therapeutic) targets of human atherosclerotic plaque rupture using 2D gel electrophoresis, however, was hindered by the limitations of the technique. Identification of differential expressed proteins is difficult when using whole-mount tissue samples and broad $\mathrm{pH}$ ranges. Nevertheless, 2D gel electrophoresis remains a powerful separation technique for differential-display proteomics, especially for resolving post-translational modification.

In this thesis we also evaluated the use of SELDI-TOF MS to discover a proteomic profile in serum as a diagnostic tool to discriminate atherosclerotic plaque rupture. Although this technique also has some limitations (e.g. reproducibility) that have to be overcome, it is a promising high-throughput technique for inclusion in daily clinical use. The rapid development of bioinformatics tools and high resolution mass spectrometry techniques probably will further improve proteomic analysis in the future. 


\section{References}

1. Orford $J L$, Selwyn AP, Ganz P. Popma $\mathbb{J}$, Rogers $C$. The comparative pathobiology of atherosclerosis and restenosis. Am J Cardiol $2000 ; 86: 6 \mathrm{H}-11 \mathrm{H}$.

2. Mohacsi PJ, Tuller D, Hulliger B, Wijngaard PL. Different inhibitory effects of immunosuppressive drugs on human and rat aortic smooth muscle and endothelliall cell proliferation stimulated by platelet-derived growth factor or endothelial cell growth factor. $J$ Heart Lung Transplant. 1997;16:484-92.

3. Matsumoto $T$, Saito E, Watanabe H, Fujioka $T$, Yamada T, Takahashi $Y$, Ueno T, Tochihara $T$, Kanmatsuse $K$. Influence of FK506 on experimental atherosclerosis in cholesterol-fed rabbits. Atherosclerosis. 1998;139:95-106.

4. Ruygrok PN, Muller DW, Serruys PW. Rapamycin in cardiovascular medicine. Intern Med J. 2003;33:103-9.

5. Cheng-Lai A, Frishman WH. Sirolimus-eluting coronary stents: novel devices for the management of coronary artery disease. Am $J$ Ther. 2004;11:218-28.

6. Waller JR, Murphy GJ, Bicknell GR, Toomey D, Nicholson ML. Effects of the combination of rapamycin with tacrolimus or cyclosporin on experimental intimal hyperplasia. $B r J S u r g$. 2002;89:1390-5.

7. Elloso MM, Azrolan N, Sehgal SN, Hsu PL, Phiel KL, Kopec CA, Basso MD, Adelman SJ. Protective effect of the immunosuppressant sirolimus against aortic atherosclerosis in apo E-deficient mice. Am I Transplant. 2003;3:562-9.

8. Basso MD, Nambi P, Adelman SJ. Effect of sirolimus on the cholesterol content of aortic arch in ApoE knockout mice. Transplant Proc. 2003;35:3136-8.

9. Castro $C_{v}$ Campistoll JM, Sancho $D_{*}$ Sanchez-Madrid F, Casals $E$, Andres V. Rapamycin attenuates atherosclerosis induced by dietary cholesterol in apolipoprotein-deficient mice through a p27 Kip1 -independent pathway. Atherosclerosis. 2004;172:31-8.

10. Randomised trial of cholesterol lowering in 4444 patients with coronary heart disease: the Scandinavian Simvastatin Survival Study (4S). Lancet. 1994;344:1383-9.

11. Rosenson RS. Statins in atherosclerosis: lipid-lowering agents with antioxidant capabilities. Atherosclerosis. 2004;173:1-12.

12. Halcox JP, Deanfield JE. Beyond the laboratory: clinical implications for statin pleiotropy. Circulation. 2004; 109:1142-8.

13. Hsueh WA, Bruemmer D. Peroxisome proliferator-activated receptor gamma: implications for cardiovascular disease. Mypertension. 2004,43:297-305.

14. Jacoby DS, Rader DJ. Renin-angiotensin system and atherothrombotic disease: from genes to treatment. Arch Intern Med. 2003;163:1155-64.

15. Schieffer B, Bunte $C$, Witte $J_{\text {, Hoeper }} \mathrm{K}_{\mathrm{v}}$ Boger $\mathrm{RH}$, Schwedhelm $\mathrm{E}$, Drexler $\mathrm{H}$, Comparative effects of AT1-antagonism and angiotensin-converting enzyme inhibition on markers of inflammation and platelet aggregation in patients with coronary artery disease. I Am Coll Cardiol 2004;44:362-8.

16. Altman R. Acute coronary disease Athero-Inflammation: Therapeutic approach. Thromb $J$. $2003 ; 1: 2$

17. Clelland JG. Is aspirin "the weakest link" in cardiovascular prophylaxis? The surprising lack of evidence supporting the use of aspirin for cardiovascular disease. Prog Cardiovasc Dis. 2002;44:275-92. 
18. Libby $P$, Aikawa M. Mechanisms of plaque stabilization with statins. $A m$ J Cardiol. $2003 ; 91: 4 \mathrm{~B}-8 \mathrm{~B}$.

19. Shepherd $₫$, Cobbe $S M$, Ford I, Isles $C_{\text {, }}$ Lorimer $\mathrm{AR}_{8}$ MacFariane PW, Mckillop $\mathrm{JH}_{\text {, }}$ Packard CJ. Prevention of coronary heart disease with pravastatin in men with hyperchollesterolemia. West of Scotland Coronary Prevention Study Group. N Engl J Med. $1995 ; 333: 1301-7$.

20. Wilt $T J$, Bloomfield HE, MacDonald R, Nelson D, Rutks I, Ho M, Larsen G, McCall A, Pineros S, Sales A. Effectiveness of statin therapy in adults with coronary heart disease. Arch Intern Med. 2004;164:1427-36.

21. Ridker PM, Cushman $M_{2}$ Stampfer MJ, Tracy RP. Hennekens $\mathrm{CH}$. Inflammation, aspirin, and the risk of cardiovascular disease in apparently healthy men. $N$ Eng/ J Med. 1997;336:973-9.

22. Pitt $B_{n}$ Pepine $C$, Willerson JT. Cyclooxygenase-2 inhibition and cardiovascular events. Circulation. 2002;106:167-9.

23. Lutgens $E$, Cleutjens KB, Heeneman $S$, Koteliansky VE, Burkly LC, Daemen MJ. Both early and delayed anti-CD4OL antibody treatment induces a stable plaque phenotype. Proc NatI Acad SciU S A. 2000;97:7464-9.

24. Mach F, Schonbeck $U$ "Sukhova GK, Atkinson E, Libby P. Reduction of atherosclerosis in mice by inhibition of CD40 signalling. Nature. 1998;394:200-3.

25. Gupta S, Pablo AM, Jiang $X$, Wang N, Tall AR, Schindler C. IFN-gamma potentiates atherosclerosis in ApoE knock-out mice. J Clin Invest. 1997;99:2752-61.

26. Cyrus $T$, Sung $S$, Zhao L, Funk $C D$, Tang $S$, Pratico $D$. Effect of low-dose aspirin on vascular inflammation, plaque stability, and atherogenesis in \|ow-density lipoprotein receptor-deficient mice. Circulation. 2002;106:1282-7.

27. Tous M, Ferre N, Vilella E, Riu F, Camps J, Joven J. Aspirin attenuates the initiation but not the progression of atherosclerosis in apolipoprotein E-deficient mice fed a high-fat, highcholesterol diet. Basic C/in Pharmacol Toxicol. 2004;95:15-9.

28. Brown DL, Desai KK, Vakili BA, Nouneh C, Lee HM. Golub LM. Clinical and biochemical results of the metalloproteinase inhibition with subantimicrobial doses of doxycycline to prevent acute coronary syndromes (MIDAS) pilot trial. Arterioscler Thromb Vasc Biol. $2004 ; 24: 733-8$.

29. Baldwin MA. Protein Identification by Mass Spectrometry: Issues to be Considered. Mol Cell Proteomics. 2003.

30. Pietrogrande MC, Marchetti N, Dondi F, Righetti PG. Spot overlapping in two-dimensional polyacrylamide gel electrophoresis maps: relevance to proteomics. Electrophoresis. 2003;24:217-24.

31. Doud MK, Schmidt MW, Hines D, Naumann C, Kocourek A, Kashani-Poor $N$, Zeidler $R$, Wolf DA. Rapid prefractionation of complex protein lysates with centrifugal membrane adsorber units improves the resolving power of 2D-PAGE-based proteome analysis. BMC Genomics. 2004;5:25.

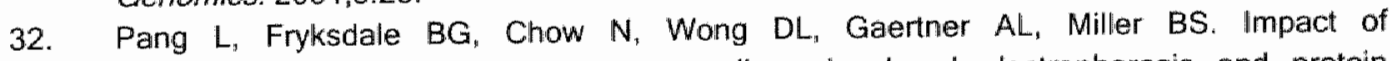
prefractionation using Gradiflow on two-dimensional gel electrophoresis and protein identification by matrix assisted laser desorption/ionization-time of flight-mass spectrometry. Electrophoresis. 2003;24:3484-92.

33. Unlu M, Morgan ME, Minden JS. Difference gel electrophoresis: a single gel method for detecting changes in protein extracts. Electrophoresis. 1997;18:2071-7. 
34. Friedman DB, Hill S, Keller JW, Merchant NB, Levy SE, Coffey RJ, Caprioll RM. Proteome analysis of human colon cancer by two-dimensional difference gel electrophoresis and mass spectrometry. Proteomics. 2004;4:793-811.

35. Aebersold R, Mann M. Mass spectrometry-based proteomics. Nature. 2003;422:198-207.

36. Wittke $S$, Kaiser T, Mischak H. Differential polypeptide display: the search for the elusive target. J Chromatogr B Analyt Technol Biomed Life Scl. 2004;803:17-26.

37. Bischoff $R$, Luider TM. Methodological advances in the discovery of protein and peptide disease markers. J Chromatogr B Analyt Technol Biomed Life Sck. 2004;803:27-40.

38. Neuhoff $N$, Kaiser $T$, Wittke $S$, Krebs $R$, Pitt A, Burchard A, Sundmacher $A$, Schlegelberger $B$, Kolch $W$, Mischak H: Mass spectrometry for the detection of differentially expressed proteins: a comparison of surface-enhanced laser desorption/ionization and capillary electrophoresis/mass spectrometry. Rapid Commun Mass Spectrom. 2004;18:149-56.

39. Petricoin EF, Ardekani AM, Hitt BA, Levine PJ, Fusaro VA, Steinberg SM, Mills GB, Simone C, Fishman DA, Kohn EC, Liotta LA. Use of proteomic patterns in serum to identify avarian cancer. Lancet. 2002;359:572-7.

40. Diamandis EP. Point: Proteomic patterns in biological fluids: do they represent the future of cancer diagnostics? C/in Chem. 2003;49:1272-5.

41. Petricoin EF, Liotta LA. SELDL-TOF-based serum proteomic pattern diagnostics for early dletection of cancer. Curr Opin Biotechnol. 2004; 15:24-30.

42. Petricoin $\mathbb{E}, 3$ rd, Liotta LA. Counterpoint: The vision for a new diagnostic paradigm. C/in Chem. 2003;49:1276-8.

43. Stoeckli $M$, Chaurand $P$, Hallahan DE, Capriolli RM. Imaging mass spectrometry: a new technology for the analysis of protein expression in mammalian tissues. Nat Med. 2001;7:493-6.

44. Todd $P J$, Schaaff TG, Chaurand $P$, Caprioli RM. Organic ion imaging of biological tissue with secondary ion mass spectrometry and matrix-assisted laser desorption/ionization. $J$ Mass Spectrom. 2001;36:355-69.

45. de Wildt RM, Mundy $C R$, Gorick BD, Tomlinson IM. Antibady arrays for high-throughput screening of antibody-antigen interactions. Nat Biotechnol. 2000;18:989-94.

46. Espina V, Woodhouse EC, Wulfkuhle J, Asmussen HD, Petricoin EF, 3rd "Liotta LA. Protein microarray detection strategies: focus on direct detection technologies. $J /$ mmunol Methods. 2004;290:121-33.

47. Rusnak F Mertz P. Calcineurin: form and function. Physio/ Rev. 2000;80:1483-521.

48. Rao A, Luo C, Hogan PG. Transcription factors of the NFAT family: regulation and function. Annu Rev /mmunol. 1997; 15:707-47.

49. Satonaka $H$, Suzuki E, Nishimatsu $H$, Oba $S$, Takedla $R$, Goto A, Omata M, Fujita T, Nagai $R$, Hirata $Y$. Calcineurin promotes the expression of monocyte chemoattractant protein- 1 in vascular myocytes and mediates vascular inflammation. Circ Ries. 2004;94:693-700.

50. Porter CM, N.A. C. Sustained NFAT signaling promotes a Th1-like pattern of gene expression in primary murine CD4+ cells. J. Immunol. 2002; 168:4936-4945.

51. Frostegard J, Ulfgren A., Nyberg P., Hedin U., Swedenborg J., Andersson U., K. HG. Cytokine expression in adwanced human atherosclerotic plaques: dominance of proinflammatory (Th1) and macrophage-stimulating cytokines. Atherosclerosis. 1999;145:3343.

52. Baba $Y$, Hirukawa N, Tanohira N, Sodeoka M. Structure-based design of a highly selective catalytic site-directed inhibitor of Ser/Thr protein phosphatase 2B (calcineurin). J Am Chem Soc. $2003 ; 125: 9740-9$. 
53. Roehrt MH, Kang S, Aramburu J, Wagner G, Rao A, Hogan PG. Selective inhibition of calcineurin-NFAT signaling by blocking protein-protein interaction with small organic molecules. Proc Nat/ Acad SciUS A. 2004; 101:7554-9.

54. Yang J, Rothermel B, Vega RB, Frey N, Mckinsey TA, Olson EN, Bassel-Duby R, Whliams RS. Independent signals control expression of the calcineurin inhibitory proteins MCIPI and MCIP2 in striated muscles. Circ Res. 2000;87:E61-8.

55. Kim MJ, Jo DG, Hong GS, Kim BJ, Lai M, Cho DH, Kim KW, Bandyopadhyay A, Hong YM,

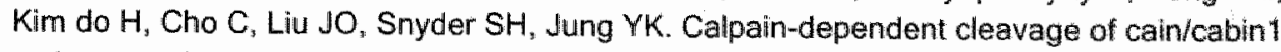
activates calcineurin to mediate calcium-triggered cell death. Proc Nall Acad Sci US A. 2002;99:9870-5.

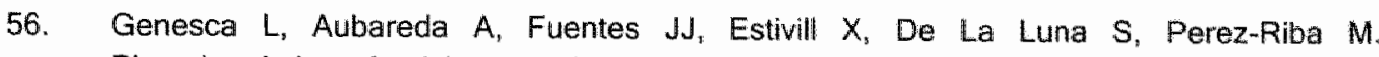
Phosphorylation of calcipressin 1 increases its ability to inhibit calcineurin and decreases calcipressin half-life. Biochem $J$ 2003;374:567-75.

57. Rioufol G, Finet $G$, Ginon I, Andre-Fouet X, Rossi $R$, Vialle $E$, Desjoyaux $E$, Convert $G$, Huret JF, Tabib A. Multiple atherosclerotic plaque rupture in acute coronary syndrome: $a$ three-vessel intravascular ultrasound study. Circulation. 2002;106:804-8.

58. Naghavi M, Libby P, Falk E, Casscells SW, Litovsky $S$, Rumberger J, Badimon JJ, Stefanadis C, Moreno P. Pasterkamp G, Fayad Z, Stone PH, Waxman S, Raggi P, Madjid M, Zarrabi A, Burke A, Yuan C, Fitzgerald PJ, Siscovick DS, de Korte CL. Aikawa M, Airaksinen KE, Assmann G, Becker $C R$, Chesebro JH, Farb A, Galis ZS, Jackson $C$, Jang IK, Koenig W, Lodder RA, March K, Demirovic J, Navab M, Priori SG, Rekhter MD, Bahr R, Grundy SM, Mehran R, Colombo A, Boerwinkle E, Ballantyne C, Insull W, Jr., Schwartz RS, Vogel R, Serruys PW, Hansson GK, Faxon DP, Kaul S, Drexler H, Greenland P, Muller JE, Virmani $R$, Ridker PM, Zipes DP, Shah PK, Willerson JT. From vulnerable plaque to vulnerable patient: a call for new definitions and risk assessment strategies: Part ll. Circulation. 2003;108:1772-8.

59. Naghavi M, Libby $P$, Falk E, Casscells SW, Litovsky S, Rumberger J, Badimon JJ, Stefanadis C, Moreno P, Pasterkamp G, Fayad Z, Stone PH, Waxman S, Raggi P, Madjid M, Zarrabi A, Burke A, Yuan C, Fitzgerald PJ, Siscovick DS, de Korte CL, Aikawa M, Juhani Airaksinen KE, Assmann G, Becker CR, Chesebro JH, Farb A, Galis ZS, Jackson C, Jang IK, Koenig W, Lodder RA, March K, Demirovic J, Navab M, Priori SG, Rekhter MD, Bahr R, Grundy SM, Mehran R, Colombo A, Boerwinkle E, Ballantyne C, Insull W, Jr., Schwartz RS, Vogel R, Serruys PW, Hansson GK, Faxon DP, Kaul $S$, Drexier H, Greenland P, Muller JE, Virmani $R$, Ridker PM. Zipes DP, Shah PK, Willerson JT. From vulnerable plaque to vulnerable patient: a call for new definitions and risk assessment strategies: Part I. Circulation. 2003;108:1664-72.

60. Virmani $R$, Kolodgie FD, Burke AP, Farb A, Schwartz SM. Lessons from sudden coronary death: a comprehensive morphological classification scheme for atheroscierotic llesions. Anterioscler Thromb Vasc Biol, 2000;20:1262-1275.

61. Roselaar SE, Schonfeld G, Daugherty A. Enhanced development of atherosclerosis in cholesterol-fed rabbits by suppression of cell-mediated immunity. $J$ Clin linvest. 1995;96:1389-94.

62. Emeson EE, Shen ML. Accelerated atherosclerosis in hyperlipidemic C57BL/6 mice treated with cyciosporin A. Am J Pathoi. 1993;142:1906-15.

63. Boumpas DT, Chrousos GP, Wilder RL, Cupps TR, Balow JE. Glucocorticoid therapy for immune-mediated diseases: basic and clinical correlates. Ann Intern Med. 1993;119:1198208. 
64. Andersen HO, Hansen BF, Holm P, Stender S, Nordestgaard BG. Effect of cyclosporine on arterial balloon injury lesions in cholesterol-clamped rabbits: $T$ lymphocyte-mediated immune responses not involved in balloon injury-induced neointimal proliferation. Arterioscler Thromb Vasc Biol. 1999;19:1687-94.

65. Waller JR, Brook NR, Bicknell GR, Nichoison ML. Differential effects of modern irmmunosuppressive agents on the development of intimall hyperplasia. Transp/ Int. $2004 ; 17: 9-14$.

66. Babapulle MN. Eisenberg MJ. Coated stents for the prevention of restenosis: Pant I. Circulation. 2002;106:2734-40.

67. Radke PW, Weber C, Kaiser A, Schober A, Hoffmann R. Dexamethasone and restenosis after coronary stent implantation: new indication for an old drug? Curr Pharm Des. 2004; 10:349-55.

68. Chen Z, Fukutomi T, Zago AC, Ehlers R, Detmers PA, Wright SD, Rogers C, Simon DI. Simvastatin reduces neointimal thickening in low-density lipoprotein receptor-deficient mice after experimental angioplasty without changing plasma lipids. Circulation. 2002;106:20-3.

69. Yokoyama T, Miyauchi $K$, Kurata T, Satoh H, Daida H. Inhibitory efficacy of pitavastatin on the early inflammatory response and neointimal thickening in a porcine coronary after stenting. Atherosclerosis. 2004;174:253-9.

70. Scheller B, Schmitt A, Bohm M, Nickenig G. Atorvastatin stent coating does not reduce neointimal proliferation after coronary stenting. Z Kardiol. 2003;92:1025-8.

71. Walter $\mathrm{DH}$, Schachinger $\mathrm{V}$, Elsner M, Mach S, Auch-Schwelk W, Zeiher AM. Effect of statin therapy on restenosis after coronary stent implantation. Am J Cardiol. 2000;85:962-8.

72. Brooks G, Yu XM, Wang Y, Crabbe MJ, Shattock MJ, Harper JV. Non-steroidal antiinflammatory drugs (NSAIDs) inhibit vascular smooth muscle cell proliferation via differential effects on the cell cycle. I Pharm Pharmacol. 2003;55:519-26.

73. Pratt RE, Dzau VJ. Pharmacological strategies to prevent restenosis: lessons learned from blockade of the renin-angiotensin system. Circulation. 1996;93:848-52.

74. Anderson JL, Muhlestein JB. Antibiotic trials for coronary heart disease. Tex Heart inst $J$. $2004 ; 31: 33-8$. 



\section{Summary}

Atherosclerosis is a complex "progressive disease of the large arteries and the leading cause of death in Western society. Although the build-up of lipids, cells and extracelular matrix can cause severe stenosis of the artery, most clinical complications (i.e. myocardial infarction or stroke) occur due to acute rupture of a plaque and thrombus fomation. Despite extensive research, the underlying molecular mechanism of atherosclerotic plaque development and progression are still not completely clarified. Nevertheless, it is now generally accepted that atherosclerosis involves a chronic inflammatory disease as a response to oxidized lipids. We therefore hypothesized that the immunosuppressive drug FK506 (tacrolimus) would attenuate atherosclerotic plaque development. Besides the evaluation of the therapeutic potential of FK506, we also described the search for new therapeutic targets or diagnostic tools for atherosclerotic plaque rupture using proteomic analysis.

Recent advances in atherosclerotic and (transplant) arteriosclerotic research are described in chapter 2. These include quantitative trait locus (QTL) analysis, which is a 'reverse-genomics' approach correlating phenotype and genotype to identify genes that modify complex disease development. In vivo models of atherosclerosis and transplant arteriosclerosis increasingly use more complex interventions, such as bone marrow transplantation and double knockout mice, to unravel the molecular mechanisms and the contribution of distinct cell types to the development of these diseases. Although several in vivo models exist that display some features of atherosiclerotic plaque instability, the search for animal models of true plaque rupture perseveres. Most likely, this will require multiple interventions or larger animals that more closely resemble humans.

In chapters 3 and 4 we investigated the effect of a low dose of the immunosuppressive drug FK506 on the development and progression of atherosclerosis in ApoE-/. mice. In chapter 3, we used a mouse model in which atherosclerotic plaque development was accelerated by collar placement around the common carotid artery and using an atherogenic diet. Low dose FK506 (0.05 $\mathrm{mg} / \mathrm{kg} / \mathrm{day})$ attenuated atherosclerotic plaque development, but also significantly inhibited the progression of previously developed plaques. Furthermore, low dose FK506 induced a more stable plaque phenotype by increasing plaque cell density and collagen content, while reducing necrotic core content of the plaques.

In chapter 4 we used the conventional ApoE-/- mouse model in which atherosclerosis develops spontaneously, even when using a normal diet. As in the model of accelerated, collar-induced atherosclerosis, low dose FK506 also inhibited spontaneous atherosclerotic plaque development and progression. Low dose FK506 increased alpha-smooth muscle actin-positive smooth muscle cell content and reduced $T$ cell content of initial lesions in the left subclavian artery and brachiocephalic trunk, respectively. Although these effects on 
lesion morphology were less evident than in the model of accelerated atherosclerosis, this again indicated an increase in plaque stability after treatment with low dose FK506.

Restenosis is the process of luminal narrowing after an intra-arterial intervention and, like atherosclerosis, this process also involves an inflammatory reaction. In chapter 5 we tested the hypothesis that low dose FK506 would also inhibit restenosis-related processes (i.e. neointima formation and vascular remodelling) in the mouse model of carotid artery ligation. We found little effect on neointima formation, which was reduced after FK506treatment but only in the area near the ligation. However, low dose FK506 affected arterial remodelling by an increase in lumen size and medial area.

The underlying molecular mechanism of atherosclerotic plaque rupture is far from elucidated, despite several gene expression studies that have been performed. Chapter 6 describes the study of differential protein expression of human thrombus-containing plaques (i.e. plaques with intraplaque hemorrhage, plaque erosion or ruptured plaques) compared to stable plaques using 2D gel electrophoresis. This proteomics technique proved to be a sensitive and reproducible technique, although protein identification was difficult when using complex samples such as whole-mount atherosclerotic plaques in combination with broad $\mathrm{pH}$-ranges $(\mathrm{pH} 4-7)$. Analysis of differential $2 \mathrm{D}$ spots revealed multiple proteins in a single spot, including vinexin- $\beta$ and alpha- 1 antitrypsin in a spot uniquely expressed in plaques with a thrombus. Although this is the first report of vinexin- $\beta$ expression in atherosclerotic plaques, the differential expression of this protein appeared to be false-positive, since expression levels (as determined by Western Blotting) in stable plaques and thrombus-containing plaques were comparable. Differential expression of alpha- 1 antirypsin was confirmed by Western blotting of the $2 \mathrm{D}$ gels. We found 6 isoforms of alpha- 1 antitrypsin to be expressed in advanced atherosclerotic plaques, one of which was uniquely expressed in plaques with a thrombus. Thus, this study showed that $2 \mathrm{D}$ gel electrophoresis is a powerful separation technique for differential-display proteomics, especially for resolving post-translational modifications, although validation of the results is required.

Chapter 7 describes a preliminary study to evaluate Surface-Ehanced Laser Desorption/lonization Time-of-flight mass spectrometry (SELDI-TOF MS) as a new diagnastic tool for atherosclerotic plaque rupture. Comparison of serum proteomic profiles revealed eight peaks that could significantly discriminate patients with a stable plaque with those containing a lesion with a thrombus. This study shows that SELDI-TOF MS is a promising high-throughput technique and could serve as a diagnostic tool to find new biomarkers for atherosclerotic plaque rupture.

In chapter 8 the findings of this thesis are discussed. In the first part, we evaluated the therapeutic potential of low dose FK506, and anti-inflammatory therapy in general, in vascular pathologies. In the second part we discussed the value of proteomic analysis to 
identify new therapeutic targets and diagnostic tools for human atherosclerotic plaque rupture.

From the studies described in this thesis we conciude that low dose FK506 minimally affects neointima formation after carotid artery ligation, whereas it significantly inhibits atherosclerotic plaque development and progression, accompanied by increased features of plaque stability. Furthermore, $2 \mathrm{D}$ gel electrophoresis is a powerful separation technique for differential display analysis of atherosclerotic plaques, especially for post-translational modification, although identification of differential expressed proteins is difficult when using complex samples, such as whole-mount plaques. SELDI-TOF MS is a high-throughput technique to compare serum proteomic profiles that can discriminate patients with ruptured atherosclerotic plaques from those with stable lesions, which could serve as a diagnostic tool in the future. 


\section{Samenvatting}

Atherosclerose (aderverkalking) is een complexe en multifactoriële ziekte van de slagaders en doodsoorzaak nummer 1 in de Westerse wereld. Ophoping van vet en ontstekingscellen in de vaatwand (ontwikkeling van de zogenaamde plaque) veroorzaken een chronische onstekingsreactie en zo het dichtslibben van de slagaders. De meeste klinische complicaties, zoals het hartinfarct of een beroerte, ontstaan echter door het openbarsten van zo'n plaque (ruptuur). Het precieze mechanisme van zo'n plaque ruptuur is nog steeds niet bekend, hoewel ontsteking een belangrijke rol speelt.

In dit proefschrift wordt het effect van het onderdrukken van het ontstekingsproces door middell van het immunsuppressivum FK506 (tacrolimus) op de ontwikkeling van atherosclerose bestudeerd. Daarnaast wordt het mechanisme van plaque ruptuur onderzocht door verschillen in aanwezigheid (expressie) van eiwitten in de laatste twee stadia van atherosclerose te vergelijken met behulp van zogenaamde proteomics technieken.

De laatste nieuwe ontwikkelingen op het gebied van atherosclerose onderzoek worden beschreven in hoofdstuk 2. Hiertoe behoort de QTL (quantitative trait locus) analyse techniek waarbij genotype en phenotype aan elkaar worden gecorreleerd om zo genen te vinden die de ontwikkeling van atherosclerose beïnvloeden. In vivo modellen voor atherosclerose maken meer en meer gebruik van complexe interventies, zoals beenmergtransplantatie en knockout muizen, om het ziekte-mechanisme te ontrafelen. Hoewel er diermodellen zijn die kenmerken vertonen van plaque instabiliteit, is men nog steeds op zoek naar een in vivo model voor een echt plaque ruptuur.

In hoofdstuk 3 en 4 hebben we het effect van een lage dosis van het immunsuppressivum FK506 op de ontwikkeling van atherosclerose bestudeerd in ApoEdeficiente muizen. In hoofdstuk 3 hebben we de ontwikkeling van atherosclerose versneld door een collar om beide carotiden van de muizen te plaatsen en de muizen een vetrijk dieet te voeren. Behandeling met een lage dosis FK506 $(0.05 \mathrm{mg} / \mathrm{kg} /$ day $)$ verminderde de ontwikkeling van atherosclerose en remde de progressie van bestaande plaques. Daarnaast leidde de FK506-behandeling tot meer stabiele plaques.

Hoofdstuk 4 beschrijft het effect van behandeling met dezelfde lage dosis FK506 op de spontane ontwikkeling van atherosclerose in de Apo-J-muizen op een normaal dieet. Ook in dit model remde de FK506-behandeling de ontwikkeling van atherosclerose en waren er tekenen van verhoogde plaque stabiliteit.

Restenose is het proces van vaatvernauwing dat vaak optreedt na dotteren. Net als atherosclerose spelen ontstekingsreacties een belangrijke rol in de ontwikkeling van restenose. In hoofdstuk 5 onderzochten we het effect van behandeling met de lage dosis FK506 op de onderliggende processen van restenose: de vorming van een neointima (groei van gladde spiercellen) en remodellering van de vaatwand (het krimpen van het 
vat). Hiervoor hebben we gebruik gemaakt van een muizenmodel, waarbij de arteria carotis wordt afgebonden. De FK506-behandeling had weinig effect op de neointima vorming, hoewel dit dicht bij de ligatie wel verminderd was. FK506 had wel een gunstig effect op vaatwandremodelleren, wat tot uiting kwam in een groter lumen en een dikkere media.

Hoewel er al veel studies gedaan zijn naar het ontstaan van een plaque ruptuur, is het onderliggende mechanisme dat tot deze klinische complicatie leidt nog verre van bekend. In hoofdstuk 6 hebben we de verschillen in eiwitexpressie bestudeerd tussen vergevorderde, maar stabiele plaques en plaques met een thrombus (geruptureerde plaques en lesies met intra-plaque bloeding) afkomstig van patiënten. Dit hebben we gediaan met behulp van 2D gel electroforese, een techniek waarmee de eiwitten uit de plaques op grootte en lading gescheiden worden. Hoewel we hebben aangetoond dat dit een gevoelige en reproduceerbare techniek is, bleek de identificatie van de eiwitten moeilijk met name door de complexe samenstelling van de plaques en het gebruik van brede $\mathrm{pH}$-ranges voor de eiwitscheiding. Er werden meerdere eiwitten in eenzelfde $2 \mathrm{D}$ spot gevonden, waaronder alpha-1 antitrypsine en vinexine- $\beta$. Deze 2 eiwitten komen alleen tot expressie in plaques met een thrombus. Dit is de eerste studie die vinexine- $\beta$ expressie beschrijft in vergevorderde atherosclerotische plaques, hoewel het verschil in expressie tussen de 2 plaque stadia vals-positief bleek te zijn. Het verschil in expressie van alpha- 1 antirypsine in deze laatste stadia van atherosclerose werd nog extra bevestigd met behulp van Western Blots van de 2D gels. Hierbij vonden we expressie van 6 vormen van alpha-1 antitrypsine in vergevorderde atherosclerose, waarvan 1 vorm alleen voorkwam in plaques met een thrombus. Uit deze studie concluderen we dat $2 \mathrm{D}$ gel electroforese een goede techniek is om verschillen in eiwitexpressie, en met name posttransilationele modificaties, in atherosclerose te bestuderen. Echter het valideren van de resultaten blijft zeer belangrijk. De verschillen in eiwitexpressie kunnen verder inzicht geven in het mechanisme van atherosclerotische plaque ontwikkeling en plaque ruptuur.

Hoofdstuk 7 beschrift een eerste evaluatie van de Surface-Enhanced Laser Desorption/lonization Time-of-flight massa spectrometrie (SELDI-TOF MS) techniek als new diagnositsch middel om atherosclerotische plaque ruptuur op te sporen in het serum van patiënten. Serum profielen van patiënten met een stabiele plaque werden vergeleken met dat van patiẻnten met een plaque met een thormbus, waarbij 8 pieken werden gevonden die onderscheid konden maken tussen de beide patiënten-groepen. Deze eerste evaluatie liet zien dat SELDI-TOF MS een snelle techniek is voor het opsporen van plaque rupturen in het serum van patiënten en die mogelijk zall leiden tot het vinden van nieuwe markers voor plaque ruptuur.

In hoofdstuk 8 worden de bevindingen van dit proefschrift in een breder perspectief geplaatst en bediscussieerd. Het eerste deel evalueert de behandeling met een lage dosis FK506 en andere ontstekingsremmende middelen als mogelijke therapie voor atherosclerose en andere vaataandoeningen. In het tweede deel wordt de waarde van het 
bestuderen van eiwitexpressie met behulp van verschillende 'proteomics' technieken besproken om nieuwe therapeutische en diagnostische middelen te vinden voor atherosclerotisch plaque ruptuur.

Uit de studies beschreven in dit proefschrift concluderen we dat behandeling met een lage dosis weinig effect heeft op de neointima vorming na carotis ligatie, maar succesvol is in het remmen van de groei en ontwikkeling van atherosclerotische plaques en leidt tot meer stabiele lesies. Daarnaast hebben we laten zien dat 2D gel electroforese een goede techniek is om verschillen in eiwitexpressie tussen de verschillende stadia van atherosclerose te bestuderen. Met name post-translationele modificaties van eiwitten kunnen met deze techniek goed in beeld gebracht worden. Identificatie van eiwitten uit complexe eiwit-mengsels biijft echter moeilijk. SELDI-TOF MS is een snelle techniek, dat als diagnostisch middel gebruikt zou kunnen worden om eiwit-profielen in het serum van patiënten te vergelijken om zo een plaque ruptuur op te sporen. 


\section{Dankwoord}

Eindelijk is het dan zover....na maanden van schrijven, quantimetten, data uitwerken en nog meer schrijven, is het boekje nu klaar. Op éen, toch niet onbelangrijk, en voor veel mensen misschien well het interessantste deel na (dit is toch immers het eerste hoofdstuk van een boekje dat iedereen leest!?)... het dankwoord. Als er iets is wat ik geleerd heb de afgelopen jaren, dan is het wel dat je onderzoek nooit alleen doet. Ik wil dan ook graag iedereen bedanken die mij op de werkvloer of daarbuiten heeft geholpen en gesteund!

Allereerst mijn promotor prof. Daemen. Beste Mat ${ }_{\text {ik }}$ heb veel respect voor al je (mensen)kennis en voor de manier waarop je in je drukke schema toch iedere keer weer tijd weet te vinden voor alles en iedereen. Ik stond vaak versteld hoe je binnen no-time weer gretig alle geschreven stukken had doorgelezen. Je waslijst aan nieuwe ideeen zorgden iedere keer weer voor een nieuwe impuls in ons onderzoek. Eerder dan ik ooit had gedacht is mijn boekje nu klaar.... heb je dus toch gelijk gekregen! Bedankt voor alle vertrouwen en begeleiding in de afgelopen jaren en hopelijk ook in de toekomst!

Als perfecte aanvulling van het promotie-team, mijn co-promotor Dr. Heeneman. Beste Sylvia, als directe begeleidster had ik het me niet beter kunnen wensen. Waar nodig kon ik altijd rekenen op je hulp of liet je me lekker mijn eigen gang gaan. Ik denk dat ik je in het begin helemaal gek gemaakt heb met al mijn vragen. Bedankt dat ik toch altijd weer bij je terecht kon. Ik heb veel van je geleerd en hoop nog eens jouw techniek van goeie vragen stellen onder de knie te krijgen.

Mijn collega-aio's, de cardio-kipjes, met jullie heb ik tijdens mijn promotie-onderzoek lief en leed gedeeld. Met 6 vrouwen op een kamer is niet altijd even makkelijk, maar vaak toch ook well heel gezellig! Linda, jij was de eerste...jammer dat het met je onderzoek niet helemaal liep zoals je wilde...maar wel fijn dat we nu samen gaan werken aan het CD40 project! Natasja, als ik ergens mijn verhaal kwijt moest, kon ik altijd bij jou terecht...bedankt voor je luisterend oor en de vele liters koffie! Suus, of er nou lemand het nodig had of niet, jij zorgde altijd voor een constante lading chocolade....en het hele lab was er als de kippen bij om hun graantje mee te pikken! Ik heb me vaak kostelijk geamuseerd met jou erbij! Kitty, super-squirrel, ik heb altijd handig gebruik kunnen maken van jouw Canadese afkomst...bedankt voor alle hulp met de engelse spreek-en schrijftaal! Judith, aan jouw daadkracht en doorzettingsvermogen kunnen velen nog een voorbeeld nemen! Het is goed te zien dat het sinds je trip naar Parijs met je onderzoek alleen maar bergopwaarts gaat. Meiden bedankt en veel succes met jullie eigen onderzoek.

Ook de rest van mijn collega"s wil ik bedanken voor alle gezelligheid en hulp. Kitty, je enthousiasme werkt aanstekelijk en je kennis is enorm. Bedankt voor al je interesse en adviezen! Esther, jij ook bedankt voor alle raad en daad, met name bij de muizenexperimenten, en natuurlijk voor het leuke post-doc project...ik denk dat we wel een goed 
team zullen wormen! Mijn nieuwe kamergenootjes Ann-Pascale en Wanwisa...bij jullie op de kamer is het veel rustiger, maar toch ook genoeg te beleven! lk denk dat we nog veel aan elkaar kunnen hebben. Birgit en Cherida, toen ik begon waren jullie als ouderejaars aio"s mijn voorbeeld... het was dan ook raar toen jullie er niet meer waren. Bedankt voor alle hulp en gezelligheid.

Dan de mensen op het lab... Anouk, Moniek, Anique, Petra, Ine, Coby, Mat, Barry en Jack. In alle drukte wisten jullie toch ledere keer weer tijd te maken voor "effe een kleuring" of "(wel meer dan) een paar coupes snijden". Ook al is het misschien niet altijd even duidelijk, jullie hulp wordt enorm gewaardeerd!! Barry, jou wil ik nog speciaal even bedanken voor alle hulp met de computers...die kop koffie had ik toch nooit gedurfd! Jack, jouw programma's voor de quantimet hebben ook zeer zeker vele uurtjes in het donkere hok gescheeld...bedankt!

Monique, ondertussen ben je al een tijdje een ex-collega, maar jouw bijdrage aan dit boekje wordt ook niet vergeten hoor... $\mathrm{k}$ hoop dat je ondertussen je plekkie gevonden hebt! Rik, bedankt voor je hulp met de muizen....je bent geweldig! Marjan, bedankt voor het op weg helpen met de FACS.

De afdeling pathologie is groot en de hulp komt dan ook van alle kanten. Met name Cor en Elly wil ik graag bedanken voor het regelen van alle financiele en administratieve dingen. Carine, bedankt voor alle interesse en het bekijken van de muizen-niertjes. Robert-Jan, je bent een geweldige onderwijzer en je hebt ons goed geholpen met de cursus classificeren.

Tijdens mijn promotie-onderzoek heb ik meerdere malen de waarde van samenwerkingsverbanden ervaren. Daarom wil ik dan ook graag enkele mensen uitvoerig bedanken voor alle hulp.

Allereerst de mensen uit Leiden, Ilze Bot, Eric Biessen en prof. Van Berkel... bedankt voor alle hulp tijdens onze FK506-experimenten. Ilze, jij hebt vaak lange dagen gemaakt voor deze experimenten... het duurt nu niet lang meer, dan ben jij ook klaar. Heel erg bedankt voor alles en succes met je eigen promotie. Eric, de vele discussies en je kritische commentaar hebben zeker ertoe geleid dat het FK-verhaal steeds sterker en uitgebreider werd.

Leon de Windt, van het Hubrecht Laboratorium in Utrecht, ook jij bedankt voor het meedenken met de FK-experimenten en het lezen van de manuscripten.

Prof van Hooff, bedankt voor uw interesse en de introductie in de transplantatie-wereld.

Karin Hoogtanders, bedankt voor alle tacrolimus concentratie-bepalingen. Toch wel bijzonder dat zo'n klinische bepaling ook toegepast kon worden op het muizenbloed!

De mensen van de farmacologie wil ik graag bedanken voor alle medewerking en het lenen van alle apparatuur en materialen voor de muizenoperaties. Alle mensen bij het CPV, bedankt voor alle medewerking en de goede zorgen om mijn muisjes.

Graag wil ik ook alle chirurgen bedanken voor hun medewerking bij het verzamelen van de plaque samples op de OK's. Prof. Dr. Kitslaar, Dr. Van den Akker en Dr. Ortije, hartelijk 
dank voor alle prachtige stukjes plaque. Ik hoop dat we nog vaak op bezoek mogen komen.

Aan het begin van mijn aio-schap werd het Maastricht Proteomics Center opgericht om zo optimaal gebruik te kunnen maken van alle kennis en apparatuur die in huis waren. Met name Freek Bouwman en prof. Mariman wil ik graag bedanken voor alle hulp bij het identificeren van de 2D spots. Helaas ging het niet helemaal vlekkeloos en moesten we uitwijken naar de MS/MS faciliteit in de Universiteit van Gent. Prof. Devreese, Prof. Van Beeumen en Frank Vanrobaeys, hartelijk dank voor alle hulp en moeite! Ik ben blij dat het uiteindelijk toch allemaal de moeite waard was!

Prof. Van Dieijen, Etienne Michielsen en Will Wodzig, de resultaten in hoofdstuk 7 zijn helemaal aan jullie te danken. Ik hoop dat we onze vruchtbare samenwerking nog even voort kunnen zetten... Etienne, jij hebt hier flink wat werk in gestoken...bedankt voor alle moeite en je geduld om het mij allemaal uit te leggen hoe het nu precies werkte!

Het is altijd fijn om te merken dat er buiten de werkvloer ook mensen zijn die interesse voor je hebben en er tijd is voor ontspanning. Hiervoor wil ik dan ook alle collega's, vrienden en familie bedanken, waarbij ik enkelen toch graag nog even apart wil noemen.

ledere ochtend is het altijd weer een gezellige boel met 'Brad en de treinmeisjes'. Guido, Debby, Claudia, Sandra, Manon, Angelique, Eveline en Kim...het is fijn te merken hoe iedereen zo met je meeleeft. Bedankt dat jullie die treinreis toch altijd weer heel wat aangenamer weten te maken. Claudia, ook al is het uiteindelijk niet gelukt hoe we het in gedachten hadden, ik wil je toch graag uitvoerig bedanken voor alle tijd die je hebt gestopt in de vormgeving van mijn boekje.

Angelique, Jean, Jorg en Linda, door alle drukte hebben we mekaar heel wat minder gezien dan we eigenlijk zouden willen. Maar nu kunnen jullie dan ook eindelijk zien, wat 'mijn roman' nu eigenlijk voorstelt! Cristel, we hebben elkaar tijdens de studie leren kennen en waren al snel dikke vriendinnen. Fijn, dat we ondanks de afstand toch contact blijven houden.

Bianca, ook wij zijn snel uitgegroeid tot goeie vriendinnen. Je hebt altijd veel interesse getoond voor alles wat me bezighoudt en onze gesprekken waren altijd heel verhelderend en opbeurend. Ik ben dan ook heel blij dat je me ook tijdens mijn promotie wil bijstaan als paranimf.

Dan het thuisfront, voor wie het nog allemaal extra moeilijk is om bij te houden wat ik nou allemaal gedaan heb. Pap en mam, het is heel fijn om te weten dat ik altijd op jullie kan terugvallen...bedankt voor alle steun en liefde die jullie me altijd hebben gegeven.

Jack, als 'big brother' ben je toch altijd een beetje mijn grote woorbeeld geweest. Ik weet dat als ik je nodig heb je er altijd voor me zult zijn. Daarom ben ik blij jou als tweede 
paranimf naast me te hebben staan bij mijn promotie. I hoop dat je met Jenn heel gelukkig wordt, ook al is dat dan in Amerika!

Last, but not least, Freddy.....het is ontzettend fijn om bij jou de rust te vinden die iedereen zo nu en dan nodig heeft. Ik vind het geweldig hoe je iedere keer weer probeert mee te denken met mijn onderzoek en je af en toe nog met goede ideen komt ook. Bedankt voor al je steun; liefde en vertrouwen. Na om de beurt onze promotie afgerond te hebben, kunnen we nu hopelijk sameri gaan genieten van een mooie toekomst! 
- Curriculum Vitae

Marjo Donners

18 July 1978

Born in Sittard

Education

1990-1996

1996-1997

$1997-2001$

VWO (Gymnasium), College Sittard

Propaedeuse Medical Biology, University of Utrecht, the

Netherlands

Doctoral phase Medical Biology, University of Utrecht, the

Netherlands, Cum Laude

Research

Febr. 2001- Dec. 2004

PhD student Department of Pathology, University of Maastricht the Netherlands

Dec. 2004- present

Postdoctoral Fellow Department of Pathology, University of Maastricht, the Netherlands 


\section{List of publications}

Inflammation and restenosis: implications for therapy Marjo M.P.C. Donners, Mat J.A.P. Daemen, Kitty B.J.M. Cleutjens, Sylvia Heeneman. Annals of Medicine 2003; 35: 523-531.

Models of atherosclerosis and transplant arteriosclerosis: the quest for the best Marjo M.P.C. Donners, Sylvia Heeneman, Mat J.A.P. Daemen. Drug Discovery Today 2004; 1(3): 257-263.

Low dose FK506 blocks collar-induced atherosclerotic plaque development and stabilizes plaques in ApoE-1- mice Marjo M.P.C. Donners, llze Bot, Leon J. De Windt, Theo J.C. van Berkel, Mat J.A.P. Daemen, Erik A.L. Biessen, Sylvia Heeneman. American Journal of Transplantation; in press.

Proteomic analysis of differential protein expression in human atherosclerotic plaque progression Marjo M.P.C. Donners, Monique J. Verluyten, Freek G. Bouwman, Edwin C.M. Mariman, Bart Devreese, Frank Vanrobaeys, Jozef van Beeumen, Luc H.J.M. van den Akker, Mat J.A.P. Daemen, Sylvia Heeneman. Journal of Pathology; in press.

Serine protease inhibitor Serp-1 strongly impairs atherosclerotic lesion formation and induces a stable plaque phenotype in ApoE-/-mice.

Bot I, von der Thusen JH, Donners MM, Lucas A, Fekkes ML, de Jager SC, Kuiper J, Daemen MJ, van Berkel TJ, Heeneman S, Biessen EA.

Circulation Research $2003 ; 93(5)$ : 464-71

Increased arterial expression of a glycosylated haptoglobin isoform after balloon dilation. Smeets MB, Sluijter JP, Donners MM, Velema E, Heeneman S, Pasterkamp G, de Kleijn DP.

Cardiovascular Research 2003;58(3): 689-95. 